\title{
Estudio de prefactibilidad para la exportación de espárragos orgánicos argentinos en Alemania
}

\author{
"Trabajo de carácter científico libre para lograr el grado \\ de Magister en Marketing Internacional en la \\ Escuela de Postgrado de Marketing Internacional"
}

Facultad de Ciencias Económicas

\section{Universidad Nacional de La Plata}

Profesor Director de Tesis

Prof. Dra. Cristina I. Zapata
Presentado por:

Lic. Emanuel Borthiry Buide Calle Burgueño $N^{\circ} 904$, General Belgrano provincia de Buenos Aires emanuel.borthiry@gmail.com 


\section{Introducción Metodológica}

El objetivo general del presente trabajo es realizar un estudio de prefactibilidad sobre el potencial exportador PyME con relación al sector hortícola orgánico argentino, más precisamente, sobre los espárragos orgánicos, teniendo como mercado objetivo Alemania.

Como punto de partida, se comenzó a investigar sobre factores sociales, económicos, políticos, culturales de Alemania mediante fuentes de información secundaria, más precisamente sitios web relacionados con la actividad del sector hortícola orgánico tanto a nivel mundial, alemán y argentino.

Considerando que uno de los objetivos era viajar al país teutón, comencé a estudiar el idioma con una anticipación de 2 años a fin de contar con los conocimientos básicos para desenvolverme como alumno de intercambio en la Fachhochschule de Reutlingen. Posteriormente, en Junio de 2010 realicé el viaje a Alemania a fin de estudiar la situación actual del país, la evolución del sector hortícola orgánico, las regiones productoras, el potencial del mercado y el perfil de los consumidores. Se pretendió también hacer foco en el estado federado alemán de Baden Württemberg; estado federado donde está situada la Universidad de Reutlingen, la cual posee un acuerdo de cooperación con la Escuela de Postgrado en Marketing Internacional de la Facultad de Ciencias Económicas de la UNLP.

Mediante este estudio de campo in situ realizado entre los meses de junio a noviembre de 2010, en varias ciudades alemanas, se estudiaron los principales canales de distribución de las hortalizas orgánicas (haciendo hincapié en los espárragos orgánicos); los principales productores y comercializadores alemanes; países proveedores al mercado alemán; precios al por mayor y menor; hábitos y comportamientos de los consumidores alemanes; y nuevas tendencias con relación al producto. Todo esto se puede considerar como fuentes de información primaria que luego se sumó a lo realizado previamente con las fuentes de información secundaria estudiadas en Argentina.

Como resultado del presente trabajo, en el Capítulo 1 se realiza un estudio a nivel mundial, situación alemana y situación argentina respecto a la producción de hortalizas y más precisamente, espárragos orgánicos. Dentro del Capítulo 2 se esboza la situación de Oferta y Demanda tanto a nivel internacional, alemán, como local. La tercera parte, mostrada en el Capítulo 3, está basada en las conclusiones, sugerencias e instancias superadoras del caso. 


\section{Agradecimientos}

En especial a mi hijo Joaquín, mi mujer Adriana y a toda mi familia.

Quiero agradecer a la Escuela de Posgrado en Marketing Internacional (EPMI) de la Facultad de Ciencias Económicas de la Universidad Nacional de La Plata por el apoyo brindado, siendo sus miembros el Dr. Rogelio Simonato (Director EPMI), Cra. Liesel Bischoff y Cra. María de los Ángeles Espinosa. A la directora del presente trabajo, por su guía y consejo constante, la Dra. Cristina I. Zapata; Mg. Martín López Armengol (Decano de la Facultad de Ciencias Económicas de la Universidad Nacional de La Plata); Cr. Daniel Dardo Lorea (Secretario de Desarrollo Institucional de la H. Cámara de Diputados de la provincia de Buenos Aires); Cr. Darío Álvarez (Director General de Desarrollo Institucional de la H. Cámara de Diputados de la provincia de Buenos Aires); Ing. Carlos Alberto Cheppi (Embajador Plenipotenciario en Asuntos Agrícolas); Sr. Daniel Gurzi (Secretario PyME del Ministerio de la Producción de la provincia de Buenos Aires); Ing. Agr. Juan Carlos Ramírez (SENASA); Ing. Agr. Eduardo Rollero (Ministerio de Agricultura, Ganadería y Pesca); Ing. Agr. Diego Pinasco (SENASA); Ing. Agr. Carlos Selas (SENASA); Ing. Agr. María Verónica Stuarts (Consejo Federal de Inversiones); Lic. Diego Niki Rossi (AHK); Damián Andrada (AHK); Mg. Ana Castagnino (CRESCA); Sr. Rubén Giordano, Gerente de CERA (Cámara de Exportadores de la República Argentina; Instituto Cultural Argentino Alemán de La Plata; Lic. Azul Molina (Embajada de la República Argentina en Alemania); Sr. Federico Piccone, CEO Pampa Store; Sr. Armando Castillo, CEO Agro Los Andes, S.A.; Srta. María Pía Larsson, La Meco S.R.L.

En Alemania: Dr. Rolf Pfeiffer y familia (Tübingen); Dr. Peter Miez-Mangold y familia (Freiburg); Prof. Thomas Busch y familia (Reutlingen); Prof. Marco La Sala y Franziska Dittloff (Reutlingen, Münich); Paul Worthington (Fachhochschule Reutlingen); Sr. Gabriel Billota y Caroline Hartmann (Nürnberg) y a las demás personas que contribuyeron de una forma u otra en la realización del presente trabajo. 


\section{Índice Temático}

Capítulo 1: Producción orgánica y de espárragos a nivel mundial, en Alemania y Argentina ............. 1

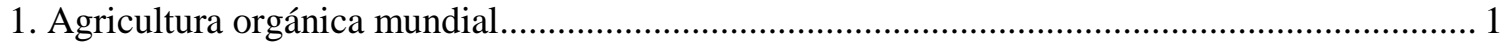

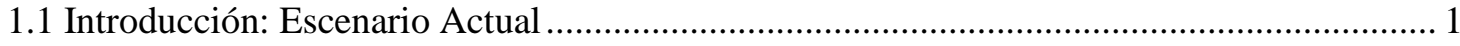

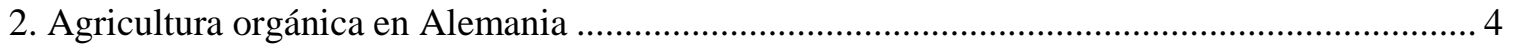

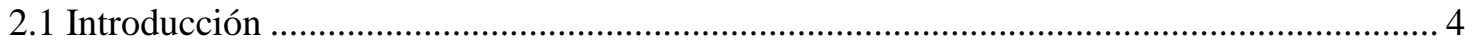

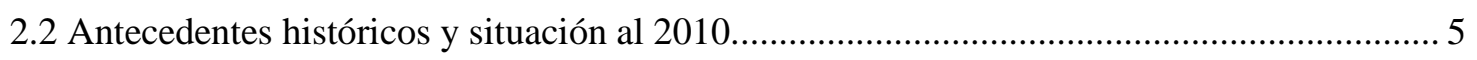

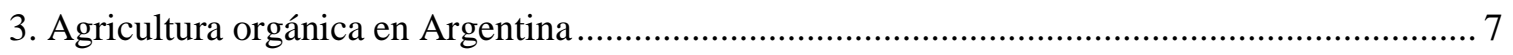

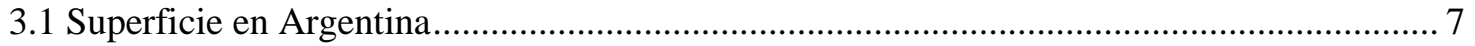

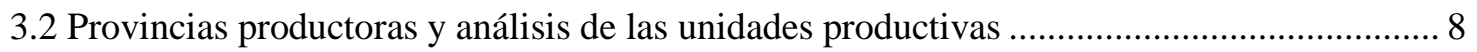

3.3 Análisis del destino de la producción............................................................................. 9

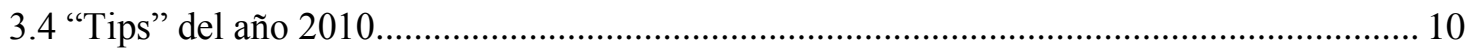

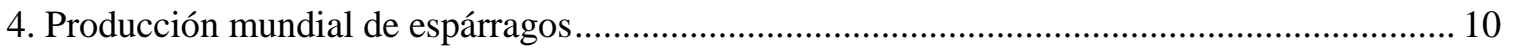

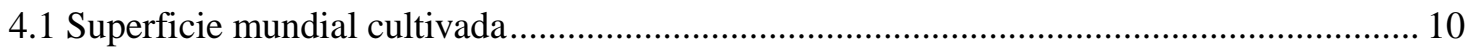

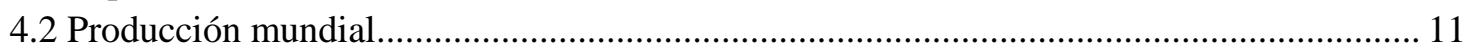

4.3 Evolución de la producción mundial por variedad de espárrago ......................................... 12

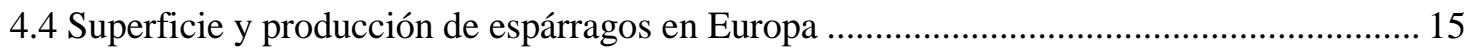

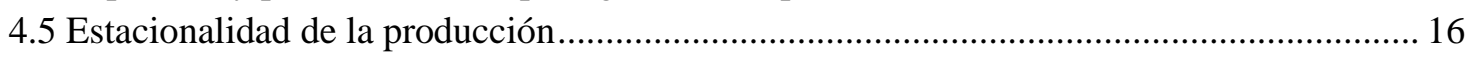

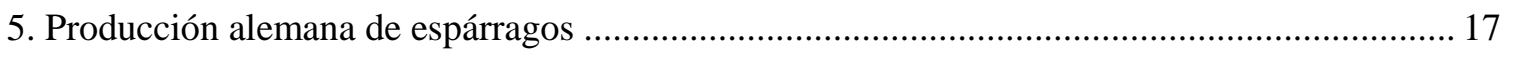

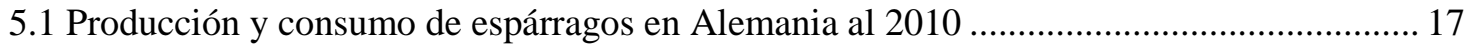

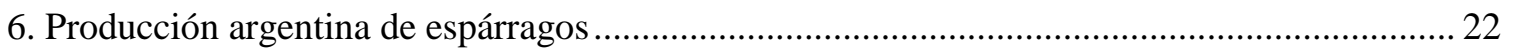

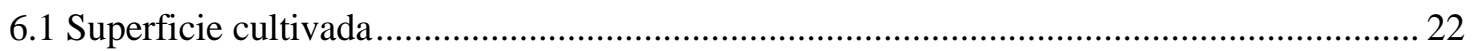

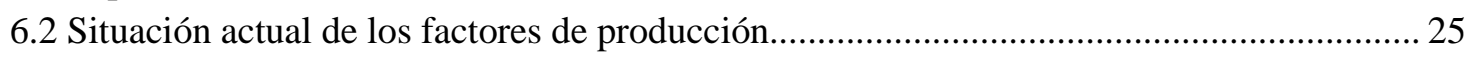

Capítulo 2: Oferta y demanda orgánica, de espárragos en el mundo, Alemania y Argentina............ 26

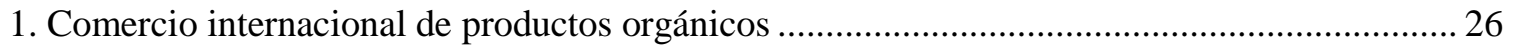

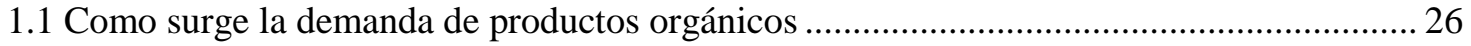

1.2 Los productos orgánicos como nicho de mercado internacional....................................... 26

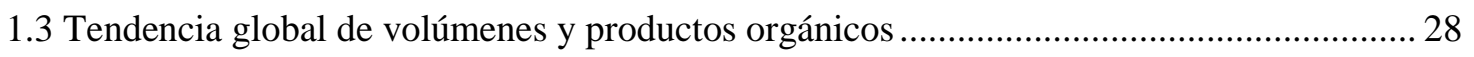

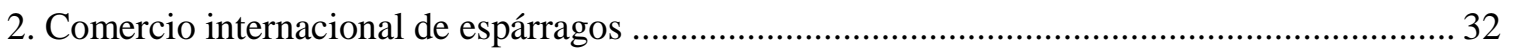

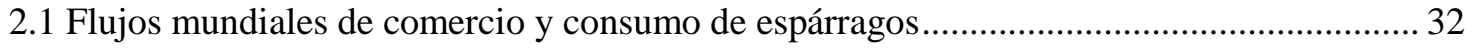

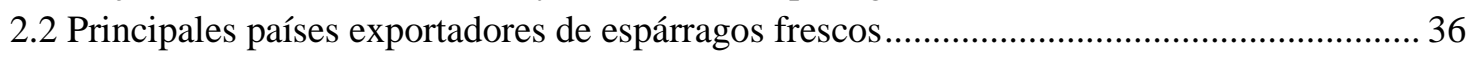

2.3 Exportaciones e importaciones en la Unión Europea......................................................... 37

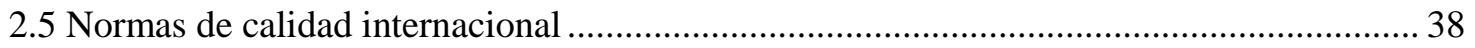

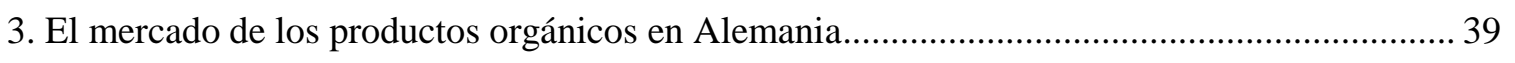

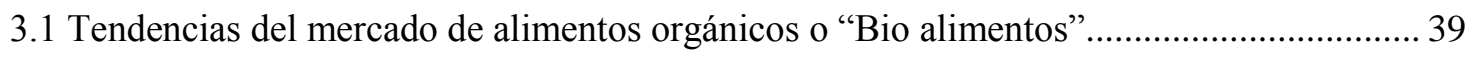

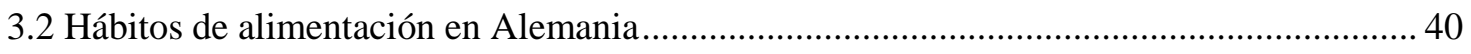

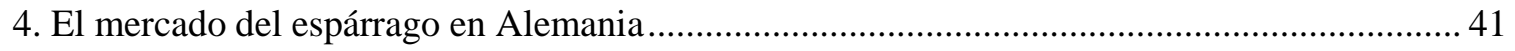




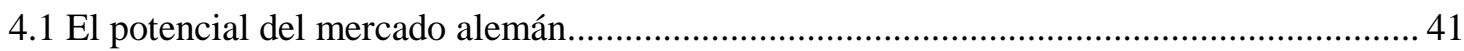

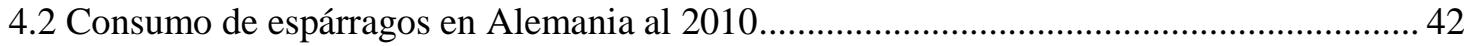

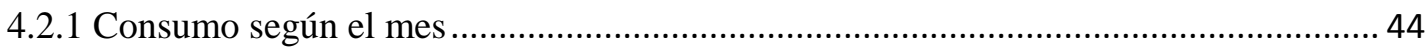

4.2.2 Variedad de espárrago consumido y consumo por edades .......................................... 44

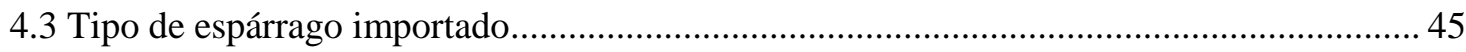

4.3.1 Importaciones alemanas de espárragos frescos o refrigerados ................................... 46

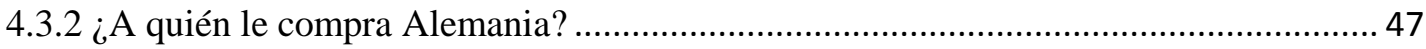

4.3.3 Principales proveedores de espárragos del mercado alemán........................................ 48

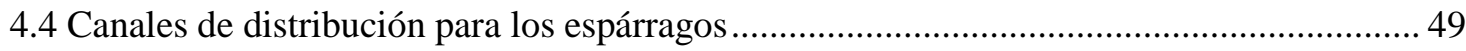

4.4.1 Canales de distribución para verduras orgánicas y espárragos orgánicos ..................... 50

4.5 Las 10 verduras orgánicas más consumidas en Alemania.................................................. 51

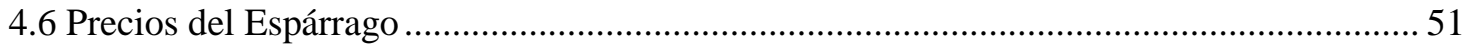

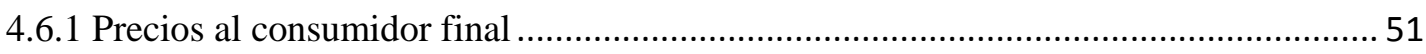

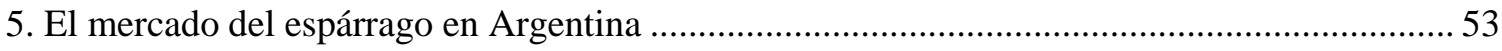

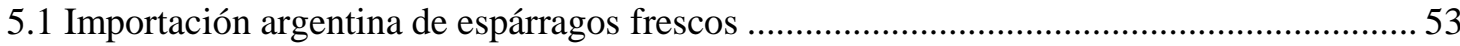

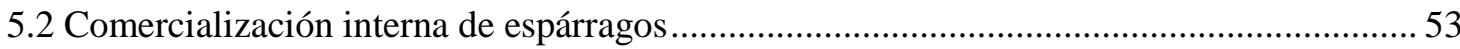

5.3 Exportaciones argentinas de espárragos frescos convencionales .........................................54

5.3.1 Exportaciones argentinas de espárragos frescos orgánicos .......................................... 56

5.3.2 Aranceles de importación de terceros países.......................................................... 57

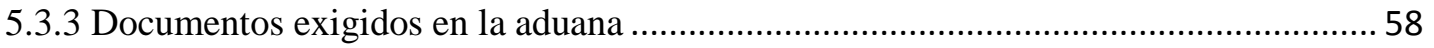

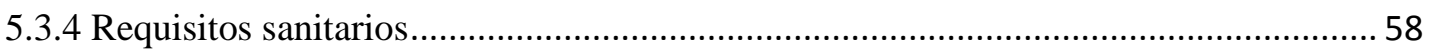

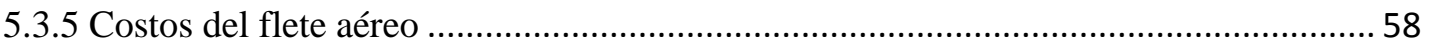

Capítulo 3: Análisis y conclusiones de los espárragos argentinos frente al mercado alemán .............59

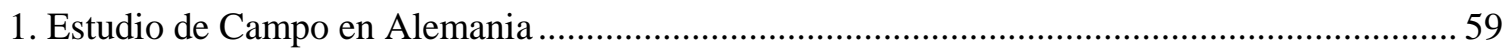

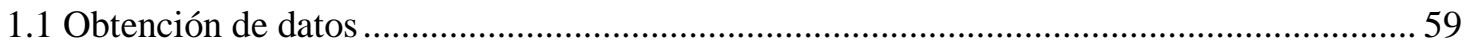

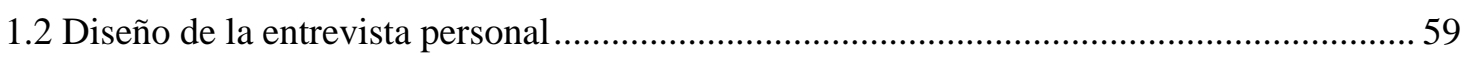

1.3 Resumen de los aspectos de importancia en la compra de espárragos en Alemania............ 66

2. Matriz FODA de los espárragos orgánicos argentinos respecto de Alemania ........................... 69

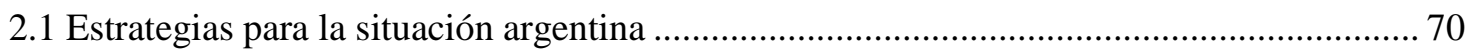

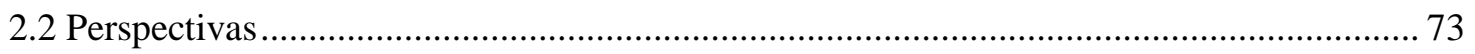

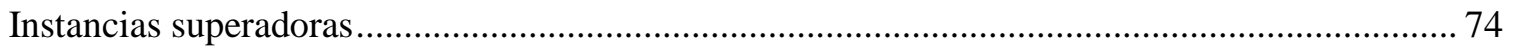

Anexo Cap. 1: Producción orgánica, de espárragos a nivel mundial, en Alemania y Argentina....... 76

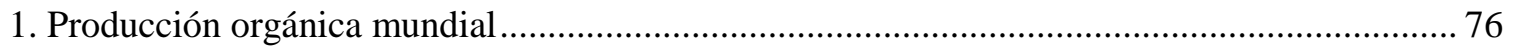

1.1 Producción, oferta, demanda y características de mercados por continente ....................... 76

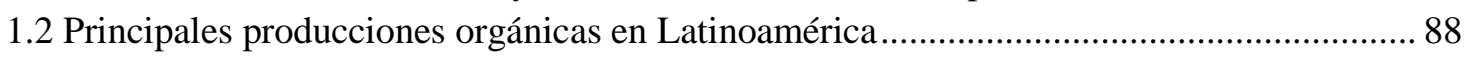

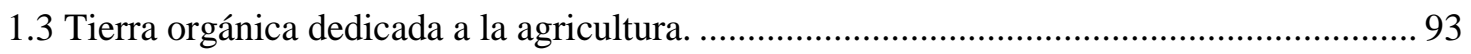

2. Detalle de áreas de producción de espárragos por continente ................................................97

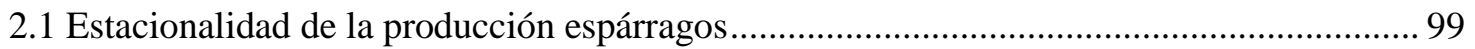

2.2 Costos de mano de obra por kilo cosechado ............................................................... 100 


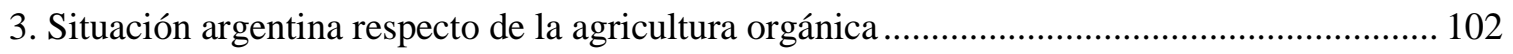

3.1 Superficie bajo seguimiento y tamaño medio de las explotaciones ................................. 102

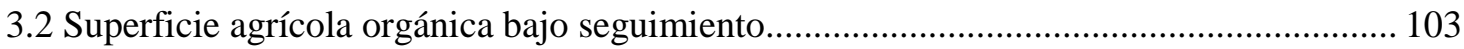

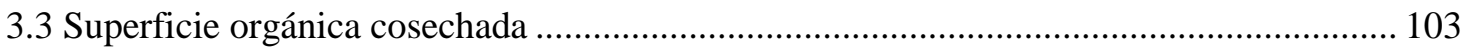

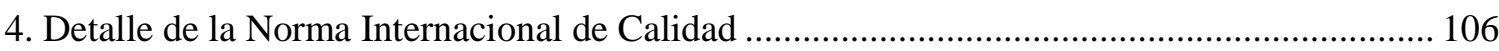

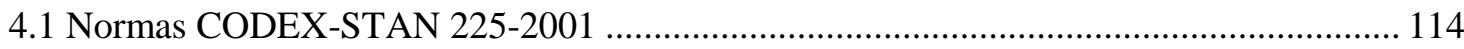

Anexo Cap. 2: Oferta y Demanda de espárragos a nivel mundial, en Alemania y Argentina .......... 116

1. Importaciones y Exportaciones mundiales de espárragos en conserva .................................... 116

2. Diferenciación entre exportación y consumo interno por continente ........................................ 117

3. Importaciones alemanas de espárragos en conserva año 2010 ............................................ 121

3.1 Importaciones mensuales de espárragos preparados o conservados año 2010.................. 122

4. Importaciones alemanas de espárragos congelados año 2010............................................. 123

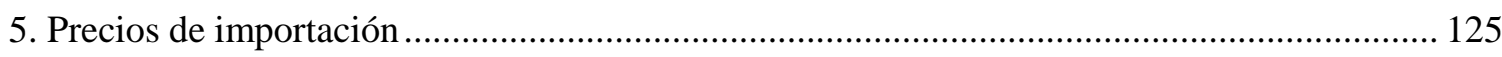

6. Exportaciones alemanas de espárragos frescos o refrigerados .............................................. 126

7. Precios espárragos por mayor y menor dependiendo de la semana del año........................... 129

8. Canales de distribución en el mercado alemán para bienes de consumo perecederos ............. 131

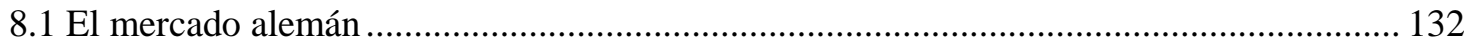

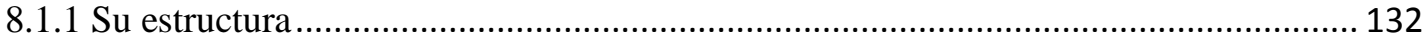

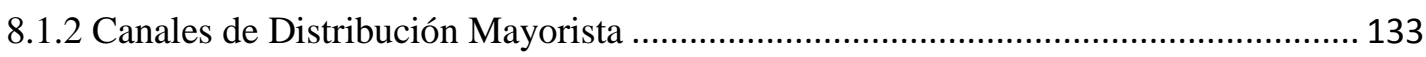

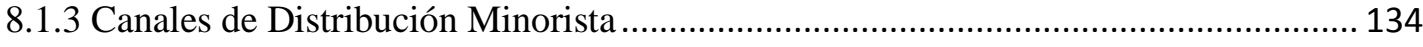

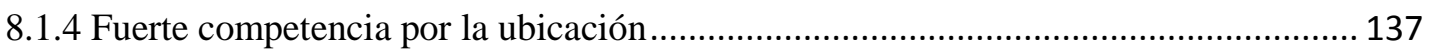

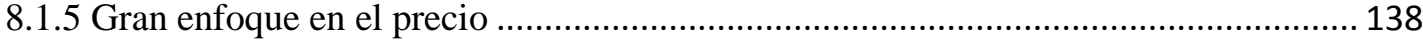

8.1.6 Triunfo de las marcas propias y de las tiendas de descuento .................................... 139

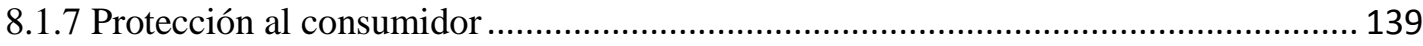

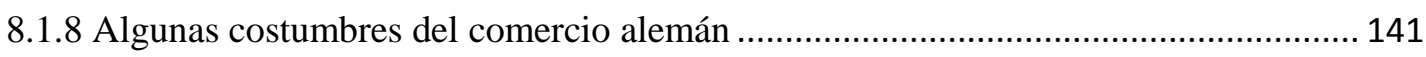

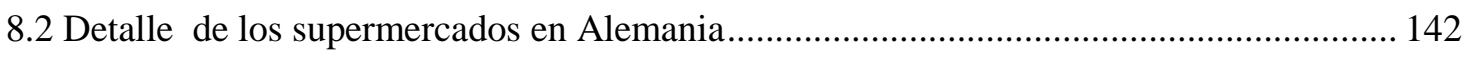

8.2.1 Listado de los principales supermercados ................................................................ 144

8.2.2 Listado de importadores alemanes de espárragos frescos ......................................... 145

8.2.3 Listado de importadores alemanes de espárragos en conserva ................................. 147

8.2.4 Listado de Importadores alemanes de alimentos orgánicos ..................................... 149

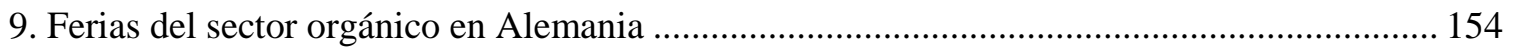

10. Productos orgánicos argentinos con destino a exportación................................................. 156

11. El caso productivo - comercial del Perú .......................................................................... 163

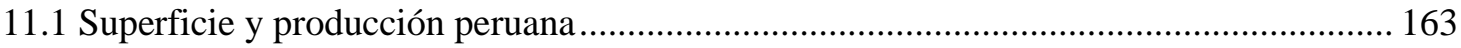

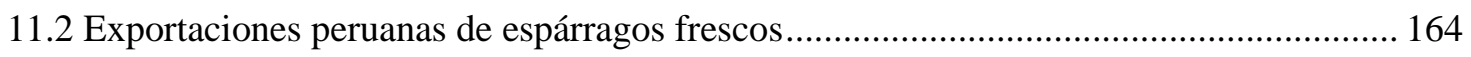

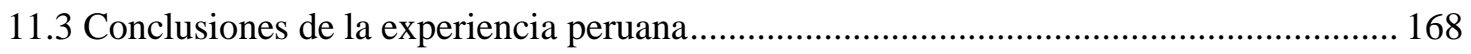

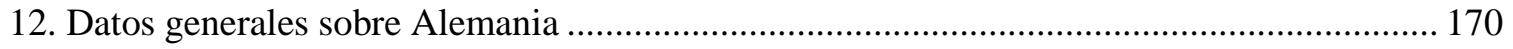

12.1 Situación, superficie, superficie agrícola, relieve y clima........................................... 170 
12.2 Población, etnias, densidad demográfica y tasa de crecimiento.................................... 170

12.2.1 Población urbana y de las principales ciudades .................................................... 171

12.2.2 Distribución de la población por edades y sexos ................................................... 171

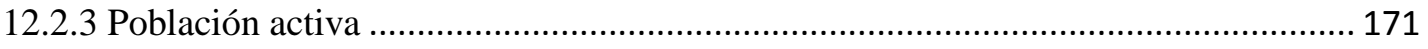

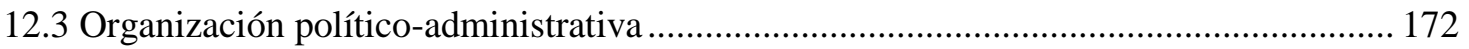

12.3.1 Gobierno, partidos políticos y parlamento …….................................................... 172

12.3.2 Organización administrativa y territorial del Estado ............................................. 173

12.3.3 La Administración Económica y Comercial y distribución de competencias ........... 173

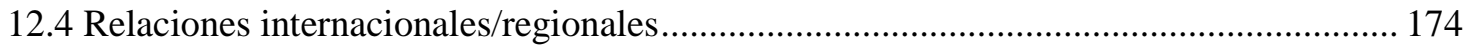

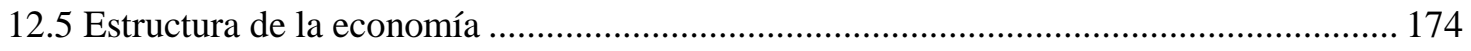

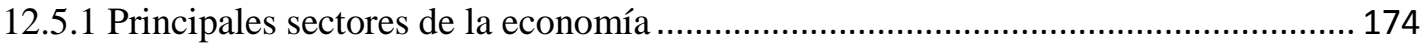

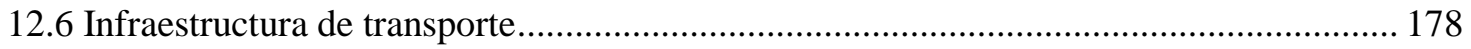

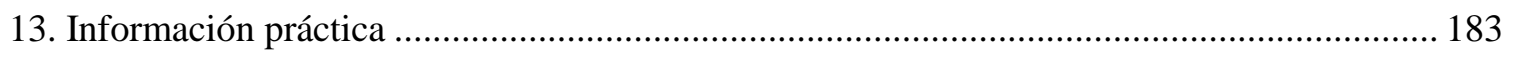

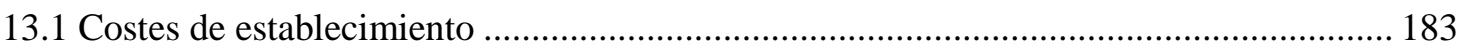

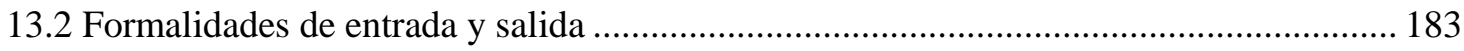

13.3 Costumbres peculiares en el trato de clientes y socios comerciales.............................. 183

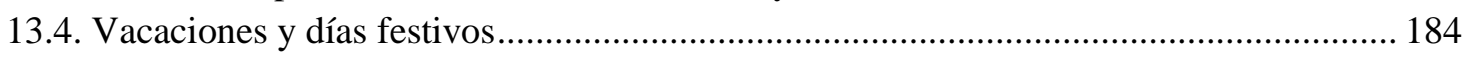

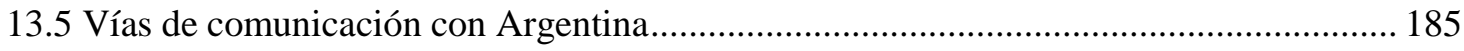

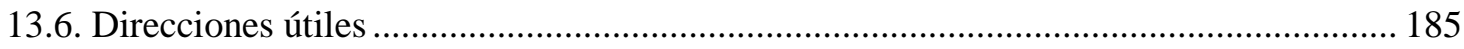

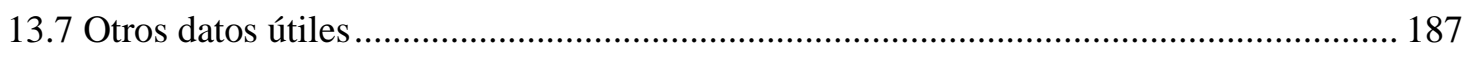

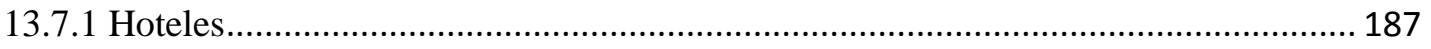

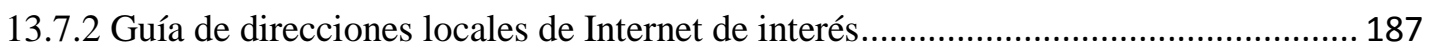

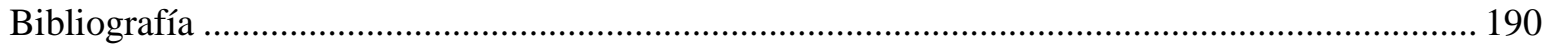

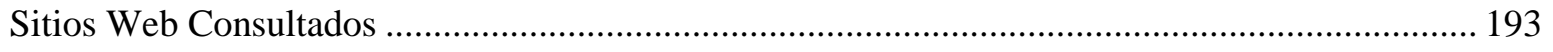

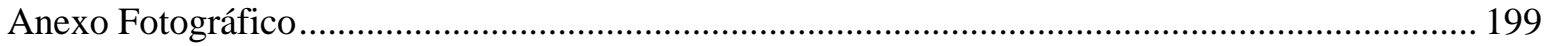




\section{Índice de gráficos}

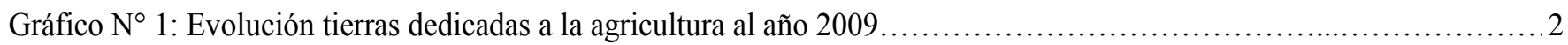

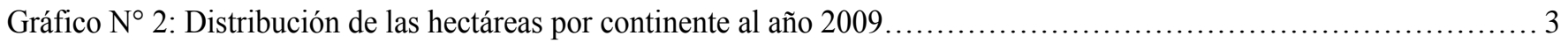

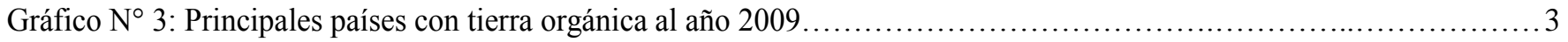

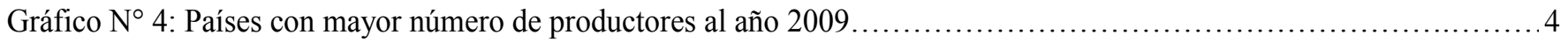

Gráfico $\mathrm{N}^{\circ}$ 5: Total de hectáreas orgánicas discriminadas por estado federado alemán al 2010.........................6

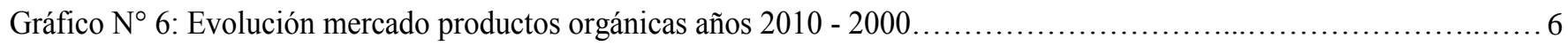

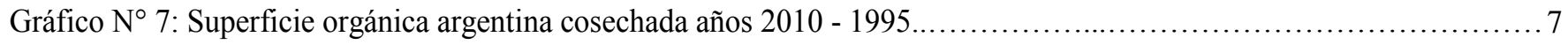

Gráfico $\mathrm{N}^{\circ}$ 8: Distribución de establecimientos discriminados por provincia al año $2010 \ldots \ldots \ldots \ldots \ldots \ldots \ldots \ldots \ldots \ldots \ldots \ldots$

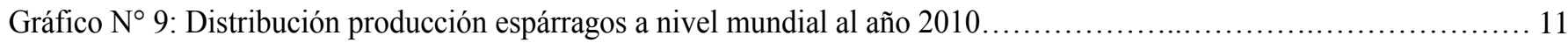

Gráfico $\mathrm{N}^{\circ}$ 10: Evolución de la producción anual en toneladas (excluida China) al año 2010.......................... 12

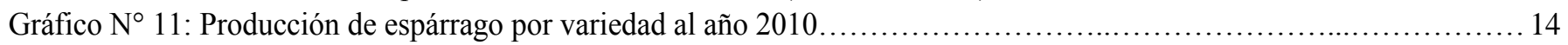

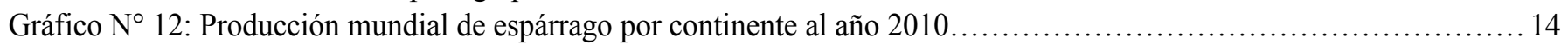

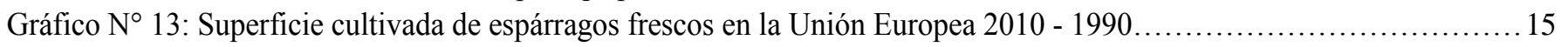

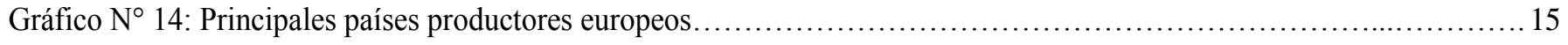

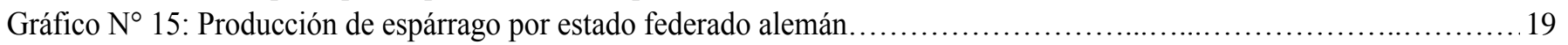

Gráfico $\mathrm{N}^{\circ}$ 16: Hectáreas dedicadas a la producción de espárrago fresco en Alemania..................................20

Gráfico $\mathrm{N}^{\circ}$ 17: Cultivo de hortalizas en Baden Württemberg, año 2010, en porcentaje sobre un total de 9.464 hectáreas..... 21

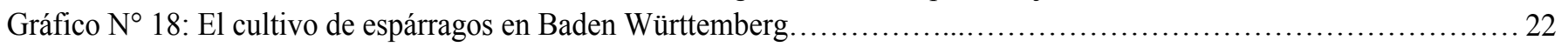

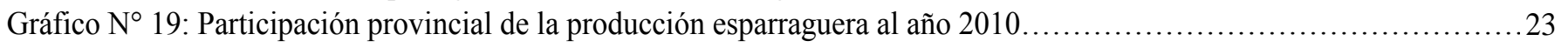

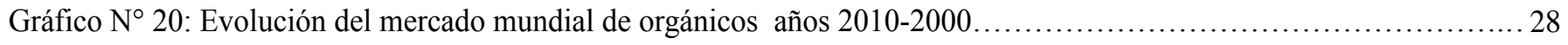

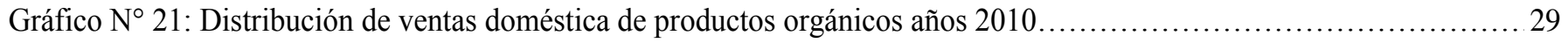

Gráfico $\mathrm{N}^{\circ} 22$ : Exportaciones e importaciones de espárragos frescos en la Unión Europea................................29

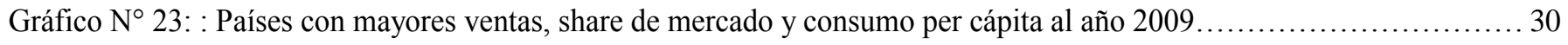

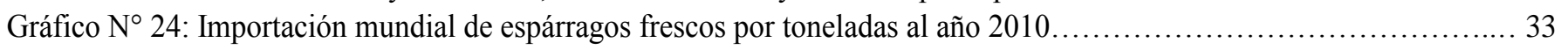

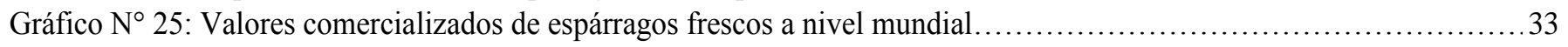

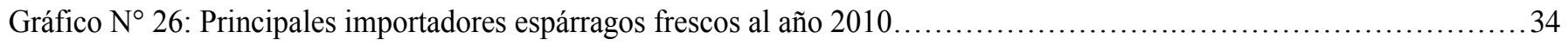

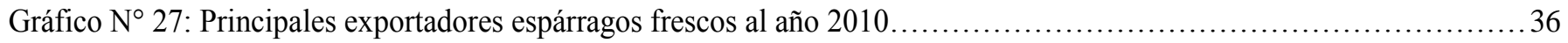

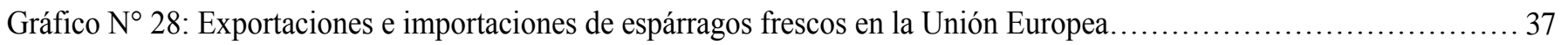

Gráfico $\mathrm{N}^{\circ}$ 29: Origen de la provisión de espárrago fresco en Alemania en toneladas.................................. 42

Gráfico $\mathrm{N}^{\circ}$ 30: Total Neto de espárragos en el mercado alemán (Pcción. + Impo - expo - pérdida en producción)........... 43

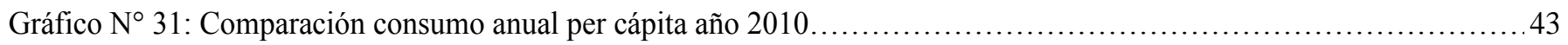

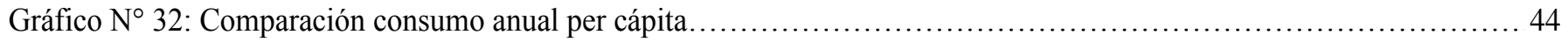

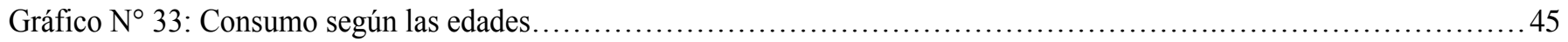

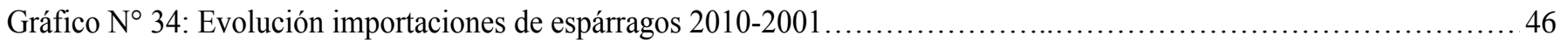

Gráfico $\mathrm{N}^{\circ} 35$ : importaciones de espárragos según el mes del año 2010 en toneladas....................................47

Gráfico $\mathrm{N}^{\circ}$ 36: proveedores de espárragos frescos para el mercado alemán en toneladas................................ 47

Gráfico $\mathrm{N}^{\circ}$ 37: Principales canales de distribución para los espárragos frescos en Alemania................................49

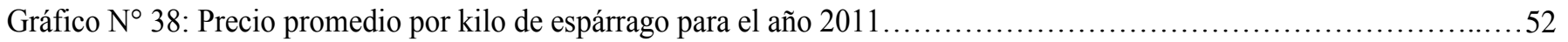

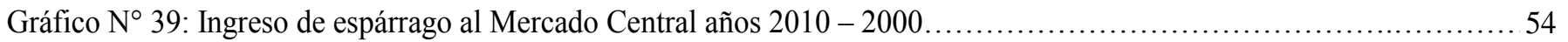

Gráfico $N^{\circ} 40$ : Evolución de las exportaciones argentinas de espárragos en toneladas 2010 - 2001........................55

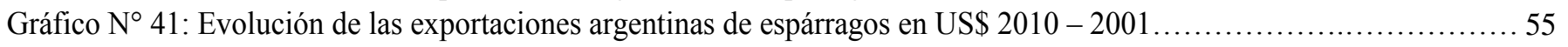

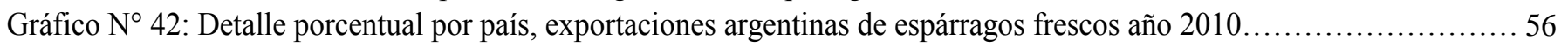

Gráfico $\mathrm{N}^{\circ}$ 43: Respuestas de encuestados alemanes sobre una alimentación sana...................................... 64

Gráfico $\mathrm{N}^{\circ}$ 44: Respuestas de encuestados alemanes sobre consumo de alimentos orgánicos............................64

Gráfico $\mathrm{N}^{\circ} 45$ : Respuestas de encuestados alemanes sobre consumo y nivel de renta.................................65 


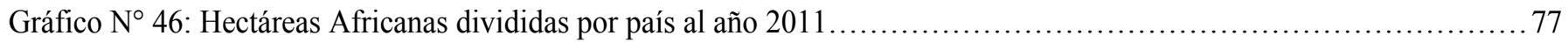

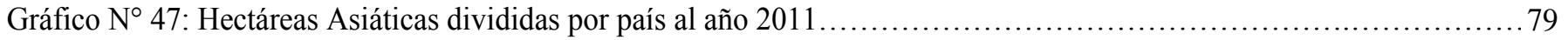

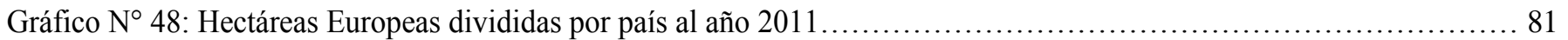

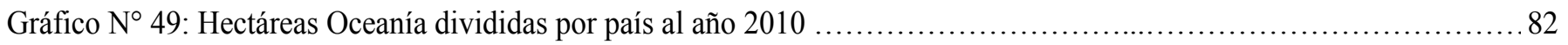

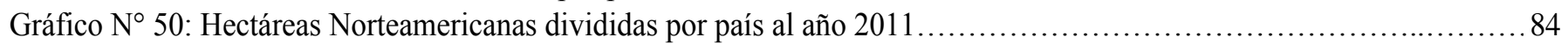

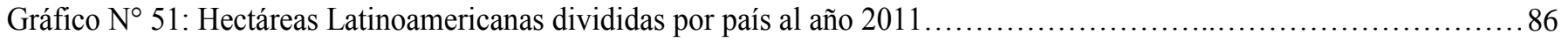

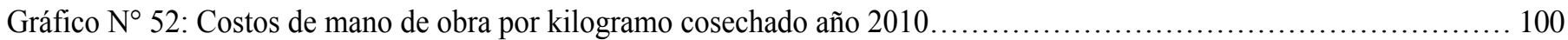

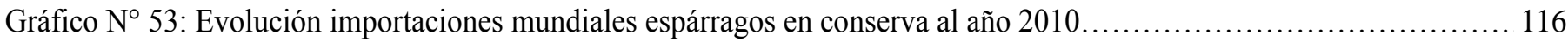

Gráfico $N^{\circ}$ 54: Evolución de las importaciones alemanas en espárragos en conserva...................................... 120

Gráfico $\mathrm{N}^{\circ}$ 55: Evolución de las importaciones mensuales en espárragos en conserva año 2010........................ 121

Gráfico $\mathrm{N}^{\circ}$ 56: Evolución de las importaciones mensuales en espárragos congelados año 2010......................... 122

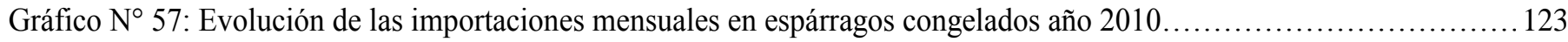

Gráfico $N^{\circ}$ 58: Participación de los grupos empresarios en la distribución......................................... 136

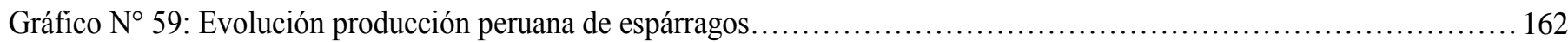

Gráfico $\mathrm{N}^{\circ}$ 60: Evolución de las exportaciones peruanas de espárragos frescos...................................... 164

Gráfico $\mathrm{N}^{\circ}$ 61: Evolución de las exportaciones peruanas de espárragos en conserva...................................... 165

Gráfico $\mathrm{N}^{\circ}$ 62: Evolución de las exportaciones peruanas de espárragos congelados................................ 166

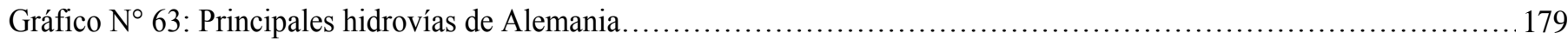

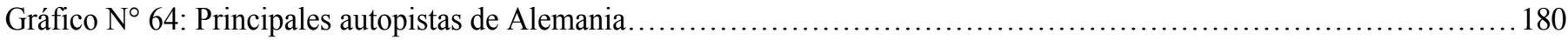

Gráfico $\mathrm{N}^{\circ}$ 65: Principales aeropuertos de Alemania................................................................... 181 


\section{Índice de tablas}

Tabla $\mathrm{N}^{\circ}$ 1: Evolución de las hectáreas por continente según informe FiBL año 2011:.................................. 2

Tabla $\mathrm{N}^{\circ}$ 2: Número de Establecimientos dedicados a la producción orgánica años $2010-2009 \ldots \ldots \ldots \ldots \ldots \ldots \ldots \ldots \ldots . \ldots . \ldots \ldots$

Tabla $\mathrm{N}^{\circ} 3$ : Evolución de la producción por principales países productores en toneladas.............................. 11

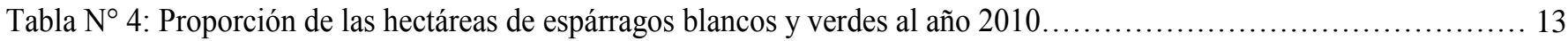

Tabla $\mathrm{N}^{\circ}$ 5: Estacionalidad de la producción de los principales países productores.................................... 16

Tabla $\mathrm{N}^{\circ}$ 6: Estados productores, rendimiento por hectárea y producción en toneladas años $2010-2009 \ldots \ldots \ldots \ldots \ldots \ldots \ldots 18$

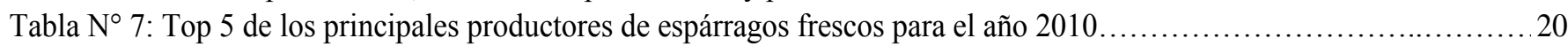

Tabla $\mathrm{N}^{\circ}$ 8: Espárragos, producción y neto disponible en el mercado alemán en la última década......................... 21

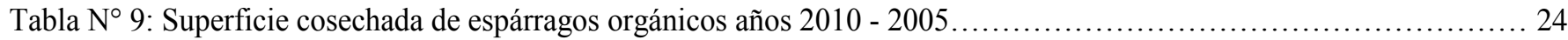

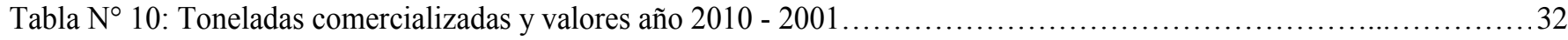

Tabla $\mathrm{N}^{\circ}$ 11: Principales importadores mundiales espárragos frescos: Cifras en toneladas................................ 33

Tabla $\mathrm{N}^{\circ}$ 12: Principales exportadores mundiales espárragos frescos o refrigerados en toneladas............................36

Tabla $\mathrm{N}^{\circ}$ 13: Detalle principales proveedores espárragos frescos al mercado alemán años 2010-2001 en toneladas...........48

Tabla $\mathrm{N}^{\circ}$ 14: Detalle principales proveedores de espárragos frescos al mercado alemán año 2010 en toneladas............. 49

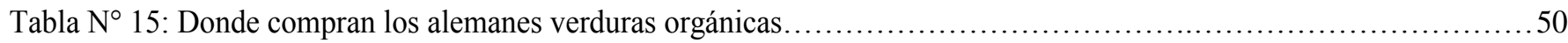

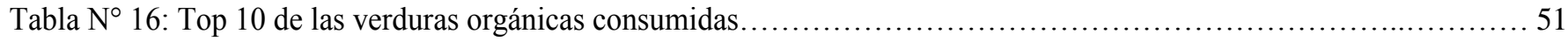

Tabla $\mathrm{N}^{\circ}$ 17: Importaciones argentinas de espárragos frescos en toneladas........................................... 53

Tabla $\mathrm{N}^{\circ}$ 18: Comparación ingreso de espárragos al Mercado Central...............................................5 54

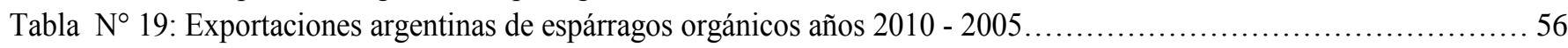

Tabla $\mathrm{N}^{\circ}$ 20: Caracterización de la muestra encuestada en el estado de Baden Württemberg............................. 61

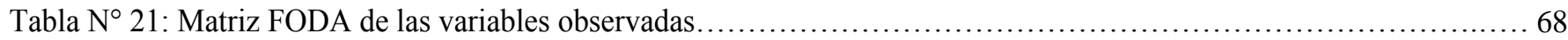

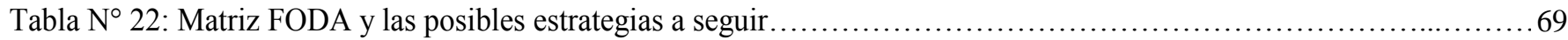

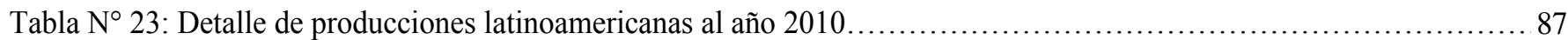

Tabla $\mathrm{N}^{\circ}$ 24: Detalle del total de hectáreas y número de productores a nivel mundial...................................992

Tabla $\mathrm{N}^{\circ} 25$ : Áreas producción asiática espárragos año 2010, cambios hectáreas y rendimientos promedios..................96

Tabla $N^{\circ}$ 26: Áreas producción norteamericana espárragos año 2010, cambios área y rendimientos promedios..............96 96

Tabla $\mathrm{N}^{\circ} 27$ : Áreas producción latinoamericana espárragos año 2010, cambios área y rendimientos promedios..............96

Tabla $\mathrm{N}^{\circ}$ 28: Producción africana espárragos año 2010, cambios en área y rendimientos promedios....................... 97

Tabla $\mathrm{N}^{\circ}$ 29: Áreas Oceanía producción espárragos año 2010, cambios en área y rendimientos promedios..................97

Tabla $\mathrm{N}^{\circ}$ 30: Áreas europeas producción espárragos año 2010, cambios en área y rendimientos promedios...................97

Tabla $\mathrm{N}^{\circ}$ 31: Estacionalidad de la producción de los productores de espárragos...................................... 98

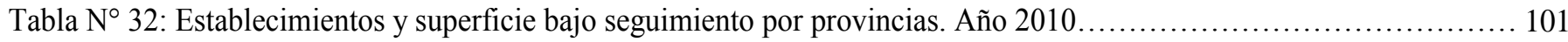

Tabla N 33: Superficie Orgánica Cosechada por Grupos de Cultivos. (Ha) Año 2010 ............................... 103

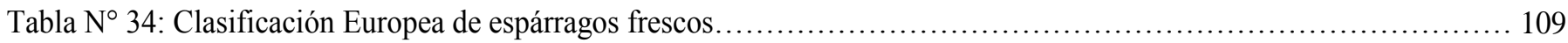

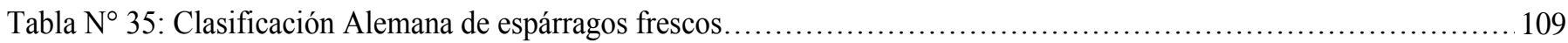

Tabla $N^{\circ}$ 36: Detalle de la evolución de las importaciones de espárragos en conserva.................................. 115

Tabla $N^{\circ} 37$ : Asia: consumo doméstico y exportación de espárragos frescos o refrigerados años 2005-2009............... 116

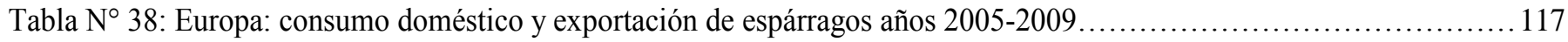

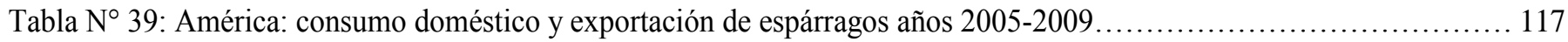

Tabla $N^{\circ}$ 40: Sudamérica: consumo doméstico y exportación de espárragos frescos años 2005-2009..................... 118

Tabla $N^{\circ} 41$ : África: consumo doméstico y exportación de espárragos años 2005-2009................................ 118

Tabla $N^{\circ} 42$ : Oceanía: consumo doméstico y exportación de espárragos años 2005-2009.................................118

Tabla N 43: Detalle Europeo de Exportaciones e Importaciones año 2010 - 2001 en toneladas...........................119

Tabla $N^{\circ} 44$ : Detalle principales proveedores espárragos conserva mercado alemán años 2010-2001 toneladas.............. 121

Tabla $N^{\circ} 45$ : Detalle principales proveedores espárragos conserva mercado alemán año 2010 toneladas.................... 121 
Tabla N 46: Principales proveedores espárragos congelados mercado alemán años 2010-2001 toneladas.................. 122

Tabla $\mathrm{N}^{\circ}$ 47: Detalle mensual proveedores espárragos congelados mercado alemán año 2010 toneladas.................... 123

Tabla $\mathrm{N}^{\circ}$ 48: Detalle anual precio pagado por Alemania tonelada espárrago fresco años 2010-2001 ..................... 124

Tabla $N^{\circ}$ 49: Detalle anual precio pagado por Alemania tonelada espárrago conserva años 2010-2001_................. 125

Tabla $\mathrm{N}^{\circ}$ 50: Detalle anual precio pagado por Alemania tonelada espárrago congelado años 2010-2001...................125

Tabla $\mathrm{N}^{\circ}$ 51: Detalle anual de las exportaciones alemanas de espárrago fresco en toneladas años 2010-2001............... 126

Tabla $\mathrm{N}^{\circ}$ 52: Detalle anual exportaciones alemanas espárrago conserva en toneladas años 2010-2001....................126

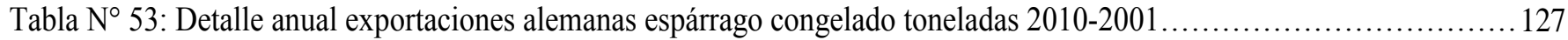

Tabla $\mathrm{N}^{\circ}$ 54: Detalle precio mayorista espárragos alemanes y griegos "Clase Extra" semana/euros por Kg.................. 128

Tabla $\mathrm{N}^{\circ}$ 55: Detalle de precio mayorista de espárragos alemanes y griegos "Clase I" detallado por semana.................129

Tabla $\mathrm{N}^{\circ}$ 56: Listado de los principales supermercados en Alemania................................................... 143

Tabla $\mathrm{N}^{\circ}$ 57: Listado de los principales importadores alemanes de espárragos frescos................................ 144

Tabla $\mathrm{N}^{\circ}$ 58: Listado de los principales importadores alemanes de espárragos en conserva................................ 146

Tabla $\mathrm{N}^{\circ}$ 59: Listado de los principales importadores alemanes de alimentos orgánicos................................... 148

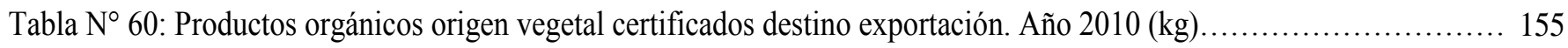

Tabla $N^{\circ}$ 61: Productos orgánicos de origen vegetal certificados destino Unión Europea. Año $2010(\mathrm{~kg}) \ldots \ldots \ldots \ldots \ldots \ldots \ldots \ldots \ldots$

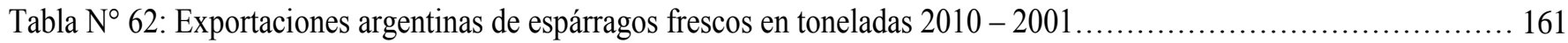

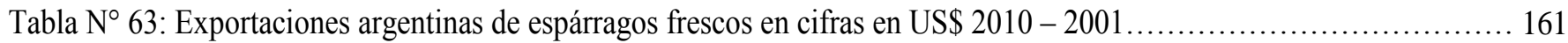

Tabla $N^{\circ}$ 64: Evolución de la producción de espárragos en el Perú año 2010 - 2000................................... 163

Tabla $\mathrm{N}^{\circ}$ 65: Detalle de las exportaciones peruanas de espárragos frescos por país 2010 - 2001_........................ 164

Tabla $\mathrm{N}^{\circ}$ 66: Detalle de las exportaciones peruanas de espárragos en conserva por país................................ 165

Tabla $\mathrm{N}^{\circ}$ 67: Detalle de las exportaciones peruanas de espárragos congelados por país.................................... 166

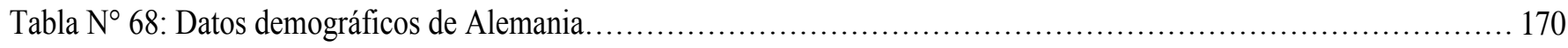

Tabla N 69: Antiguos y Nuevos Länder de Alemania............................................................ 172 


\section{Capítulo 1: Producción orgánica y de espárragos a nivel mundial, en Alemania y Argentina}

\section{Agricultura orgánica mundial}

\subsection{Introducción: Escenario Actual}

La agricultura y ganadería orgánica es la forma más antigua de producción de alimentos. Sin embargo, con el correr de los años, sobre todo durante las últimas seis décadas, fue perdiendo espacio a partir de las necesidades de mayor producción ante una población que creció hasta superar los 6.000 millones de habitantes. El avance de la técnica y el desarrollo de otras formas de producción, apoyado en el uso de productos químicos tanto para el cuidado de las plantas como para su nutrición, y más recientemente la manipulación genética de vegetales y animales, ha sido una de las soluciones encontradas a los problemas de volumen productivo y condiciones climáticas y geógrafas adversas.

Hoy en día observamos que los habitantes de los países más desarrollados del planeta, cada día se vuelcan mas a demandar alimentos naturales, producidos sin la intervención de agentes externos a la naturaleza, mostrándose dispuestos a pagar precios superiores por este tipo de productos. Según la Organización de las naciones Unidas para la Agricultura y la Alimentación, en la actualidad el porcentaje de consumo de alimentos orgánicos sobre el total de alimentos consumidos en los principales países desarrollados va desde un $1 \%$ a un $10 \%$ en algunos casos, cifra alcanzada en los últimos 20 años principalmente.

En la actualidad coexisten un gran número de movimientos en el mundo que se encargan de promover y profundizar esta temática. En la República Argentina ha adquirido singular importancia en el sector productivo y se ha organizado principalmente bajo el Movimiento Argentino para la Producción Orgánica (MAPO), y más recientemente el Sistema Orgánico Argentino (SOA) constituido por MAPO, la Cámara de Certificadores de Argentina (CACER) y la Cámara de Productores Orgánicos de Argentina (CAPOC). En la Argentina reviste características particulares, coincidentemente con otros países en desarrollo productores de orgánicos, dado que la producción se orienta casi en su totalidad para la exportación. Aunque se prevé que la producción de alimentos de manera convencional seguirá liderando la producción masiva de alimentos, la demanda de consumo de alimentos y fibras producidas 
orgánicamente brinda nuevas oportunidades de mercado a los agricultores y a las actividades empresariales en todo el mundo.

\subsection{Tierras orgánicas dedicadas a la producción orgánica por continente}

Otras de las variables que considero importante destacar es la evolución de la tierra dedicada a la producción de alimentos orgánicos certificados y en proceso de certificación. Esto nos muestra la tendencia que están teniendo los distintos países. A continuación se puede evidenciar la evolución que han experimentado los continentes, como así también cual es la situación al año 2009.

Tabla $N^{\circ}$ 1: Evolución de las hectáreas por continente según informe FiBL año 2011:

\begin{tabular}{|c|c|c|c|c|c|}
\hline Continente (hts) & $\mathbf{2 0 0 5}$ & $\mathbf{2 0 0 6}$ & $\mathbf{2 0 0 7}$ & $\mathbf{2 0 0 8}$ & $\mathbf{2 0 0 9}$ \\
\hline África & 331.697 & 417.059 & 870.329 & 948.659 & 1.026 .632 \\
\hline Asia & 2.682 .630 & 3.090 .924 & 2.881 .745 & 3.141 .102 & 3.581 .918 \\
\hline Europa & 6.886 .078 & 7.389 .085 & 7.758 .526 & 8.456 .793 & 9.259 .934 \\
\hline América Latina & 4.712 .562 & 4.915 .643 & 6.402 .875 & 6.979 .134 & 8.558 .910 \\
\hline América del Norte & 2.199 .225 & 2.224 .755 & 2.197 .077 & 2.394 .814 & 2.652 .624 \\
\hline Oceanía & 11.760 .884 & 12.380 .261 & 12.110 .758 & 13.200 .726 & 12.152 .108 \\
\hline Total & $\mathbf{2 8 . 5 7 3 . 0 7 6}$ & $\mathbf{3 0 . 4 1 7 . 7 2 7}$ & $\mathbf{3 2 . 2 2 1 . 3 1 0}$ & $\mathbf{3 5 . 1 2 1 . 2 2 8}$ & $\mathbf{3 7 . 2 3 2 . 1 2 6}$ \\
\hline
\end{tabular}

Fuente: Elaboración propia en base a datos obtenidos en FiBL e IFOAM

Gráfico $N^{\circ}$ 1: Evolución tierras dedicadas a la agricultura al año 2009:

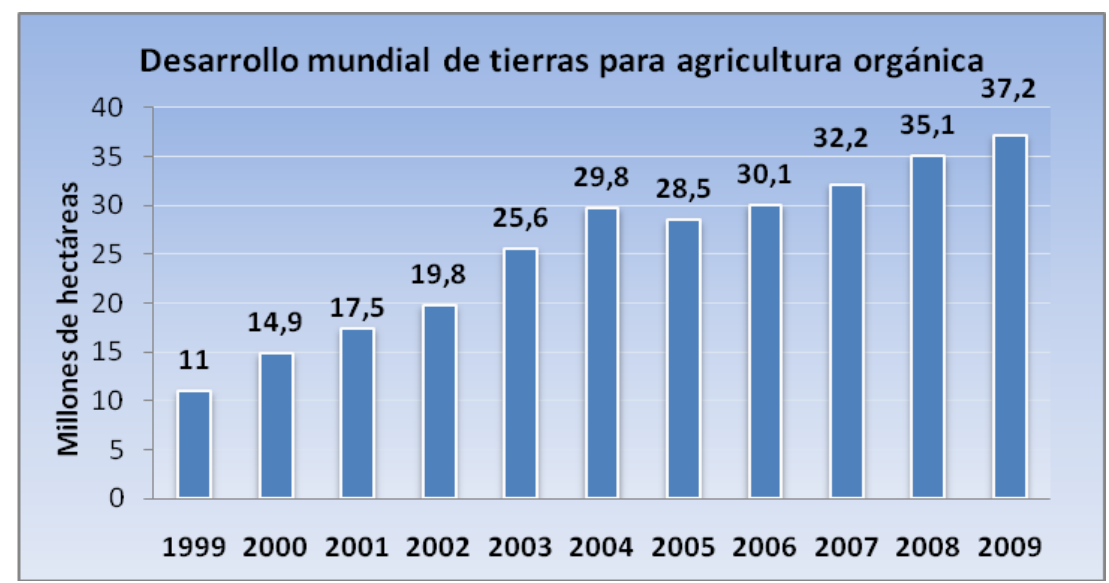

Fuente: elaboración propia en base a datos obtenidos en FiBL, IFOAM año 2011 
Gráfico N 2: Distribución de las hectáreas por continente al año 2009:

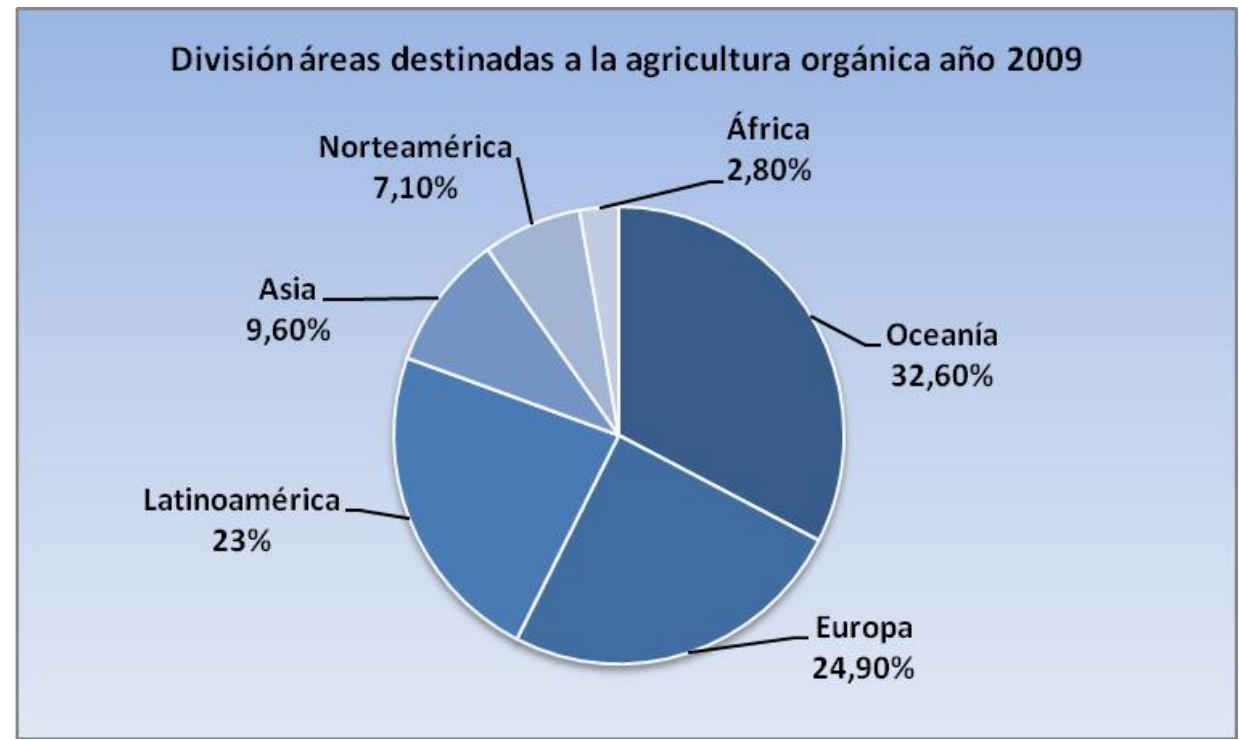

Fuente: elaboración propia en base a datos obtenidos en FiBL e IFOAM año 2011.

Gráfico $\mathrm{N}^{\circ}$ 3: Principales países con tierra orgánica al año 2009:

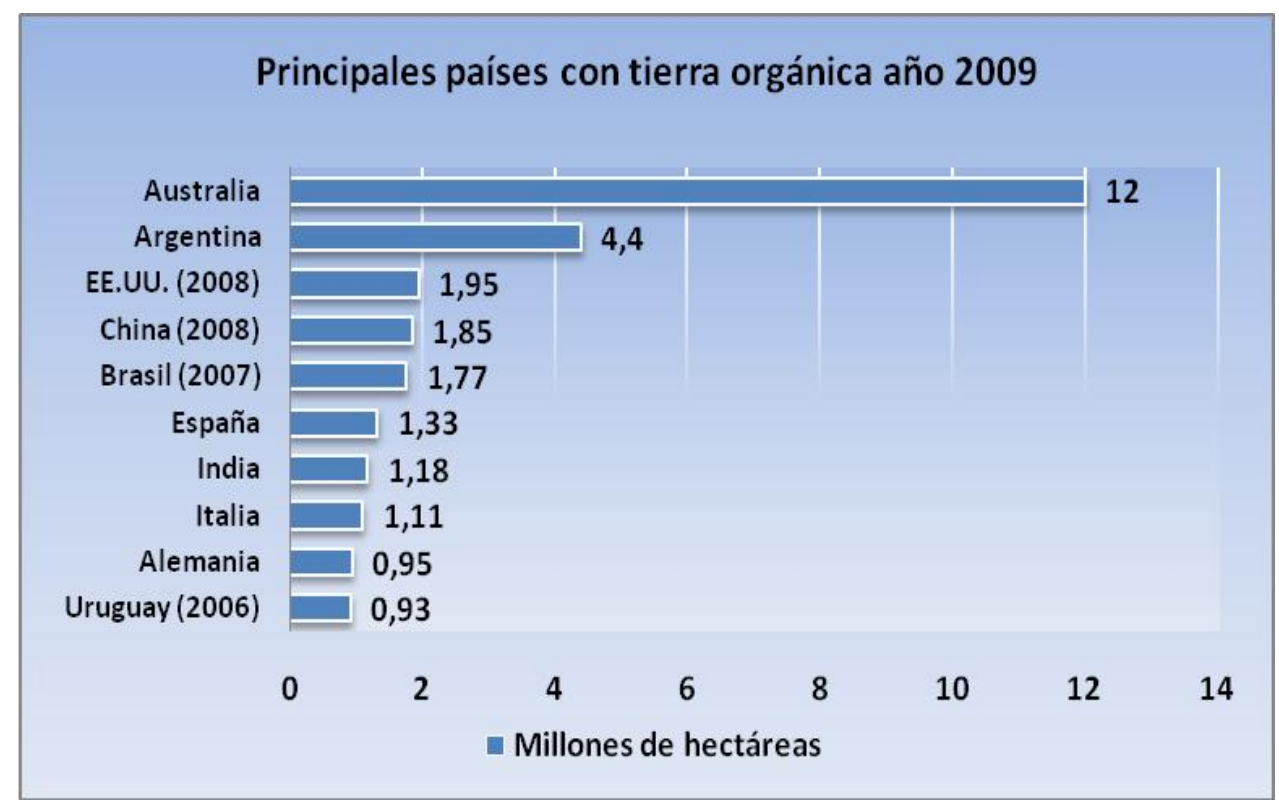

Fuente: elaboración propia en base a datos obtenidos en FiBL e IFOAM 2011. 


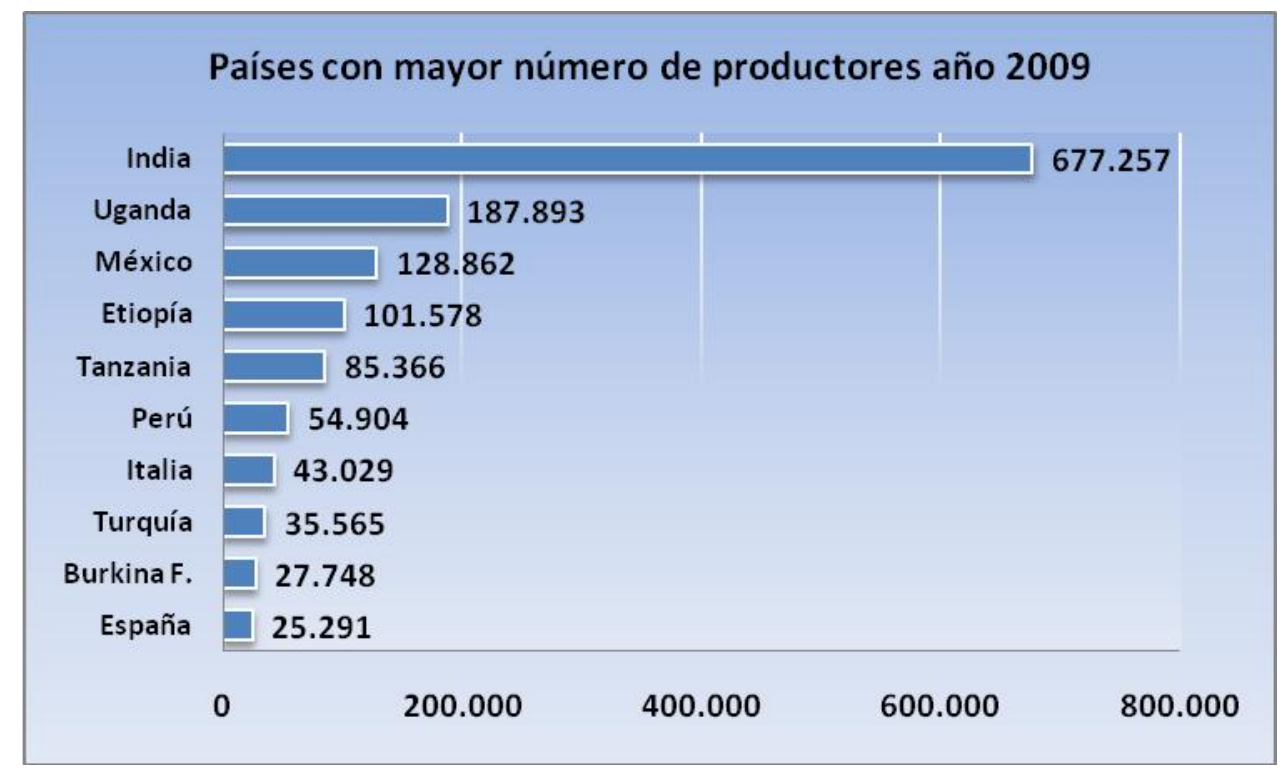

Fuente: elaboración propia en base a datos obtenidos en FiBL e IFOAM 2011.

Al ver los últimos 2 gráficos, vemos que no se condice el área destinada a la producción con el número de productores. Esto prácticamente se da por la gran cantidad de pequeños productores que se dan en África, como en la India.

\section{Agricultura orgánica en Alemania}

\subsection{Introducción}

Alemania cuenta actualmente con una población de más de 82,4 millones de habitantes, la mayor de los miembros de la Unión Europea, y es el primer importador mundial de alimentos. Alemania es asimismo el segundo mercado más grande en importaciones productos hortofrutícolas después de Estados Unidos.

Al igual que en el resto de la Unión Europea, Alemania ha registrado un cambio importante en los hábitos de consumo, con una tendencia creciente a la adquisición de productos saludables, entre los cuales las frutas y hortalizas ocupan un lugar importante.

Según Hans-Christoph Behr, representante de la Agrarmarkt-Informations-Gesellschaft de Berlín (Sociedad para la Información Agrícola) ${ }^{1}$ el sector orgánico (tanto alimentos como bebidas orgánicas)

\footnotetext{
${ }^{1}$ Disponible en www.marktundpreis.de
} 
facturó aproximadamente $€ 5.900$ millones en 2010 .

La fusión de las cadenas de descuento y la reducción de precios sin aumento del volumen de venta fueron las causas principales de este proceso. Asimismo, la Bundes Ökologische Lebensmittelwirtschaft (BÖLW) (Federación del Sector Alimentario Orgánico Alemán ${ }^{2}$ ) anunció un aumento en el número de establecimientos y de las hectáreas dedicadas al cultivo ecológico.

Si se suman las empresas que producen según el estándar UE (menos estricto que la norma alemana) el total de empresas asciende a más de 21.000 y la superficie cultivada llega a 989.400 hectáreas al año 2010. De esta forma el sector orgánico representa 5,9\% de las empresas alimentarias y cubren 5,6\% del total de hectáreas cultivadas.

\subsection{Antecedentes históricos y situación al 2010.}

Alemania es la cuna de la agricultura orgánica o ecológica. En este país comenzó su antecesora más inmediata; la agricultura biodinámica, iniciada por Rudolf Steiner, en 1924.

Hacia fines de la década del '60, la agricultura orgánica constituyó una respuesta al impacto negativo de la industrialización agrícola sobre el medioambiente. Aproximadamente el $10 \%$ de los hogares alemanes se define como consumidor habitual de alimentos orgánicos. Suelen ser familias con hijos pequeños, así como personas de entre 41 y 50 años con un mediano - alto nivel educacional, siendo las mujeres las principales decisoras sobre la compra de alimentos orgánicos, según un informe de Stiftung Ökologie und Landbau (Fundación Alemana para la Agricultura Ecológica) ${ }^{3}$.

En términos de hectáreas, Alemania, representa el segundo lugar en Europa (después de Italia con más de 1 millón de hectáreas), como el país proveedor número uno de productos orgánicos del continente. En cambio, en términos relativos, es decir, si se considera el coeficiente de hectáreas dedicadas a la agricultura orgánica respecto a la superficie de agricultura convencional total, Austria ocupa el primer lugar con $8,45 \%$ de las nombradas hectáreas. Respecto a los establecimientos, la mayoría de las explotaciones orgánicas se ubican en el sur del país, principalmente en los estados de BadenWürttemberg y Baviera.

\footnotetext{
${ }^{2}$ Disponible en www.boelw.de

${ }^{3}$ Disponible en www.soel.de
} 
Gráfico $\mathrm{N}^{\circ}$ 5: Total de hectáreas orgánicas discriminadas por estado federado alemán al 2010:

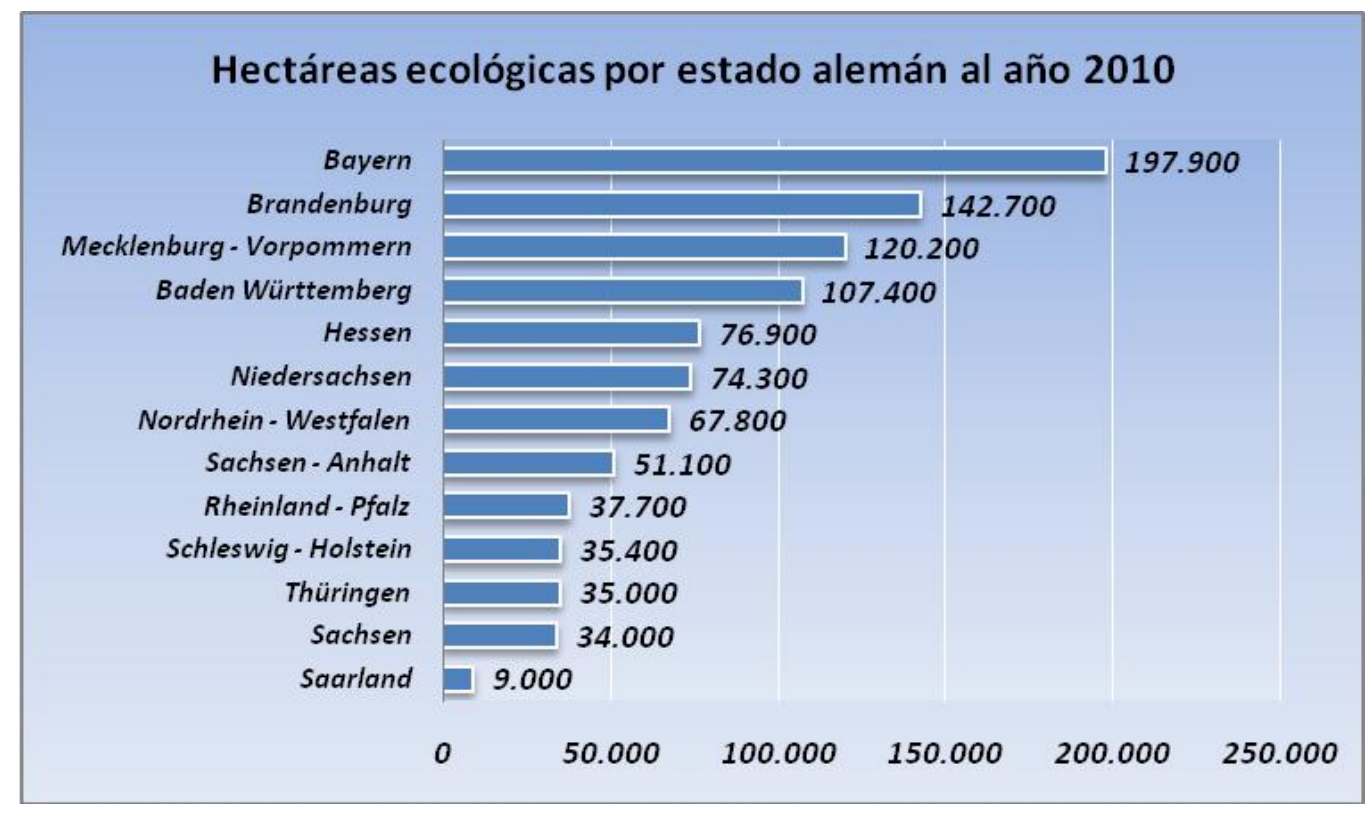

Fuente: elaboración propia en base a datos de www.ami-informiert.de año 2011.

Gráfico $N^{\circ}$ 6: Evolución mercado productos orgánicas años 2010 - 2000:

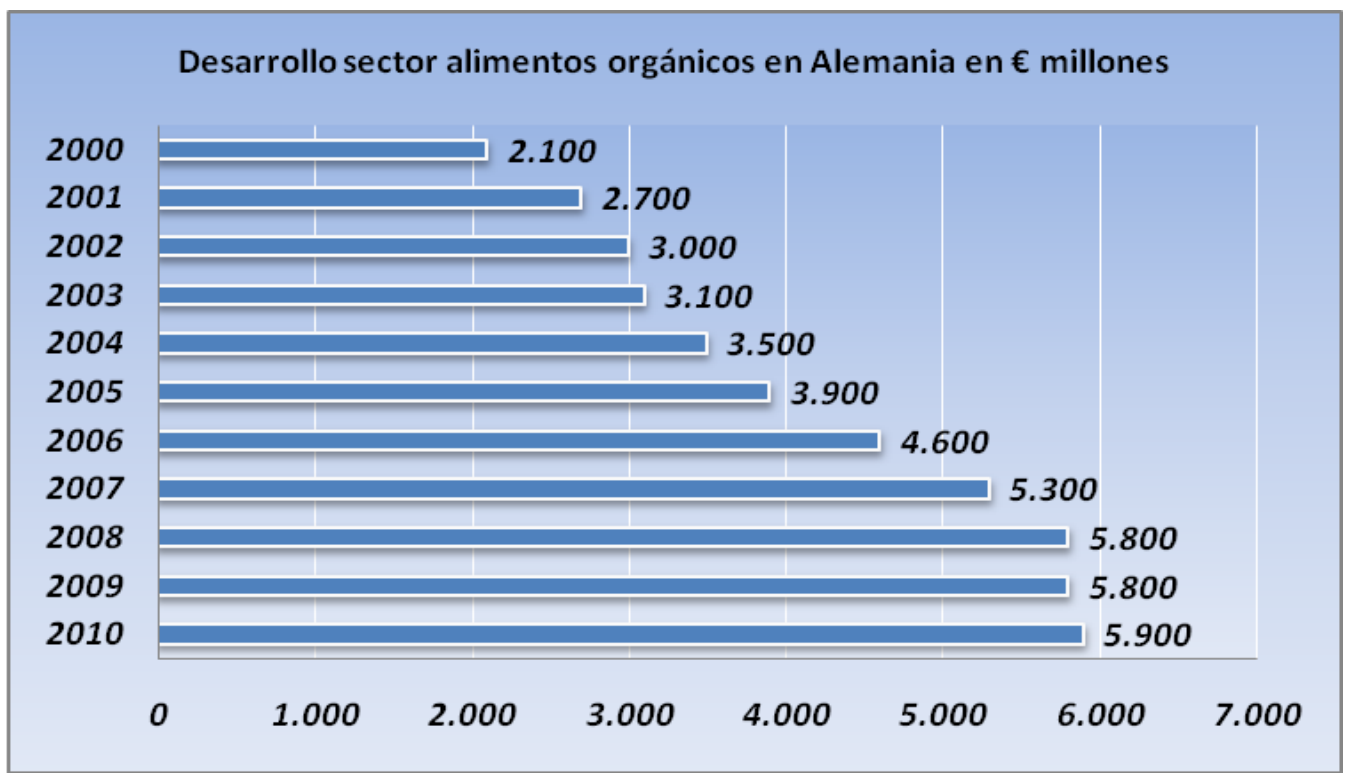

Fuente: Hamm, Universität Kassel, AMI, AC Nielsen, GfK 


\section{Agricultura orgánica en Argentina}

\subsection{Superficie en Argentina}

Para el caso de este punto, nos referimos a la superficie orgánica cosechada de cultivos industriales, de aromáticas, hortalizas, legumbres, frutales, cereales y oleaginosas. Durante el año 2010 la superficie orgánica cosechada mostró un aumento del $23 \%$ con respecto a 2009. Se pasó de 56.290 a 69.337 hectáreas. Las cifras por grupos de cultivos muestran que los cereales y oleaginosas fueron los que marcaron dicho aumento (41\%) y recuperaron la tendencia observada desde el año 2005. La superficie cosechada en el 2010 se ubica por encima del promedio de los últimos 5 años y mostró una recuperación con respecto a la caída observada en el año 2009. La provincia de Buenos Aires fue la que presentó el mayor crecimiento de la superficie agrícola orgánica cosechada, recuperando los niveles del 2008, siendo la principal productora de cultivos orgánicos. También se destacó la provincia de Río Negro la que incrementó su superficie cosechada y su participación en el total. Entre Ríos y Salta decrecieron por una disminución de la superficie cosechada. Los principales cultivos orgánicos cosechados pertenecieron, tal como en años anteriores, al grupo de los cereales y oleaginosas.

Gráfico $N^{\circ} 7$ : Superficie orgánica argentina cosechada años 2010 - 1995:

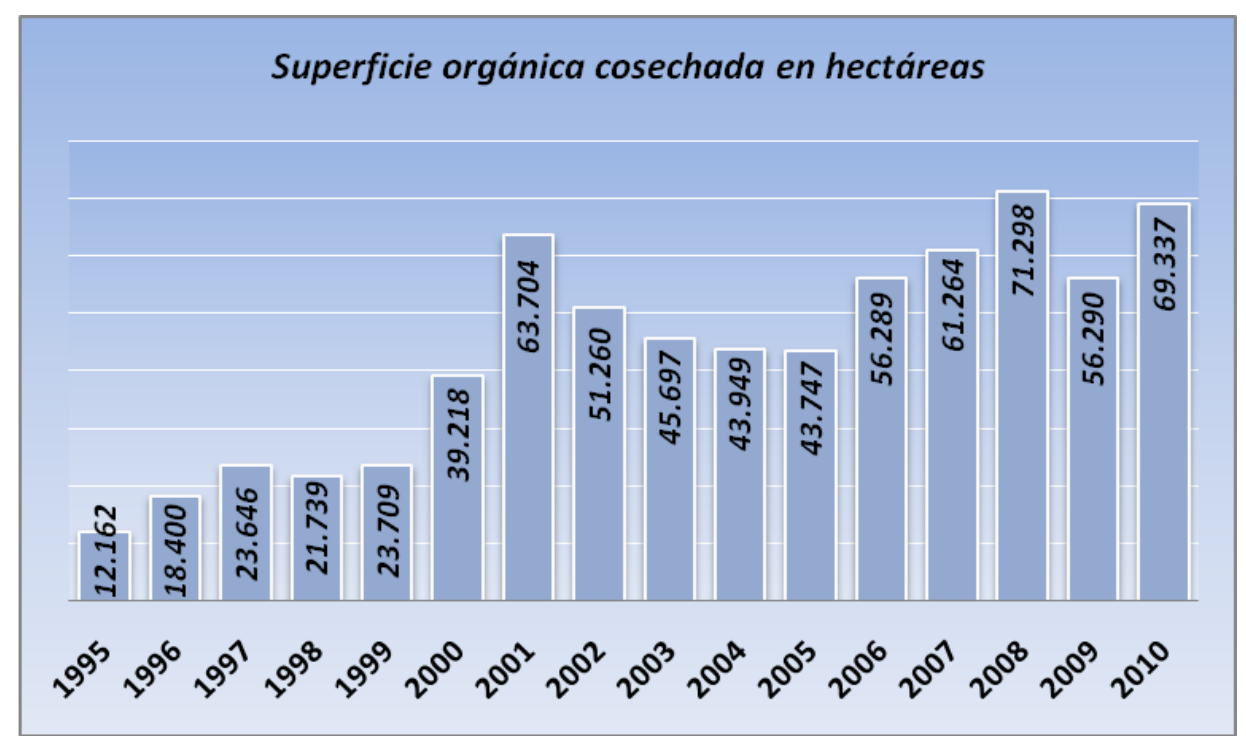

Fuente: SENASA 2011. En base a información de las certificadoras.

Tal como podemos observar en el gráfico, luego de la crisis de 2001 las hectáreas dedicadas a la explotación de orgánicos se redujo drásticamente, para luego ir recuperando terreno hasta el 2009 donde se experimentó la crisis mundial financiera inmobiliaria. Por suerte, la situación en el año 2010 
fue cambiando para ir recuperando terreno según lo informado por SENASA.

\subsection{Provincias productoras y análisis de las unidades productivas}

Según un informe del SENASA, durante el 2010 se observó una leve disminución del número de explotaciones agropecuarias comprendidas en el sistema, pasando de 1.894 establecimientos en 2009 a 1.856 en 2010.Si bien a nivel provincial la variación del número de explotaciones fue dispar (algunas aumentaron y otras bajaron) se destaca la disminución de operadores en la provincia de Córdoba que perdió 20 operadores activos en 2010, llegando a un total de 37 establecimientos.

A nivel nacional el tamaño medio de los establecimientos bajo seguimiento se mantiene similar al 2009. Respecto al detalle provincial, hubo un comportamiento dispar, pero predominan las situaciones de descenso. Cabe destacar también que la proporción de superficie bajo seguimiento con respecto a la superficie total de los establecimientos alcanza el $95 \%$.

Tabla $\mathrm{N}^{\circ}$ 2: Número de Establecimientos dedicados a la producción orgánica años 2010 - 2009:

\begin{tabular}{|c|c|c|c|c|}
\hline$N^{\circ}$ Establecimientos & 2009 & 2010 & Var. Abs. & Var. \% \\
\hline Total del País & 1.894 & 1.856 & -38 & -2 \\
\hline Buenos Aires & 227 & 229 & 2 & 1 \\
\hline Catamarca & 15 & 16 & 1 & 7 \\
\hline Chaco & 16 & 19 & 3 & 19 \\
\hline Chubut & 70 & 67 & -3 & -4 \\
\hline Córdoba & 57 & 37 & -20 & -35 \\
\hline Corrientes & 15 & 18 & 3 & 20 \\
\hline Entre Rios & 57 & 56 & -1 & -2 \\
\hline Formosa & 210 & 220 & 10 & 5 \\
\hline Jujuy & 9 & 9 & 0 & 0 \\
\hline La Pampa & 23 & 20 & -3 & -13 \\
\hline La Rioja & 26 & 26 & 0 & 0 \\
\hline Mendoza & 233 & 232 & -1 & 0 \\
\hline Misiones & 484 & 474 & -10 & -2 \\
\hline Neuquén & 68 & 63 & -5 & -7 \\
\hline Río Negro & 172 & 168 & -4 & -2 \\
\hline Salta & 25 & 26 & 1 & 4 \\
\hline San Juan & 61 & 55 & -6 & -10 \\
\hline San Luis & 14 & 12 & -2 & -14 \\
\hline Santa Cruz & 17 & 18 & 1 & 6 \\
\hline Santa $\mathrm{Fe}$ & 31 & 26 & -5 & -16 \\
\hline Santiago del Estero & 45 & 48 & 3 & 7 \\
\hline Tierra del Fuego & 6 & 6 & 0 & 0 \\
\hline Tucumán & 13 & 11 & -2 & -15 \\
\hline
\end{tabular}

Fuente: SENASA 2011. En base a información de Certificadoras. 
Gráfico $N^{\circ}$ 8: Distribución de establecimientos discriminados por provincia al año 2010:

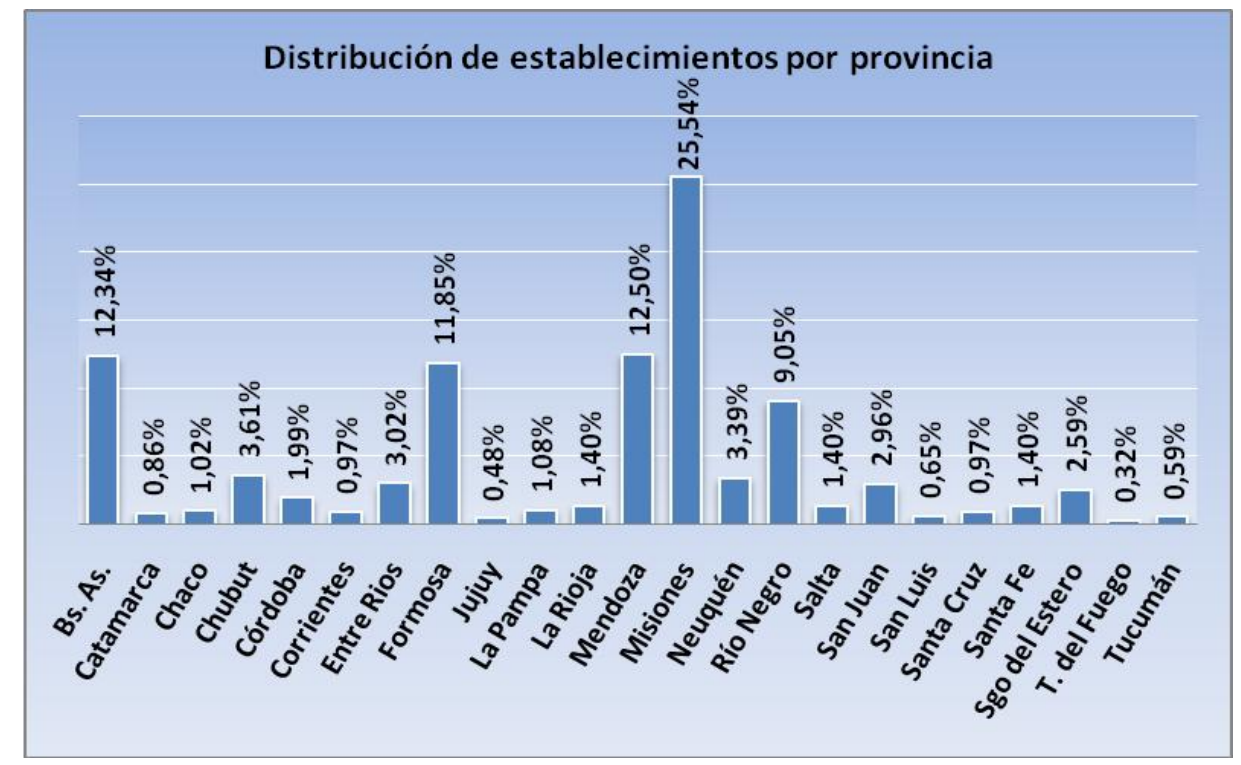

Fuente: Informe de la producción orgánica en Argentina 2010. SENASA 2011.

\subsection{Análisis del destino de la producción}

El principal destino de la producción orgánica certificada continuó siendo la exportación. Entre los destinos más importantes se encuentran, Unión Europea, EE. UU. y Suiza. Asimismo se destacan otros destinos como por ejemplo Rusia, Canadá, Ecuador, Noruega y Brasil.

Las exportaciones de origen vegetal a Unión Europea disminuyeron un 13\% respecto al $2009^{4}$. A pesar de ello la UE, con el 54\% del total exportado sigue siendo el principal destino. Dentro de la UE los principales destinos fueron Holanda, Reino Unido y Alemania. Los grupos de productos más destacados fueron las frutas, las oleaginosas y las hortalizas.

Estados Unidos aumentó su participación alcanzando el 26\% de total de lo exportado, como resultado del mayor volumen exportado respecto al año 2009. Para dicho destino han sido relevantes las exportaciones de cereales y oleaginosas. Suiza y Japón descendieron en su participación relativa en el total exportado, debido a una caída de los volúmenes de exportación del 15\% y 50\% respectivamente.

\footnotetext{
${ }^{4}$ Para mayor detalle ver pág. 158 , Tabla $\mathrm{N}^{\circ} 61$.
} 


\section{4 "Tips" del año 2010}

Según datos del SENASA, podemos mencionar que la producción orgánica argentina durante el 2010 presentó los siguientes rasgos:

1. Predominancia de las exportaciones a países de la Unión Europea.

2. Con relación a los grupos de productos de origen vegetal, el principal volumen exportado correspondió a las frutas. Con respecto a todos los productos de origen vegetal en su conjunto, se destacaron los volúmenes exportados de peras, el azúcar de caña, las manzanas y la soja orgánica.

3. Se destacó el crecimiento de los cereales y oleaginosas, frente a la caída de los otros grupos de productos. Las mayores tasas de incremento de las exportaciones de productos orgánicos de origen vegetal se registraron en oleaginosas (soja y cártamo) y en segundo lugar en cereales y productos industrializados (arroz, maíz y expeller de girasol).

4. Disminuyó la exportación de Hortalizas (cebolla y zapallo) y de cereales y oleaginosas como el trigo y el girasol.

5. Entre las exportaciones de productos orgánicos de origen animal se destaca el crecimiento de las ventas de lana y de miel.

6. La superficie cosechada creció en un $23 \%$ con respecto a 2009, alcanzando el segundo mayor valor del los últimos diez años, llegando a las 69.337 de hectáreas. Dicho incremento puede explicarse por la recuperación de la superficie cosechada con trigo y soja.

7. La mayor superficie cosechada de frutales correspondió a pera y manzana. En hortalizas se destacó el ajo, y entre las legumbres los porotos.

8. La superficie destinada a la actividad ganadera disminuyó un 5\%, principalmente por la disminución de la superficie dedicada a la actividad ovina.

\section{Producción mundial de espárragos}

\subsection{Superficie mundial cultivada ${ }^{5}$}

De acuerdo a datos de California Asparagus Seed and Transplants y del consultor internacional Christian Befve para el año 2010, la superficie total de espárragos cultivada en el mundo asciende a 201.464 hectáreas. El mayor porcentaje corresponde a la República Popular China, quien habría

\footnotetext{
${ }^{5}$ Organización Naciones Unidas para la Agricultura y la Alimentación FAO
} 
cultivado en 2010, 57.000 hectáreas, cifra que rondaría el 27,15\% de la superficie total relevada. El segundo país en cantidad absoluta de recurso tierra destinado para el cultivo del espárrago es el Perú con 26.800 hectáreas. El tercer lugar corresponde a Alemania con 18.814 hectáreas. Otros países que se mantienen por encima de las 10.000 hectáreas cultivadas, son: México, EE.UU. y España.

Gráfico N 9: Distribución producción espárragos a nivel mundial al año 2010:

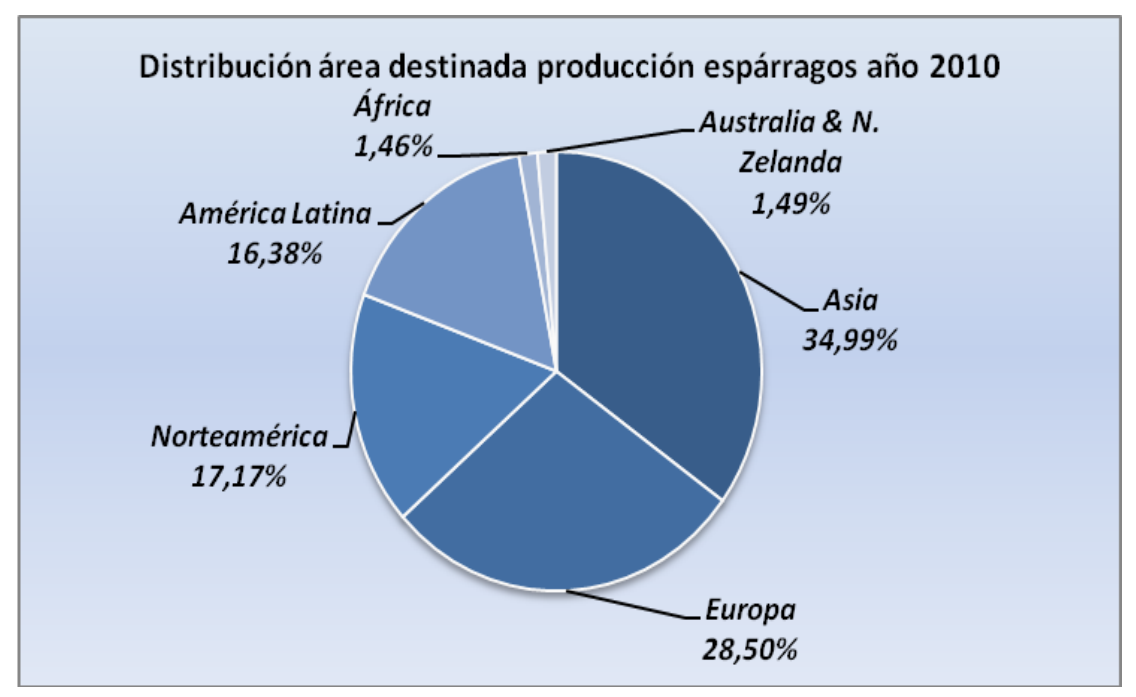

Fuente: Dr. Christian Befve, especialista mundial en espárragos

\subsection{Producción mundial}

En lo referido a las cantidades producidas tomando los datos para el año 2010 la cantidad total producida es de 1.146.215 toneladas en todo el mundo, la posición de China explicaría el 54,70\% de la producción total. El segundo país productor en importancia es el Perú quien maneja el 21,57\% del volumen total; en la campaña de 2010 obtuvo una cosecha de 247.213 toneladas y se proyecta como líder en América.

Tabla $\mathrm{N}^{\circ}$ 3: Evolución de la producción por principales países productores en toneladas:

\begin{tabular}{|c|c|c|c|c|c|c|c|c|}
\hline \multicolumn{2}{|c|}{ Cifras en toneladas } & $\mathbf{2 0 0 5}$ & $\mathbf{2 0 0 6}$ & $\mathbf{2 0 0 7}$ & $\mathbf{2 0 0 8}$ & $\mathbf{2 0 0 9}$ & $\mathbf{2 0 1 0}$ & Var. 2010-2005 \\
\hline 1 & China & 590.464 & 610.441 & 625.314 & 635.267 & 650.267 & 627.000 & $6,19 \%$ \\
\hline 2 & Perú & 206.026 & 259.954 & 283.473 & 328.374 & 310.880 & 247.213 & $19,99 \%$ \\
\hline 3 & Alemania & 82.758 & 81.984 & 94.285 & 92.653 & 98.202 & 91.017 & $9,98 \%$ \\
\hline 4 & México & 60.000 & 59.621 & 60.000 & 56.459 & 56.459 & 64.000 & $6,67 \%$ \\
\hline 5 & EE.UU. & 77.931 & 58.575 & 57.152 & 48.363 & 45.671 & 41.000 & $-47,39 \%$ \\
\hline 6 & España & 47.963 & 56.210 & 35.396 & 44.169 & 47.378 & 54.485 & $13,60 \%$ \\
\hline 7 & Grecia & 21.706 & 20.810 & 21.526 & 17.100 & 17.000 & 21.500 & $-0,95 \%$ \\
\hline
\end{tabular}

Fuente: Dr. Christian Befve. Disponible en www.befve.com 
Gráfico N 10: Evolución de la producción anual en toneladas (excluida China) al año 2010:

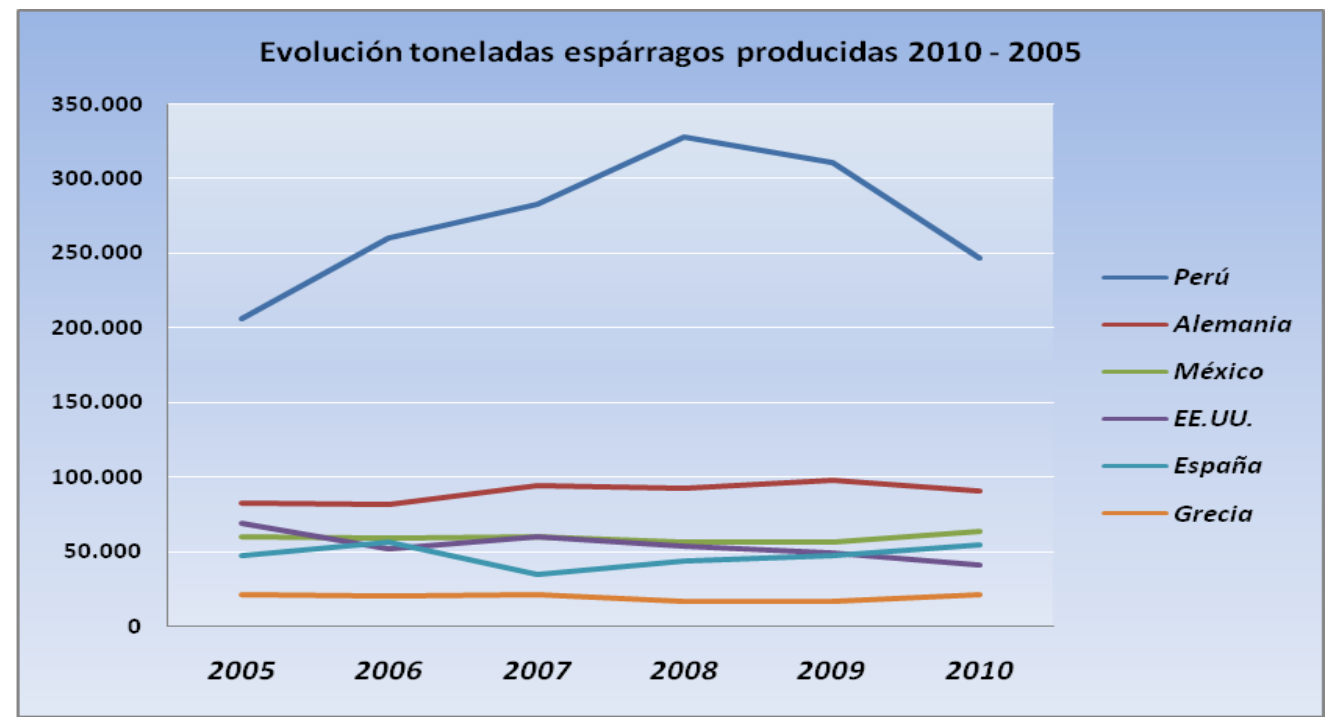

Fuente: Agrarmarkt Informations Gesellschaft ${ }^{6} ; \mathrm{FAO}^{7}$ y California Asparagus Seed and Transplants ${ }^{8}$.

Estos tres países observados (China, Perú y Alemania) presentan las variaciones positivas acumuladas más significativas en el ciclo analizado. Con respecto a los países que han disminuido su producción esparraguera, se encuentra principalmente Estados Unidos pasando de un volumen de 69.581 toneladas en 2005 a 41.000 toneladas en 2010. EE.UU. es otro gigante que ha disminuido su producción en los últimos años contradiciendo la tendencia internacional. A partir de 2005 comenzó el avance de la producción peruana compitiendo de manera agresiva en el mercado norteamericano.

\subsection{Evolución de la producción mundial por variedad de espárrago}

Hay al menos 62 países que actualmente son productores de espárragos con un área total de 201.464 hectáreas ${ }^{9}$. Con excepción de 10 países, los demás presentan estabilidad y una leve tendencia a aumentar las hectáreas destinadas a la producción. Estos países con situación estable y de crecimiento en la producción presentan indicadores de que tanto el consumo interno, como sus exportaciones ascenderán. De las 201.464 hectáreas reportadas en el año 2010, muestra que ha habido un retroceso en la cantidad de hectáreas desde al año 2005. La cantidad perdida asciende a 25.321 hectáreas. Esta caída ha tenido su origen en la crisis mundial acaecida desde el año 2007 al 2009. La mayor caída registrada la ha experimentado China con un total de 23.000 hectáreas. Sin embargo, países como el Perú y

\footnotetext{
${ }^{6}$ Disponible en www.marktundpreis.de

${ }^{7}$ Disponible en: Organización de las Naciones Unidas para la Agricultura y la Alimentación FAO año 2010.

${ }^{8}$ Trabajo realizado por el Dr. Brian Benson, CEO California Asparagus Seed and Transplants, Inc. Año 2010

${ }^{9}$ Ver cuadros en el anexo del capítulo 1.
} 
México han incrementado sus áreas de producción para continuar abasteciendo a los crecientes mercados actuales.

La siguiente tabla nos muestra los significantes cambios ocurridos en la producción de espárragos blancos y verdes, como así también en su posterior utilización para el año 2010. Para este año, la producción de espárrago verde alcanzó el 71,88\% y un $78 \%$ de esta producción fue destinada al mercado como espárrago fresco, mostrando un aumento en comparación con el año 2005.

Tabla $N^{\circ}$ 4: Proporción de las hectáreas de espárragos blancos y verdes al año 2010:

\begin{tabular}{|c|c|c|c|c|c|c|c|}
\hline & \multirow{2}{*}{$\begin{array}{c}\text { Total } \\
\text { Hectáreas }\end{array}$} & $\%$ MUNDO & Blanco & Verde & Fresco & Conserva & Congelado \\
\hline & & Hectáreas & Hectáreas & Hectáreas & Hectáreas & Hectáreas & Hectáreas \\
\hline \multirow{2}{*}{ Asia } & \multirow{2}{*}{70.500} & $34,99 \%$ & $10,00 \%$ & $90,00 \%$ & $84,00 \%$ & $11,00 \%$ & $5,00 \%$ \\
\hline & & 70.500 & 7.050 & 63.450 & 59.220 & 7.755 & 3.525 \\
\hline \multirow{2}{*}{ Europa } & \multirow{2}{*}{57.414} & $28,50 \%$ & $75,00 \%$ & $25,00 \%$ & $95,00 \%$ & $3,00 \%$ & $2,00 \%$ \\
\hline & & 57.414 & 43.061 & 14.354 & 54.543 & 1.722 & 1.148 \\
\hline \multirow{2}{*}{ Norteamérica } & \multirow{2}{*}{34.600} & $17,17 \%$ & $2,00 \%$ & $98,00 \%$ & $92,00 \%$ & $3,00 \%$ & $5,00 \%$ \\
\hline & & 34.600 & 692 & 33.908 & 31.832 & 1.038 & 1.730 \\
\hline \multirow{2}{*}{ América Latina } & \multirow{2}{*}{33.000} & $16,38 \%$ & $13,00 \%$ & $87,00 \%$ & $56,00 \%$ & $31,00 \%$ & $13,00 \%$ \\
\hline & & 33.000 & 4.290 & 28.710 & 18.480 & 10.230 & 4.290 \\
\hline \multirow{2}{*}{ África } & \multirow{2}{*}{2.950} & $1,46 \%$ & $48,00 \%$ & $52,00 \%$ & $93,00 \%$ & $5,00 \%$ & $2,00 \%$ \\
\hline & & 2.950 & 1.416 & 1.534 & 2.744 & 148 & 59 \\
\hline \multirow{2}{*}{$\begin{array}{c}\text { Australia \& N. } \\
\text { Zelanda }\end{array}$} & \multirow{2}{*}{3.000} & $1,49 \%$ & $5,00 \%$ & $95,00 \%$ & $90,00 \%$ & $8,00 \%$ & $2,00 \%$ \\
\hline & & 3.000 & 150 & 2.850 & 2.700 & 240 & 60 \\
\hline \multirow{2}{*}{ Total } & \multirow{2}{*}{201.464} & & $28,12 \%$ & $71,88 \%$ & $78,00 \%$ & $13,00 \%$ & $9,00 \%$ \\
\hline & & & 56.659 & 144.806 & 157.142 & 26.190 & 18.132 \\
\hline
\end{tabular}

Fuente: Dr. Christian Befve, www.befve.com. Año 2010

Para el caso de las conservas y los espárragos congelados ha mostrado una leve caída del 17\% en conservas y del 18\% en congelados para el año 2005 hacia un 13\% en las conservas y un 9\% en los congelados para el año 2010. El consumo doméstico del espárrago se ha incrementado desde el 2005 al 2010 un 4\% (53\% hacia 57\%) y contrariamente, las exportaciones mundiales han caído en porcentajes a un 43\% de la producción mundial (siendo esta misma en el año 2005 del 47\%).

Los datos recolectados nos muestran la complejidad en las interrelaciones entre el consumo y la producción de los espárragos por países ${ }^{10}$.

Según la FAO (Organización de las Naciones Unidas para la Alimentación y la Agricultura), a nivel global en los últimos 5 años han acontecido algunos cambios en las políticas llevadas adelante por determinados países productores. Por ejemplo en China, una directiva del gobierno estableció la intensificación de la producción del espárrago verde para el mercado fresco exportador

\footnotetext{
${ }^{10}$ En el anexo del presente capítulo se muestran cuadros detallados de los mismos.
} 
(principalmente hacia Japón), como así también para incrementar la provisión al mercado interno. Estas medidas han afectado la producción de ambas variedades de espárragos, como así también en las políticas de exportación de EE.UU. (principalmente California), Nueva Zelanda, Australia, Filipinas hacia Japón.

Gráfico N 11: Producción de espárrago por variedad al año 2010:

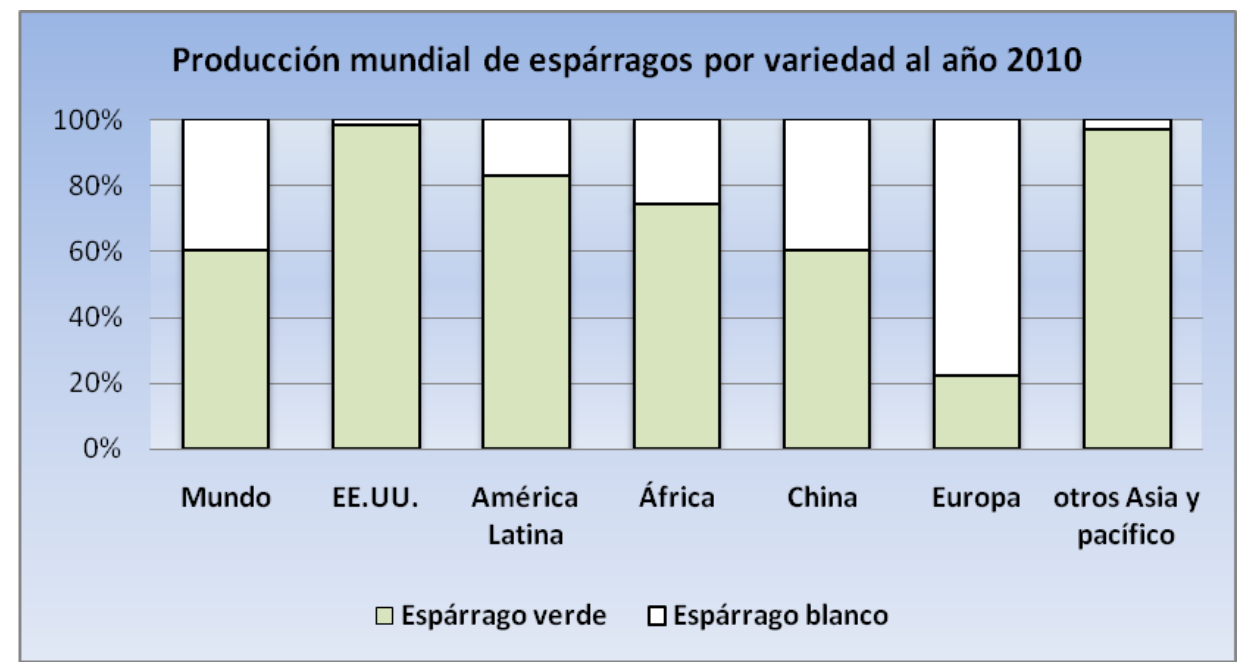

Fuente: Agrarmarkt Informations Gesellschaft; FAO y California Asparagus Seed and Transplants. Año 2010

Gráfico N ${ }^{\circ}$ 12: Producción mundial de espárrago por continente al año 2010:

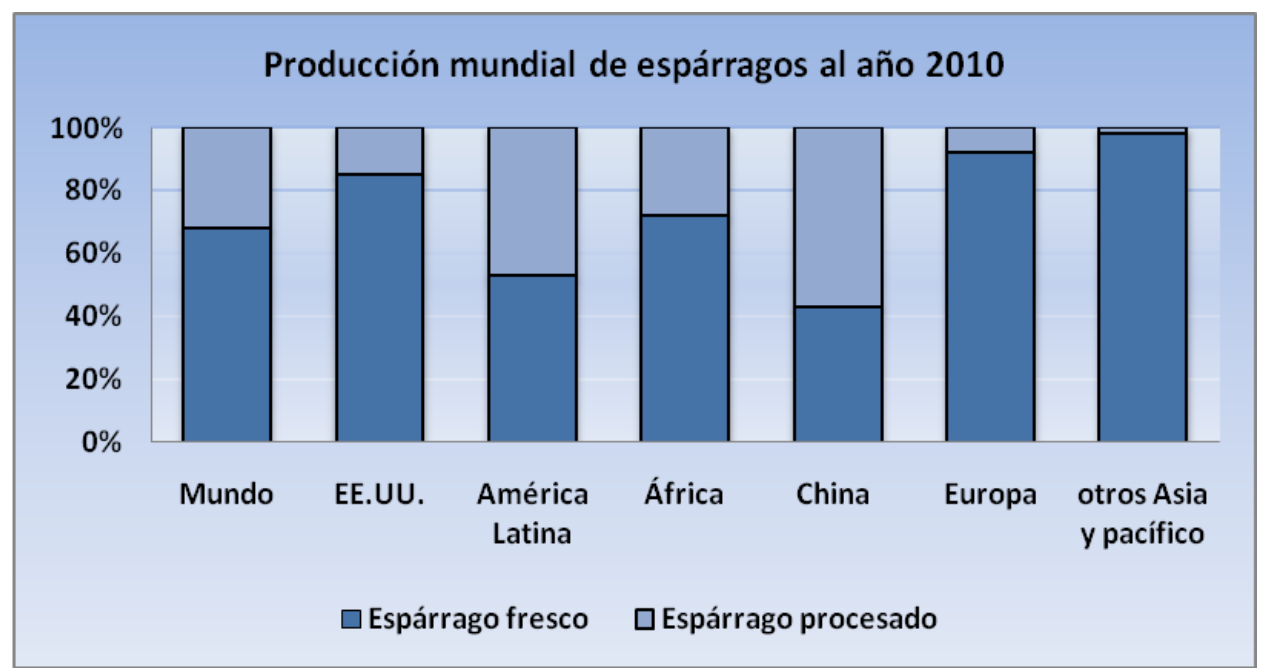

Fuente: Agrarmarkt Informations Gesellschaft; FAO y California Asparagus Seed and Transplants. 


\subsection{Superficie y producción de espárragos en Europa}

En el gráfico siguiente se muestra la tendencia del cultivo de la UE a lo largo de las últimas dos décadas (hasta el año 2010). La superficie cultivada de espárragos muestra un proceso de decrecimiento considerable hasta el 2009, a consecuencia de la crisis económica financiera del 2008. Ya para el año 2010 se experimentó una recuperación llegando a los niveles experimentados en 2006.

Gráfico $\mathrm{N}^{\circ}$ 13: Superficie cultivada de espárragos frescos en la Unión Europea 2010 - 1990 :

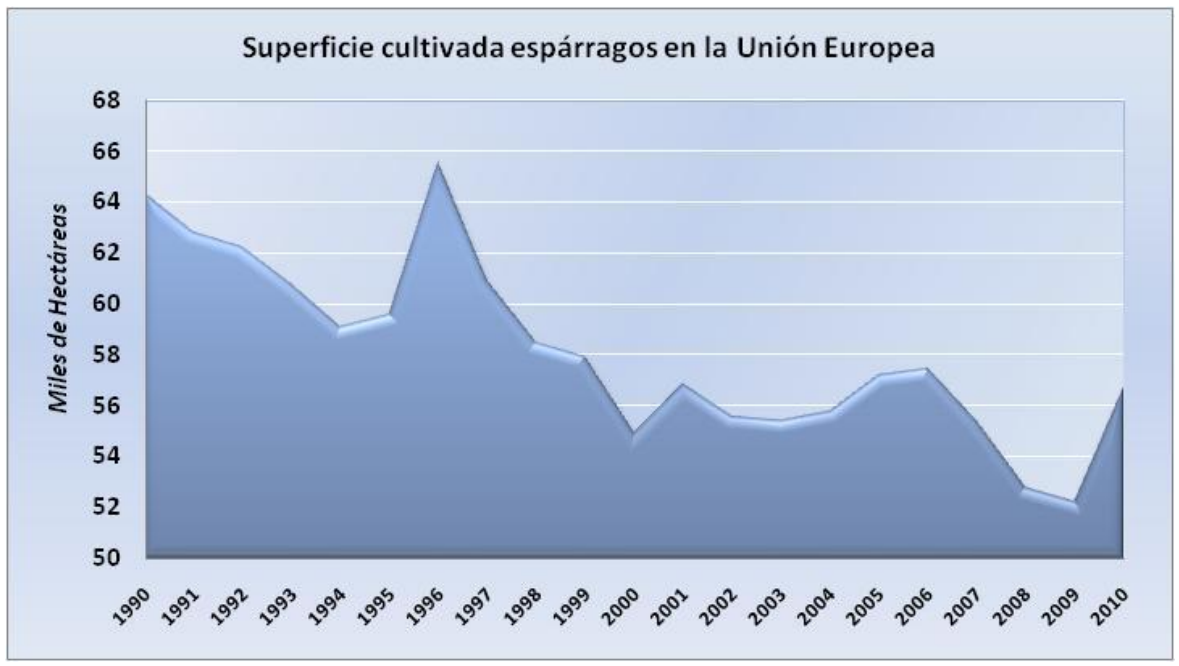

Fuente: Dr. Christian Befve, especialista mundial en espárragos. Año $2011^{11}$

Gráfico $\mathrm{N}^{\circ}$ 14: Principales países productores europeos:

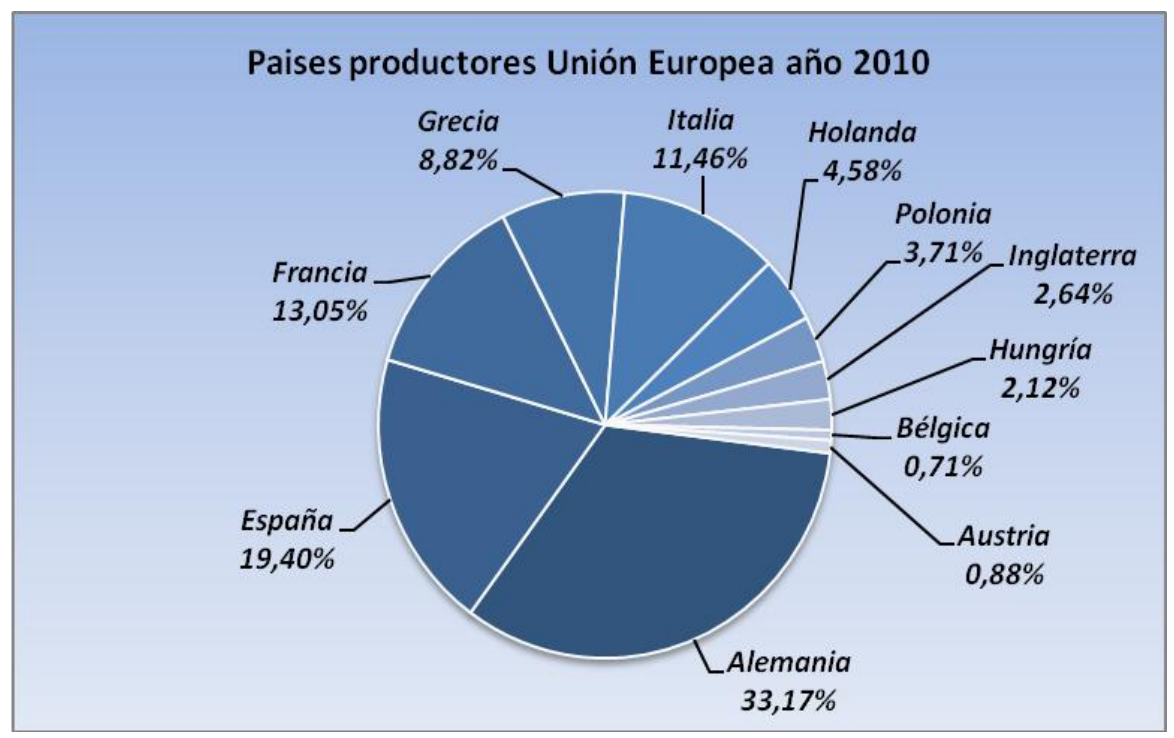

Fuente: Dr. Christian Befve, especialista mundial en espárragos. Año 2011

\footnotetext{
${ }^{11}$ Disponible en www.befve.com
} 


\subsection{Estacionalidad de la producción}

Tabla $\mathrm{N}^{\circ}$ 5: Estacionalidad de la producción de los principales países productores:

\begin{tabular}{|c|c|c|c|c|c|c|c|c|c|c|c|c|}
\hline & Ene & $\mathrm{Feb}$ & Mar & $A b r$ & May & Jun & Jul & Ago & Sep & Oct & Nov & Dic \\
\hline \multicolumn{13}{|l|}{ Alemania } \\
\hline \multicolumn{13}{|l|}{ Argentina } \\
\hline \multicolumn{13}{|l|}{ Australia } \\
\hline \multicolumn{13}{|l|}{ Canadá } \\
\hline \multicolumn{13}{|l|}{ Chile } \\
\hline \multicolumn{13}{|l|}{ Ecuador } \\
\hline \multicolumn{13}{|l|}{$E E . U U$} \\
\hline \multicolumn{13}{|l|}{ España } \\
\hline \multicolumn{13}{|l|}{ Francia } \\
\hline \multicolumn{13}{|l|}{ Grecia } \\
\hline \multicolumn{13}{|l|}{ Holanda } \\
\hline \multicolumn{13}{|l|}{ Indonesia } \\
\hline \multicolumn{13}{|l|}{ Italia } \\
\hline \multicolumn{13}{|l|}{ México } \\
\hline \multicolumn{13}{|l|}{ N. Zelanda } \\
\hline \multicolumn{13}{|l|}{ Pakistán } \\
\hline \multicolumn{13}{|l|}{ Perú } \\
\hline \multicolumn{13}{|l|}{ Portugal } \\
\hline \multicolumn{13}{|l|}{ R. Unido } \\
\hline \multicolumn{13}{|l|}{ Tailandia } \\
\hline Zimbawe & & & & & & & & & & & & \\
\hline
\end{tabular}

Fuente: California Asparagus Seed \& Transplant. www.calif-asparagus-seed.com

Tal como observamos en el cuadro anterior, dentro de los principales productores a nivel mundial, sólo Perú y Tailandia logran producir espárrago durante todo el año. En el resto, la producción es muy estacional concentrándose entre abril y junio. Los meses de septiembre hasta febrero son pocos los países abastecedores, dando buenas perspectivas para la producción del espárrago argentino en comparación con el periodo de producción en Alemania.

En el Perú, la producción de espárrago se incrementa notoriamente a partir de agosto/septiembre hasta febrero/marzo, disminuyendo un poco en los meses restantes por la baja de temperatura. Más allá de esta variación, presenta producción a lo largo de todo el año. El espárrago verde tiene dos campañas. Una inicial de enero a mayo/junio y la principal de septiembre a diciembre realizándose las exportaciones de espárrago fresco de acuerdo con las ventas en los mercados de destino y el saldo de la producción son envasados en conservas o destinados a la producción de producto congelado. 


\section{Producción alemana de espárragos}

\subsection{Producción y consumo de espárragos en Alemania al 2010}

El mercado de espárragos frescos en Alemania registró en la última década un desarrollo considerable.

Según un estudio de Agramarkt Informations Gesellschaft ${ }^{12}$, la producción anual alcanzó en el año 2010 la cifra de 91.017 toneladas, disminuyendo a lo experimentado en el año 2009 que fue de 98.161 toneladas producidas.

Para el caso de las hectáreas cultivadas, vemos que en los últimos 2 años se ha mantenido invariable, llegando a un total de 18.178 hectáreas. Esto nos muestra una reducción en el rendimiento, experimentado particularmente por factores climáticos. Más allá de esto, Alemania es el principal productor de espárragos blancos dentro de la Unión Europea hasta el día de hoy.

\subsubsection{Producción de espárrago por Estado Federado Alemán en toneladas}

Según el mismo informe, el espárrago se produce prácticamente en todos los Estados Federados de Alemania. La región más importante para el cultivo es Niedersachen con el 24,89\% del total de la producción, seguido por Nordrhein-Westfalen con 16,49\%, Brandenburg con un 13,86\% y Hessen con un $11,46 \%$. Otras importantes áreas de producción son Bayern 10,61\% y Baden Württemberg con $8,31 \%$.

${ }^{12}$ Disponible en www.marktundpreis.de 
Tabla $\mathrm{N}^{\circ}$ 6: Estados productores, rendimiento por hectárea y producción en toneladas años 2010 - 2009:

\begin{tabular}{|c|c|c|c|c|}
\hline & Años & Hectáreas & Kg / ha. & Pcción en Tns. \\
\hline \multirow{2}{*}{ Total Alemania } & $\mathbf{2 0 0 9}$ & $\mathbf{1 8 . 1 7 8}$ & $\mathbf{5 . 4 0 0}$ & $\mathbf{9 8 . 1 6 1}$ \\
\cline { 2 - 5 } Baden Württemberg & $\mathbf{2 0 1 0}$ & $\mathbf{1 8 . 8 1 4}$ & $\mathbf{4 . 9 1 0}$ & $\mathbf{9 1 . 0 1 7}$ \\
\hline \multirow{2}{*}{ Bayern } & 2009 & 1.769 & 4.610 & $\mathbf{8 . 1 5 5}$ \\
\cline { 2 - 5 } & 2010 & 2.046 & 3.900 & $\mathbf{7 . 9 7 9}$ \\
\hline \multirow{2}{*}{ Brandenburg } & 2009 & 1.857 & 5.610 & $\mathbf{1 0 . 4 1 8}$ \\
\cline { 2 - 5 } & 2010 & 1.857 & 4.680 & $\mathbf{8 . 6 9 1}$ \\
\hline \multirow{2}{*}{ Hessen } & 2009 & 2.408 & 5.650 & $\mathbf{1 3 . 6 0 5}$ \\
\cline { 2 - 5 } & 2010 & 2.767 & 5.330 & $\mathbf{1 4 . 7 4 8}$ \\
\hline \multirow{2}{*}{ Mecklenburg- Vorpommern } & 2009 & 1.847 & 6.090 & $\mathbf{1 1 . 2 4 8}$ \\
\cline { 2 - 5 } & 2010 & 1.847 & 5.970 & $\mathbf{1 1 . 0 2 7}$ \\
\cline { 2 - 5 } & 2009 & 257 & 3.460 & $\mathbf{8 8 9}$ \\
\hline \multirow{2}{*}{ Niedersachen } & 2010 & 257 & 3.430 & $\mathbf{8 8 2}$ \\
\cline { 2 - 5 } & 2009 & 4.071 & 6.000 & $\mathbf{2 4 . 4 2 6}$ \\
\hline \multirow{2}{*}{ Nordrhein - Westfalen } & 2010 & 4.071 & 5.730 & $\mathbf{2 3 . 3 2 7}$ \\
\cline { 2 - 5 } & 2009 & 3.161 & 5.120 & $\mathbf{1 6 . 1 8 4}$ \\
\hline \multirow{2}{*}{ Rheinland - Pfalz } & 2010 & 3.161 & 4.190 & $\mathbf{1 3 . 2 4 5}$ \\
\cline { 2 - 5 } & 2009 & 904 & 5.780 & $\mathbf{5 . 2 2 5}$ \\
\hline \multirow{2}{*}{ Sachsen } & 2010 & 904 & 5.050 & $\mathbf{4 . 5 6 5}$ \\
\cline { 2 - 5 } & 2009 & 284 & 3.270 & $\mathbf{9 2 9}$ \\
\hline \multirow{2}{*}{ Sachsen - Anhalt } & 2009 & 983 & 4.060 & $\mathbf{8 . 9 9 1}$ \\
\cline { 2 - 5 } & 2010 & 983 & 3.960 & $\mathbf{3 . 8 9 3}$ \\
\hline \multirow{2}{*}{ Schleswig - Holstein } & 2009 & 289 & 3.690 & $\mathbf{1 . 0 6 6}$ \\
\cline { 2 - 5 } & 2010 & 289 & 3.760 & $\mathbf{1 . 0 8 7}$ \\
\hline \multirow{2}{*}{ Thüringen } & 2009 & 348 & 5.720 & $\mathbf{1 . 9 9 1}$ \\
\cline { 2 - 5 } & 2010 & 348 & 5.760 & $\mathbf{2 . 0 0 4}$ \\
\hline
\end{tabular}

Fuente: Información provista por Birgit Nöthen (BMELV). Mayo 2011.

Bundesministerium für Ernährung Landwirtschaft und Verbraucherschutz (BMELV). www.bmelv.bunb.de

\section{Estados Productores:}

\begin{tabular}{|c|c|}
\hline$B W$ & Baden Württemberg \\
\hline$B Y$ & Bayern \\
\hline$B B$ & Brandenburg \\
\hline$H E$ & Hessen \\
\hline MV & Mecklenburg - Vorpommern \\
\hline NDS & Niedersachen \\
\hline NRW & Nordrhein - Westfalen \\
\hline RP & Rheinland - Pfalz \\
\hline SN & Sachsen \\
\hline$S A$ & Sachsen - Anhalt \\
\hline$S H$ & Schleswig - Holstein \\
\hline TH & Thüringen \\
\hline
\end{tabular}


Gráfico N 15: Producción de espárrago por estado federado alemán:

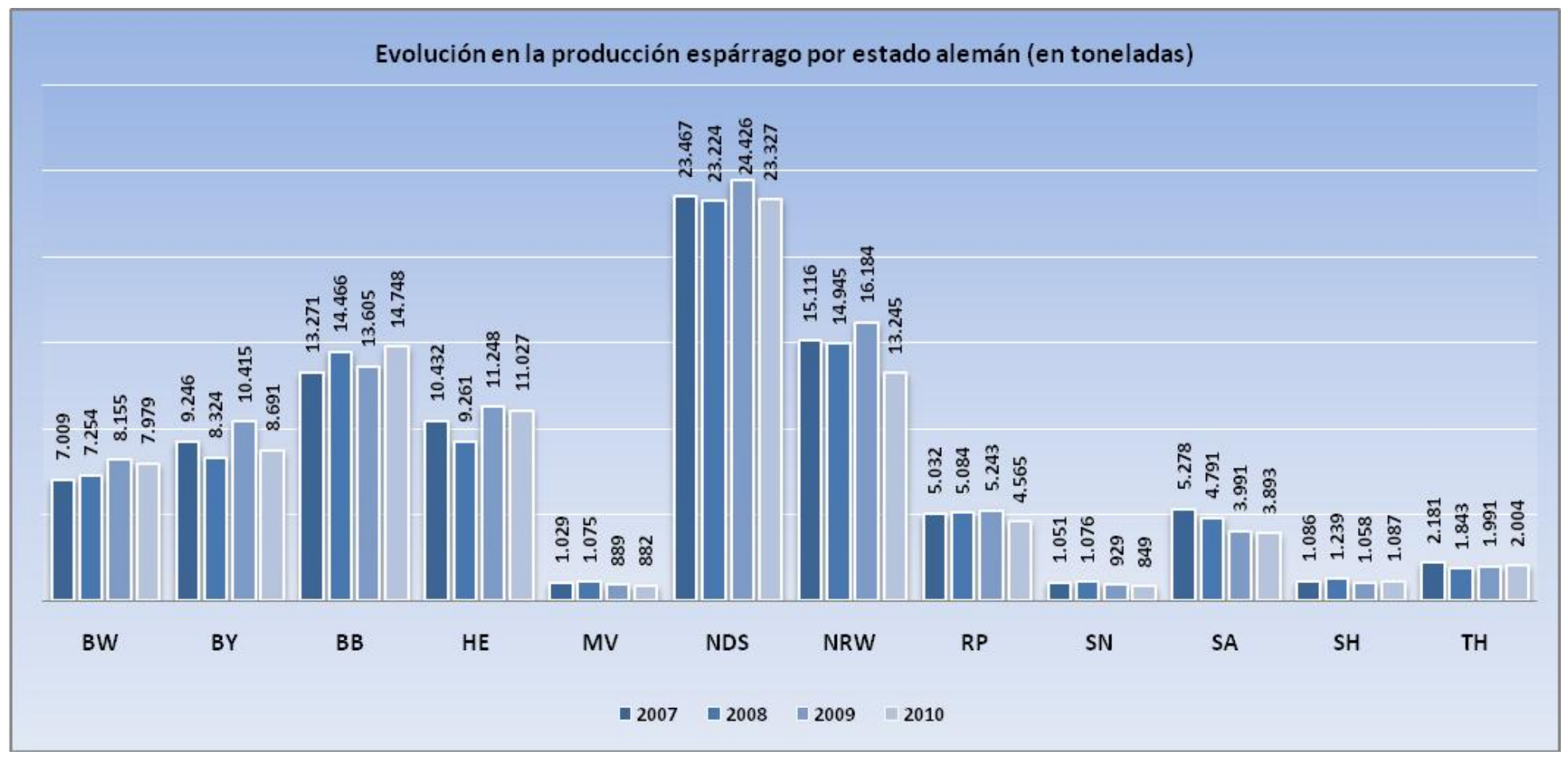

Fuente: Elaboración propia en base a datos obtenidos en Statisches Bundesamt año 2011.

Como se puede apreciar en el gráfico, solo 5 de los 12 estados productores (recordemos que Alemania tiene 16 estados federados) han reducido mínimamente su producción. Estos 5 estados representan solamente el 1,81\% del total de la producción. Es dable destacar que se percibió un leve descenso en el año 2008 producto de la crisis financiera internacional, para luego mostrar un leve repunte en 2009.

Para el caso del año 2010, podemos decir que fue un año atípico para el espárrago alemán. Las condiciones climáticas provocaron un $20 \%$ menos de producción, dada las prolongadas bajas temperaturas, comparado con el año 2009 donde se cosecharon más de 98.000 toneladas. Para muchas empresas ha sido un reto organizativo lograr una óptima gestión bajo estas condiciones; especialmente para empresas pequeñas. Otras firmas finalmente han conseguido tener, a pesar del frío, algunas cantidades de buena calidad que han colocado en el mercado local. 
Tabla $\mathrm{N}^{\circ}$ 7: Top 5 de los principales productores de espárragos frescos para el año 2010:

\begin{tabular}{|c|c|c|c|c|c|c|}
\hline Región & $\mathbf{K g} / \mathbf{h a}$ & \% Medio & Hectáreas & \% Alemania & Pcción en Tns. & \% Alemania \\
\hline Alemania & $\mathbf{4 . 9 2 0}$ & $\mathbf{1 0 0 \%}$ & $\mathbf{1 8 . 7 9 4}$ & $\mathbf{1 0 0 \%}$ & $\mathbf{9 1 . 0 1 7}$ & $\mathbf{1 0 0 \%}$ \\
\hline Niedersachen & 5.730 & $116,46 \%$ & 4.176 & $22,22 \%$ & 23.947 & $26,31 \%$ \\
\hline Nordrhein-Westfalen & 4.220 & $85,77 \%$ & 3.077 & $16,37 \%$ & 12.976 & $14,26 \%$ \\
\hline Brandenburg & 5.330 & $108,33 \%$ & 2.708 & $14,41 \%$ & 14.749 & $16,20 \%$ \\
\hline Baden Württemberg & 3.900 & $\mathbf{7 9 , 2 7 \%}$ & 2.046 & $10,89 \%$ & 7.979 & $8,77 \%$ \\
\hline Bayern & 4.680 & $95,12 \%$ & 1.855 & $9,87 \%$ & 8.691 & $9,55 \%$ \\
\hline Top 5 en Alemania & $\mathbf{4 . 7 7 2}$ & $\mathbf{9 6 , 9 9 \%}$ & $\mathbf{1 3 . 8 6 2}$ & $\mathbf{7 3 , 7 6 \%}$ & $\mathbf{6 8 . 3 4 2}$ & $\mathbf{7 5 , 0 9 \%}$ \\
\hline
\end{tabular}

Fuente: Statisches Bundesamt año 2011

Dada la tabla anterior, podemos ver que para nuestro caso de estudio, el estado de Baden Württemberg es de los 5 estados con mayor producción, el que está por debajo de la media en lo que se refiere a rendimientos por hectáreas.

\subsubsection{Hectáreas de espárragos productivas y no productivas}

Tal como dijimos en párrafos precedentes, las condiciones climáticas provocaron un 20\% menos de producción, comparado con el año 2009. A nivel de hectáreas, vemos que desde el año 2005 al año 2010 se han mantenido en promedio 18.000 hectáreas. Para el caso de las hectáreas no productivas vemos que en el año 2010 llegó a ser la mayor de los últimos 10 años, causado principalmente por problemas climáticos.

Gráfico $N^{\circ}$ 16: Hectáreas dedicadas a la producción de espárrago fresco en Alemania:

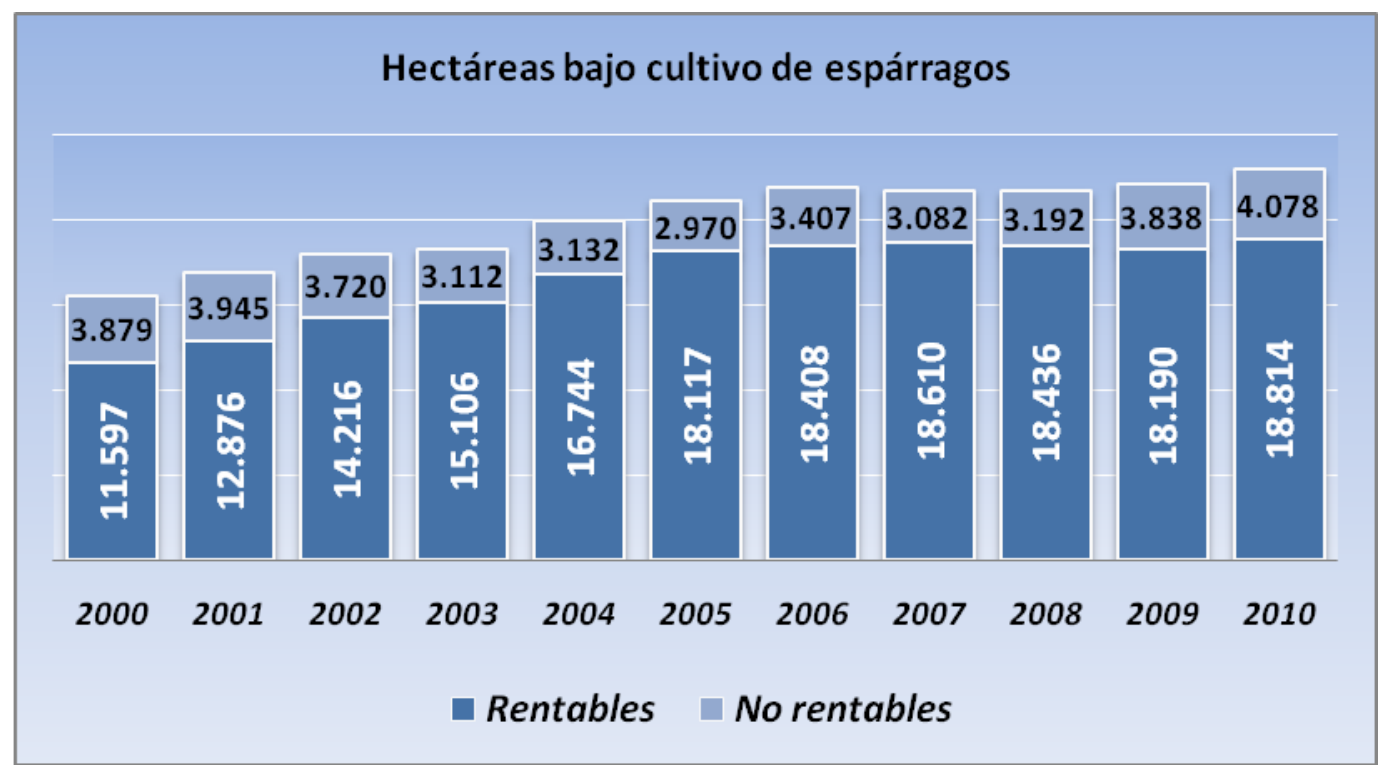

Fuente: Datos obtenidos en Statisches Bundesamt 2011. 


\subsubsection{Cálculos sobre producción y disponibilidad para consumo en toneladas}

Tabla $\mathrm{N}^{\circ}$ 8: Espárragos, producción y neto disponible en el mercado alemán en la última década en toneladas:

\begin{tabular}{|c|c|c|c|c|c|c|c|c|c|c|}
\hline Toneladas & 2001 & 2002 & 2003 & 2004 & 2005 & 2006 & 2007 & 2008 & 2009 & 2010 \\
\hline Producción & 52.150 & 57.170 & 65.340 & 72.520 & 82.728 & 81.984 & 94.285 & 92.653 & 98.193 & 91.017 \\
\hline Importaciones & 39.057 & 40.129 & 31.522 & 29.419 & 28.259 & 29.041 & 27.451 & 30.243 & 25.266 & 24.438 \\
\hline Exportaciones & 3.093 & 1.488 & 1.195 & 1.232 & 1.970 & 2.149 & 3.016 & 3.556 & 2.778 & 3.624 \\
\hline Pérdida de pcción. & 13.961 & 15.394 & 17.079 & 19.276 & 22.974 & 22.896 & 25.588 & 25.554 & 26.234 & 24.784 \\
\hline Neto en mercado & 74.153 & 80.417 & 78.588 & 81.431 & 86.043 & 85.980 & 93.132 & 93.786 & 94.447 & 87.047 \\
\hline \% provisión local & $73,23 \%$ & $73,07 \%$ & $73,86 \%$ & $73,42 \%$ & $72,23 \%$ & $72,07 \%$ & $72,86 \%$ & $72,42 \%$ & $73,28 \%$ & $72,77 \%$ \\
\hline
\end{tabular}

Fuente: Elaboración propia en base a datos obtenidos en Statisches Bundesamt, AMI y Zentral Markt und Preis

Tal como observamos en el cuadro anterior, la producción ha ido en aumento. Más allá de esto, el mercado continúa en crecimiento, llevando a que la producción alemana llega a proveer el $73 \%$ del total consumido.

\subsubsection{Producción y Consumo en Baden Württemberg}

Baden Württemberg es sin duda una de las regiones más fuertes de Europa por varias de sus industrias. Según la oficina de estadística del Estado de Baden Württemberg, a nivel de producción de hortalizas, durante el año 2010, el estado alcanzó las 9.464 hectáreas de cultivo, experimentando una disminución en comparación con el año 2009 (10.217 hectáreas). El 95\% de las hectáreas cultivadas son cultivadas a campo abierto, mientras que el resto es desarrollado en invernaderos.

La hortaliza más importante es el Espárrago y la producción alcanza las 2.461 hectáreas.

Gráfico N 17: Cultivo de hortalizas en Baden Württemberg, año 2010, en porcentaje sobre un total de 9.464 hectáreas:

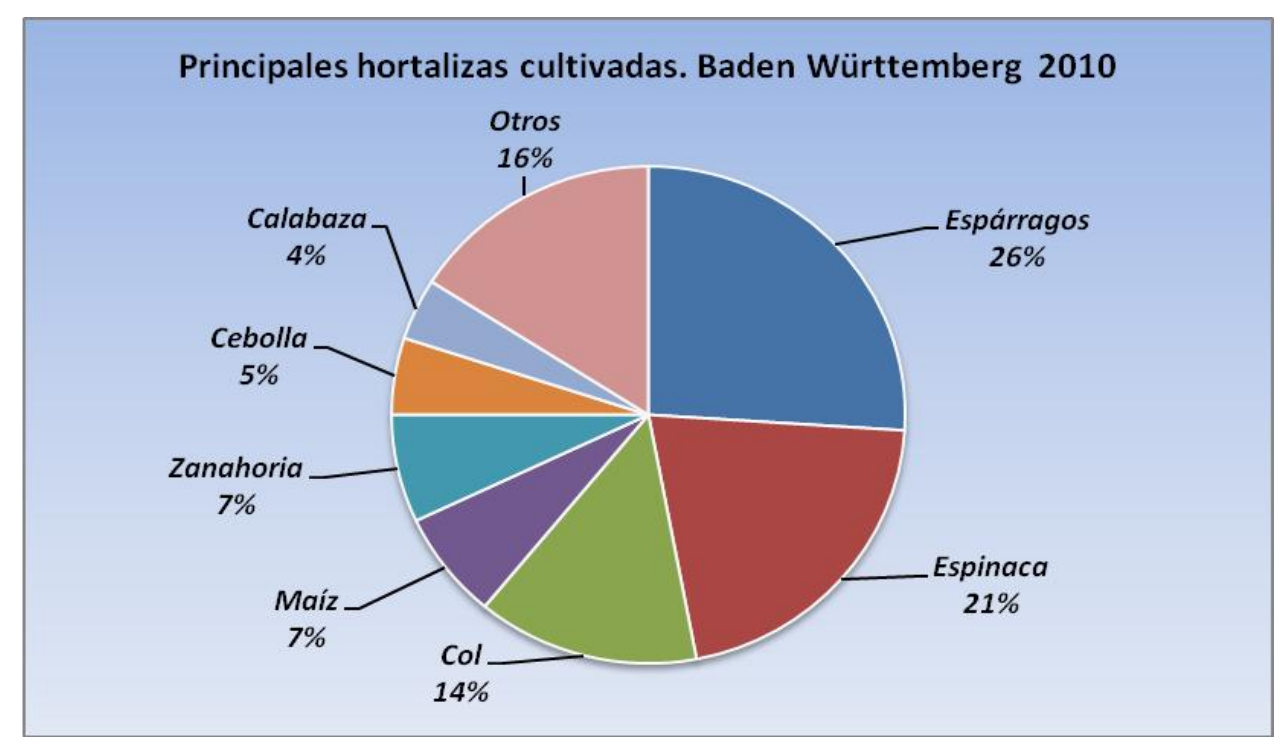

Fuente: Statistisches Landesamt Baden Württemberg año 2011. 
Gráfico ํㅜ 18: El cultivo de espárragos en Baden Württemberg:

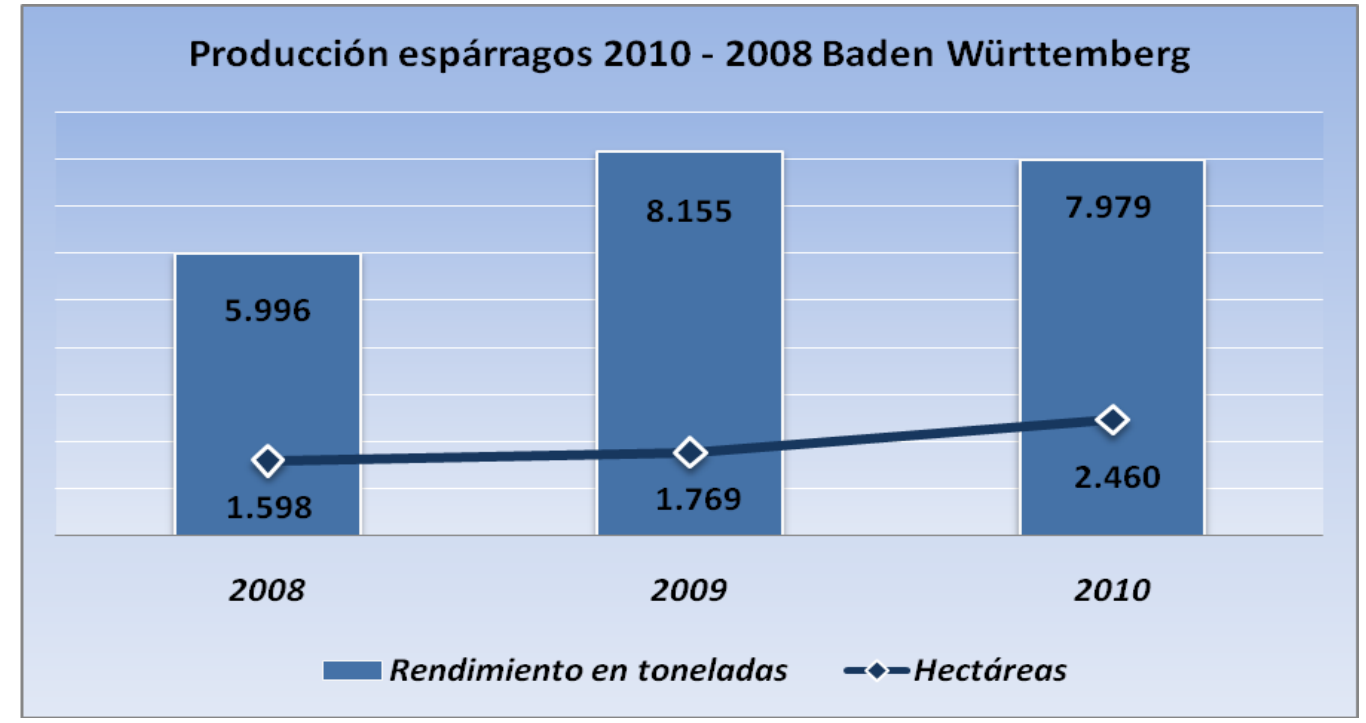

Fuente: Statistisches Landesamt Baden Württemberg año 2011.

\subsubsection{Consumo de espárragos en Baden Württemberg}

Consumo anual: 10.757 millones de habitantes en $\mathrm{BW} * 1,145 \mathrm{Kg} /$ habitante $=12.314$ toneladas

Producción bruta Baden Württemberg en $2010=7.979$ toneladas

Porcentaje general Alemania de perdida promedio en producción $=27,23 \%{ }^{13}$

Producción neta $=5.807$ toneladas

Resultado = Para el caso de la nombrada zona, la demanda fue de 6.507 toneladas de espárragos frescos.

\section{Producción argentina de espárragos}

\subsection{Superficie cultivada}

De la información brindada por Mg. Ana Castagnino y el Ing. Agr. Oscar Liverotti, se desprende la importancia de dos provincias preponderantes en la producción de espárragos en el ámbito nacional: San Juan y Mendoza; entre ambas concentran casi el 60\% del total nacional. En la provincia de Buenos Aires se llegó a producir en las zonas de General Alvarado, Mercedes y en menor proporción en las localidades de Bahía Blanca, Coronel Rosales, Escobar, General Pueyrredón, La Plata, Lobería, 9 de

\footnotetext{
${ }^{13}$ Según datos obtenidos en AMI-Marktbilanz Gemüse 2011. AMI-Informiert.de
} 
Julio, Azul, Pilar y Tres Arroyos. Asimismo hubo producciones menores bajo cubierta y a campo, en el cinturón verde del Gran La Plata. Otras zonas llegaron a observarse a lo largo de la ruta 7, desde Luján hasta Chacabuco y Junín. Por desgracia, actualmente casi no se registran producciones en Buenos Aires. Según datos obtenidos en SENASA, para la provincia de Buenos Aires la última cosecha ha sido en el año 2007, mostrando una marcada caída hasta casi desaparecer este cultivo.

Gráfico $N^{\circ}$ 19: Participación provincial de la producción esparraguera al año $2010^{14}$ :

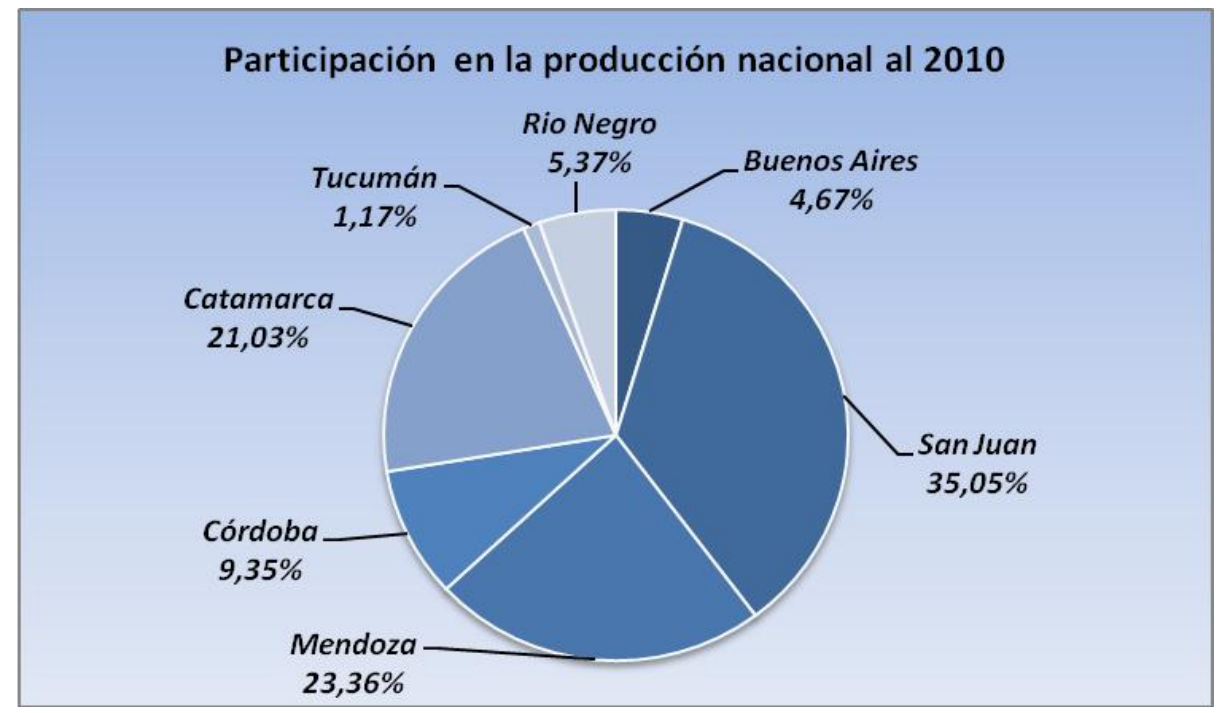

\begin{tabular}{|c|c|}
\hline Provincias & Hectáreas \\
\hline Buenos Aires & 20 \\
\hline San Juan & 150 \\
\hline Mendoza & 100 \\
\hline Catamarca & 90 \\
\hline Córdoba & 40 \\
\hline Rio Negro & 23 \\
\hline Tucumán & 5 \\
\hline Total & 428 \\
\hline
\end{tabular}

Fuente: CRESCA

Fuente: Mg. Ana Castagnino, Ing. Agr. Oscar Liverotti año 2011

Para el caso de la provincia de Catamarca podemos nombrar que ha logrado tener producción sobre un total de casi 50 hectáreas. La producción está a cargo de la empresa "Cultivos del Ancasti"15 S.A. ubicada en el departamento de Valle Viejo, a solo 4 kilómetros del aeropuerto local, lo cual representa una gran ventaja para el transporte de los espárragos debido a lo necesario de transportarlos en cámaras de frío. Es dable destacar que este emprendimiento posee diferimientos impositivos, situación que favorece el desarrollo de la explotación. Respecto a la comercialización, el 90\% de la producción fue con destino a Estados Unidos y el resto a España.

\footnotetext{
14 Información suministrada por Mg. Ana Castagnino, CRESCA (Centro Regional de Estudio Sistémico de Cadenas Agroalimentarias).

${ }^{15}$ Cultivos de Ancasti S.A. pertenece a una empresa constructora de la provincia de Córdoba.
} 
Tabla № 9: Superficie cosechada de espárragos orgánicos años 2010 - 2005:

\begin{tabular}{|c|c|c|c|c|c|c|}
\hline \multicolumn{7}{|c|}{ Superficie cosechada de espárragos orgánicos (ha) } \\
\hline Provincia & $\mathbf{2 0 0 5}$ & $\mathbf{2 0 0 6}$ & $\mathbf{2 0 0 7}$ & $\mathbf{2 0 0 8}$ & $\mathbf{2 0 0 9}$ & $\mathbf{2 0 1 0}$ \\
\hline Buenos Aires & 101,50 & 81,48 & 92,00 & - & - & - \\
\hline Catamarca & - & - & - & - & - & 49,50 \\
\hline Córdoba & - & - & - & 27,00 & 37,00 & 26,00 \\
\hline Mendoza & 12,50 & 46,21 & 33,52 & 51,35 & 46,56 & 45,76 \\
\hline Rio Negro & - & - & 8,00 & 26,60 & 31,64 & 20,00 \\
\hline San Juan & 4,00 & 13,45 & 2,50 & 16,00 & 14,80 & 13,30 \\
\hline Santa Fe & - & - & 10,00 & - & - & - \\
\hline Total general & $\mathbf{1 1 8 , 0 0}$ & $\mathbf{1 4 1 , 1 4}$ & $\mathbf{1 4 6 , 0 2}$ & $\mathbf{1 2 0 , 9 5}$ & $\mathbf{1 3 0 , 0 0}$ & $\mathbf{1 5 4 , 5 6}$ \\
\hline
\end{tabular}

Fuente: SENASA 2011

Respecto a la provincia de Córdoba, podemos destacar que las hectáreas que figuran, corresponden a la empresa "La Meco" s.r.l. que es una productora creada en el año 2001. La empresa posee 140 hectáreas, de las cuales 110 son destinadas a la producción convencional mientras que el resto a la producción orgánica. Ésta, cuenta con la certificación de EUREGSP, NOP, IFOAM y actualmente produce espárragos verdes y blancos. Además de producirlos, los procesa en el mismo predio de cosecha, los empaca para su exportación.

Para el caso de la provincia de Mendoza observamos que ha mostrado un comportamiento más constante. Para el año 2010 la provincia contó con más de 45 hectáreas dedicada a la producción orgánica de espárragos. A modo de ejemplo, podemos destacar el caso del ex capitán del seleccionado argentino de rugby, Agustín Pichot, que a su producción de aceite de oliva que posee en San Rafael, sumó la finca "La Guevarina" a $15 \mathrm{~km}$. de Villa Atuel. Según información proporcionada por la empresa, lograron una importante venta en Miami. En la actualidad están avanzando con una planta de enfriamiento y de packaging. La nombrada finca cuenta de 10 hectáreas que incluye galpones de empaque. Asimismo, para la nombrada provincia, también se encuentra la empresa "Marianita S.A."16, que se encuentra también en San Rafael. La empresa se dedica a la producción y comercialización tanto de espárragos, como ajo y cebolla orgánica. Otra empresa que se destaca, el "El Secreto de los Andes"17. Ésta, se encuentra en San Rafael, y se dedica además de la producción de espárragos orgánicos, a la producción y comercialización de ajos, cebollas, echalotes y frutas secas. Otra empresa importante de Mendoza es “Agro Los Andes S.A.”, situada en el Valle de Uco, donde su CEO, Armando Castillo, nos brindó importante información acerca de la actualidad de los espárragos

\footnotetext{
16 “Marianita S.A.” Perret 320, Cuadro Nacional, San Rafael. Tel: (02627) 443-321. Email: marianespr@infovia.com.ar 17 “El secreto de los Andes”, San Rafael. Tel. (02627) 15-614-693. www.elsecretodelosandes.com.ar
} 
argentinos. Por ejemplo, el nombrado CEO, pudo concurrir a importantes ferias de productos orgánicos a nivel mundial, tal como a la Biofach de Nürnberg, y comparar los espárragos orgánicos argentinos con espárragos provenientes de otras latitudes; llegando a la conclusión que a nivel de “sabor" y "presentación” (calidad en largo y en diámetro) los espárragos son muy superiores a la media mundial.

\subsection{Situación actual de los factores de producción}

Tal como pude indagar mediante entrevistas a empresas como La Meco S.R.L., Agro Los Andes S.A. y Pampa Store S.A., uno de los puntos críticos que posee la producción es la falta de mano de obra calificada. Asimismo, las cuestiones salariales y gremiales contribuyen a que el costo de la mano de obra sea fijo, con un producto que presenta precios estacionales.

Otro de los grandes inconvenientes se da a partir de la logística hacia Ezeiza. En resumen, todas las acciones a fomentar la actividad, debieran de apuntar a toda la estructura de la cadena hortícola, esto es: Cultivo - Cosecha, Acondicionamiento, Manipulación, Fraccionamiento, Empaque, Almacenamiento, Industrialización y Transporte.

Más allá de las complicaciones enunciadas, uno de los profesionales más reconocidos a nivel mundial como Christian Befve, ha establecido que nuestro país tiene un gran potencial en la producción orgánica de espárragos, debido a sus grandes extensiones y su especial clima. 


\section{Capítulo 2: Oferta y demanda orgánica, de espárragos en el mundo,}

\section{Alemania y Argentina}

\section{Comercio internacional de productos orgánicos ${ }^{18}$}

\subsection{Como surge la demanda de productos orgánicos}

La agricultura ecológica comenzó, según los datos existentes a la fecha, en Alemania a fines del siglo XIX. En esa época se inició también una amplia reforma agraria y de la producción de que llegó hasta el primer cuarto del siglo XX y que favoreció posteriormente el desarrollo ecológico.

Posteriormente en la década del `60 y `70 la alimentación naturista tomó mayor importancia en Alemania y generó un circuito de agricultores, transformadores, mayoristas y tiendas de alimentos naturistas. Luego, a partir de los años 80 empezó a crecer con fuerza, como resultado de la venta, en comercios minoristas de alimentos convencionales, de productos ecológicos y naturales, llegando en la actualidad a ser uno de los mercados más importantes del mundo para productos orgánicos.

Si bien la actividad genera actualmente una pequeña rama de la actividad económica, está adquiriendo una creciente importancia en el sector agrícola-alimenticio de algunos países, independientemente de su estado de desarrollo. Por ejemplo, en varios países desarrollados la agricultura orgánica ha llegado a representar una parte significativa del sistema alimentario (el 10\% en Austria, el 7,8\% en Suiza) y en muchos otros se están registrando tasas de crecimiento anual superiores al 20\% (por ejemplo, Estados Unidos, Francia, Japón, Singapur). Algunos países en desarrollo tienen pequeños mercados orgánicos internos (por ejemplo, Argentina y Egipto) y han empezado a aprovechar las lucrativas oportunidades de exportación que ofrece la agricultura orgánica (por ejemplo, exportaciones de cereales y carnes de Argentina, café de México, de algodón de Uganda).

\subsection{Los productos orgánicos como nicho de mercado internacional}

Hoy en día, el sector de la agricultura orgánica es el sector alimenticio que muestra mayor crecimiento. Las tasas de aumento en las ventas de alimentos orgánicos han oscilado entre el $18 \%$ y $25 \%$ anual a lo

\footnotetext{
${ }^{18}$ En base al trabajo realizado por la Fundación ExportAR. Sector orgánico argentino. Análisis de la situación de la demanda internacional, competencia y exportaciones argentinas. Propuesta para una planificación estratégica.
} 
largo de 15 años. Los índices que corresponden a las tierras orgánicas de Europa, América Latina y EE.UU. son excelentes. Entre 1995 y 2008, se ha cuadruplicado la superficie total de tierras orgánicas en Europa y Estados Unidos. El crecimiento en Asia, Latinoamérica y Oceanía también ha sido altísimo. No obstante, estos reportes de aumentos en los porcentajes se deben analizar dentro del contexto de sus bajos niveles absolutos, lo que explica su calificación de "nicho" para el mercado de los productos orgánicos. El mercado de alimentos orgánicos certificados comprende una pequeña pero creciente participación (1-2\%) del total del mercado alimentario. En especial en Europa, este crecimiento se fortaleció desde el lado de la oferta, mediante los subsidios a la producción que se otorgaron a los agricultores orgánicos y, desde el lado de la demanda, por las impresiones adversas relacionadas con la seguridad de los alimentos convencionales. Sin embargo, el crecimiento en el mercado orgánico también ha sido fuerte en los mercados donde estos factores fueron menos evidentes, como sucedió en Australia, Japón, EE.UU. y en algunos países en vías de desarrollo como Brasil o México.

Para el año $2012^{19}$, el mercado habrá crecido a US\$ 60.000 millones en los países con mercados orgánicos certificados, o entre un 3,5 y un 5\% del mercado alimentario global. Este cálculo se basa en los mercados certificados en la actualidad y la expansión sería aún mayor si se incluyeran los mercados orgánicos no certificados. Las implicancias para los gobiernos que desean desarrollar el sector orgánico incluyen el desarrollo de un marco político adecuado que asegure la transparencia y la calidad apropiada de los productos de agricultura orgánica, mas aun teniendo en cuenta la presión que pueden ejercer las multinacionales productoras de productos químicos. Esto es particularmente importante para los países exportadores como la Argentina.

Otro factor determinante lo constituyen la investigación y el desarrollo para colaborar con los agricultores a fin que gocen de los beneficios de la mejora en la productividad y del aumento de la eficiencia en la producción, transporte, la manipulación, la calidad de los productos, el almacenamiento, el procesamiento y la venta al por menor, incluyendo el desarrollo y promoción de los mercados. 


\subsection{Tendencia global de volúmenes y productos orgánicos}

Según datos obtenidos en Forschungsinstitut für biologischen Landbau ${ }^{20}$, el mercado para productos orgánicos certificados superó los € 50 billones en el año 2010. Más del 90\% de la nombrada cifra tiene su origen en el hemisferio norte; asimismo de esta cifra, Europa cuenta con el $48 \%$ de las ventas globales de alimentos orgánicos, al igual que América del Norte con 48\%. Los mercados más importantes fueron los EE.UU. con $€ 15.9$ billones, seguido por Alemania con $€$ 5,9 billones y Francia con $€ 2,6$ billones (según datos de FiBL 2010). Asimismo Organic Monitor ${ }^{21}$ informa que el volumen superó en 2010 por primera vez los $€ 50.000$ millones. La superficie de cultivo ecológico asciende en todo el mundo a 30,4 millones de hectáreas y seguirá aumentando, dice Helga Willer del Instituto de Investigación de Cultivo Ecológico, $\mathrm{FiBL}^{22}$, Suiza.

Sin embargo, en términos de gasto anual per cápita, Alemania ocupa el $5^{\circ}$ puesto con $€ 56$ al año por habitante. Suiza es el país donde los consumidores realizan un mayor desembolso (€ 102) en productos orgánicos, por delante de Liechtenstein (€ 86), Dinamarca (€ 80) y Austria (€ 64).

El volumen de ventas de productos orgánicos ha crecido un $207 \%$ desde el año 2000, cuando en ese momento el nivel los US\$ 17,9 billones. Con la crisis económica experimentada en el año 2009, algunos países han mostrado una merma en la demanda de orgánicos. Otros países tal como Alemania se han mantenido estables, pero algunos países han experimentado un sano crecimiento, tal es el caso de Francia $(+15 \%)$, Noruega $(+10 \%)$ o los EE.UU. $(+8 \%)$.

Gráfico Nº 20: Evolución del mercado mundial de orgánicos años 2010-2000:

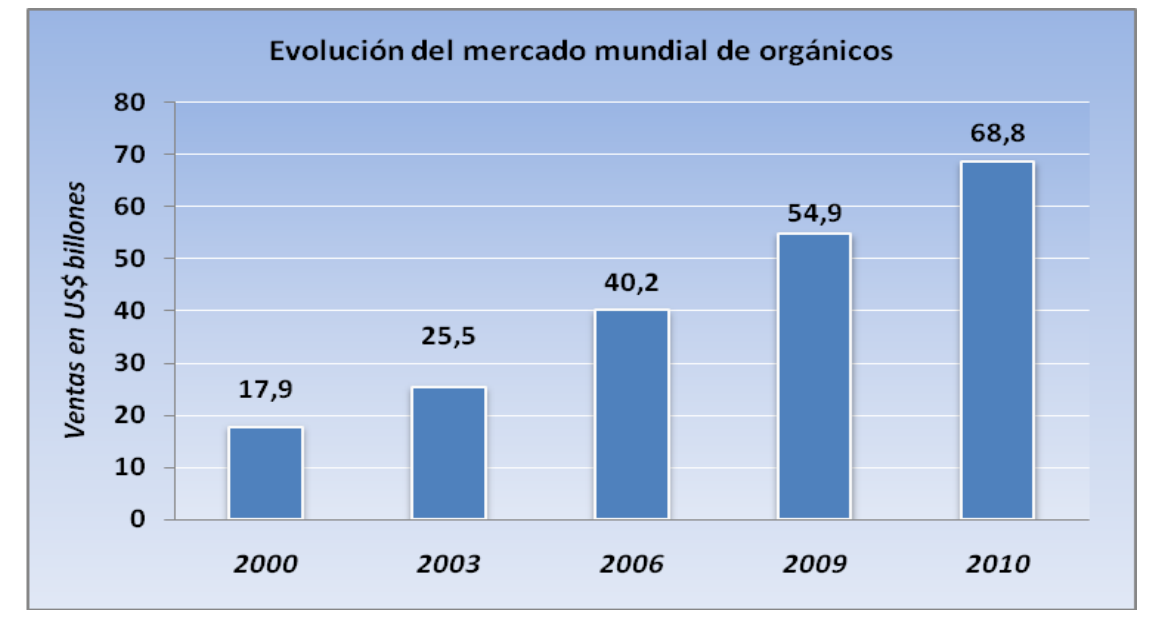

Fuente: Elaboración propia en base a datos obtenidos en Global Market for Organic Food \& Drink

\footnotetext{
${ }^{20}$ Disponible en www.fibl.org

${ }^{21}$ Organic Monitor Ltd. Rresearch and business consulting company specializing in organic products. www.organicmonitor.com 22 Disponible en www.fibl.org
} 
Gráfico $\mathrm{N}^{\circ}$ 21: Ventas doméstica de productos orgánicos años 2009:

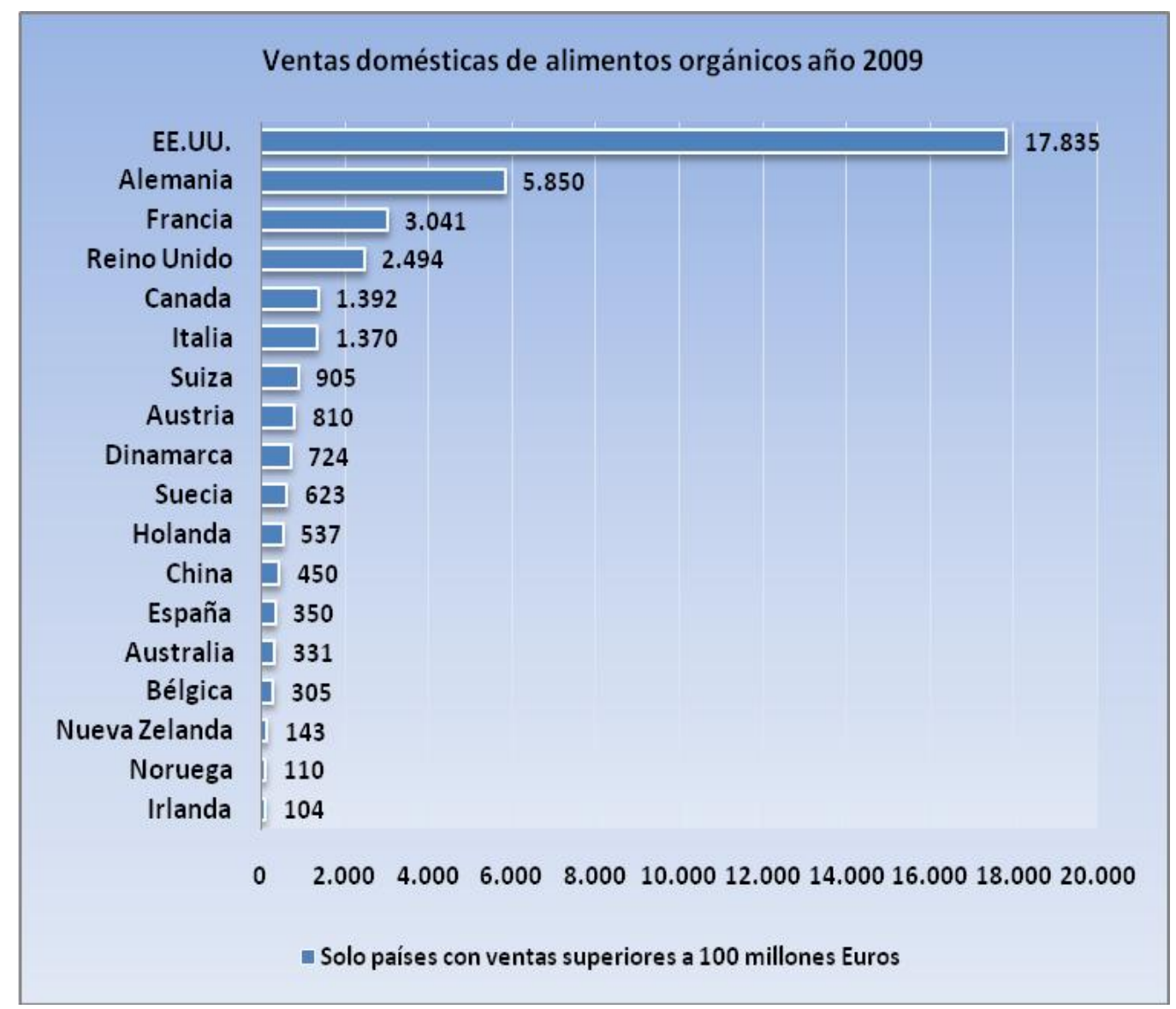

Fuente: Elaboración propia en base a datos obtenidos en FiBL und AMI, año 2011

Gráfico $N^{\circ} 22$ : Distribución de ventas doméstica de productos orgánicos años 2010 en Europa:

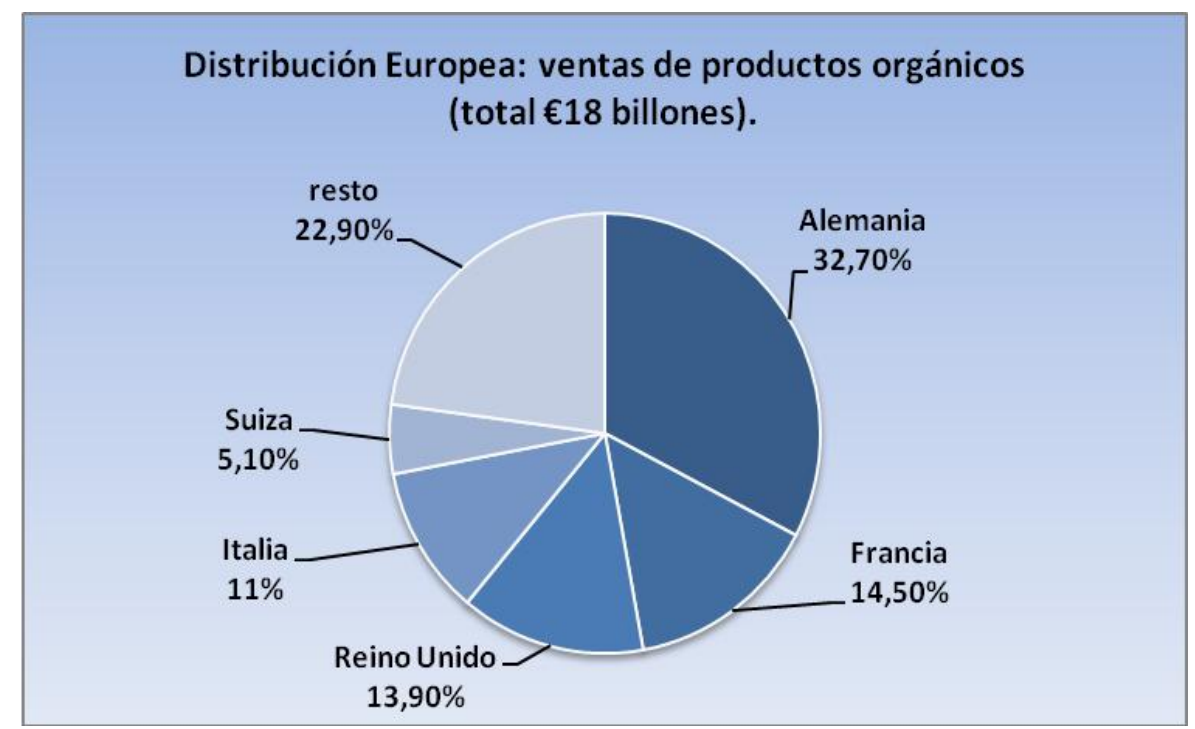

Fuente: FiBL und AMI para el año 2010 
Tal como podemos observar en el esquema, Alemania lleva la delantera en consumo de alimentos orgánicos en la UE, como el segundo lugar a nivel mundial. Más allá de esto, se evidencia el rol que estos productos tienen en demás países como Francia, Reino Unido e Italia.

Gráfico N²3: Países con mayores ventas orgánicas, share de mercado y consumo per cápita al año 2009 en Europa:

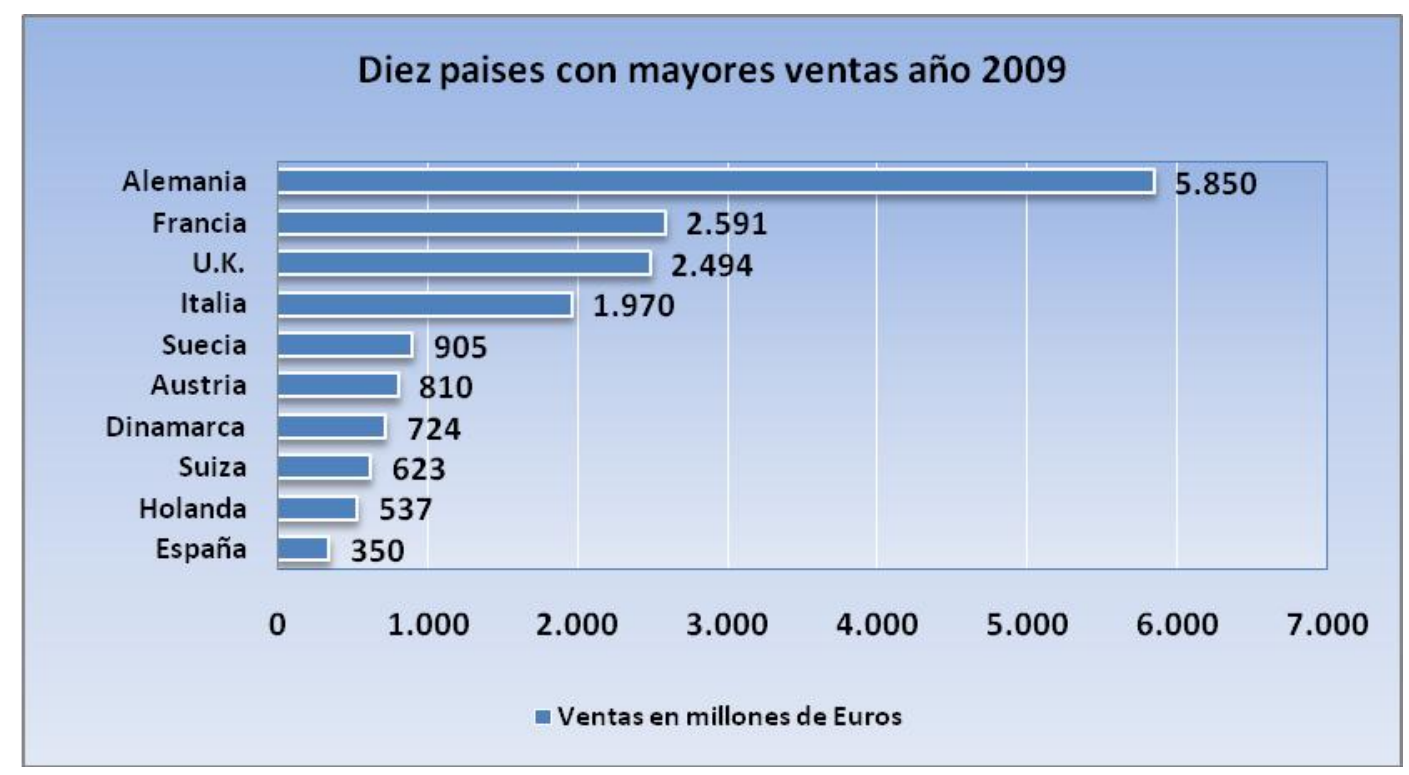

Fuente: FiBL und AMI año 2011

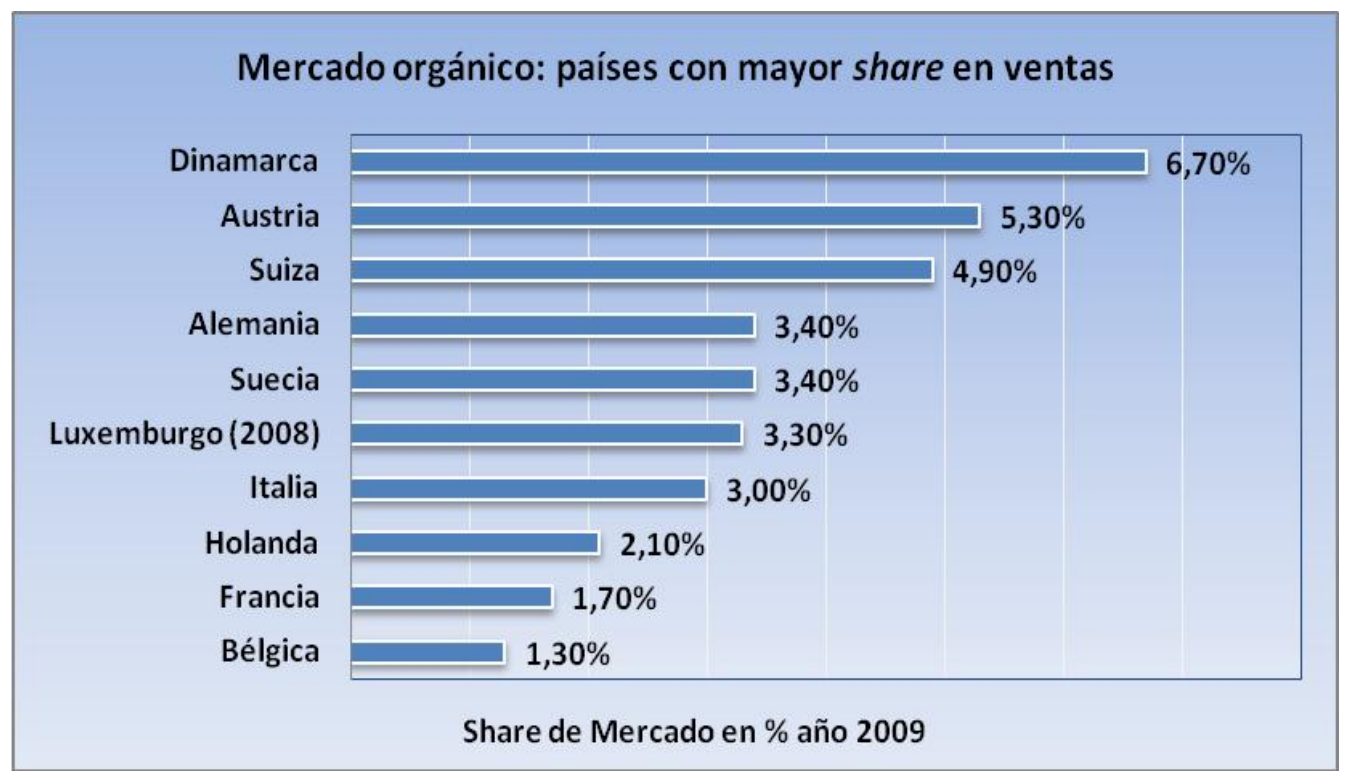

Fuente: FiBL und AMI año 2011 


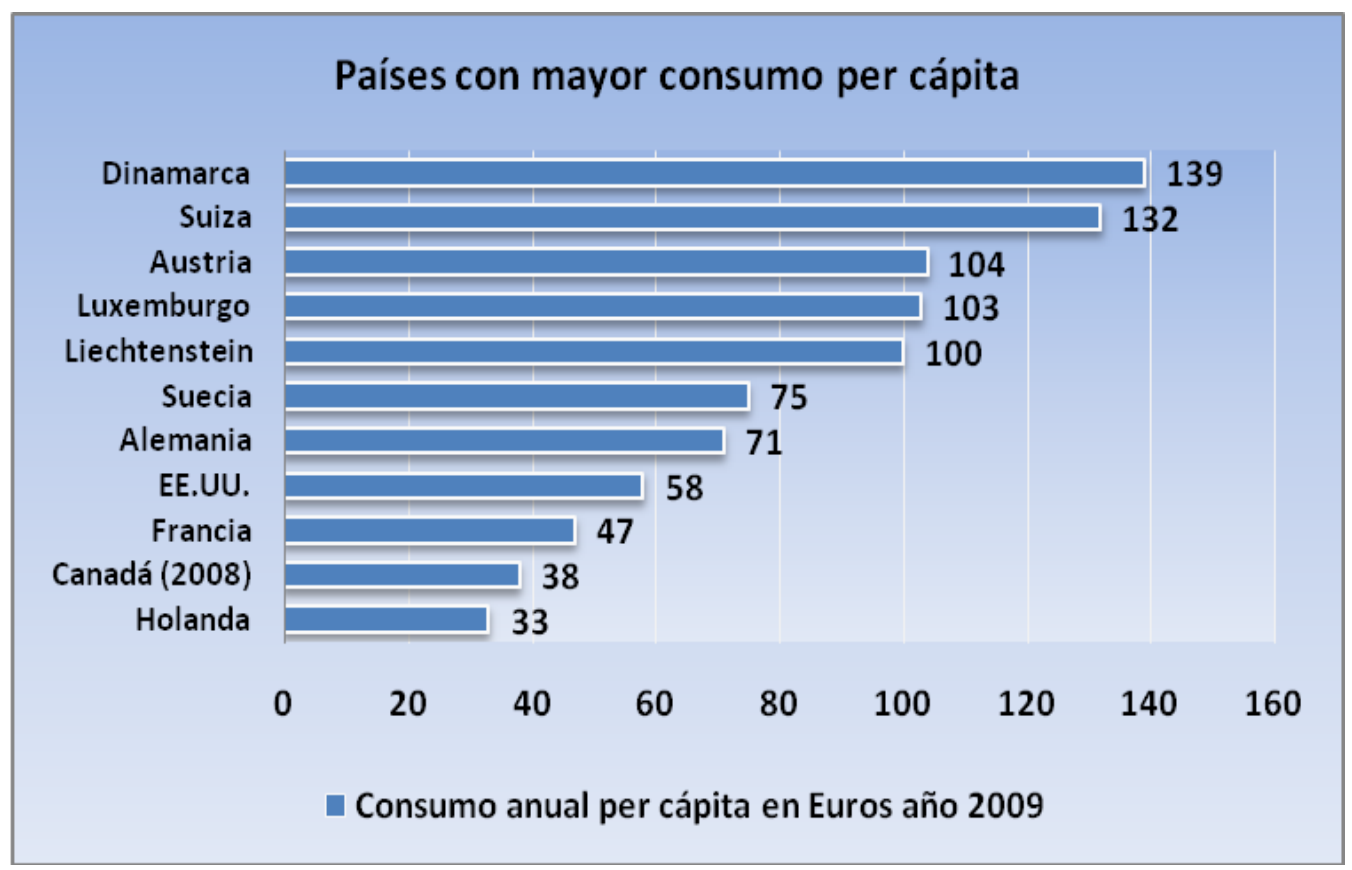

Fuente: FiBL und AMI año 2011

Basándonos en datos de la „Forschungsinstitut für biologischen Landbau”23 (Instituto de investigación para la agricultura biológica), podemos evidenciar una tendencia en alza respecto al consumo de productos orgánicos, existen dos fuerzas contrapuestas que influirán en el crecimiento de la agricultura orgánica. Desde el punto de vista de la producción, las compañías agroquímicas multinacionales, que en la actualidad también son proveedores de semillas y variedades genéticamente modificadas patentadas, no parecen estar dispuestas a aceptar la pérdida de gran parte de su participación en el mercado de insumos.

Desde el punto de vista de la demanda, los grandes distribuidores de alimentos se están dando cuenta de que no se puede esperar que todos los consumidores se comprometan con la cultura de la "comida rápida", ni todos ellos pueden aceptar la cultura de alimentos orgánicos. Dentro de la categoría de consumidores de orgánicos están aquellos que demandan alimentos orgánicos de preparación rápida (por ejemplo, las cenas preparadas en cajas para microondas). La mayor parte de la demanda de alimentos orgánicos, sin embargo, está basada en alimentos poco procesados, en el rechazo de las tendencias masivas del mercado y en el aumento de la fragmentación y especialización de los mercados.

${ }^{23}$ Disponible en: http://www.fibl.org/ 


\section{Comercio internacional de espárragos}

\subsection{Flujos mundiales de comercio y consumo de espárragos ${ }^{24}$}

Según datos de la Organización Mundial de Comercio, la tendencia de la demanda internacional del espárrago va en aumento (salvo en el año 2008 causada por la crisis financiera mundial), tanto a corto como a largo plazo. El crecimiento del consumo de espárragos, ocurre debido a la influencia y preocupación de los países de rentas más altas por cuidar la alimentación con alimentos más saludables.

Europa ocupa el primer lugar en la demanda mundial, teniendo a Alemania como uno de los más importantes consumidores (1,145 Kg. per cápita/año 2010). En segundo lugar se encuentra la región asiática, particularmente Japón y en tercer lugar EE.UU. La magnitud total de espárragos frescos comercializada en el mundo en 2010 se ubicó en 325.443 toneladas, lo que representó en términos monetarios unos US\$ 1.112 millones. En términos absolutos en 10 años, el mundo aumentó su consumo de espárragos en 119.406 toneladas.

Tabla Nº 10: Toneladas comercializadas y valores año 2010 - 2001:

\begin{tabular}{|c|c|c|}
\hline \multicolumn{3}{|c|}{ Datos mundiales en espárragos frescos } \\
\hline Año & Toneladas & Valores en miles de US\$ \\
\hline 2001 & 206.037 & 544.036 \\
\hline 2002 & 223.779 & 568.687 \\
\hline 2003 & 222.467 & 631.654 \\
\hline 2004 & 219.536 & 701.504 \\
\hline 2005 & 245.704 & 782.713 \\
\hline 2006 & 263.514 & 886.019 \\
\hline 2007 & 283.871 & 927.559 \\
\hline 2008 & 239.920 & 998.253 \\
\hline 2009 & 299.996 & 948.645 \\
\hline 2010 & 325.443 & 1.111 .952 \\
\hline Var. \% 10-01 & $\mathbf{5 7 , 9 5 \%}$ & $\mathbf{1 0 4 , 3 9 \%}$ \\
\hline Var. Abs. 10-01 & $\mathbf{1 1 9 . 4 0 6}$ & $\mathbf{5 6 7 . 9 1 6}$ \\
\hline
\end{tabular}

Fuente: "International Trade Center" 2011. Http://www.intracen.org

\footnotetext{
${ }^{24}$ En base a datos obtenidos en "International Trade Center" http://www.intracen.org. Año 2011.
} 
Gráfico N²4: Importación mundial de espárragos frescos por toneladas al año 2010:

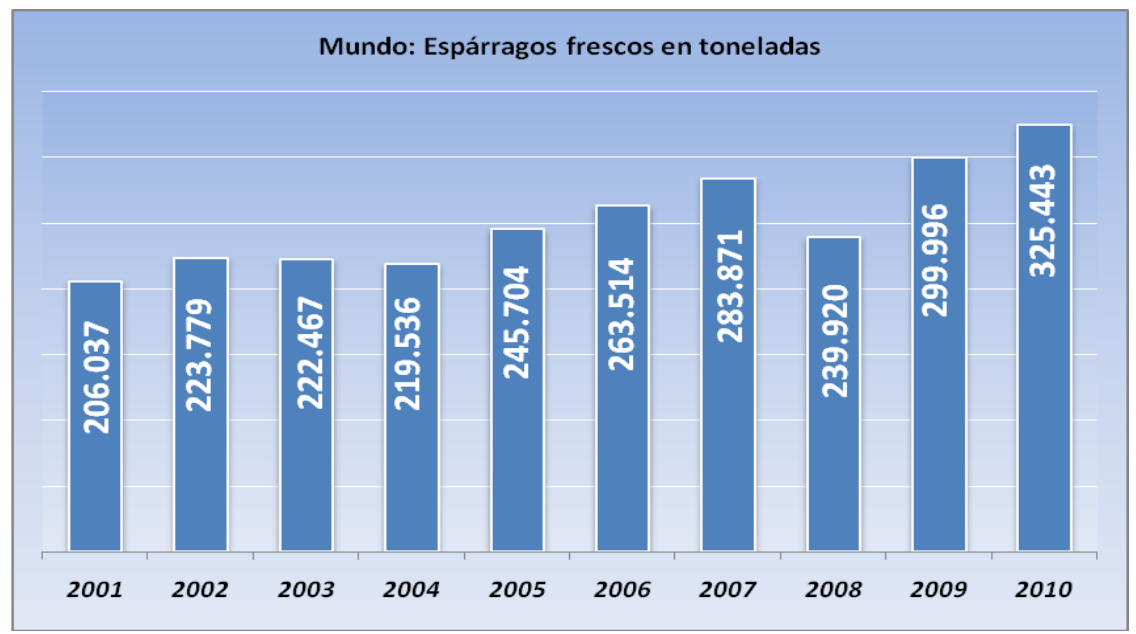

Fuente: Elaboración propia en base a datos de International Trade Centre año 2011.

Gráfico $\mathrm{N}^{\circ} 25$ : Valores comercializados de espárragos frescos a nivel mundial:

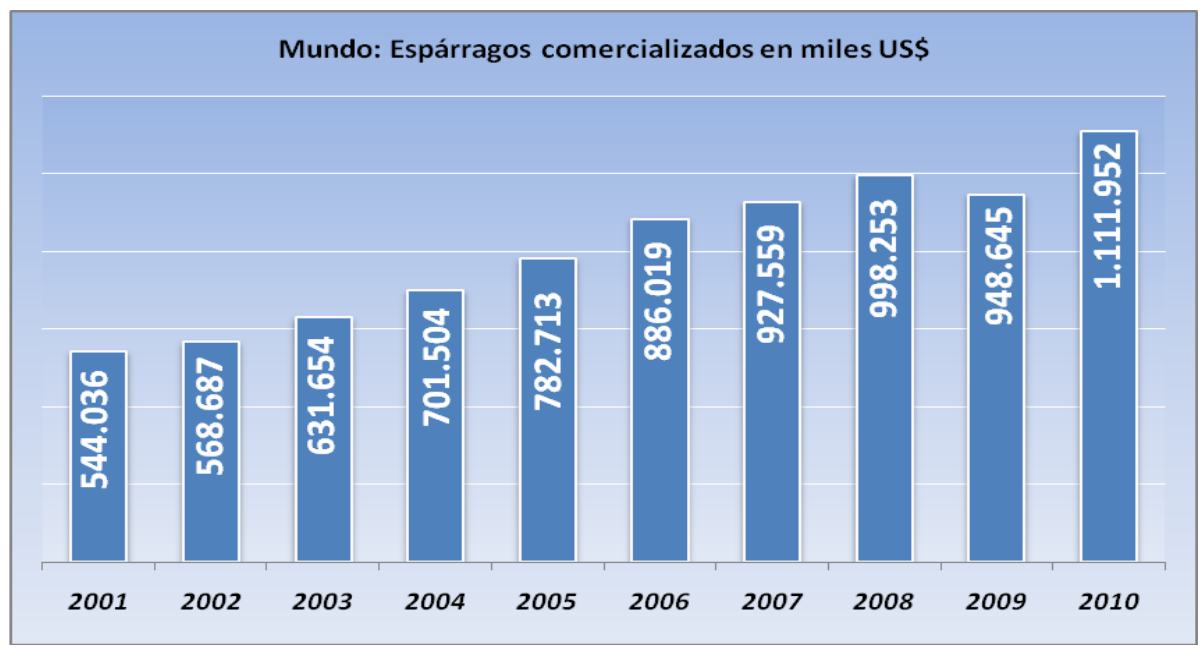

Fuente: Elaboración propia en base a datos de International Trade Centre año 2011.

Tabla $\mathrm{N}^{\circ}$ 11: Principales importadores mundiales espárragos frescos: Cifras en toneladas:

\begin{tabular}{|c|c|c|c|c|c|c|c|c|c|c|}
\hline & $\mathbf{2 0 0 1}$ & $\mathbf{2 0 0 2}$ & $\mathbf{2 0 0 3}$ & $\mathbf{2 0 0 4}$ & $\mathbf{2 0 0 5}$ & $\mathbf{2 0 0 6}$ & $\mathbf{2 0 0 7}$ & $\mathbf{2 0 0 8}$ & $\mathbf{2 0 0 9}$ & $\mathbf{2 0 1 0}$ \\
\hline MUNDO & $\mathbf{2 0 6 . 0 3 7}$ & $\mathbf{2 2 3 . 7 7 9}$ & $\mathbf{2 2 2 . 4 6 7}$ & $\mathbf{2 1 9 . 5 3 6}$ & $\mathbf{2 4 5 . 7 1 1}$ & $\mathbf{2 6 4 . 0 0 8}$ & $\mathbf{2 8 3 . 8 7 1}$ & $\mathbf{2 3 9 . 9 9 0}$ & $\mathbf{2 9 4 . 6 9 5}$ & $\mathbf{3 2 5 . 4 4 3}$ \\
\hline EEUU & 71.195 & 81.770 & 96.405 & 92.444 & 108.321 & 120.314 & 124.045 & 84.584 & 156.036 & 171.090 \\
\hline Alemania & 39.051 & 40.129 & 29.251 & 25.932 & 28.260 & 28.791 & 23.607 & 26.954 & 22.609 & 24.437 \\
\hline Países Bajos & 4.168 & 6.965 & 7.424 & 7.224 & 6.895 & 5.938 & 8.423 & 10.858 & 15.211 & 22.406 \\
\hline Canadá & 10.333 & 11.995 & 10.045 & 13.660 & 13.032 & 17.935 & 17.861 & 19.704 & 19.579 & 21.498 \\
\hline Japón & 22.055 & 19.363 & 17.850 & 17.148 & 17.469 & 14.976 & 12.542 & 10.437 & 10.780 & 12.538 \\
\hline Francia & 14.987 & 18.375 & 13.153 & 14.299 & 12.511 & 13.481 & 17.118 & 15.266 & 14.912 & 12.320 \\
\hline España & 3.760 & 4.804 & 6.329 & 6.271 & 9.211 & 9.371 & 8.820 & 9.997 & 10.110 & 10.752 \\
\hline Reino Unido & 6.427 & 5.667 & 6.103 & 6.035 & 8.076 & 9.215 & 8.745 & 9.930 & 9.245 & 9.823 \\
\hline
\end{tabular}

Fuente: Elaboración propia según datos de International Trade Centre, año 2011. 
Gráfico N²6: Principales importadores espárragos frescos al año 2010:

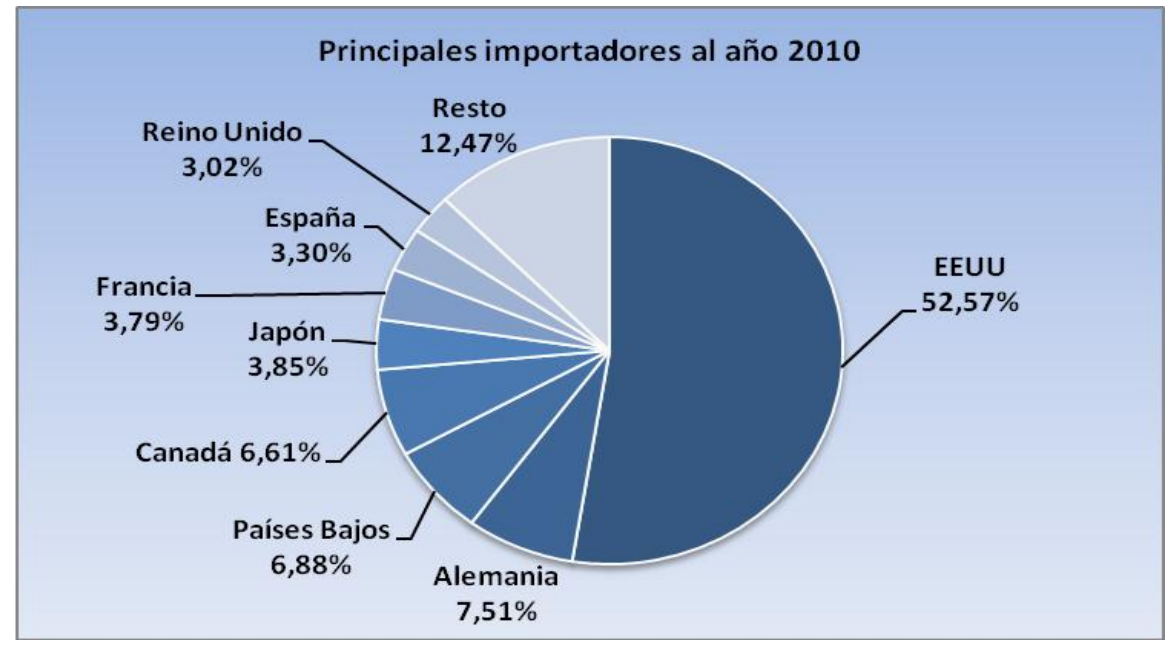

Fuente: Elaboración propia en base a datos de International Trade Centre año 2011.

Existen países con una fuerte demanda interna. Estos son generalmente los de mejores ingresos per cápita a escala mundial, lo que confirma la característica especial del espárrago como hortaliza de lujo.

Estados Unidos: Los datos obtenidos en International Trade Centre, establecen que EE.UU., es el principal importador de espárrago fresco del mundo. En 2010 se contabilizaron 171.090 toneladas importadas, significando US\$ 500.923 millones. Estas diferencias se fundamentan en dos causas fundamentales, una, es el estancamiento y lento declive de la producción local por la pérdida de rentabilidad frente a la presión de la competencia externa con precios significativamente menores; la segunda se refiere al fuerte aumento del consumo per cápita en los últimos años.

El público estadounidense consume casi exclusivamente el espárrago verde aunque puede encontrarse excepcionalmente la variedad blanca. En California se produce el 80\% del total nacional, seguido por Washington, Arizona y Michigan. En California los volúmenes producidos comienzan a ingresar en el mercado en el mes de febrero, pero logran mayor fuerza en marzo y abril. Esto indicaría en principio los meses donde el mercado se encuentra más desprovisto de producción local y es abastecido por importaciones. En lo referido a la procedencia de las importaciones como ya fue dicho, Perú y México comparten el mercado históricamente, sin embargo hubo un cambio de supremacía a manos del aumento de la productividad peruana en los últimos años. 
Alemania: Es el segundo importador mundial de espárragos frescos y el segundo importador del producto procesado o en conserva. El habitante alemán es el que más espárrago consume anualmente, con un total de 1,145 Kg. por persona, sumando ambas modalidades de presentación del producto. Participa como centro neurálgico del comercio europeo, y junto con Holanda, Francia, España y Reino Unido son los países europeos que inciden directamente en el desenvolvimiento del mercado mundial.

Según datos de la O.M.C., en 2010 la importación del producto fresco alcanzó las 24.437 toneladas, significando US\$ 95.249 millones. Este patrón demuestra la tendencia al consumo del habitante alemán. Pese a esto, la tendencia importadora es decreciente, neutralizada por el aumento de la producción local y los buenos rendimientos en la productividad obtenida. El déficit de producción actual con respecto al consumo en el mercado alemán es saldado principalmente por Grecia quien en 2010 exportó a Alemania 12.236 toneladas a un valor total de US\$ 42.934 millones. Perú fue el segundo proveedor de Alemania en espárrago fresco hasta 2009; el volumen negociado en dicho año llegó a las 3.955 toneladas, por un valor cercano a los US\$17.211 millones, lo que implica un precio aproximado de US\$ 4,35 por kilo. La situación en el año 2010 fue de 3.155 toneladas exportadas, siendo desplazada por España que en 2010 logró 3.252 toneladas vendidas.

Holanda: Uno de los países que ha mostrado un comportamiento muy interesante, tanto en producción, consumo interno y exportación en los últimos años ha sido Holanda. En la última década ha aumentado en consumo en 18.238 toneladas. En 2010, la cifra por lo importado asciende a US\$ 59.745 millones. Esto muestra que Holanda se ha transformado en el $3^{\circ}$ país importador de espárragos frescos después de EE.UU. y Alemania, mostrando un destino interesante para las potenciales exportaciones argentinas. Asimismo, el país se ha convertido en el año 2010 en el segundo proveedor de Alemania, con 4.895 toneladas y por un valor de US\$20.981 millones. El primer proveedor ha sido Grecia, con un total de 12.236 toneladas y US\$ 42.934 millones. 


\subsection{Principales países exportadores de espárragos frescos ${ }^{25}$}

Tabla $\mathrm{N}^{\circ}$ 12: Principales exportadores mundiales espárragos frescos o refrigerados en toneladas:

\begin{tabular}{|c|c|c|c|c|c|c|}
\hline Toneladas & $\mathbf{2 0 0 5}$ & $\mathbf{2 0 0 6}$ & $\mathbf{2 0 0 7}$ & $\mathbf{2 0 0 8}$ & $\mathbf{2 0 0 9}$ & $\mathbf{2 0 1 0}$ \\
\hline Perú & 80.021 & 92.807 & 96.329 & 109.808 & 122.131 & 123.176 \\
\hline México & 53.772 & 52.220 & 55.776 & 63.489 & 68.362 & 83.196 \\
\hline EE.UU. & 23.339 & 21.928 & 20.786 & 23.315 & 28.334 & 35.205 \\
\hline Países Bajos & 7.356 & 8.068 & 10.210 & 11.981 & 13.875 & 11.688 \\
\hline Grecia & 11.423 & 12.424 & 12.713 & 14.655 & 13.729 & 10.275 \\
\hline España & 16.836 & 17.582 & 14.164 & 13.700 & 13.376 & 11.950 \\
\hline Argentina & 679 & 381 & 343 & 165 & 274 & 245 \\
\hline
\end{tabular}

Fuente: Elaboración propia en base a datos obtenidos en International Trade Center y SENASA

Gráfico $N^{\circ} 27$ : Principales exportadores espárragos frescos al año 2010:

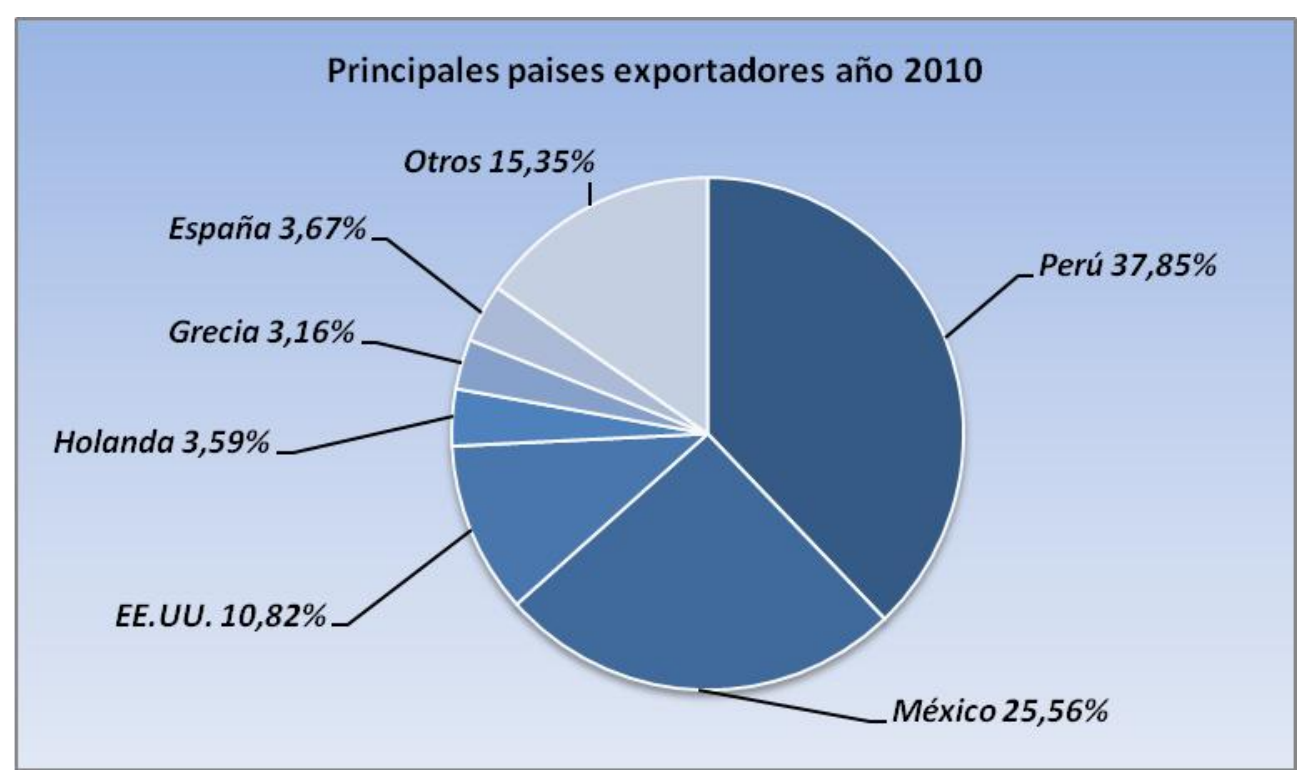

Fuente: Elaboración propia en base a datos de International Trade Centre.

Si bien China es el principal productor de espárragos, ocupa el lugar número 13 en la lista de exportadores del producto fresco. El principal exportador de espárragos frescos es el Perú, llegando a un share de mercado mundial en 2010 del 37,85\%, con 123.176 toneladas comerciadas. Su principal comprador es EE.UU. con un volumen de 85.340 toneladas, representando el $70 \%$ de lo vendido en 2010.

El segundo exportador es México, quien colocó en 2010 el 99,03\% (83.196 toneladas) de sus envíos en

\footnotetext{
${ }^{25}$ Datos expresados en toneladas y participación porcentual de las importaciones mundiales; Fuente: International Trade Centre.
} 
EE.UU. La evolución de las exportaciones del espárrago mexicano se ha mantenido creciente a partir del año 2006. Ambos países, tienen como principal mercado los EE.UU. El mismo EE.UU., pese a su patrón importador también participa en las exportaciones. Sus mercados más importantes son Canadá, Japón y Suiza (en ese orden de importancia).

Tanto Grecia como España son países productores tradicionales que abastecen al mercado europeo, que se encuentran favorecidos por las barreras arancelarias y para-arancelarias, que impone la Comunidad Económica Europea a la competencia externa. A partir del año 2005, Grecia ha mostrado un decrecimiento del 10\% (1.148 toneladas) respecto al año 2010. En el mismo periodo, España ha mostrado una caída del 29,02\%, lo que significan 4.486 toneladas de producto.

\subsection{Exportaciones e importaciones en la Unión Europea}

Según datos obtenidos en International Trade Centre, la balanza comercial del espárrago en la Unión Europea es negativa, puesto como se observa en el gráfico, en la actualidad hay más importaciones de espárragos que exportaciones. Los países mayormente importadores de espárragos dentro de la Unión Europea son Alemania, Francia, Holanda, Reino Unido, Italia, España y Suiza. El principal proveedor de espárrago fresco de la Unión Europea es Perú. En cuanto al espárrago congelado y en conserva los principales proveedores son China, seguido de Perú.

Gráfico $\mathrm{N}^{\circ} 28$ : Exportaciones e importaciones de espárragos frescos en la Unión Europea:

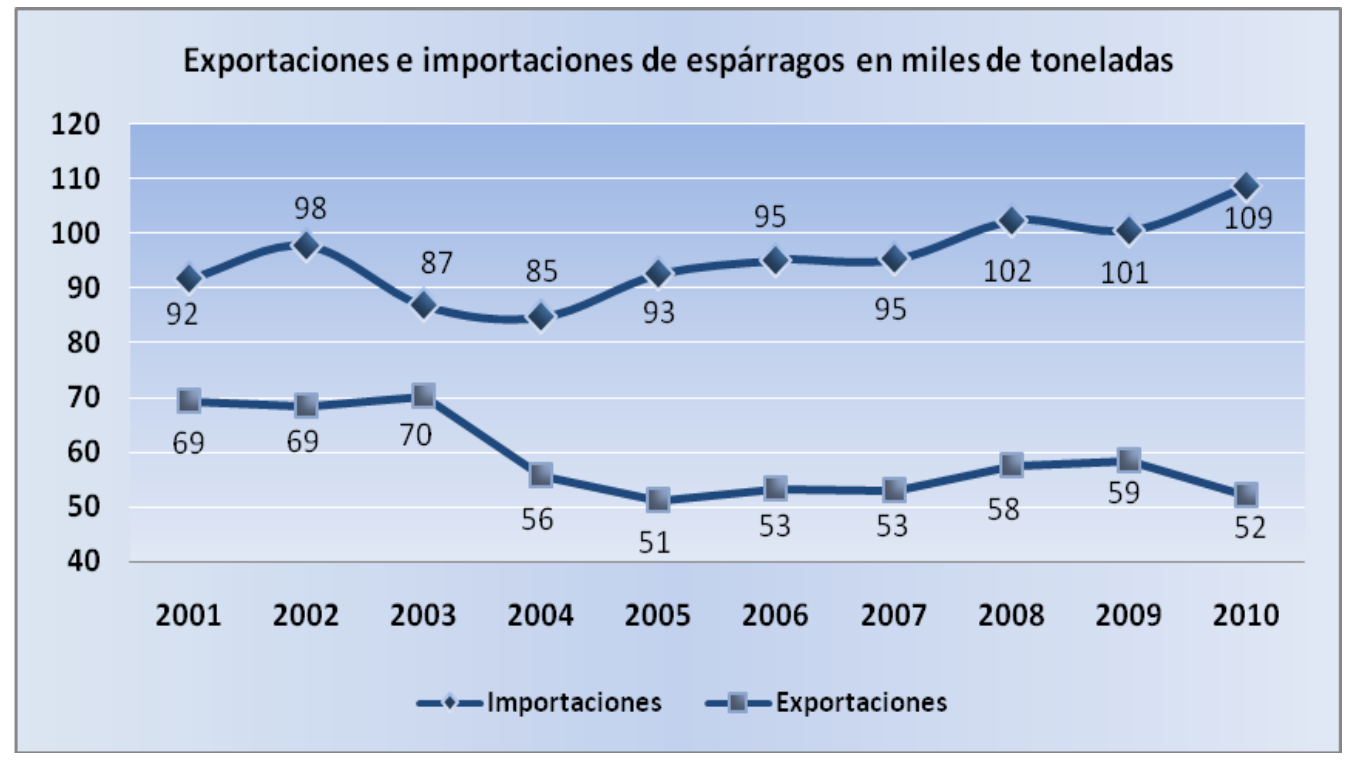

Fuente: Elaboración propia. Datos obtenidos en International Trade Center www.intracen.org. 2011 


\subsection{Consumo de espárragos en la Unión Europea}

Según datos de International Trade Centre, Europa ocupa el primer lugar en la demanda mundial de espárragos, teniendo a Alemania como el principal consumidor. En este país ha aumentado su producción de espárragos en los últimos años; aunque no llega a abastecer la totalidad de su consumo interno. Esto lleva a que su principal proveedor de espárragos sea Grecia, seguida de Holanda, España, Polonia, Hungría, Italia y Perú.

Generalmente, las preferencias del mercado alemán se inclinan hacia el espárrago fresco. El consumo de espárragos en Alemania absorbe el $95 \%$ de la producción doméstica, que sale desde fines de marzo hasta junio. En Europa se prefiere el espárrago blanco, donde se ha concentrado el desarrollo de nuevas variedades y la investigación tecnológica sobre manejo y producción. Para el caso del espárrago verde, se observa que queda restringido para el mercado norteamericano, japonés e inglés.

\subsection{Normas de calidad internacional ${ }^{26}$}

Para los espárragos no existe ninguna norma de comercialización específica por parte de la Unión Europea, y por lo tanto, se aplica la norma general de comercialización que figura en el Anexo I, Parte A, del Reglamento de la Comunidad Europea, $N^{\circ} 1580 / 2007$.

El problema de esta norma de calidad ${ }^{27}$, muy generalizada, es que no permite la comercialización con la definición de clases de calidad, que los distribuidores alemanes en muchos casos requieren. Sin embargo, la Unión Europea permite la comercialización bajo las normas de la UNECE (United Nations Economic Commission for Europe).

Para espárragos se puede aplicar la siguiente normativa:

\section{UN/ECE FFV-04 relativa a la comercialización y control de calidad comercial de los ESPÁRRAGOS.}

En el anexo al presente capítulo, en la página $\mathrm{N}^{\circ} 105$ se ofrece un detalle de la nombrada normativa de calidad para la Unión Europea.

\footnotetext{
${ }^{26}$ Según información brindada por el Consulado Argentino en Hamburgo.

${ }^{27}$ En el anexo del presente apartado, se detallan ambas normas.
} 


\section{El mercado de los productos orgánicos en Alemania}

\subsection{Tendencias del mercado de alimentos orgánicos o "Bio alimentos"}

Según un estudio difundido por el portal Ökomarkt ${ }^{28}$, la disponibilidad de materias primas procedentes de cultivos orgánicos controlados está sujeta al agotamiento de las fuentes de producción que imponen los límites naturales. Un estudio online sobre el comportamiento de los consumidores realizado en 2010 con personas que adquieren productos orgánicos, muestra además que en la decisión de las compras tiene una importancia primordial las propiedades respecto a la salud. Un $47 \%$ de los consultados mencionaron como motivo de sus compras el que sea "beneficioso para mi salud", porcentaje que se eleva al $58 \%$ en el caso de los consumidores de productos orgánicos. Como segundo motivo, con un 16\%, figura la respuesta "mejor para mis hijos", mientras que un 11\% en Alemania y un $14 \%$ de los consumidores globales de productos orgánicos ven como motivación que "resultan mejores para el medio ambiente".

Entre los consultados en Alemania que "nunca" compran productos orgánicos, "el precio" figura como motivo principal de su actitud. Un $54 \%$ de los consultados hicieron mención al elevado precio como argumento desalentador a la hora de comprar; un 16\% rechaza la compra de productos orgánicos "por falta de convicción" y $30 \%$ por otros motivos. En cuanto a la brecha de precios entre productos orgánicos y convencionales, se destaca el segmento de productos de panificación dulce con una diferencia promedio de $82 \%$ respecto a los productos convencionales. Las harinas orgánicas son $104 \%$ más caras que las convencionales mientras que la diferencia de precios en la leche es de $49 \%$.

El mismo informe establece que, respecto a las empresas "Bio", por ejemplo, una de las líderes, Alnatura, opera sobre dos pilares: el primero es la venta en sus propios negocios; el segundo consiste en vender sus artículos a través de otras tiendas como por ejemplo DM, Tegut y Globus. Alnatura en la actualidad cuenta con un surtido de 780 artículos orgánicos. Aunque existen los supermercados especializados en productos orgánicos, también las cadenas convencionales están disputando crecientemente este segmento, cada vez más dinámico. Las cadenas de supermercados como Aldi o Lidl, que controlan el 55\% de las ventas generales por sus precios bajos, se han sumado en los últimos años a la venta de estos productos orgánicos. Lidl se encuentra a la cabeza con más de 40 productos diferentes bajo la marca "bioness", ofreciendo desde queso, hasta yogurts y salsas de tomate.

${ }^{28}$ Disponible en http://www.oekomarkt-hamburg.de 
Dado que la oferta se ha incrementado enormemente, los artículos orgánicos han dejado de ser productos minoritarios de alto precio de muy buena calidad y se están convirtiendo gradualmente en productos de alcance masivo pero de menor calidad. No obstante, resulta interesante que los supermercados comunes han logrado llegar a consumidores que nunca antes habrían comprado productos orgánicos, significando una fuerte competencia para los auténticos supermercados orgánicos como Alnatura, Basic, Erdkorn y BioCompany, cuya oferta de productos oscila entre 6 y 8 mil.

El perfil del consumidor en Alemania ha cambiado en los últimos años. Mientras antes lo más importante era la protección del "medio ambiente" hoy lo primordial es que los productos sean "saludables", perdiendo importancia su procedencia

\subsection{Hábitos de alimentación en Alemania}

La "alimentación de conveniencia" cada vez cuenta con mayor demanda en Alemania. Esta situación se ve fortalecida gracias a fenómenos como: ritmos de vida cada vez más acelerados, familias con menos miembros, mayor esperanza de vida, la preocupación por la salud y la sostenibilidad o el aumento de la movilidad de las personas. De esta forma, las "soluciones de conveniencia" (comidas preparadas y listas para consumir) son cada vez más importantes, según afirma el director ejecutivo de la firma Lekkerland, Chistian Berner, en Lebensmittel Zeitung ${ }^{29}$ el semanario especializado en sector alimentos de Alemania.

En la misma postura se declara el directivo de Edeka, Alfons Frenk, que señala la propensión hacia lo ecológico y los productos de conveniencia (comprados con mucha asiduidad y con un esfuerzo mínimo), así como a la necesidad de innovación en los sistemas de almacenado y logística, son las pautas que definirán el paisaje comercial de la industria alimentaria.

También otras organizaciones han comenzado a batallar para que se consuma más frutas y hortalizas. Por ejemplo, a través de una campaña 5 am Tag ( 5 al día) elaborada por la Sociedad Alemana Contra el Cáncer (Deutsche Krebsgesellschaft) ${ }^{30}$ en colaboración con el Ministerio Federal de Salud y Asuntos Sociales y el de Protección del Consumidor, Alimentación y Agricultura ${ }^{31}$, se trata de instalar

\footnotetext{
${ }^{29}$ Disponible en www.lebensmittelzeitung.net

${ }^{30}$ Disponible en www.krebsgesellschaft.de

${ }^{31}$ Bundesministerium für Ernährung, Landwirtschaft und Verbraucherschutz, disponible en: www.bmelv.de
} 
el tema, ya que el consumo de fruta y verduras reduce considerablemente el riesgo de contraer enfermedades graves.

Según escribe Die Tageszeitung de Berlín ${ }^{32}$; Grosso Modo en la sociedad alemana pueden distinguirse dos tipos de ciudadanos atendiendo a sus costumbres culinarias: el que lleva una alimentación sana, y el que no. El sano suele disponer de más recursos económicos y mejor formación. Las clases más bajas y de menor nivel educacional se alimentan peor. Pero no sólo el dinero es determinante a la hora de comer bien. El habitante de Alemania consume un promedio de 1,7 kilos de carne y embutidos a la semana, cuando con 300 a 600 gramos es suficiente. Así, el dinero no invertido en carne podría emplearse en comprar frutas y verduras.

\section{El mercado del espárrago en Alemania}

\subsection{El potencial del mercado alemán}

Alemania, con más de 82,5 Millones de habitantes y $€ 1.495 .000$ Millones en poder adquisitivo, se ubica como una de las potencias más fuertes del mundo. Según un informe del Der Standard de Austria $^{33}$, más del $19 \%$ del total del poder adquisitivo europeo se concentra en Alemania. Este pais consume anualmente 16,9 millones de toneladas en frutas y hortalizas, teniendo un consumo per cápita de $204 \mathrm{Kg}$. El consumo per cápita de verduras frescas y elaboradas ha tenido un aumento constante desde principios de los 90 . El comportamiento de consumo a comienzos de los 70 ascendía a $65 \mathrm{~kg}$ por persona, para luego llegar a un nivel récord de consumo de $93.3 \mathrm{~kg}$ en el 2005.

Con una producción anual de 4,5 millones de toneladas de frutas y hortalizas, Alemania puede satisfacer la demanda interna de frutas y hortalizas únicamente en un $27 \%$, viéndose obligada a satisfacer el resto de la demanda a través de las importaciones. De esta manera, se convierte en uno de los países importadores de frutas y hortalizas más importante de Europa. Entre sus principales proveedores se encuentra España, seguido por Italia. Mientras que terceros países, especialmente los países latinoamericanos desempeñan un papel muy importante. A lo anterior, se debe agregar que las verduras frescas, según estimaciones del ZMP (Zentrale Markt und Preisberichststelle - Centro de Información de Mercado y Precios) han tenido un incremento de aproximadamente un 50\% del total de

${ }^{32}$ Disponible en: www.taz.de

33 Disponible en www.derstandard.at 
verduras consumidas desde el año 2005.

Basándonos en los trabajos realizados por AMI-Agramarkt Informations Gesellschaft, y respecto al mercado de espárragos se puede decir que Alemania es el país que registra el consumo por habitante más alto del mundo y el segundo importador mundial de espárragos frescos. Sin embargo, en la última década, su capacidad productiva se ha ampliado y sus requerimientos externos han disminuido. Alemania tiene un consumo anual per cápita de espárrago fresco de 1,145 kg.

\subsection{Consumo de espárragos en Alemania al 2010}

El consumo de espárragos en Alemania ha crecido desde el año 1996 un 49\% ${ }^{34}$, llegando a la cantidad de 121.311 toneladas al año 2010, lo que da como resultado que éste país es el principal consumidor mundial con miras a continuar esta tendencia. Más allá de esto, se observa conjuntamente al aumento de la cantidad demandada, un aumento de la producción local con la disminución de las cantidades importadas. El estudio de estas cantidades nos arrojaron que el 72,77\% del total de la demanda fue prácticamente cubierta por los espárragos alemanes.

Gráfico $\mathrm{N}^{\circ} 29$ : Origen de la provisión de espárrago fresco en Alemania en toneladas:

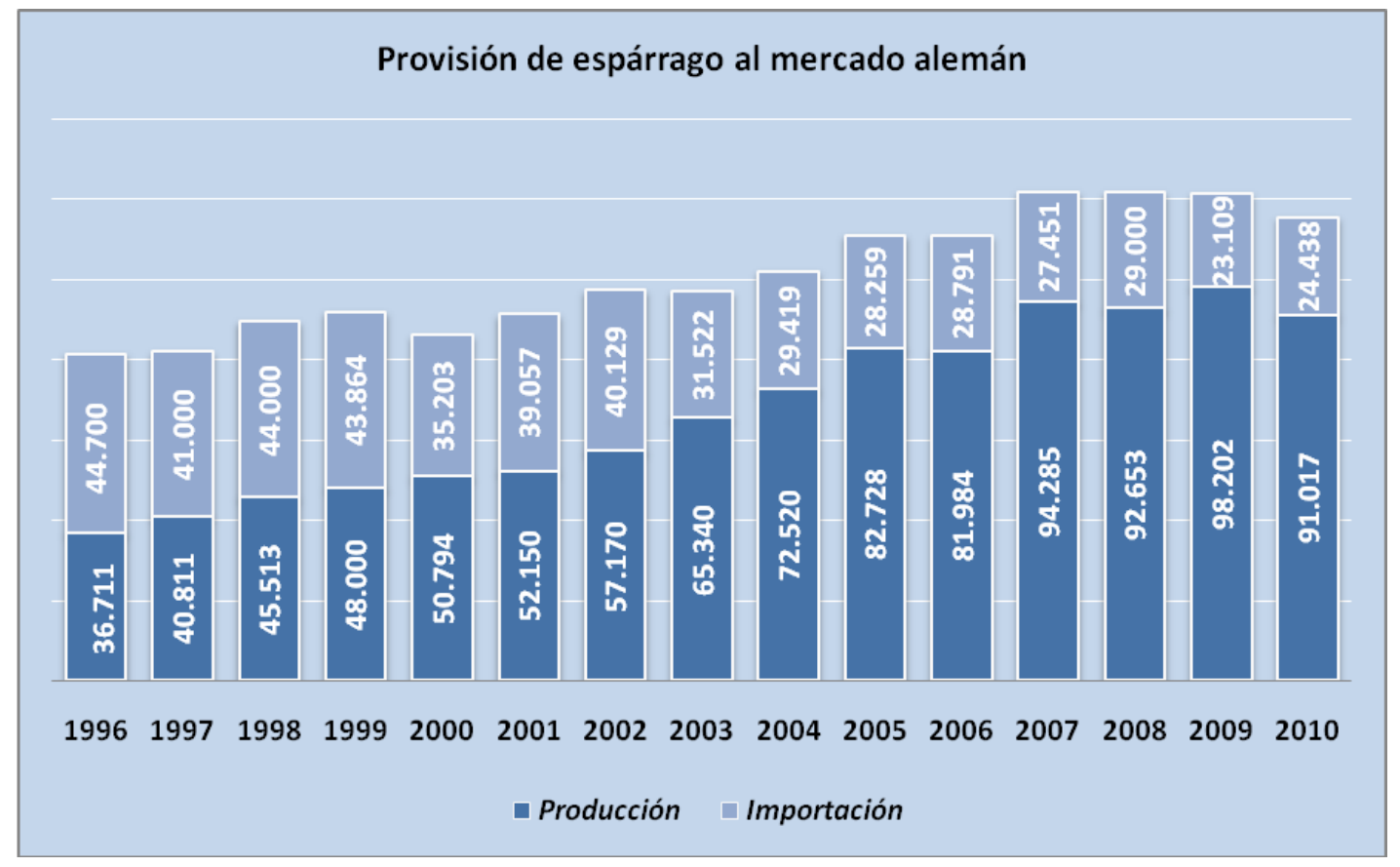

Fuente: Elaboración propia en base a datos obtenidos en Statisches Bundesamt y AMI año 2011.

\footnotetext{
34 Elaboración Propia en base a datos obtenidos en la Oficina de Estadística del Gobierno Alemán (disponible en www.destatis.de) y en AMI, Agramarkt Informations Gesellschaft (disponible en www.marktundpreis.de).
} 
Un estudio realizado por la Agencia de Estadística Alemana ${ }^{35}$ estima que el consumo per cápita de espárragos en Alemania en 2010 fue de 1,145 Kg, ubicándose de esta manera como el país con el índice de consumo per cápita más alto en la Unión Europea, seguido por España con 0,59 Kg, Italia y Francia con $0,38 \mathrm{Kg}$. respectivamente y Holanda con 0,27 Kg. Cabe mencionar que Alemania es el único país cuyo consumo per cápita ha crecido en los últimos años. Para el caso de la producción hay que tomar en cuenta un porcentaje de pérdida para el caso de los espárragos frescos.

Gráfico N³0: Total Neto de espárragos en el mercado alemán (Pcción. + Impo - expo - pérdida en producción):

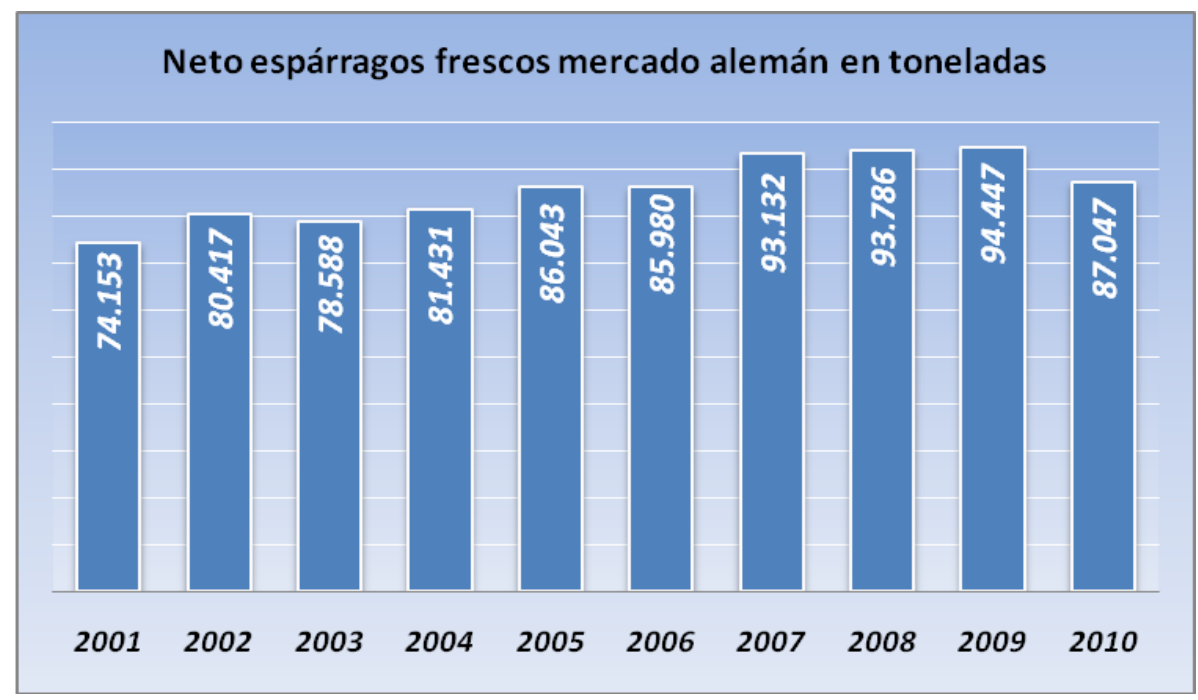

Fuente: Propia en base a datos obtenidos en Statisches Bundesamt y Zentral Markt und Preis.

Gráfico N³1: Comparación consumo anual per cápita año 2010:

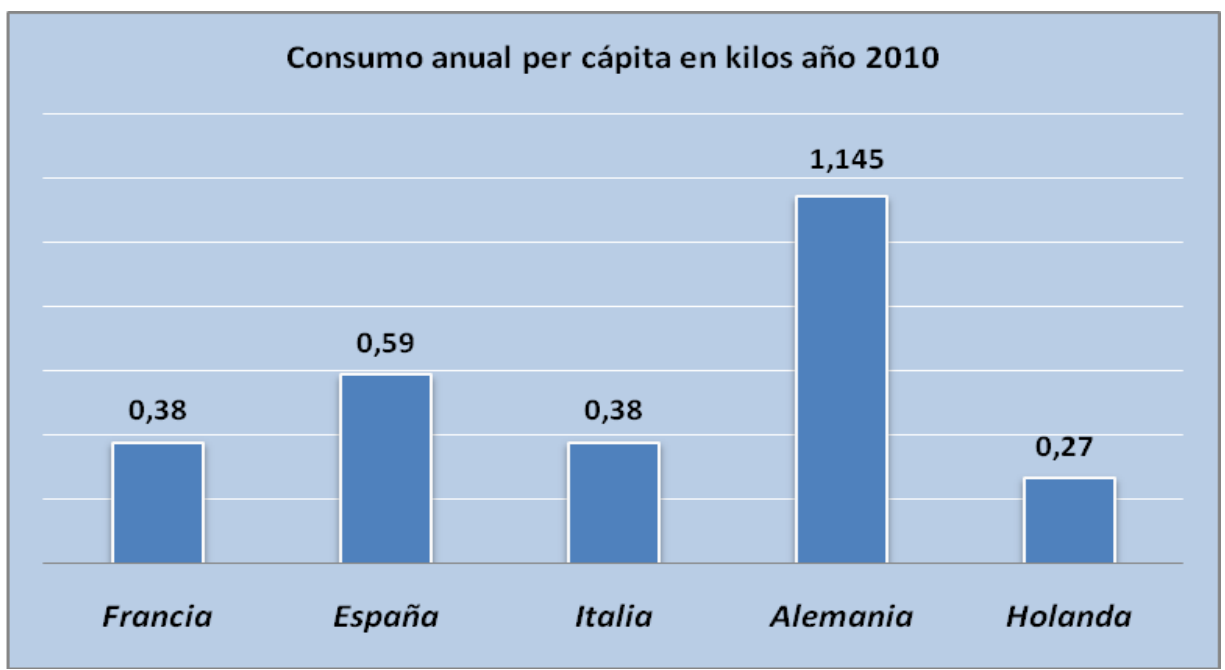

Fuente: Statisches Bundesamt 2011

\footnotetext{
${ }^{35}$ Statisches Bundesamt. Disponible en www.destatis.de
} 


\subsubsection{Consumo según el mes}

En cuanto a la distribución del consumo, se puede observar que el mes de mayo es el mes de mayor consumo, seguido por los meses de junio y abril.

\subsubsection{Variedad de espárrago consumido y consumo por edades}

En cuanto al tipo de espárragos consumido, según datos de Agramarkt Informations Gesellschaft se ha podido apreciar que, del consumo total de espárrago el 95,5\% corresponde al mercado de espárragos blancos, mientras que sólo el 4,5\% al mercado de espárragos verdes. Sin embargo, durante los últimos años se ha podido apreciar un leve crecimiento de la cuota de mercado de los espárragos verdes.

Este comportamiento es contrario a lo que sucede por ejemplo en EE.UU., donde prácticamente el 100\% del espárrago consumido es verde. Lo mismo ocurre en Asia y el pacífico, donde el porcentaje llega al $95 \%$.

Gráfico Nº 32: Comparación consumo anual per cápita:

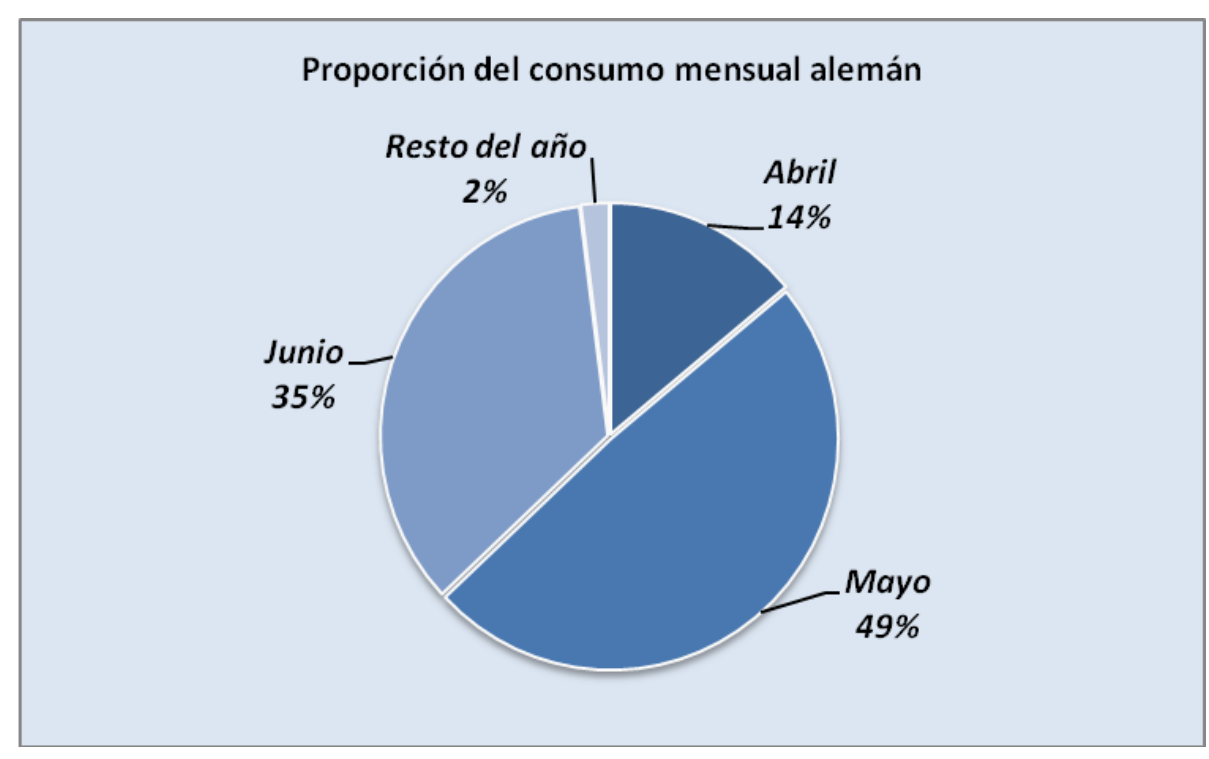

Fuente: ZMP Zentrale Markt- und Preis año 2011

El periodo entre abril y junio representan aproximadamente el $98 \%$ del consumo total a lo largo de todo el año, mientras que el resto del año, el consumo representa solo el $2 \%$ del total del consumo. Una encuesta realizada por la Central Alemana de Precios y Mercados $(Z M P)^{36}$ a un panel de

\footnotetext{
${ }^{36}$ ZMP Zentrale Markt- und Preis, disponible en http:// www.zmp.de
} 
consumidores, señala que durante los meses de cosecha (Abril-Junio) se consumen principalmente espárragos de origen alemán, en cambio, durante el mes de marzo (mes fuera de la temporada) más del $50 \%$ de los espárragos consumidos fueron extranjeros. Esto brinda una ventaja para el caso de espárragos argentinos, ya que el periodo de cosecha de Alemania coincide con el período de sus principales proveedores europeos tal como Grecia, España, Holanda y Polonia. También se desprende del nombrado estudio que el $38 \%$ del consumo lo realizan personas entre 50 y 64 años y un $77 \%$ si lo referimos a personas mayores de 50 años.

Gráfico $N^{\circ} 33$ : Consumo según las edades:

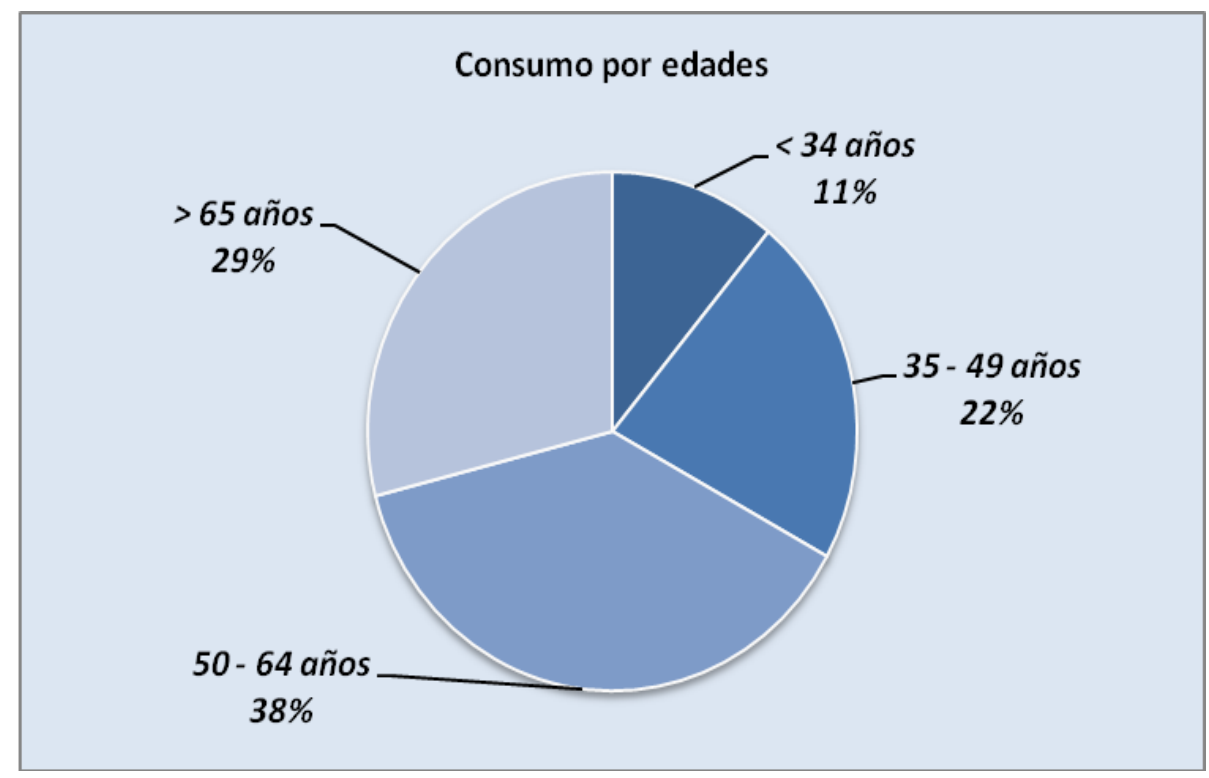

Fuente: Statisches Bundesamt año $2010^{37}$

\subsection{Tipo de espárrago importado}

La importación de espárragos se clasifica en tres partidas arancelarias:

07092000: Espárragos frescos o refrigerados.

07108085: Espárragos cocidos en agua o vapor, congelados.

20056000: Espárragos preparados o conservados, sin congelar.

A los fines del presente estudio dejamos establecido en el cuerpo principal, datos relacionados a los espárragos frescos. Dentro del anexo al presente capítulo, se encuentran datos con relación a los

${ }^{37}$ Disponible en www.destatis.de 
espárragos refrigerados y los espárragos congelados.

\subsubsection{Importaciones alemanas de espárragos frescos o refrigerados}

En los últimos años, las cantidades importadas por Alemania han ido en descenso. Esto se debe tanto al aumento en las hectáreas cultivadas, como al rendimiento por hectárea obtenido. Para el año 2009, Alemania importó 23.109 toneladas. Dentro de lo acaecido en el año 2010, vemos un leve repunte respecto al 2009, llegando lo importado a 24.438 toneladas de espárragos frescos. Considerando a sus principales proveedores, debemos destacar a Grecia, que viene manteniendo el primer lugar como exportador a lo largo de la última década.

Gráfico N³4: Evolución importaciones de espárragos 2010-2001:

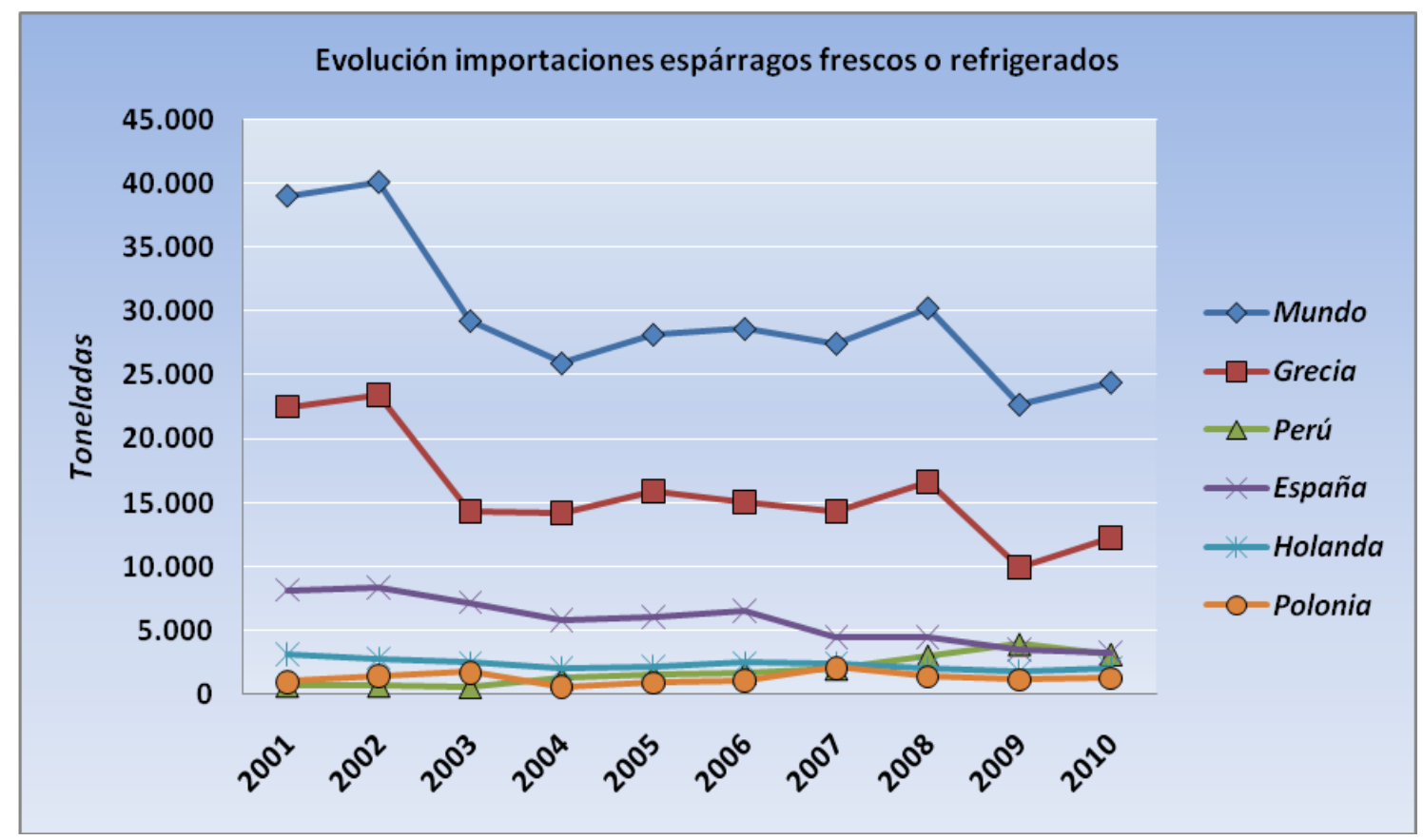

Fuente: elaboración propia en base a datos obtenidos en World Trade Centre año 2011

El pico de consumo del espárrago ocurre en el mes de mayo, coincidiendo con la época de cosecha que se desarrolla en los meses de mayo y junio. Si bien esto nos muestra un consumo estacional, se observa que los consumidores alemanes tienen una tendencia a consumir espárragos a lo largo del año, situación que es aprovechada por ejemplo por el Perú, el cual posee producción todo el año calendario. Asimismo en el gráfico puede observarse un repunte de las importaciones en el mes de noviembre; situación que se da por motivo de las fiestas de navidad y año nuevo. 
Gráfico N 35: Evolución importaciones de espárragos según el mes del año 2010 en toneladas:

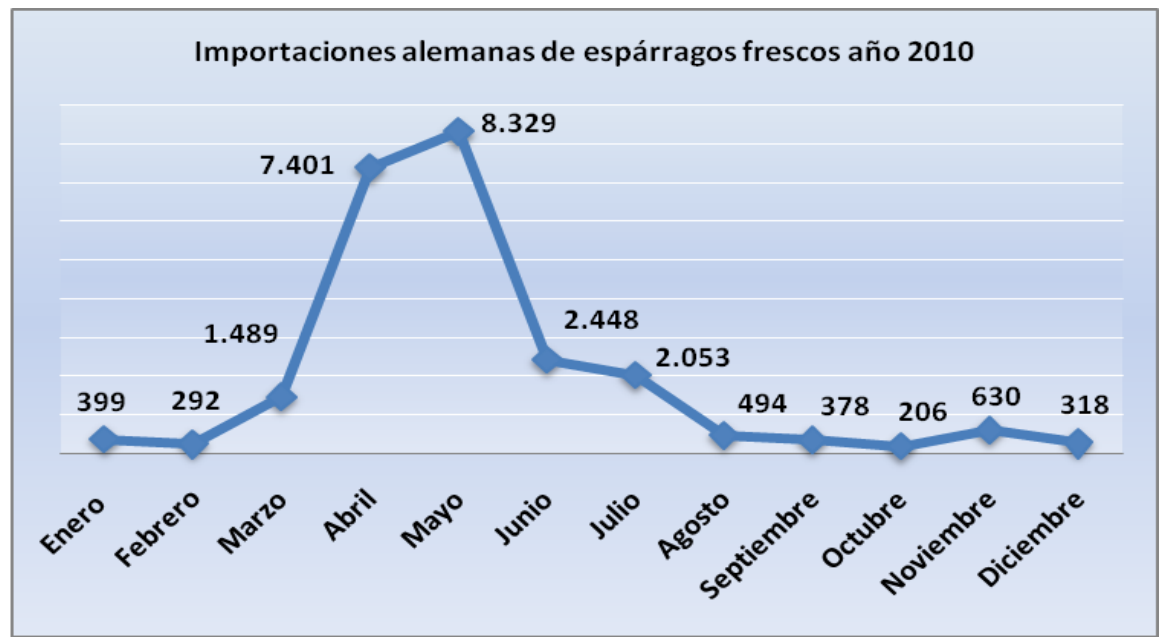

Fuente: elaboración propia en base a datos obtenidos en International Trade Centre año $2011^{38}$

\subsection{2 ¿A quién le compra Alemania?}

Dentro del proceso importador alemán, hay que destacar la presencia del espárrago griego. Más allá de esto, Alemania ha reducido las cantidades importadas de sus proveedores, salvo para el caso de Holanda y el Perú que vienen con un crecimiento sostenido en las cantidades exportadas.

Gráfico $\mathrm{N}^{\circ}$ 36: Principales proveedores de espárragos frescos para el mercado alemán en toneladas:

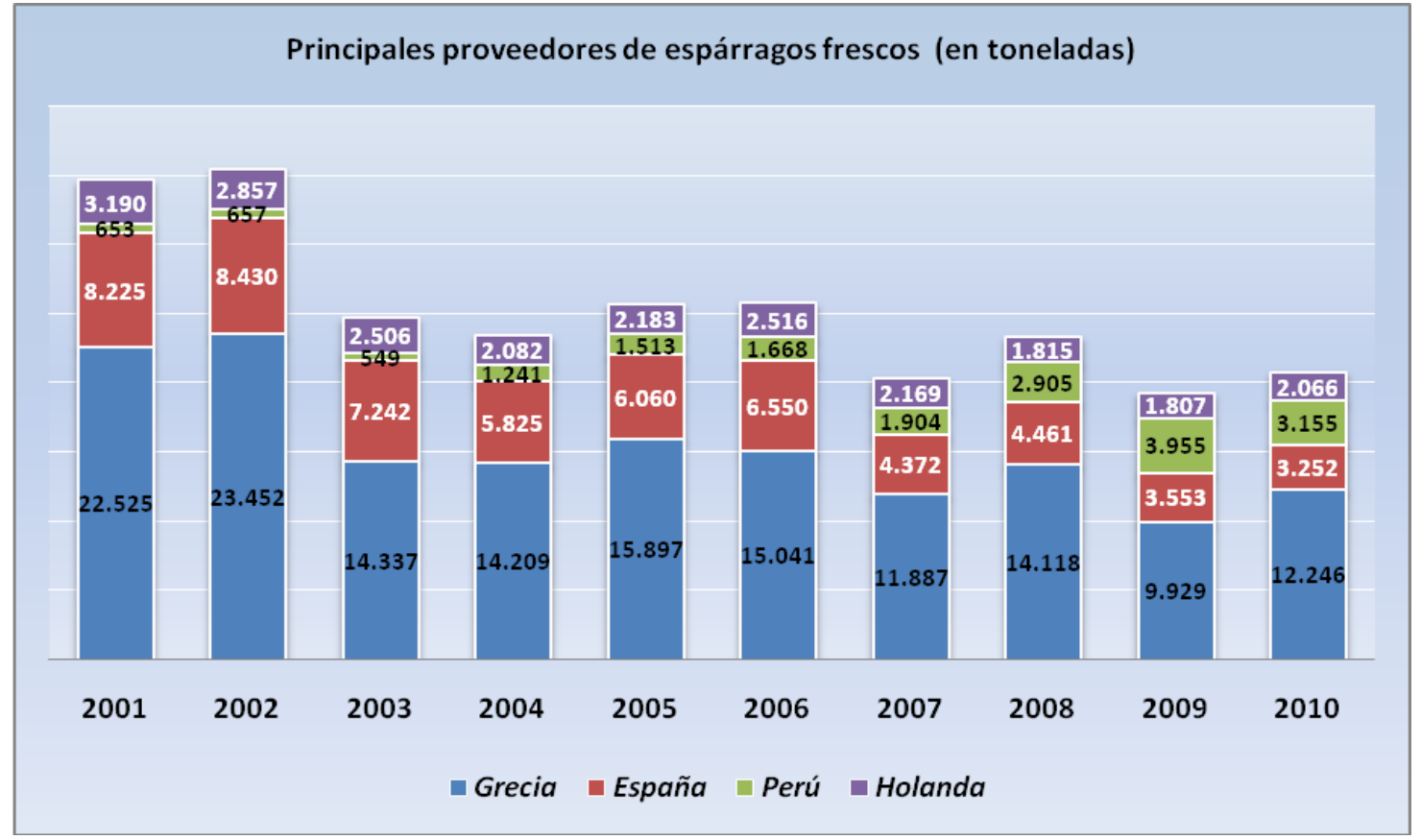

Fuente: Statisches Bundesamt y Agramarkt Informations Gesellschaft año $2011^{39}$

${ }^{38}$ Disponible en www.trademap.org 
Unos puntos a tener en cuenta relacionado con los importadores alemanes, son los siguientes:

-El Retail compra directamente al exportador o a través de Traders.

-Los compradores trabajan con programas anuales, evitando las compras "ocasionales".

- Los alemanes son compradores agresivos, buscan sobretodo precio bajo a través de su fuerza en el volumen de compra.

\subsubsection{Principales proveedores de espárragos del mercado alemán}

En los cuadros siguientes se exponen listados de los principales proveedores del mercado alemán durante la última década para espárragos frescos o refrigerados.

Tabla $\mathrm{N}^{\circ}$ 13: Detalle principales proveedores espárragos frescos al mercado alemán años 2010-2001 en toneladas:

\begin{tabular}{|c|c|c|c|c|c|c|c|c|c|c|}
\hline Exportadores & 2001 & 2002 & 2003 & 2004 & 2005 & 2006 & 2007 & 2008 & 2009 & 2010 \\
\hline Mundo & 39.051 & 40.129 & 29.251 & 25.932 & 28.260 & 28.791 & 23.607 & 26.954 & 22.609 & 24.437 \\
\hline Grecia & 22.525 & 23.452 & 14.337 & 14.209 & 15.897 & 15.041 & 11.887 & 14.118 & 9.929 & 12.246 \\
\hline España & 8.225 & 8.430 & 7.242 & 5.825 & 6.060 & 6.550 & 4.372 & 4.461 & 3.553 & 3.252 \\
\hline Perú & 653 & 657 & 549 & 1.241 & 1.513 & 1.668 & 1.904 & 2.905 & 3.955 & 3.155 \\
\hline Holanda & 3.190 & 2.857 & 2.506 & 2.082 & 2.183 & 2.516 & 2.169 & 1.815 & 1.807 & 2.066 \\
\hline Polonia & 1.045 & 1.487 & 1.784 & 636 & 966 & 1.115 & 1.460 & 1.162 & 1.225 & 1.322 \\
\hline Hungría & 1.166 & 1.388 & 1.230 & 811 & 466 & 663 & 841 & 926 & 822 & 1.075 \\
\hline Italia & 309 & 423 & 400 & 307 & 382 & 266 & 293 & 700 & 539 & 612 \\
\hline México & 6 & 4 & 1 & 0 & 24 & 6 & 8 & 30 & 65 & 125 \\
\hline Tailandia & 55 & 56 & 46 & 48 & 68 & 85 & 100 & 110 & 128 & 123 \\
\hline Bélgica & 24 & 112 & 155 & 89 & 68 & 60 & 39 & 22 & 104 & 116 \\
\hline Francia & 1.156 & 574 & 552 & 185 & 198 & 348 & 147 & 174 & 169 & 99 \\
\hline República Checa & 1 & 27 & 34 & 0 & 3 & 2 & 0 & 0 & 0 & 95 \\
\hline EE.UU. & 65 & 31 & 83 & 58 & 52 & 24 & 59 & 55 & 22 & 60 \\
\hline Austria & 41 & 32 & 86 & 81 & 115 & 93 & 18 & 136 & 49 & 23 \\
\hline Eslovaquia & 228 & 161 & 111 & 155 & 159 & 33 & 230 & 167 & 176 & 19 \\
\hline Egipto & 0 & 0 & 0 & 0 & 0 & 0 & 1 & 0 & 1 & 4 \\
\hline Kenya & 0 & 1 & 1 & 3 & 8 & 10 & 0 & 11 & 13 & 2 \\
\hline China & 0 & 0 & 0 & 0 & 0 & 0 & 23 & 0 & 5 & 1 \\
\hline
\end{tabular}

Fuente: Elaboración propia en base a datos obtenidos en World Trade Centre 2011

Como se puede apreciar en la tabla anterior, Grecia ha mantenido a lo largo de toda la década la principal posición en lo que a exportaciones se refiere. Es dable destacar a lo largo de estos años la caída que ha experimentado España. Un dato también importante a nombrar es el ascenso en las exportaciones por parte de Holanda y de Perú. 
Tabla N 14: Detalle principales proveedores de espárragos frescos al mercado alemán año 2010 en toneladas:

\begin{tabular}{|c|c|c|c|c|c|c|c|c|c|c|c|c|c|}
\hline Exportadores & Ene & Feb & Mar & Abr & May & Jun & Jul & Ago & Sep & Oct & Nov & Dic & Total 2010 \\
\hline Mundo & $\mathbf{5 1 3}$ & $\mathbf{5 2 9}$ & $\mathbf{3 . 3 5 2}$ & $\mathbf{4 . 5 8 6}$ & $\mathbf{7 . 5 3 0}$ & $\mathbf{3 . 6 7 1}$ & $\mathbf{1 . 2 7 8}$ & $\mathbf{5 9 5}$ & $\mathbf{4 9 9}$ & $\mathbf{7 1 1}$ & $\mathbf{5 6 6}$ & $\mathbf{6 0 9}$ & $\mathbf{2 4 . 4 3 8}$ \\
\hline Grecia & 0 & 1 & 660 & 5.333 & 4.500 & 457 & 1.296 & 0 & 0 & 0 & 0 & 0 & 12.246 \\
\hline España & 234 & 168 & 323 & 365 & 529 & 440 & 266 & 201 & 166 & 68 & 356 & 136 & 3.252 \\
\hline Perú & 2 & 0 & 118 & 1.123 & 1.420 & 282 & 177 & 11 & 19 & 0 & 1 & 2 & 3.155 \\
\hline Holanda & 0 & 0 & 0 & 11 & 1.032 & 743 & 64 & 83 & 46 & 33 & 53 & 0 & 2.066 \\
\hline Polonia & 0 & 0 & 0 & 173 & 647 & 362 & 9 & 126 & 6 & 0 & 0 & 0 & 1.322 \\
\hline Hungría & 16 & 11 & 31 & 129 & 437 & 294 & 70 & 6 & 68 & 2 & 5 & 7 & 1.075 \\
\hline Italia & 20 & 17 & 118 & 108 & 12 & 24 & 62 & 31 & 28 & 49 & 46 & 98 & 612 \\
\hline Bélgica & 0 & 0 & 0 & 55 & 146 & 67 & 8 & 0 & 0 & 0 & 0 & 0 & 275 \\
\hline México & 4 & 2 & 3 & 9 & 56 & 3 & 7 & 2 & 3 & 28 & 7 & 0 & 125 \\
\hline Tailandia & 1 & 0 & 8 & 32 & 46 & 12 & 22 & 0 & 0 & 2 & 0 & 1 & 123 \\
\hline Francia & 8 & 6 & 13 & 6 & 7 & 8 & 7 & 9 & 9 & 8 & 7 & 10 & 99 \\
\hline R. Checa & 0 & 0 & 0 & 0 & 38 & 57 & 0 & 0 & 0 & 0 & 0 & 0 & 95 \\
\hline \% Participación & $\mathbf{2 , 1 0 \%}$ & $\mathbf{2 , 1 7 \%}$ & $\mathbf{1 3 , 7 2 \%}$ & $\mathbf{1 8 , 7 6 \%}$ & $\mathbf{3 0 , 8 1 \%}$ & $\mathbf{1 5 , 0 2 \%}$ & $\mathbf{5 , 2 3 \%}$ & $\mathbf{2 , 4 3 \%}$ & $\mathbf{2 , 0 4 \%}$ & $\mathbf{2 , 9 1 \%}$ & $\mathbf{2 , 3 2 \%}$ & $\mathbf{2 , 4 9 \%}$ & $\mathbf{1 0 0 \%}$ \\
\hline
\end{tabular}

Fuente: Elaboración propia en base a datos obtenidos en World Trade Centre 2011.

Se puede evidenciar que los principales meses de compra se da entre marzo - junio. Asimismo se puede observar que la procedencia de los espárragos es en un 50\% de Grecia.

\subsection{Canales de distribución para los espárragos ${ }^{40}$}

Los Länder (Estados) de Alemania con una alta producción también cuentan con un alto grado de consumo. A diferencia del resto de las hortalizas que son comercializadas en supermercados, en el mercado de espárragos, la venta se realiza principalmente a través de la venta directa del productor y en las ferias ambulantes.

Gráfico N 37: Principales canales de distribución para los espárragos frescos en Alemania:

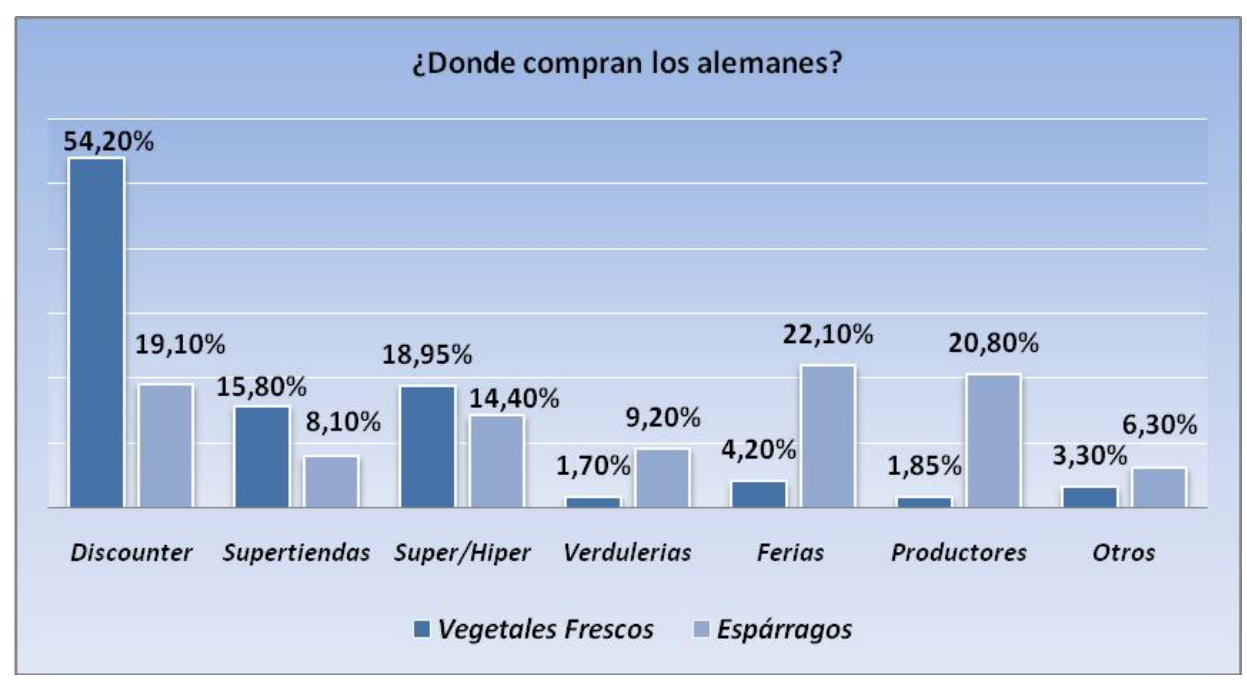

Fuente: Agramarkt Informations Gesellschaft año $2011^{41}$.

\footnotetext{
${ }^{40}$ Basado en datos obtenidos en Land Brandenburg, http://www.brandenburg.de
} 
Las vías de distribución muestran la gran importancia que tienen tanto la venta directa por parte del productor y la venta en ferias ambulantes. La tendencia apunta a un aumento a través de hipermercados y discounters, así como una disminución a través de pequeños supermercados. Aunque más lentamente, las grandes cadenas de supermercados están ganando terreno al retail tradicional.

Como muestra el cuadro anterior, en el caso de las verduras, el dominio de los supermercados no es tan grande como en alimentos en general. Esto se debe fundamentalmente a la importancia que tienen las ferias en las ciudades y pueblos alemanes. En las grandes ciudades, cada barrio tiene una feria de fruta y verdura por lo menos una vez a la semana, desarrollada en las plazas principales, llamadas Marktplatz.

\subsubsection{Canales de distribución para verduras orgánicas y espárragos orgánicos}

Como se puede observar en la tabla siguiente, y como ocurre con las verduras convencionales, los Discounters son los favoritos a la hora de comprar. En mi estudio de campo pude observar que los supermercados como las supertiendas, están dejando parte de sus instalaciones para la venta de orgánicos o "Bio", tal como se llama en Alemania. En el anexo fotográfico se puede observar estos espacios en los nombrados centros comerciales. Para el caso de la compra de espárragos orgánicos, el comportamiento de compra con relación a los lugares, presenta el mismo patrón que los espárragos convencionales.

Tabla $\mathrm{N}^{\circ}$ 15: Donde compran los alemanes verduras orgánicas:

\begin{tabular}{|c|c|c|c|}
\hline Lugar de compra & $\mathbf{2 0 0 8}$ & $\mathbf{2 0 0 9}$ & $\mathbf{2 0 1 0}$ \\
\hline Supertiendas & $7,70 \%$ & $9,30 \%$ & $9,20 \%$ \\
\hline Supermercados & $17,20 \%$ & $15,00 \%$ & $15,00 \%$ \\
\hline Discounter & $44,10 \%$ & $48,30 \%$ & $48,30 \%$ \\
\hline Tiendas orgánicas & $16,80 \%$ & $14,30 \%$ & $14,30 \%$ \\
\hline Verdulerias & $1,10 \%$ & $0,90 \%$ & $0,90 \%$ \\
\hline Productor & $3,30 \%$ & $2,70 \%$ & $2,70 \%$ \\
\hline Ferias & $6,70 \%$ & $5,20 \%$ & $5,20 \%$ \\
\hline Otros & $3,10 \%$ & $4,30 \%$ & $4,40 \%$ \\
\hline
\end{tabular}

Fuente: AMI - Marktbilanz Gemüse 2011

${ }^{41}$ Disponibles en www.marktundpreis.de 


\subsection{Las 10 verduras orgánicas más consumidas en Alemania.}

Tabla $\mathrm{N}^{\circ}$ 16: Top 10 de las verduras orgánicas consumidas:

\begin{tabular}{|c|c|c|c|c|c|c|}
\hline \multirow{2}{*}{ Variedad } & \multicolumn{2}{|c|}{ Cantidad comprada en toneladas } & \multicolumn{3}{c|}{ Cifras en miles de $\boldsymbol{\epsilon}$} \\
\cline { 2 - 7 } & $\mathbf{2 0 0 8}$ & $\mathbf{2 0 0 9}$ & $\mathbf{2 0 1 0}$ & $\mathbf{2 0 0 8}$ & $\mathbf{2 0 0 9}$ & $\mathbf{2 0 1 0}$ \\
\hline Zanahoria & 49.976 & 60.326 & 64.200 & 57.720 & 62.313 & 65.064 \\
\hline Lechuga & 841 & 737 & 809 & 3.593 & 3.186 & 3.738 \\
\hline Repollo & 1.181 & 963 & 962 & 2.756 & 2.169 & 2.320 \\
\hline Espárrago blanco & $\mathbf{1 . 8 1 6}$ & $\mathbf{1 . 6 8 5}$ & $\mathbf{3 . 1 9 7}$ & $\mathbf{1 4 . 2 2 4}$ & $\mathbf{1 2 . 2 0 4}$ & $\mathbf{2 0 . 9 0 3}$ \\
\hline Zucchini & 3.210 & 2.569 & 3.058 & 10.077 & 7.637 & 9.811 \\
\hline Pepino & 4.316 & 5.126 & 5.658 & 11.962 & 12.700 & 15.189 \\
\hline Tomate & 16.454 & 14.781 & 14.627 & 71.297 & 62.577 & 64.991 \\
\hline Tomate cherry & 7.140 & 6.854 & 7.549 & 28.251 & 25.875 & 30.858 \\
\hline Ajíes & 2.435 & 2.461 & 2.334 & 13.301 & 12.495 & 13.023 \\
\hline Cebolla seca & 6.008 & 5.802 & 7.082 & 11.726 & 10.091 & 13.129 \\
\hline
\end{tabular}

Fuente: AMI - Marktbilanz Gemüse 2011

Como podemos observar, el espárrago es una de las verduras orgánicas más consumidas en Alemania. En comparación con las demás verduras, debemos decir que los espárragos son una de las verduras consideradas como gourmet.

\subsection{Precios del Espárrago}

\subsubsection{Precios al consumidor final}

El espárrago es un producto cuyo precio es elevado debido principalmente a los altos costos de inversión que tienen que realizar los productores y los altos costos de mano de obra, necesaria para su cosecha. Asimismo al ser un producto estacional, el precio fluctúa dependiendo de la época del año que se esté considerando.

Los precios al consumidor dependen del origen y el frescor de los espárragos. Tal como pude averiguar en mi estudio de campo, el espárrago alemán se puede obtener directamente donde el productor o en los puestos ambulatorios a un precio que va de 8,5 a 11 Euros el kilogramo, siempre considerando que nos encontramos en época de cosecha y dependiendo de la clase de que estemos hablando.

Tal como dijimos, el espárrago es considerado como "El Rey dentro de las hortalizas" (Spargel ist der König unter den Gemüsen) en Alemania. 
Gráfico N 38: Precio promedio por kilo de espárrago para el año 2011:

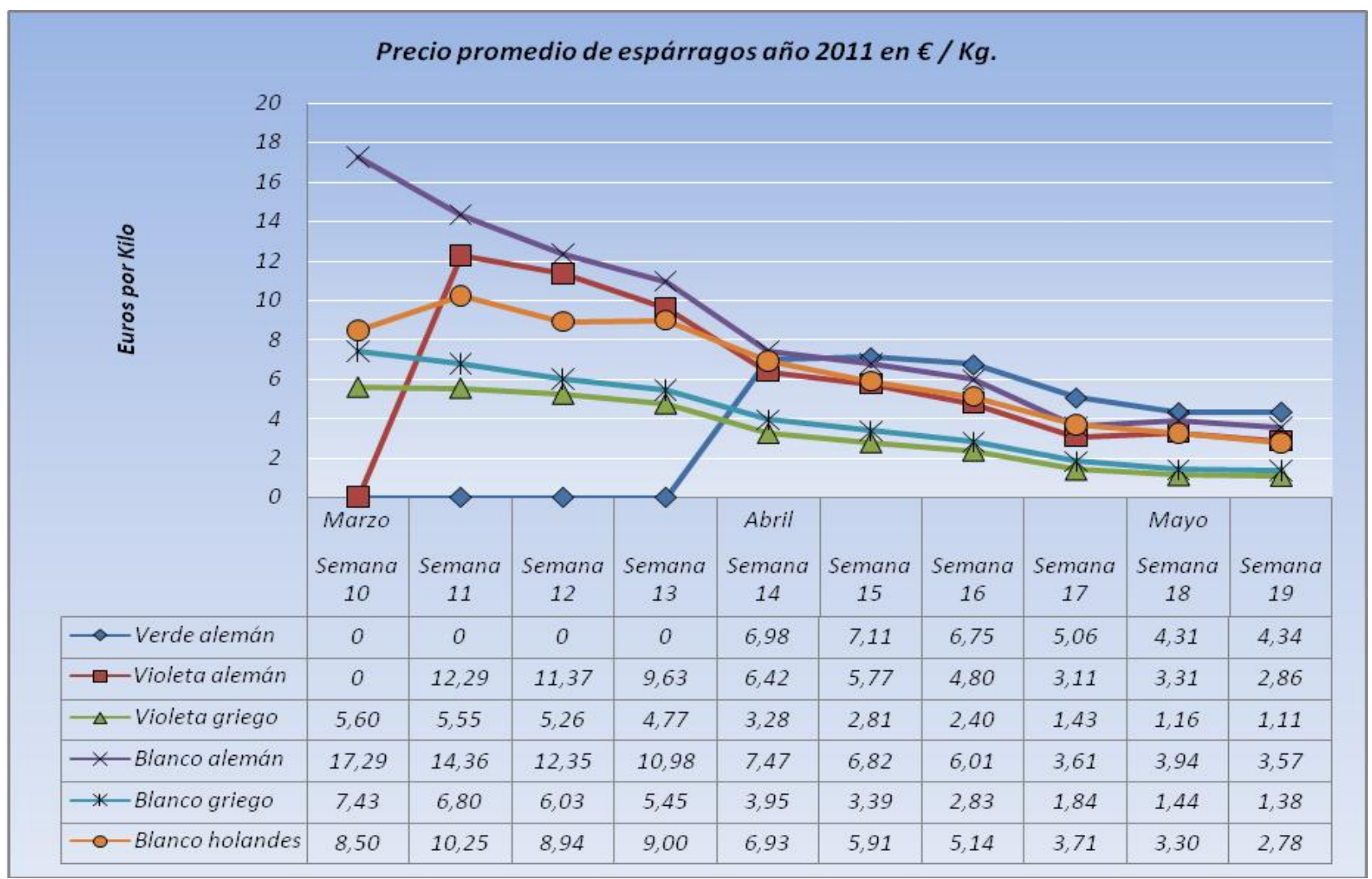

Fuente: Proplanta - Agrar Nachrichten Junio 2011. www.proplanta.de

Como observamos en el gráfico anterior y corroborado así mismo por un informe del 28/03/2011 (Aktuelle Preislage) $^{42}$, se establece que para el espárrago de Clase EXTRA en la Semana 12 del año 2011 (del 21 al 27 de Marzo) el kilo de espárrago blanco alemán llegó a €12,35 y 2 semanas antes (Semana 10, del 7 al 13 de Marzo) el kilo llegó a € 17,29 el kilo. Asimismo es de destacar que en la semana 12 del año 2010, el kilo de espárrago llegó a los € 14,50. Esta situación se dio ya que en nivel de producción en el 2010 fue de 91.017 toneladas (98.202 toneladas en el 2009), situación que impacta directamente en el precio.

El mismo artículo estableció que en el 2010, Alemania importó cerca de 21.000 toneladas de países de

\footnotetext{
${ }^{42}$ Disponible en Bundesanstalt für Landwirtschaft und Ernährung. www.ble.de
} 
la Unión Europea (Grecia, España y Holanda). Las importaciones de terceros países, llegaron a las 3.500 toneladas provenientes del Perú.

Dada la gráfica, vemos que el precio comienza a reducirse notoriamente a partir del mes de mayo, donde las cosechas van aumentando sus rendimientos. En los discounters y supermercados se pueden obtener los espárragos alemanes a partir de 4 Euros el kilogramo, una vez comenzada la cosecha.

Dentro del anexo al presente capítulo, en la página $\mathrm{N}^{\circ} 127$, se puede apreciar una lista completa de los precios de espárragos frescos semana a semana, tanto para consumidor final, como en niveles mayoristas para los años 2010 y 2009.

Por otro lado, los espárragos importados, se pueden obtener en los Hipermercados y Discounters como Lidl y Aldi a un precio que va desde los $€ 3 \mathrm{Kg}$. Esto se debe principalmente a la fuerte competencia que existe entre los países nombrados anteriormente, lo que empuja los precios del espárrago hacia abajo.

\section{El mercado del espárrago en Argentina}

\subsection{Importación argentina de espárragos frescos}

Tal como observamos en el cuadro siguiente, las importaciones no han mantenido un comportamiento constante a lo largo de la última década. Más allá de esto, vemos que nuestro país consume espárragos y que con medidas apropiadas, estas cantidades podrían ser sustituidas con producción local.

Tabla $\mathrm{N}^{\circ}$ 17: Importaciones argentinas de espárragos frescos en toneladas:

\begin{tabular}{|c|c|c|c|c|c|c|c|c|c|c|}
\hline Exportadores & $\mathbf{2 0 0 1}$ & $\mathbf{2 0 0 2}$ & $\mathbf{2 0 0 3}$ & $\mathbf{2 0 0 4}$ & $\mathbf{2 0 0 5}$ & $\mathbf{2 0 0 6}$ & $\mathbf{2 0 0 7}$ & $\mathbf{2 0 0 8}$ & $\mathbf{2 0 0 9}$ & $\mathbf{2 0 1 0}$ \\
\hline Mundo & 141 & 30 & 12 & 24 & 21 & 5 & 16 & 22 & 61 & 86 \\
\hline Perú & 77 & 0 & 12 & 24 & 21 & 5 & 16 & 22 & 61 & 86 \\
\hline Chile & 64 & 30 & 0 & 0 & 0 & 0 & 0 & 0 & 0 & 0 \\
\hline
\end{tabular}

Fuente: International Trade Centre, año 2011

\subsection{Comercialización interna de espárragos}

Según información brindada por el Ing. Agr. Oscar Liverotti, miembro de la Gerencia de Calidad y Tecnología, Área de Capacitación y Tecnología de la corporación del Mercado Central de Buenos Aires, las cantidades ingresadas al mercado central, han ido disminuyendo en la última década. Esto se contrasta con la caída de los niveles de producción experimentados en el país. 
Gráfico $N^{\circ}$ 39: Ingreso de espárrago al Mercado Central años 2010 - 2000:

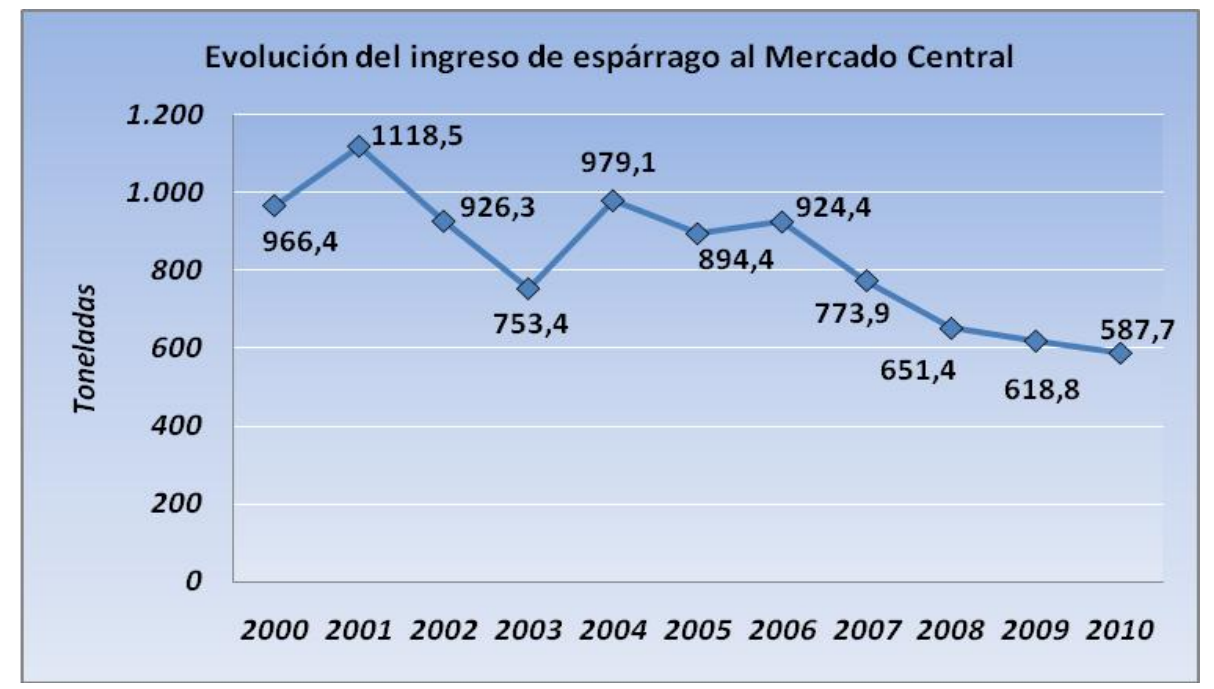

Fuente: Ing. Agr. Oscar Liverotti. Mercado Central año 2011.

Si nos referimos a la estacionalidad del ingreso del espárrago al mercado central, podemos establecer que los meses con mayor ingreso ocurren en septiembre, octubre y noviembre. Más allá de esta estacionalidad, hay que tomar en cuenta la caída en la producción de esta hortaliza viene experimentando.

Tabla $N^{\circ}$ 18: Comparación ingreso de espárragos al Mercado Central:

\begin{tabular}{|c|c|}
\hline \multicolumn{2}{|c|}{ Datos comparativos del ingreso de espárragos en el MCBA } \\
\hline Año 2000 & Año 2010 \\
\hline Espárrago verde: $71,5 \%$ & Espárrago verde: $99 \%$ \\
Espárrago blanco: $28,5 \%$ & Espárrago blanco: $1 \%$ \\
$0,11 \%$ ingreso hortalizas al MCBA & $0,06 \%$ ingreso hortalizas al MCBA \\
\hline
\end{tabular}

Fuente: Ing. Agr. Oscar Liverotti. Mercado Central año 2011.

\subsection{Exportaciones argentinas de espárragos frescos convencionales 43}

En 2010, Argentina participó en el comercio mundial con el 0,078\% del total de las exportaciones, ocupando el puesto 21 como nación exportadora. Los picos máximos históricos de exportación se obtuvieron en la década del '90, especialmente en el año 1997 donde se exportaron 1.714 toneladas. En la última década, en el año 2002, se exportaron 781 toneladas, siendo esta cifra la más alta. Anteriormente, Alemania fue el primer mercado fuertemente explotado por Argentina. En el año 1985

\footnotetext{
${ }^{43}$ Datos obtenidos en International Trade Center www.intracen.org.2010
} 
ese país se llevaba el 65\% de las exportaciones nacionales. Esta misma relación en 1991 era del $43 \%$. A partir del año 1994 esta situación se revierte pasando Estados Unidos a ser el principal demandante de la producción argentina, centralizando en el año 2010 el 68,49\% de las exportaciones. A partir de allí (año 1994) Alemania se retiró abruptamente de la compra de espárrago argentino. A partir de 1997 se incorporaron nuevos compradores del mercado europeo como Suiza, Suecia y Gran Bretaña quienes posibilitaron diversificar la oferta argentina, aunque con volúmenes muy pequeños. A partir de allí el ritmo de exportación comenzó a decaer, paralelamente con la producción.

Gráfico N 40: Evolución de las exportaciones argentinas de espárragos en toneladas 2010 - 2001:

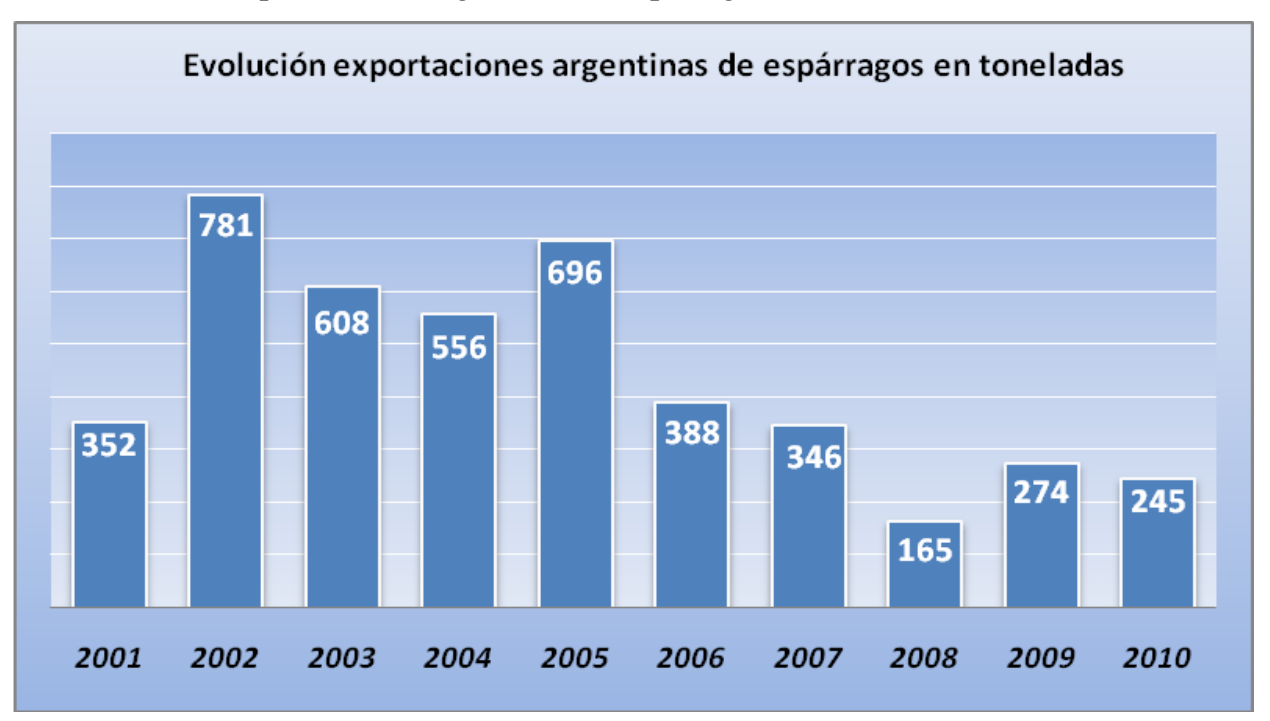

Fuente: Elaboración propia. Datos obtenidos en International Trade Center www.intracen.org.2011

Gráfico $N^{\circ}$ 41: Evolución de las exportaciones argentinas de espárragos en US\$ 2010 - 2001:

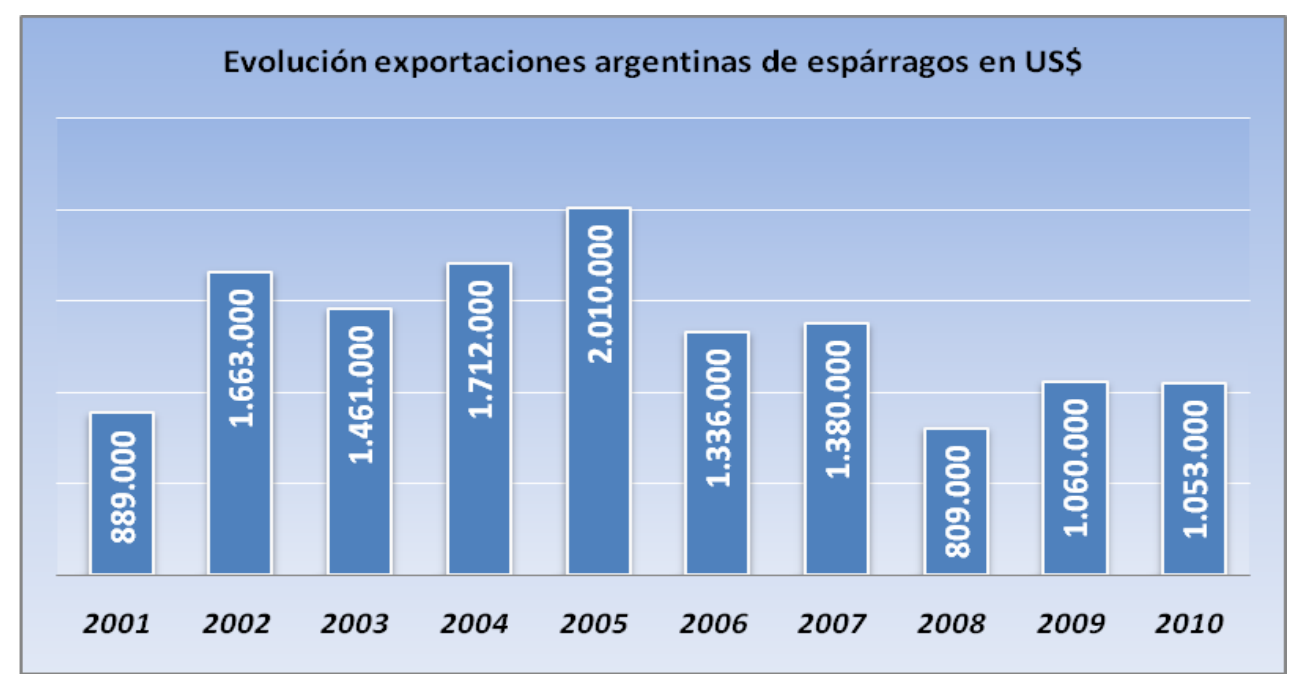

Fuente: Elaboración propia. Datos obtenidos en International Trade Center www.intracen.org.2011 
Gráfico $N^{\circ} 42$ : Detalle porcentual por país de las exportaciones argentinas de espárragos frescos año 2010:

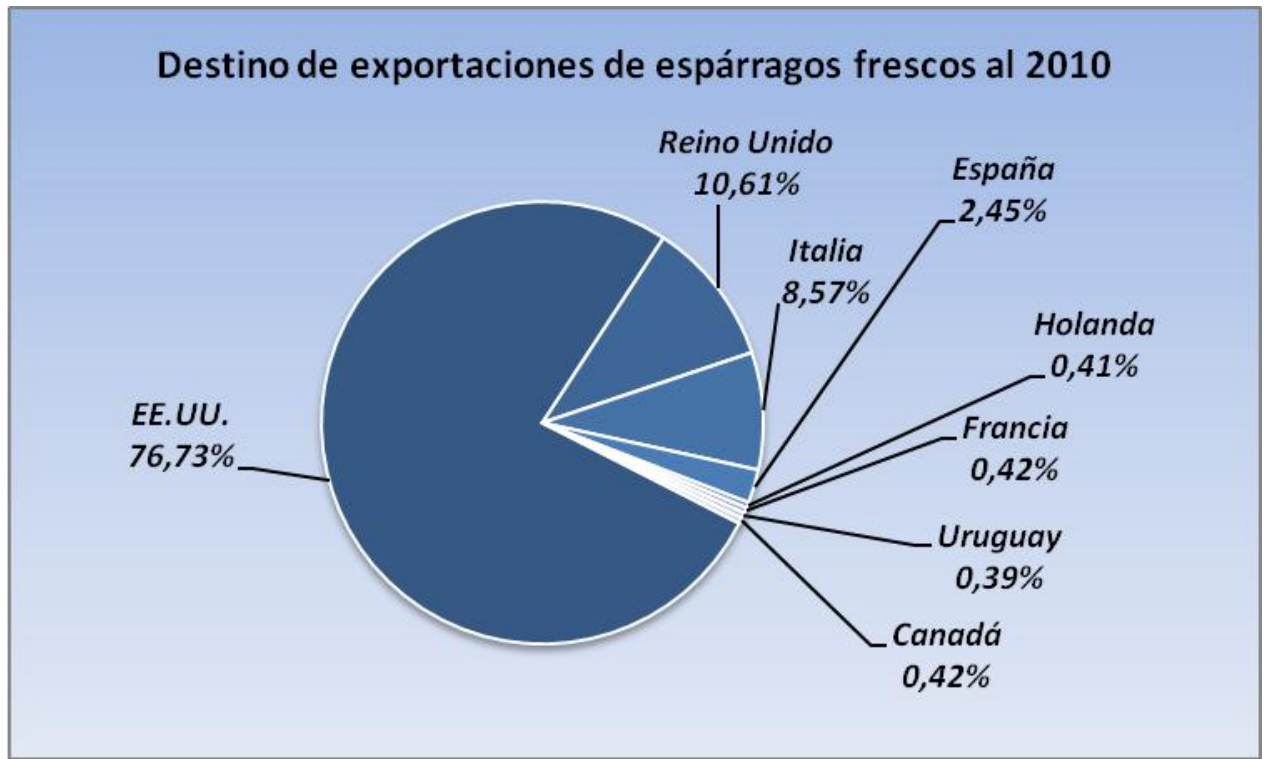

Fuente: Elaboración propia. Datos obtenidos en International Trade Center. Año 2011.

\subsubsection{Exportaciones argentinas de espárragos frescos orgánicos}

Tabla ํ 19: Exportaciones argentinas de espárragos orgánicos años 2010 - 2005:

\begin{tabular}{|c|c|c|c|c|c|c|}
\hline \multicolumn{7}{|c|}{ Exportaciones argentinas de espárragos orgánicos (kg) } \\
\hline Destino & $\mathbf{2 0 0 5}$ & $\mathbf{2 0 0 6}$ & $\mathbf{2 0 0 7}$ & $\mathbf{2 0 0 8}$ & $\mathbf{2 0 0 9}$ & $\mathbf{2 0 1 0}$ \\
\hline Alemania & - & - & 2.700 & - & - & - \\
\hline Canadá & 2.200 & - & 2.000 & - & - & 450 \\
\hline EE.UU. & 33.805 & 5.600 & 71.580 & 9.900 & 102.579 & 91.264 \\
\hline Francia & 3.300 & - & 5.400 & - & - & - \\
\hline Holanda & - & 1.088 & 2.450 & - & 416 & 1.916 \\
\hline Inglaterra & - & - & 19.935 & - & 7.347 & - \\
\hline Italia & - & 544 & - & - & - & - \\
\hline Países Bajos & 2.400 & - & - & - & 900 & - \\
\hline Reino Unido & 3.470 & 37.761 & 42.426 & 11.000 & - & 28.464 \\
\hline Total general & $\mathbf{4 5 . 1 7 5}$ & $\mathbf{4 4 . 9 9 3}$ & $\mathbf{1 4 6 . 4 9 0}$ & $\mathbf{2 0 . 9 0 0}$ & $\mathbf{1 1 1 . 2 4 2}$ & $\mathbf{1 2 2 . 0 9 4}$ \\
\hline
\end{tabular}

Fuente: SENASA 2011

Dado la tabla anterior, podemos observar que las exportaciones de espárragos orgánicos no han mantenido un comportamiento constante a lo largo de los últimos 6 años. Este comportamiento también se ha visto para el caso de los espárragos frescos normales. Si bien para el caso de los primeros, solo pude acceder a datos a partir del año 2005, vemos que la participación de los espárragos orgánicos sobre las exportaciones de los convencionales ha ido en ascenso. Por ejemplo en el año 2010 
el 49,83\% de las exportaciones de espárragos han sido orgánicos.

Considerando los compradores, vemos que tanto los EE.UU., como el Reino Unido, han sido los principales tanto para los espárragos frescos convencionales, como los orgánicos. Para el caso de nuestro país objetivo, Alemania, vemos que las ventas han ido descendiendo drásticamente. La última venta ha sido en el año 2007, donde la cantidad ascendió a 3 toneladas; siendo 2,7 de éstas, de los espárragos orgánicos.

\subsubsection{Aranceles de importación de terceros países}

Actualmente, el arancel pagado como Derechos de Terceros Países asciende a 10,20\% ${ }^{\mathbf{4 4}}$. La Argentina

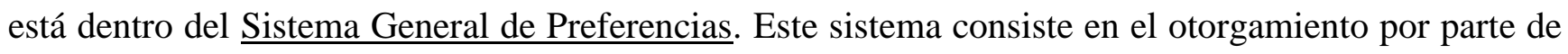
36 países desarrollados de una reducción o eliminación total de derechos de importación, de determinados productos exportados desde países en vías de desarrollo. El objetivo es incrementar las corrientes comerciales entre países en desarrollo a partir del otorgamiento de Preferencias Arancelarias y de reducción de las restricciones no tarifarias que pudieran existir entre las naciones participantes.

Quienes otorgan este beneficio son la Unión Europea, EE.UU., Suiza, Noruega, Canadá, Japón, Nueva Zelanda, Australia, Bielorusia, Turquía y la Federación Rusa.

El Régimen Preferencial ${ }^{45}$ para nuestro país es del 6,70\%. Por ejemplo otros países: (Chile: 0\%, Turquía: 0\%, Marruecos: 0\%, Turquía: 0\%, Egipto: 0\%, México: 0\%, Perú: 10,20\%).

0709.2000.100: Precio Unitario (10/06/2011 a 23/06/2011): 267,14 EurUP/100 Kg. 0709.2000.900: Precio Unitario (10/06/2011 a 23/06/2011): 198,83 EurUP/100 Kg.

Así mismo, hay que destacar que el I.V.A. en Alemania (Umsatzsteuer o Mehrwertsteuer), para los productos alimenticios, asciende al 7,00\%

\footnotetext{
${ }^{44}$ Disponible en Fiscalidad y Unión Aduanera, de la Comisión Europea. www.ec.europa.eu (taxation customs).

${ }^{45}$ Según Datos brindados por el Sr. Andrés Ventafridda, Cónsul Adjunto de Argentina en Hamburgo.
} 


\subsubsection{Documentos exigidos en la aduana}

\begin{tabular}{|c|c|c|}
\hline Factura Original & $x$ & Otros Certificados \\
\hline Certificados Sanitarios & & \multirow{4}{*}{$\begin{array}{c}\text { Se debe presentar certificado } \\
\text { de origen "Formulario } A \text { ", } \\
\text { para poder acceder al } \\
\text { tratamiento arancelario }\end{array}$} \\
\hline Certificados de Seguridad & & \\
\hline Certificado normas de fabricación & & \\
\hline Certificado de Calidad & & \\
\hline
\end{tabular}

\subsubsection{Requisitos sanitarios}

No hay control fitosanitario. Dentro del anexo a la producción mundial de espárragos se puede apreciar en detalle, todos los requisitos establecidos por la normativa UN/ECE FFV-04 relativa a la comercialización y control de calidad comercial de los ESPÁRRAGOS en la Unión Europea.

\subsubsection{Costos del flete aéreo}

Según la información que pude recabar en diversas firmas ${ }^{46}$, las exportaciones que estas empresas están realizando, se envían en Pallets de $525 \mathrm{Kg}$. en bruto y $450 \mathrm{Kg}$. netos. Los mismos están compuestos de 90 cajas de 5 kilos netos cada una de ellas.

Si bien, el kilo aéreo cotiza según la aerolínea, el país de destino y la época del año; los precios oscilan desde US\$ 1 el kilo neto, para luego ir ascendiendo hasta US\$ 2,50 el kilo neto. Actualmente varias empresas aerocomerciales ofrecen sus servicios a Alemania, siendo una de las principales, la firma Lufthansa.

\footnotetext{
${ }^{46}$ Pampa Store S.A; La Meco S.R.L. y Agro Los Andes S.A.
} 


\section{Capítulo 3: Análisis y conclusiones de los espárragos argentinos}

\section{frente al mercado alemán}

\section{Estudio de Campo en Alemania}

El presente estudio de campo en Alemania fue realizado durante los meses de Junio a Noviembre de 2010 en varias ciudades de Alemania.

\subsection{Obtención de datos}

La técnica utilizada en este trabajo para obtención de la información de los consumidores es la "investigación por encuesta" 47 , como así también la observación.

Si bien la cantidad de entrevistas realizadas fueron importantes, consideré que no eran lo suficiente para utilizar herramientas estadísticas de procesamiento (tal como el sistema SPSS).

Los lugares escogidos para realizar las entrevistas personales y las observaciones fueron en los mercados de calle (Marktplatz), donde traté de lograr un contacto con el consumidor alemán sabiendo que las personas tuviesen tiempo para contestar.

\subsection{Diseño de la entrevista personal}

La encuesta fue dirigida a personas que habitualmente realizan la compra del hogar, por ello, al ser los consumidores de distintas edades y con distintos niveles académicos, se intenta que la redacción de la preguntas sea de forma sencilla, precisa, y comprensible.

Las encuestas fueron anónimas, con la idea de incentivar la colaboración, y se dio a conocer el organismo que la respaldaba, en este caso, la European School of Business, de la Reutlingen University. Asimismo, una vez finalizada se agradeció la colaboración y se garantizó la confidencialidad absoluta de las repuestas.

Durante toda la encuesta, pretendí estimular el interés del encuestado, con preguntas concretas y discretas, sin comprometer a las personas encuestadas, nombrando mi condición de alumno de intercambio.

\footnotetext{
${ }^{47}$ MENDENHALL, William "Estadística para administradores" Ed. Iberoamericana
} 
En la nombrada encuesta se estableció un orden en las preguntas, que se diferencian en tres bloques:

1. La primera parte de la encuesta consistió en averiguar la conducta de los entrevistados hacia una alimentación sana.

2. La segunda parte trató sobre sus hábitos de consumo y preferencias hacia las hortalizas orgánicas y los espárragos orgánicos.

3. La tercera y última parte, indagué brevemente acerca del conocimiento que tienen acerca de nuestro país.

Con esta investigación de mercado, mediante la entrevista personal, además de recopilar datos de consumo sobre los espárragos, se pretendió extraer más información del consumidor, como su actitud, englobando tres aspectos; en primer lugar, la respuesta cognitiva, lo que el consumidor cree conocer del producto. En segundo lugar, lo que se refiere a los sentimientos hacia el producto (sería la respuesta afectiva). Y en tercer lugar, la respuesta en su conducta, la acción en una situación determinada (La razón de importancia de las actitudes en mercadotecnia es el nexo que generalmente se supone que hay entre ellas y el comportamiento del consumidor).

En total, logré realizar 87 encuestas en las ciudades visitadas con mayor participación de mujeres. Esto tuvo su origen en que las mujeres son las que definen la compra en los Marktplatz. Las personas encuestadas se encuentran diferenciadas en aquellos menores de 35 años, entre los 35 a los 65 años de edad y mayores a 65 años, de tamaño familiar pequeño (menor o igual a 2 miembros) a mediano (de 3 a 4 miembros). La renta media de los encuestados estuvo en: menos de $€ 1.500$ mensuales, entre $€$ 1.500 y $€ 2.000$ y renta superior a $€ 2.000$. Respecto al nivel de instrucción, este fue de medios a superiores. 
Tabla $\mathrm{N}^{\circ}$ 20: Caracterización de la muestra encuestada en el estado de Baden Württemberg:

\begin{tabular}{|c|c|c|}
\hline Características de la muestra & \multicolumn{2}{|c|}{ Alemania* } \\
\hline Género & Frecuencia & Porcentaje \\
\hline Hombres & 29 & $33 \%$ \\
\hline Mujeres & 58 & $67 \%$ \\
\hline Edad & Frecuencia & Porcentaje \\
\hline$<$ de 35 años & 21 & $24 \%$ \\
\hline entre 35 y 65 años & 51 & $59 \%$ \\
\hline$>$ de 65 años & 15 & $17 \%$ \\
\hline Grupo Familiar & Frecuencia & Porcentaje \\
\hline$<=$ de 2 miembros & 37 & $43 \%$ \\
\hline entre 3 - 4 miembros & 36 & $41 \%$ \\
\hline$>$ de 4 miembros & 14 & $16 \%$ \\
\hline Ingresos & Frecuencia & Porcentaje \\
\hline hasta $€ 1.500$ & 30 & $35 \%$ \\
\hline entre € 1.500 y $€ 2.000$ & 46 & $53 \%$ \\
\hline mas de $€ 2.000$ & 10 & $12 \%$ \\
\hline Nivel Educacional & Frecuencia & Porcentaje \\
\hline educación media & 16 & $18 \%$ \\
\hline educación intermedia & 35 & $40 \%$ \\
\hline educación universitaria & 37 & $42 \%$ \\
\hline
\end{tabular}

* Elaboración propia en base a datos obtenidos en las ciudades de:

Stuttgart, Reutlingen, Metzingen, Tübingen, Freiburg, Bodensee,

Karlsruhe y Heidelberg entre Junio y Noviembre 2010.

Las encuestas estuvieron dirigidas a personas que realizaban las compras, tanto en los días de semana, como los fines de semana. Asimismo, el público objetivo tuvo distintas edades, con distintos niveles académicos y con distinto nivel de ingreso. Las encuestas fueron anónimas, para de este modo, tratar de comprometer al encuestado en su respuesta. También se nombró a la Universidad de Reutlingen, agradeciendo la colaboración y garantizando la confidencialidad de las respuestas.

Si bien la totalidad de las encuestas realizadas no consisten en una muestra significativa como para utilizar programas estadísticos, considero que han arrojado datos valiosos sobre el perfil de los consumidores.

Grosso Modo, las preguntas realizadas respecto a la alimentación estuvieron basadas en los siguientes puntos: 


\section{DATOS PERSONALES:}

- Lugar de Residencia

$\bullet$ Edad

- $\mathrm{N}^{\circ}$ de miembros en la familia

- Estudios terciarios / Estudios universitarios

- Trabajo

- Ingresos mensuales por mes

\section{PREGUNTAS REFERIDAS A LA SALUD:}

- ¿Se preocupa por una alimentación sana? SI-NO

• ¿Practica de una alimentación sana? SI-NO

- ¿Se informa sobre alimentación sana? SI-NO

- ¿Por qué medios se informa? ¿Revistas, televisión, internet?

- ¿Realiza actividad física? ¿Con que frecuencia?

- ¿Realiza chequeos médicos periódicos? ¿Con que frecuencia?

\section{PREGUNTAS SOBRE HÁBITOS DE CONSUMO:}

- ¿Le gusta disfrutar de una buena mesa?

- ¿Quién cocina en su hogar?

- ¿Quién decide sobre las compras hogareñas?

- ¿Consume alimentos orgánicos? SI-NO ¿Cuáles y con qué frecuencia?

• ¿Conoce los beneficios de los productos "Bio"?

• ¿Percibe desventajas de los productos “Bio”? SI-NO ¿Cuáles son?

- ¿Consume verduras orgánicas? SI-NO ¿Cuáles y con qué frecuencia?

- ¿Consume espárragos orgánicos? SI-NO ¿Dónde compra los mismos?

\section{PREGUNTAS RELACIONADAS A LA REPÚBLICA ARGENTINA:}

• ¿Conoce la ubicación del país?

- ¿Conoce algunas de sus regiones?

- ¿Ha visitado la Argentina? y ¿Qué temas principales conoce del país? 
• ¿Ha consumido productos argentinos? SI-NO ¿Consumiría?

• ¿Ha consumido espárragos argentinos? SI-NO ¿Consumiría?

En la mayoría de los casos tuve una respuesta positiva ante la pregunta sobre la Práctica de una Alimentación Sana. Este resultado fue más significativo en las personas de entre 35 y 65 años y con mayor fuerza en las persona de más de 65 años. En todos los casos, dieron respuesta positiva más del $90 \%$ de los encuestados.

Gráfico $N^{\circ}$ 43: Respuestas de encuestados alemanes sobre una alimentación sana:

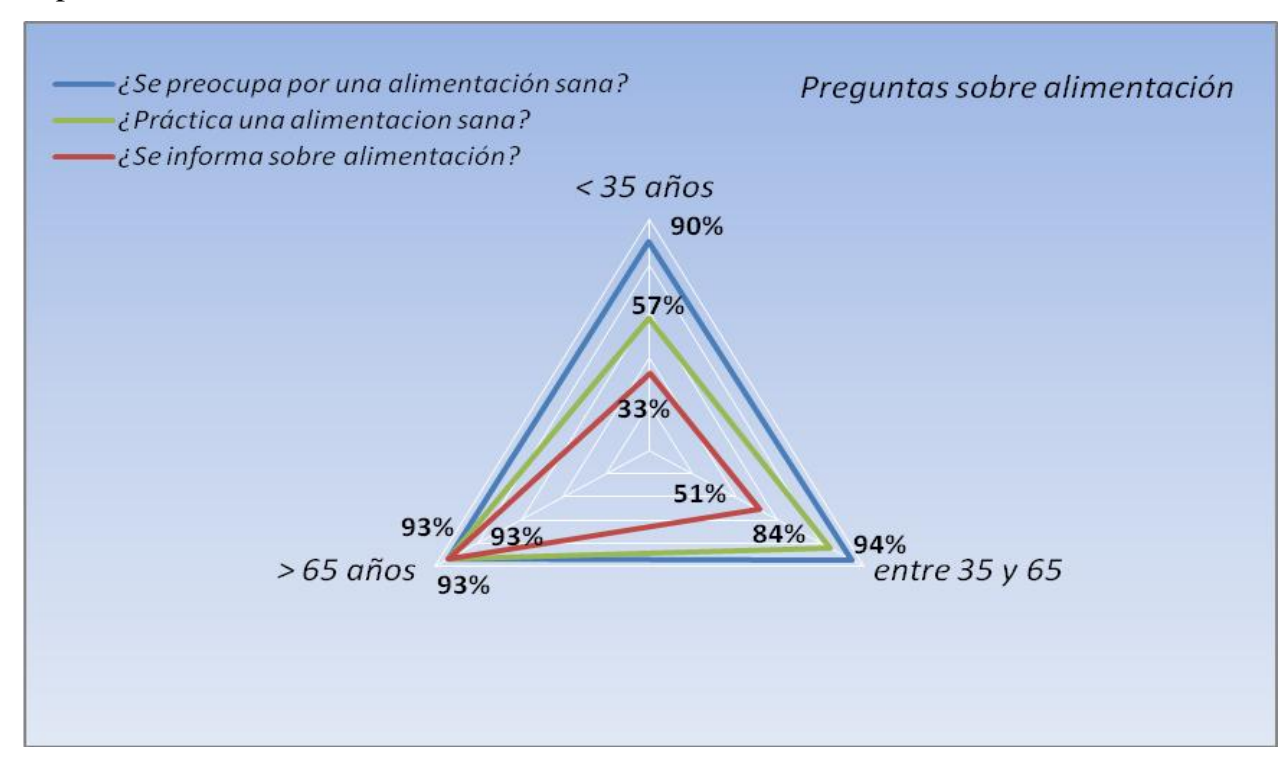

Fuente: Elaboración propia en base a encuestas realizadas.

Generalmente las personas de menos de 35 años, respondieron que les interesa una alimentación sana, pero por el ritmo de trabajo o estudio, muchas veces es difícil llevarla adelante. Por ejemplo, del $90 \%$ que se preocupa por su alimentación, solo el 57\% lleva adelante una alimentación sana. A la hora de informarse, solo un $33 \%$ se toma el tiempo de indagar acerca de una buena alimentación.

Para el caso de las personas mayores a 65 años que respondieron que les preocupa llevar adelante una alimentación sana, también la practican y se informan acerca de ella.

Con relación a las edades de los encuestados, puedo destacar que, durante los días de semana en los Marktplatz, las personas más entrevistadas fueron aquellas con edad entre 35 y 65 años, como así también los mayores de 65. Para el caso de los fines de semana, la situación cambió, ya que encontraba personas de todas las edades, siendo en la mayoría de los casos las mujeres, quienes cerraban las compras. Respecto de éstas, puedo inferir que valoran más que los hombres llegar a elaborar una 
Comida Sana o practicar una Alimentación Sana.

Para la pregunta relacionada con la Realización de Actividad Física, la franja de personas menores a 35 años es la que menos actividad realiza. Esto se da principalmente por la cantidad de horas trabajadas. Algo similar ocurre con la siguiente franja etaria, para luego ir disminuyendo. Para el caso de mayores de 65 años, quedé sorprendido de la gran cantidad de ellos que realizan actividad física. Una de las principales disciplina es la caminata. Sin dudas las personas mayores, son las que tienen en Alemania, más tiempo y esto se traduce, por ejemplo, en el "Gustar de una Buena Mesa", como así también el Placer por Cocinar o por Cuidar los Hábitos Alimenticios; situación que no se observa tanto en la franja etaria de entrevistados con menor edad.

Como vimos en el gráfico anterior, los consumidores valoran notablemente la Influencia de la Alimentación en la Salud, y esto se refleja en parte en el consumo de alimentos orgánicos. Si bien como vimos, el 90\% de los menores de 35 años se preocupa por una alimentación sana, el 57\% de ellos, la practica con frecuencia. Más allá de esto, solo el $48 \%$ consume alimentos orgánicos y en menor proporción verduras y espárragos. Para el caso de las personas entre 35 y 65 años, vimos que el $84 \%$ se interesaba y practicaba una alimentación sana. Esto significó que el $45 \%$ de ellos consume espárragos orgánicos. Para el caso de los mayores de 65 años, pude constatar que el 93\% practica una alimentación sana, siendo el $47 \%$ de ellos consumidores de espárragos orgánicos.

Gráfico $\mathrm{N}^{\circ}$ 44: Respuestas de encuestados alemanes sobre consumo de alimentos orgánicos:

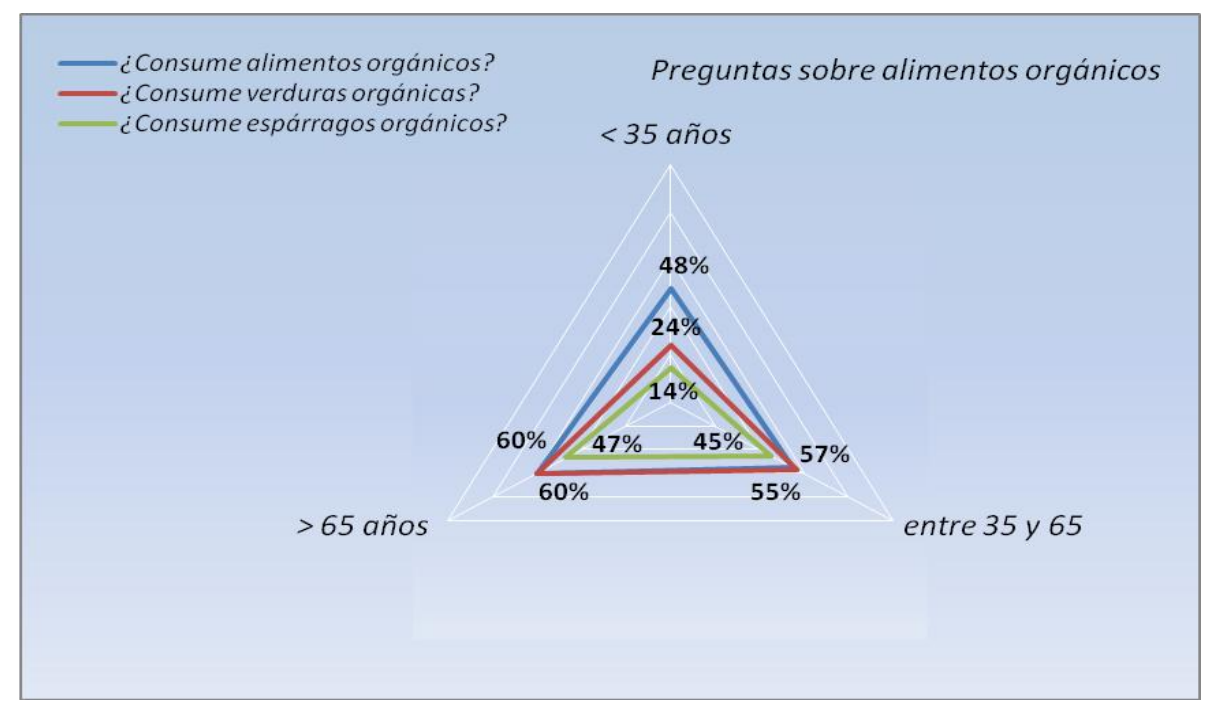

Fuente: Elaboración propia en base a encuestas realizadas. 
Respecto a la procedencia, pude evidenciar que el producto alemán tiene en el mercado un precio superior a los espárragos extranjeros. El pico de consumo del espárrago se da entre los meses de marzo y junio, con mayor acento en el mes de mayo, cuando la producción alemana llega a su pico de producción. Si bien, fuera de estos meses el consumo cae considerablemente, los entrevistados manifestaron que están consumiendo espárragos extranjeros. Respecto a estos espárragos, la mayoría de los encontrados fuera de la temporada eran provenientes del Perú. Uno de los puntos que a mi humilde entender no logran transmitir los espárragos peruanos, está basado en la pobre presentación de los mismos. Si bien los espárragos encontrados fueron de Clase I, el packaging presentado no estaba a la altura de la calidad del producto.

Otro punto a destacar es que ante la pregunta realizada, si estarían dispuestos a comprar espárragos blancos orgánicos argentinos fuera de temporada, la respuesta fue "Si”, siempre y cuando fueran "Gut und Günstig" (buenos y baratos).

Gráfico $\mathrm{N}^{\circ}$ 45: Respuestas de encuestados alemanes sobre consumo y nivel de renta:

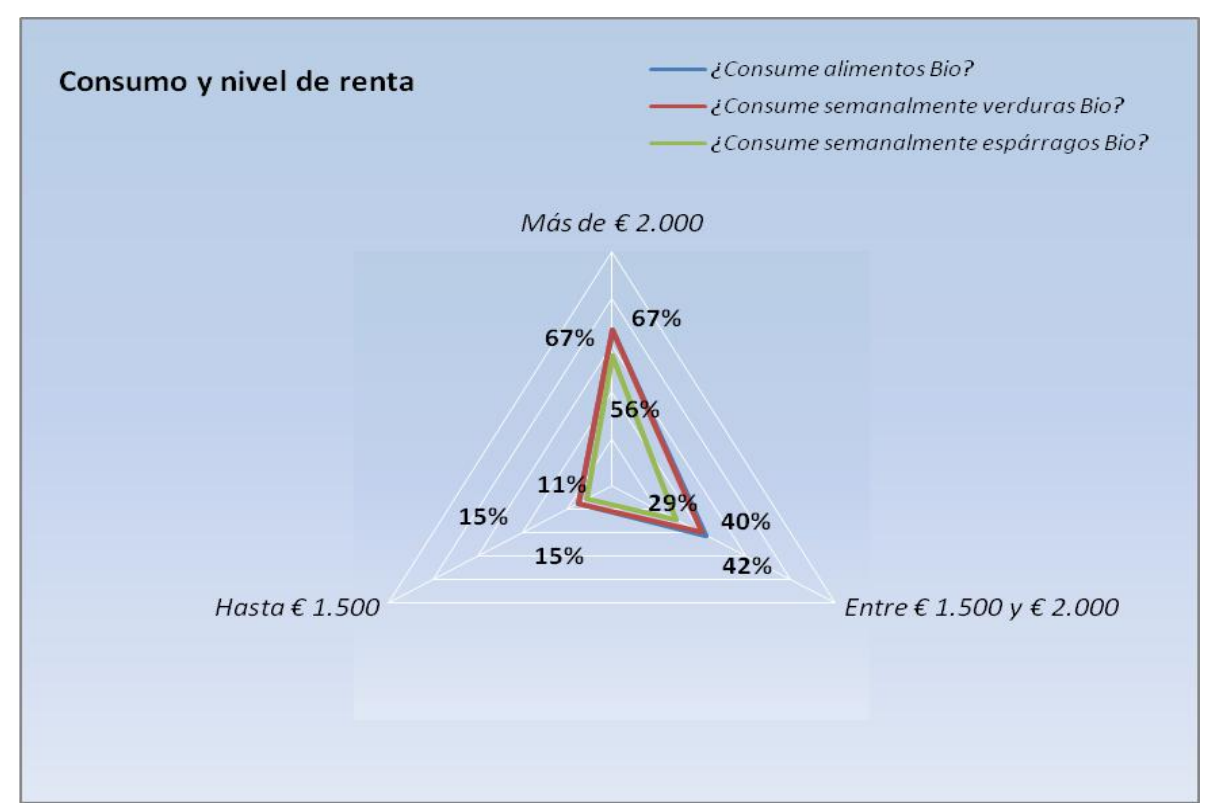

Fuente: Elaboración propia en base a encuestas realizadas.

Tal como era de esperarse, el consumo de hortalizas orgánicas está asociado al nivel de renta de los consumidores. Considerando el universo de los que practican una alimentación sana, observamos que el $67 \%$ consume al menos una vez a la semana alimentos y verduras orgánicas. Para el caso de los 
espárragos, el $56 \%$ de los encuestados consume espárragos al menos una vez a la semana, teniendo éstos, una renta superior a los $€ 2.000$ mensuales. En contrapartida, aquellos con menor nivel de renta, son los que menos consumen alimentos orgánicos. Otro punto a destacar es la correlación entre el nivel de ingresos y el nivel de educación de los encuestados.

A la hora de hablar de renta y precio de los productos alimenticios orgánicos, pude observar que en general el consumidor persigue la oferta constante y la diferencia de precios entre centros de consumo es mínima, haciendo hincapié éstas, en campañas de publicidad y promoción. Considerando además que existe una diferencia en los estratos respecto a si se "informan sobre la alimentación", podemos ver que la estrategia de comunicación debe ser distinta, ya que los que más se informan son las personas mayores a 65 años a través de medios gráficos. Las personas de entre 35 y 65 años que se interesan por la alimentación sana se informan además de los medios gráficos y por internet.

Respecto de las preguntas relacionadas a nuestro país, me llevé una sorpresa agradable, ya que prácticamente la totalidad de los encuestados tenía conocimiento de Argentina y de su ubicación. Uno de los aspectos que surgió en las entrevistas fue el fútbol. Alemania es un país con gran tradición en este deporte, por lo que al haber competido en 2 finales de la copa del mundo, el conocimiento estuvo presente; más aún, considerando que en la última copa del mundo nuestro país se enfrentó con Alemania.

A nivel de productos de consumo, la carne tiene un lugar de preferencia en la mente del consumidor y en menor proporción el vino. Asimismo, otro punto a favor de la publicidad del país, fue que en el año 2010, Argentina fue el invitado de honor en la Büchermesse de Frankfurt (Exposición del Libro de Frankfurt).

Por lo recabado, puedo decir que Argentina, tiene la imagen de ser un país limpio, "verde" (o no contaminado). El hecho de contar con paisajes como las Cataratas, el Calafate, La Pampa y la Patagonia, crean en el imaginario un concepto de país “joven y limpio"; situación por demás beneficiosa para cualquiera de los productos producidos aquí.

\subsection{Resumen de los aspectos de importancia en la compra de espárragos en Alemania}

A la hora de comprar espárragos la variable que más peso tiene en la escala valorativa del 
consumidor alemán es la calidad. En segundo lugar, el precio y el origen de los espárragos están en tercer puesto.

$\checkmark \quad$ En Alemania está bien marcado el origen de los mismos en cada uno de los puestos donde son ofrecidos, la marca u origen son expuestos por los productores a la hora de ofrecerlos.

$\checkmark \quad$ En general, las mujeres prestan mayor atención a la hora de consumir espárragos, en la calidad, en el origen, en las posibilidades culinarias, ya que son en mayoría las que cocinan y deciden las compras hogareñas.

$\checkmark \quad$ Por edad, las personas que dan más importancia al origen de los espárragos son las personas mayores de 65 años. Las de edad media, entre los 35 y 65 años, califican significativamente más alto el precio y la calidad de los espárragos.

Según la renta o ingreso familiar, los hogares con rentas modestas con diferencias significativas de las familias de rentas medias o altas, prestan más atención al precio y en menor medida a la calidad de los espárragos.

Según el nivel de estudios, personas con instrucción media, se distinguen significativamente de las personas con estudios superiores en la compra de espárragos, al atribuir mayor validez a los aspectos como el precio, dejando aspectos como la importancia para la salud, para las personas con nivel de estudios intermedios o universitarios.

$\checkmark$ Los consumidores alemanes estarían dispuestos a comprar espárragos blancos orgánicos argentinos fuera de temporada, la respuesta fue "Si", siempre y cuando fueran "Gut und Günstig" (buenos y baratos). 
Lic. Emanuel Borthiry Buide, Tomo 042, Folio 148, C.P.C.E.C.A.B.A. 


\section{Matriz FODA de los espárragos orgánicos argentinos respecto de Alemania}

Tabla $\mathrm{N}^{\circ}$ 21: Matriz FODA de las variables observadas:

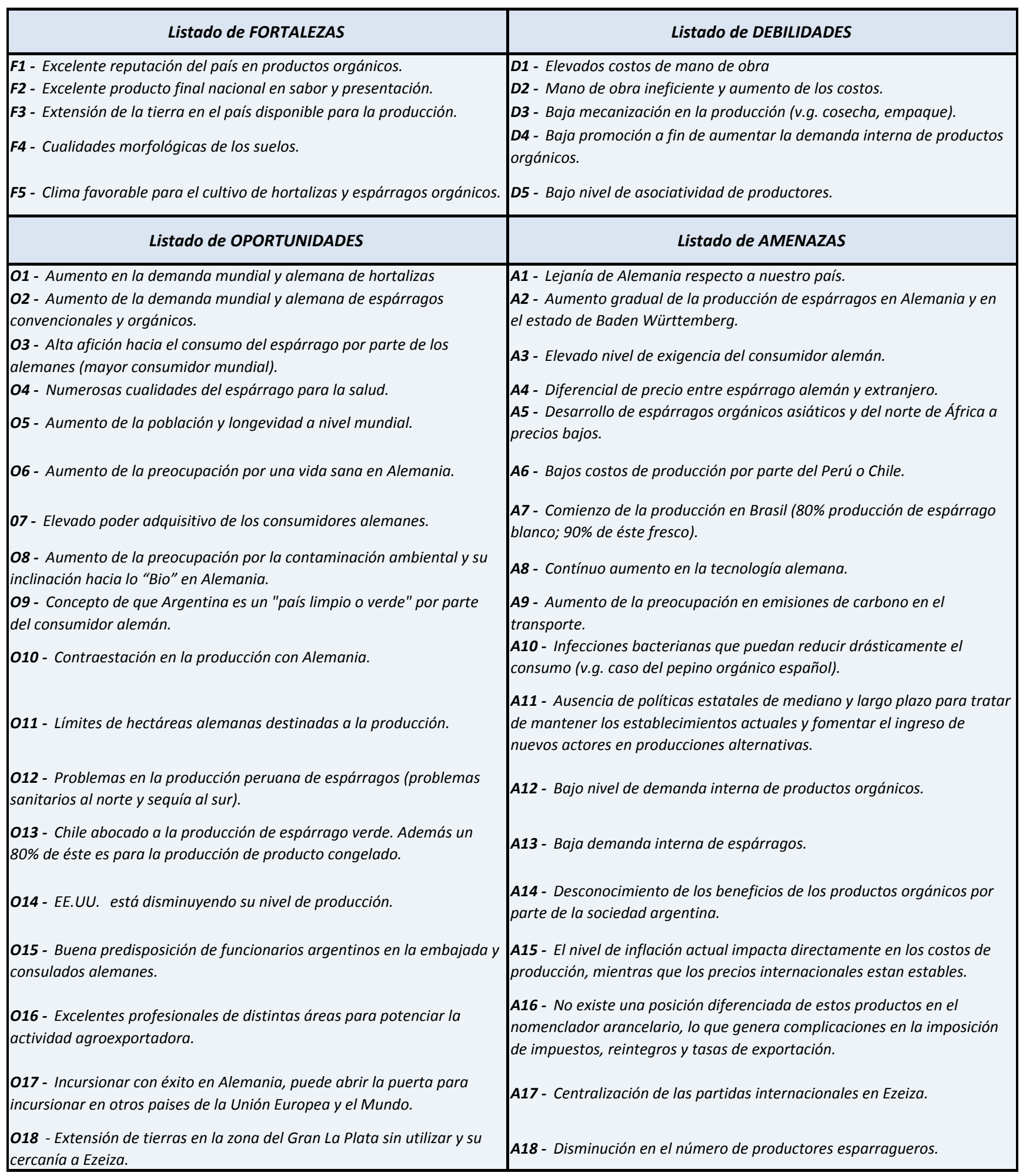


Tabla $\mathrm{N}^{\circ}$ 22: Matriz FODA y las posibles estrategias a seguir:

\begin{tabular}{|c|c|c|}
\hline & Listado de Fortalezas & Listado de Debilidades \\
\hline 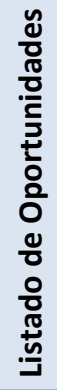 & $\begin{array}{c}\text { FO (Maxi - Maxi) } \\
\text { Estrategias para tratar de } \\
\text { maximizar las Fortalezas y } \\
\text { las Oportunidades }\end{array}$ & $\begin{array}{c}\text { DO (Mini - Maxi) Estrategias } \\
\text { para tratar de minimizar las } \\
\text { Debilidades y maximizar las } \\
\text { Oportunidades }\end{array}$ \\
\hline 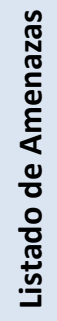 & $\begin{array}{c}\text { FA (Maxi - Mini) } \\
\text { Estrategias para tratar de } \\
\text { maximizar las Fortalezas y } \\
\text { minimizar las Amenazas }\end{array}$ & $\begin{array}{l}\text { DA (Mini - Mini) Estrategias } \\
\text { para tratar de minimizar las } \\
\text { Debilidades y las Amenazas }\end{array}$ \\
\hline
\end{tabular}

\subsection{Estrategias para la situación argentina}

La finalidad de un análisis como el anterior, nos da la posibilidad de aplicar las preguntas de unos de los padres del gerenciamiento como es Peter Drucker. ¿Cuál es mi negocio?, ¿Cuál será mi negocio? Y ¿Cuál debiera de ser mi negocio ${ }^{48}$ Respecto a la situación de nuestro país, puedo aseverar que incursionar con una mayor presencia en el mercado alemán puede traer beneficio tanto a productores actuales como potenciales. Sin duda, esto no es algo que se pueda lograr en el corto plazo y sin el compromiso de todos los actores participantes.

A continuación se enumera una lista (no taxativa) de las posibles "estrategias sugeridas" a implementar:

\section{Estrategias MAXI-MAXI (Fortalezas y Oportunidades).}

1. Consolidar la oferta de espárragos orgánicos argentinos en Alemania y en el mundo. Argentina posee gran reputación en lo que a hortalizas orgánicas se refiere. Considero que tanto las empresas productoras, como organismos como $\mathrm{MAPO}^{49}$ o la Asociación Argentina de Horticultura debieran ofrecer sus servicios y productos en varios idiomas. Mediante acciones como la sugerida estaríamos

\footnotetext{
${ }^{48}$ Peter Drucker, "La Gerencia" Tareas, responsabilidades y prácticas.

${ }^{49}$ Movimiento Argentino para la Producción Orgánica. www.mapo.org
} 
cruzando variables como: F1, F2, F3, F4, F5, O1, O2, O3, O4, O5, O6, O8, O9, O16 у O17.

2. Basándonos en el excelente sabor del producto argentino, comenzar a tener fluido trato con las autoridades argentinas en Alemania a fin lo lograr contactos comerciales, es una opción viable para desarrollar en el corto y mediano plazo. En este caso, pude constatar personalmente la buena predisposición de los funcionarios argentinos en la embajada en Berlín (F1, F2, F3, O3, O9, O10, O15, O16, O17).

3. Lograr contacto con productores peruanos a fin de realizar alguna estrategia conjunta comercial podría ser viable. Recordemos que el Perú es el principal productor y exportador de espárragos frescos y sus destinos de venta son muy variados. Sumado a esto, hay que remarcar que este país está sufriendo problemas sanitarios al norte, como problemas de agua al sur. Asimismo, si bien posee producción prácticamente todo el año, el clima no permite el desarrollo de espárragos orgánicos. (F1, F2, F3, F4, O1, O2, O8, O9, O12).

4. Para el caso de la provincia de Buenos Aires, podemos establecer que en la zona del Cinturón Verde del Gran La Plata, es una zona potencialmente óptima para el desarrollo orgánico, considerando además la cercanía del aeropuerto internacional de Ezeiza. Asimismo es dable destacar que existe la idea de desarrollar el aeropuerto de la ciudad de La Plata; situación que podría ser de mucho beneficio para los productores actuales y potenciales (F1, F2, F3, F4, O17, O18).

5. Estudiar la viabilidad de desarrollar estrategias conjuntas con actuales productores alemanes podría ser una alternativa para fomentar la actividad en el país (F1, F2, F3, F4, O2, O3, O6, O7, O8, O9, O10, O11, O15, O17, O17).

\section{Estrategias MAXI-MINI (Fortalezas y Amenazas).}

1. El aumento de la producción en Alemania y más precisamente en Baden Württemberg, puede ser contrarrestado con el excelente espárrago orgánico argentino. Sin duda para esto se necesita una estrategia de comunicación sólida, realizada en el idioma teutón. (F1, F2, F3, A1).

2. Ante el elevado nivel de exigencia del consumidor alemán, se necesita al igual que en el punto anterior, una estrategia de comunicación sólida, realizada en idioma alemán. (F1, F2, F3, A3). 
3. Respecto del diferencial de precios entre el espárrago alemán y el extranjero, hay que tratar de conseguir socios comerciales alemanes que puedan destacar las características de nuestros espárragos orgánicos a fin de lograr tratos comerciales a precios más beneficiosos para los productores locales (F1, F2, F3, A4, A15).

4. Lo mismo que el punto anterior, tanto para el caso de la aparición de nuevos productores, como los bajos costos de países como el Perú o Chile, el hecho de lograr un producto diferenciado es esencial (F1, F2, F3, A5).

5. Para el caso del desarrollo de Brasil como productor, basarse en las cualidades propias a fin de lograr integración con productores brasileros podría ser una salida viable y lograr de esta manera sinergias que apalanquen el sector (F1, F2, F3, A7).

6. Instalar el tema productos orgánicos y sus cualidades para el desarrollo de las economías regionales en la agenda tanto de los gobiernos provinciales y del gobierno nacional a fin de lograr el apoyo estatal necesario para el desarrollo del sector (F1, F2, F3, F4, F5, A11, A12, A13, A14, A15, A16, A17, A18).

\section{Estrategias MINI-MAXI (Debilidades y Oportunidades).}

1. En las debilidades en producción, comenzar a tomar contacto con productores latinoamericanos, con la finalidad de asociación, puede traer mejoras en la producción (D1, D2, D3, D5, O12, O16).

2. Lograr un aumento de la demanda internacional y alemana del espárrago argentino, considerando en contexto mundial en aumento en lo que a productos orgánicos se refiere, podría traer aparejado mejoras en los procesos productivos $(\mathrm{O} 1, \mathrm{O} 2, \ldots, \mathrm{O} 18, \mathrm{D} 1, \mathrm{D} 2, \mathrm{D} 3, \mathrm{D} 4, \mathrm{D} 5)$.

\section{Estrategias MINI-MINI (Debilidades y Amenazas).}

1. Intentar aumentar el grado de cooperación y asociación entre los productores actuales, podría derivar en la reducción de varios costos de producción y de esta manera llegar a ser más competitivos, respecto a otros productores latinoamericanos (D5, A4, A5, A6, A7, A8, A11, A15, A18).

2. Intentar aumentar la publicidad y promoción de las verduras orgánicas y más precisamente de los espárragos orgánicos con la finalidad de aumentar el nivel de demanda interna (D4, A12, A13, A14, A15, A16, A18). 


\subsection{Perspectivas}

Tal como observamos en el apartado destinado a la situación mundial del espárrago, podemos visualizar un fuerte crecimiento en los últimos años; las cifras de la Organización Mundial de Comercio dan cuenta de ello, mostrando para el año 2010 un total de 325.443 toneladas comercializadas, contra 206.037 comercializado en el año 2001. El interés sobre una alimentación más saludable y la concientización del consumidor de los beneficios de una dieta natural influyen en el aumento de las preferencias por el espárrago, además de su sabor delicado y su gran prestigio culinario.

En este contexto, la producción internacional seguirá con tendencia creciente especialmente en países de alta productividad como Perú o bajo una planificación productiva favorecida por la tecnología como es el caso de Alemania. Otros países como EE.UU. continuarán con un consumo sostenido, siendo éste mayor a su nivel de producción ${ }^{50}$. China seguirá siendo líder en la producción, tanto en espárrago fresco como procesado compitiendo con su cosecha de mejor calidad en algunos segmentos del mercado en fresco, sobre todo en Japón.

Para el caso del consumo de espárrago en todo el mundo, se puede inferir que continuará en ascenso, tal como muestran los volúmenes comerciados (año 2001: 206.037 toneladas; año 2010: 325.443 toneladas). Asimismo se prevé que Alemania, continúe por el mismo camino de ascenso.

Siguiendo uno de los postulados básicos de estrategia de Liddell Hart ${ }^{51}$ es importante llegar a identificar una contradicción de objetivos del contrincante para luego intentar ahondar en la nombrada contradicción. Para el caso del Perú, estamos observando que su producción continúa en ascenso, como así también sus exportaciones. En contrapartida, el país está experimentando problemas sanitarios en el norte, como así también problemas de agua en el sur, situación que deriva en problemas de "sabor" en sus espárragos. Además otra de las grandes oportunidades identificadas que brinda el Perú, es que al tener el clima subtropical y producción a lo largo de todo el año, se deben utilizar productos químicos, situación que ha llevado a que el país no pueda contar con producción orgánica; situación que podría ser aprovechada por la producción local.

\footnotetext{
${ }^{50}$ EE.UU. ha disminuido 7.000 hectáreas en los últimos 5 años según el NASS National Agricultural Statistics Service. www.nass.usda.gov

${ }^{51}$ Basil H. Liddell Hart. "Estrategia de la aproximación indirecta".
} 


\section{Instancias superadoras}

Lograr posicionar las hortalizas orgánicas, y más precisamente el espárrago orgánico argentino en Alemania, puede abrir la puerta tanto a productores actuales como potenciales, a una venta en toda la Unión Europea. El hecho de lograr ventas en Europa, no significa que logremos vender en Alemania; pero el hecho de vender en Alemania tanto espárragos orgánicos, como otros alimentos, nos da una gran oportunidad para desembarcar en todo el terreno europeo. Una de las fortalezas que debiera de explotar nuestro país, es la excelente calidad en presentación y sabor del espárrago orgánico argentino, sumado al concepto que tiene el consumidor alemán, respecto a nuestro país, ya que lo ven como un "país verde".

Considerando mi procedencia del interior de la provincia de Buenos Aires, estimo que una de las acciones que se podrían llevar a cabo es la integración entre varios actores tales como el Ministerio de la Producción de la provincia de Buenos Aires; las secretarias de producción de diversos municipios; instituciones educativas como la Escuela de Postgrado de Marketing Internacional (EPMI) y su staff de Docentes y Graduados, con la finalidad de crear una especie de "Incubadoras PyMEx". Es de vital importancia para la continuidad de acciones como las nombradas, que la provincia acerque a cada uno de los productores, en sus respectivos pueblos, la capacitación correspondiente a fin de que los empresarios adquieran conocimientos diversos sobre management de manera que puedan llegar a mejorar la eficacia de sus operaciones, para luego estudiar la factibilidad de internacionalizar sus productos o servicios. En este sentido la "continuidad" de las capacitaciones es fundamental. Más allá de brindar a los empresarios herramientas estratégicas y tácticas de mercadotecnia y management, es necesario que esta "Incubadora PyME" ofrezca capacitación del personal en todos los niveles de la empresa.

Otras de las acciones que considero que se podrían llevar adelante, es la creación de una especie de "Monitor Provincial en Marketing Internacional" donde las PyMEs puedan capacitarse o despejar dudas acerca de aspectos del comercio internacional (cuestiones de logística, barreras arancelarias y no arancelarias, etc.). Mediante la creación del presente organismo, se estaría integrando al Estado Universidad (Docentes, graduados y estudiantes) - Sector Pyme. Más allá del estudio de factibilidad de internacionalización de las PyMEs, otra de las funciones podría ser la búsqueda de socios extranjeros para el desarrollo de Joint Ventures. A modo de ejemplo, y utilizando el caso de los 
espárragos orgánicos, lograr alguna clase de cooperación con productores alemanes, podría elevar el nivel de tecnología de los productores locales, mientras que aquellos, podrían asegurarse la provisión de la hortaliza en los meses de no producción.

Estoy convencido que estamos en un momento más que oportuno para emprender acciones destinadas a promover que los productos orgánicos argentinos tengan una proyección hacia el mercado alemán. A modo de ejemplo, puedo nombrar que el día 17 de agosto de 2011, el Ministro de Asuntos Agrarios de la provincia de Buenos Aires, Dr. Ariel Franetovich, mantuvo una reunión en la embajada alemana en Buenos Aires, junto al consejero en Alimentación y Agricultura de Alemania, Klaus-Ludwig Keferstein; el Dr. Achim Viereck y el Ing. Agr. Cristobal Zimmermann. Según se puede observar en el portal de la embajada de Alemania en Argentina ${ }^{52}$, tanto el gobierno Alemán, como la provincia de Buenos Aires, están muy interesados en desarrollar actividades de producción orgánica de manera conjunta.

${ }^{52}$ http://www.buenos-aires.diplo.de/Vertretung/buenosaires/es/Landwirtschaft__Seite.html 


\section{Anexo Cap. 1: Producción orgánica, de espárragos a nivel mundial, en Alemania y Argentina.}

\section{Producción orgánica mundial}

\subsection{Producción, oferta, demanda y características de mercados por continente}

\subsection{1 África}

Si bien ha sido el continente con menor desarrollo en materia de productos orgánicos, hay en la actualidad más de 1.026.632 hectáreas bajo certificación orgánica al año 2009 en el continente africano ${ }^{53}$.

La cantidad de productores orgánicos, al menos 175.266, demuestra ser un número importante, sobre todo si comparamos con continentes con más "historia" productiva orgánica como Latinoamérica. Más allá de estos datos, hay que destacar que de los 57 países que tiene el continente africano, 38 cuentan con datos sobre las regulaciones orgánicas.

En África los países con más tierra dedicada a producción de orgánicos $\operatorname{son}^{54}$ :

\begin{tabular}{|c|c|}
\hline País & hectáreas \\
\hline Uganda & 226.954 \\
\hline Túnez & 167.302 \\
\hline Sudáfrica & 59.562 \\
\hline
\end{tabular}

Las tierras orgánicas en África son principalmente certificadas como recolección salvaje y ocupan un rol más importante que la orgánica tradicional. La superficie se ha convertido en importante sumando cerca de 16,4 millones de hectáreas, con productos como miel, forestación, acuicultura y recolección silvestre.

Los principales productos orgánicos de origen africano son ${ }^{55}$ :

\footnotetext{
${ }^{53}$ Según datos obtenidos en FiBL y IFOAM año 2011.

${ }^{54}$ Elaboración propia con datos IFOAM 2010.

${ }^{55}$ Fuente: Datos de IFOAM /FIBL 2010.
} 
- Frutas frescas: bananas, cítricos, uvas

- Frutas secas o disecadas: castañas de cajú, dátiles, uvas pasas, higos, damascos

- Frutas procesadas y jugos industriales

- Vegetales frescos

- Cereales: arroz

- Miel

- Azúcar

- Cacao

- Café

- Té

- Especias

- Hierbas medicinales y aromáticas

- Aceites: coco, esenciales, palma, oliva

La mayor parte de la producción está destinada a la exportación, y la mayoría es enviada a la Unión Europea, teniendo como principal exportador a Egipto.

El mercado africano para productos orgánicos es todavía muy pequeño y su tasa de crecimiento es sensiblemente inferior a las del resto el mundo y posiblemente se mantengan de esa manera en el futuro cercano. Existe un reducido mercado para estos productos en Egipto, Kenya y Sudáfrica.

La falta de mercado interno que absorba alguna parte de la producción y la alta dificultad para lograr certificaciones confiables en este continente (excluyendo ciertos países como Sudáfrica, Egipto y Marruecos) hacen pensar que no generan para la Argentina una amenaza comercial en el corto y mediano plazo.

Existen un buen numero de factores que destacan los especialistas para que el continente africano trate de continuar adoptando esta agricultura por sobre la convencional. El cuidado del medioambiente, la intensidad de la mano de obra, el mayor valor agregado de los productos obtenidos, entre otros, justifican esta línea de políticas a largo plazo. Esta estrategia choca de frente con la baja educación de 
los habitantes, la deficiencia alimentaria de casi todo el continente, las dificultades institucionales y políticas de los países y los problemas de infraestructura de todo tipo.

Gráfico N 46: Hectáreas Africanas divididas por país al año 2011:

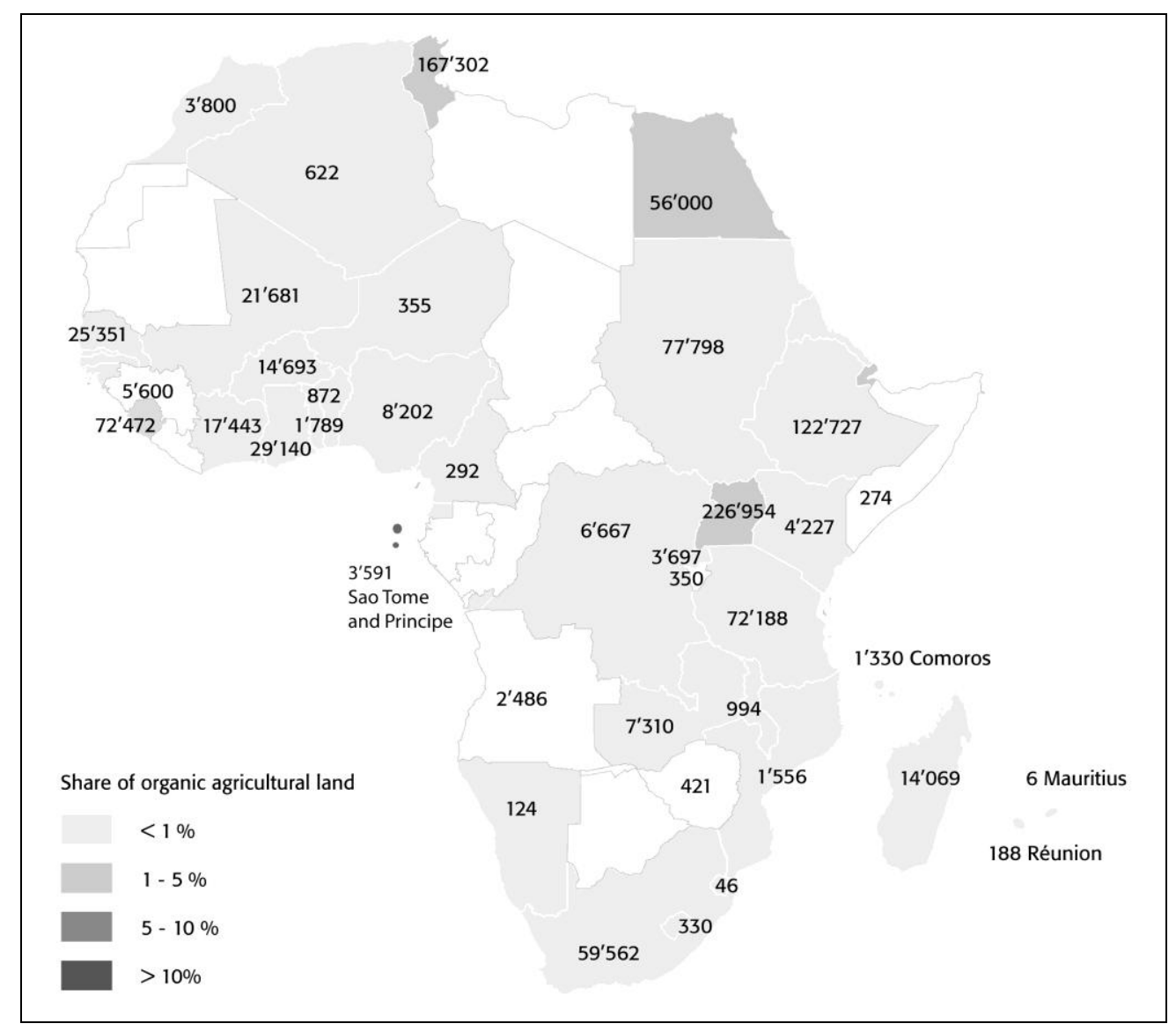

Fuente: IFOAM/FiBL año 2011

\subsubsection{Asia}

El mercado asiático para la producción y consumo de productos orgánicos ha venido creciendo de manera importante en los últimos diez años en toda la región. La razón principal que incentiva a los productores a entrar en el "mundo orgánico" es la exportación. Sin embargo, se han sumado a los ya existentes mercados (Japón, Corea del Sur, Singapur y Taiwán) nuevas ciudades consumidoras de estos productos como: Shanghái, Beijing, Nueva Delhi, Bangalore, Bombay, Kuala Lumpur, Yakarta, Manila, Bangkok. Este hecho ha dado nuevos incentivos a los productores a fin de proveer los 
mercados internos de estos países. En su totalidad, las hectáreas destinadas a la producción orgánica ascienden a 3.581 .918 .

Los principales países productores en Asia son ${ }^{56}$ :

\begin{tabular}{|c|c|}
\hline País & hectáreas \\
\hline China & 1.853 .000 \\
\hline India & 1.180 .000 \\
\hline
\end{tabular}

La demanda está concentrada en Japón, Corea del Sur, Singapur, Taiwán, y Hong Kong, los países más opulentos de la región.

La región produce una cantidad variada de productos, algunos de ellos típicamente regionales como el té, el arroz, frutas tropicales y las especias. Otros en competencia con otras regiones del mundo (como Sudamérica) como algodón, cereales, oleaginosas, semillas, miel, frutas disecadas, café o frutas secas. Los principales mercados de exportación para los países de Asia son Alemania, Holanda, Reino Unido, Estados Unidos, Japón, Suiza, Italia y Francia. No obstante, es interesante observar el desarrollo de las exportaciones entre países asiáticos y Oceanía, lo cual denota la existencia concreta de mercados poco explorados por los exportadores argentinos, como China, Sudáfrica, Australia, Nueva Zelanda, Malasia, y Taiwán.

\footnotetext{
${ }^{56}$ Elaboración propia con datos IFOAM 2010.
} 
Gráfico N 47: Hectáreas Asiáticas divididas por país al año 2011:

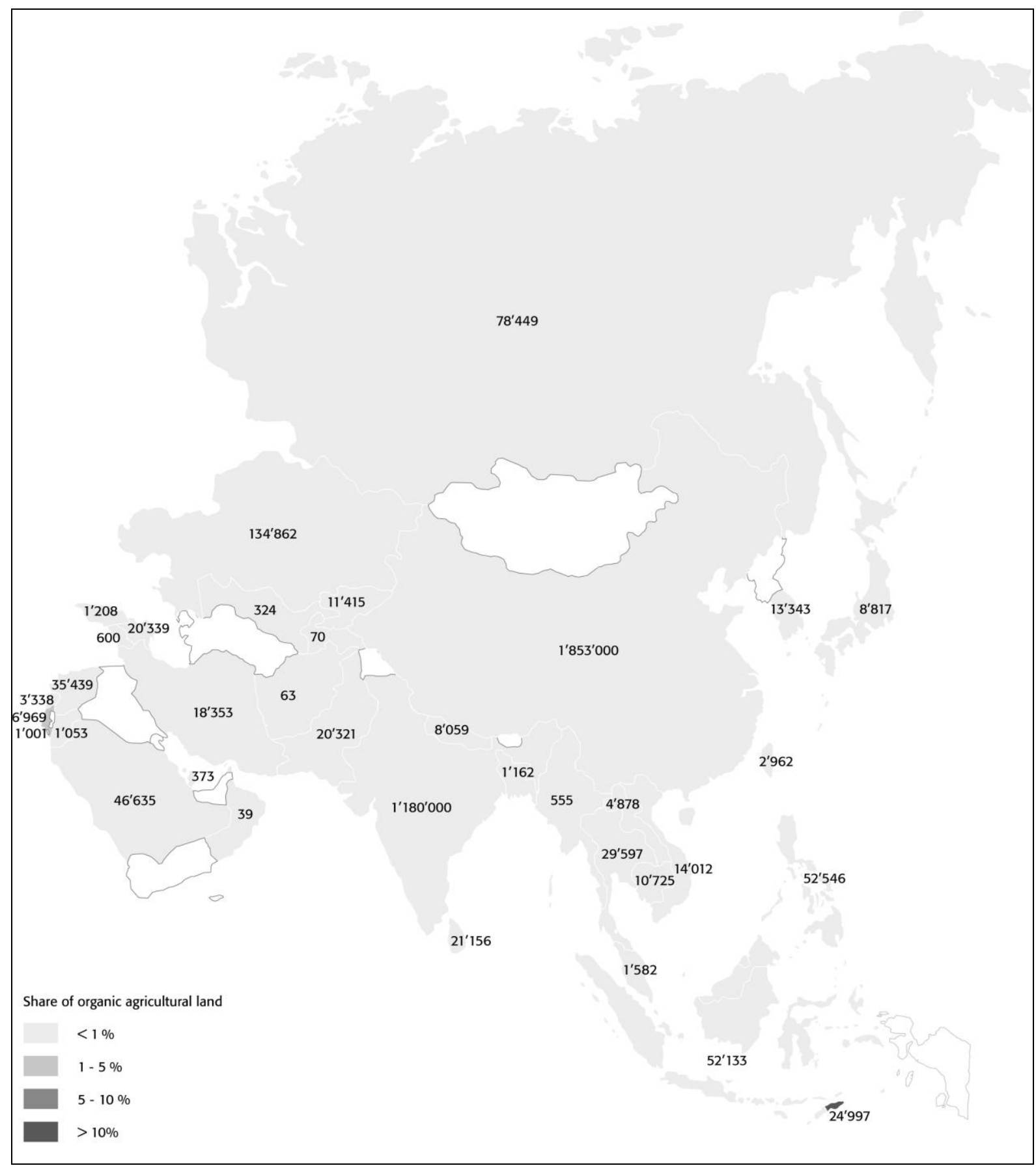

Fuente: IFOAM/FiBL año 2011 


\subsubsection{Europa}

Si bien como hemos visto en el primer capítulo del presente trabajo, la agricultura orgánica se desarrollo en Europa desde fines del siglo XIX y comienzos del siglo XX, es desde los comienzos de los años 90, donde la agricultura orgánica se desarrolló con mayor ímpetu y velocidad en casi todos los países europeos. Según datos de IFOAM de fines de 2009, 9.259.934 de hectáreas corresponden a Europa, mientras que en la Unión Europea (conformada por 27 Estados Miembros), la cifra en hectáreas alcanza las 8.346.372.

Los países con las áreas orgánicas más grandes son:

\begin{tabular}{|c|c|}
\hline País & hectáreas \\
\hline España & 1.330 .774 \\
\hline Italia & 1.106 .684 \\
\hline Alemania & 947.155 \\
\hline Francia & 677.513 \\
\hline
\end{tabular}

El mayor mercado para la producción orgánica en la Unión Europea durante el 2010 fue Alemania con una facturación 5.850 millones de euros. Por otro lado, los mercados con mayor participación de productos orgánicos como porcentaje del mercado de productos totales, son Austria, Dinamarca y Suiza. Al observar los consumos per cápita más altos para alimentos orgánicos, vemos que Dinamarca encabeza las estadísticas con 139 euros consumidos en productos orgánicos por habitante por año, seguida por Suiza (132 euros per cápita) y Austria (104 euros per cápita).

Si bien la Unión Europea es un importante productor de materias primas orgánicas y de productos industriales y elaborados, es también un importante importador de productos orgánicos, principalmente de materias primas como cereales y oleaginosas, frutas y verduras frescas, algunas carnes, frutas secas y disecadas, miel, hierbas medicinales entre los principales. 
Gráfico N 48: Hectáreas Europeas divididas por país al año 2011:

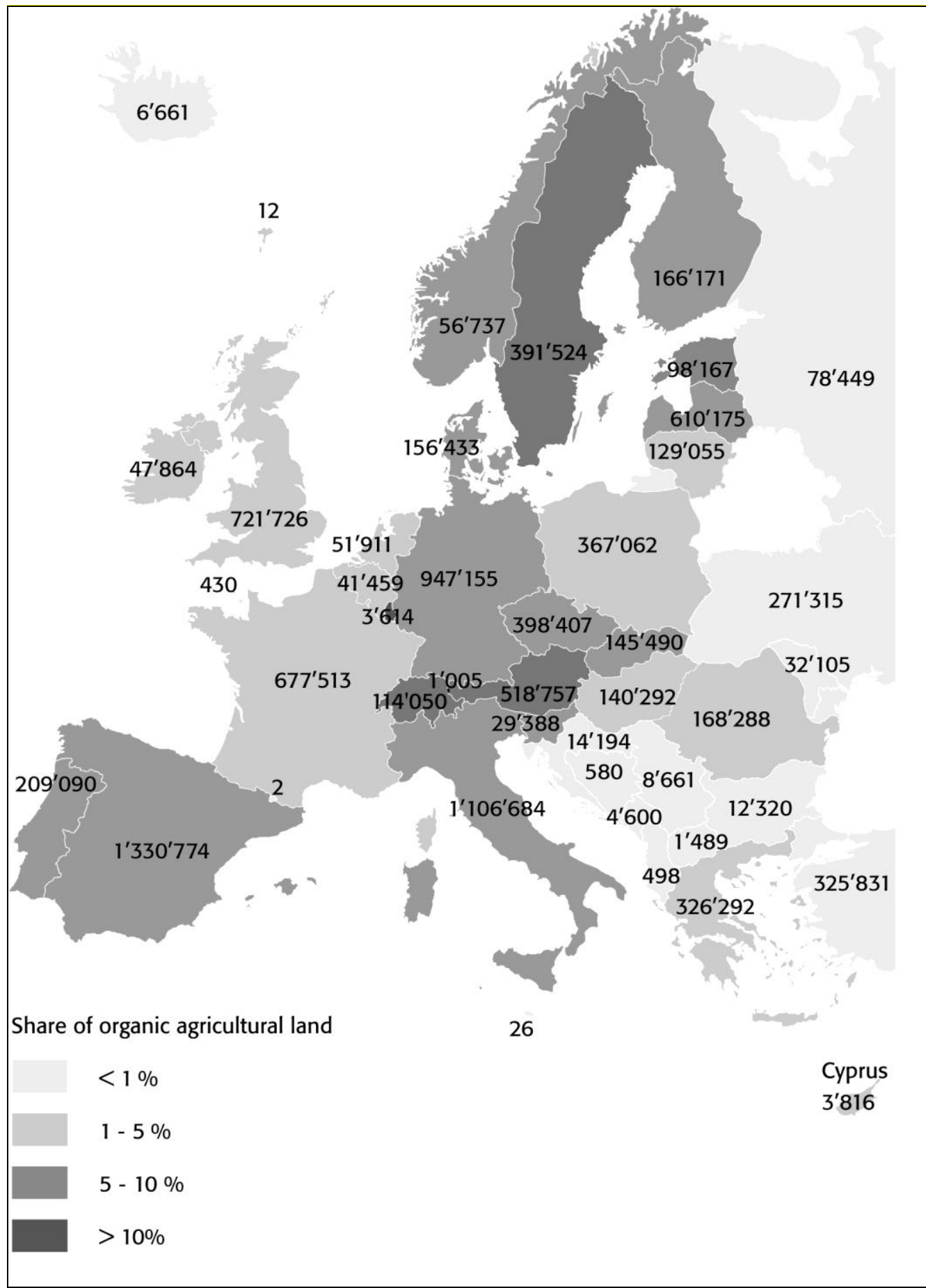

Fuente: IFOAM/FiBL año 2011 


\subsubsection{Oceanía}

Esta área incluye Australia, Nueva Zelanda, e Islas como Fiji, Papua Nueva Guinea, y Vanuatu. Todas juntas suman 12.152.108 de hectáreas.

El crecimiento de la industria orgánica se da en Australia, Nueva Zelanda e Islas del Pacífico que han sido fuertemente influenciadas por la rápida demanda de mercados extranjeros. Los mercados domésticos son crecientes aunque no pueden compararse aún con los del hemisferio norte.

Australia es dentro del continente el mayor productor y el mercado más importante de consumo. A nivel internacional es el país con mayor superficie orgánica certificada en todo el mundo, destinada esta principalmente a la producción de pasturas para la ganadería. Como se puede apreciar en el gráfico siguiente, el país con mayor cantidad de hectáreas es Australia con 12.001.724.

Gráfico N 49: Hectáreas Africanas divididas por país al año 2011:

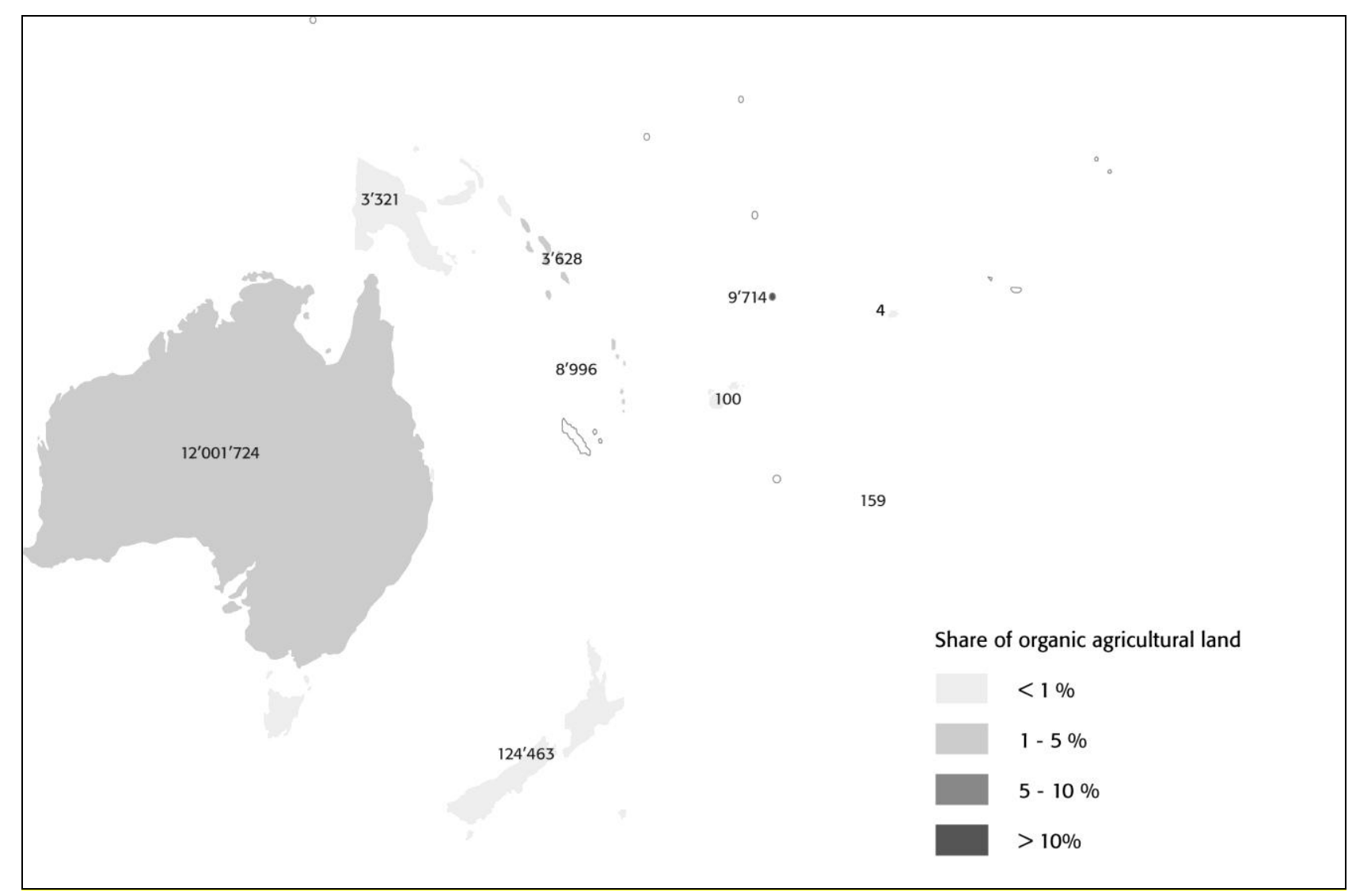

Fuente: IFOAM/FiBL año 2011 


\subsubsection{América del Norte}

En el norte del continente americano (considerando sólo Canadá y los Estados Unidos), la cantidad de hectáreas asciende a 2.652.624, representando aproximadamente el 0,7\% del total del área agrícola de estos países. Actualmente el número de unidades productivas es de 12.064, lo que habla de una concentración de tierras en pocos productores o viéndolo de otra forma, las unidades productivas son de mayor tamaño que en otros países como Europa o África, ó su país vecino, México, que cuenta con 128.862 unidades productivas en un área correspondiente a 332.485 mil hectáreas.

En resumen establecemos que los EE.UU. cuentan con 1.948.946 hectáreas bajo producción agrícola y 12.941 productores. Para el caso de Canadá tenemos 703.678 hectáreas y 4.128 productores.

Estados Unidos es el mercado más grande del mundo en cuanto a volumen y buenos precios pagados por los productos orgánicos, no pudiendo abastecer con su producción la totalidad y variedad de productos que se demandan día a día. Es por ello que sus importaciones han tomado año a año un valor muy significativo. Uno de sus principales proveedores es Canadá, quién aprovechando las ventajas de vecindad y acuerdos de libre comercio, puede abastecer una parte importante de las importaciones de los norteamericanos. No obstante, en cuanto a importaciones, sabemos que llegan a ese mercado productos de América Central y Sudamérica, África, Asia, Europa y Oceanía. 
Gráfico N 50: Hectáreas Norteamericanas divididas por país al año 2011:

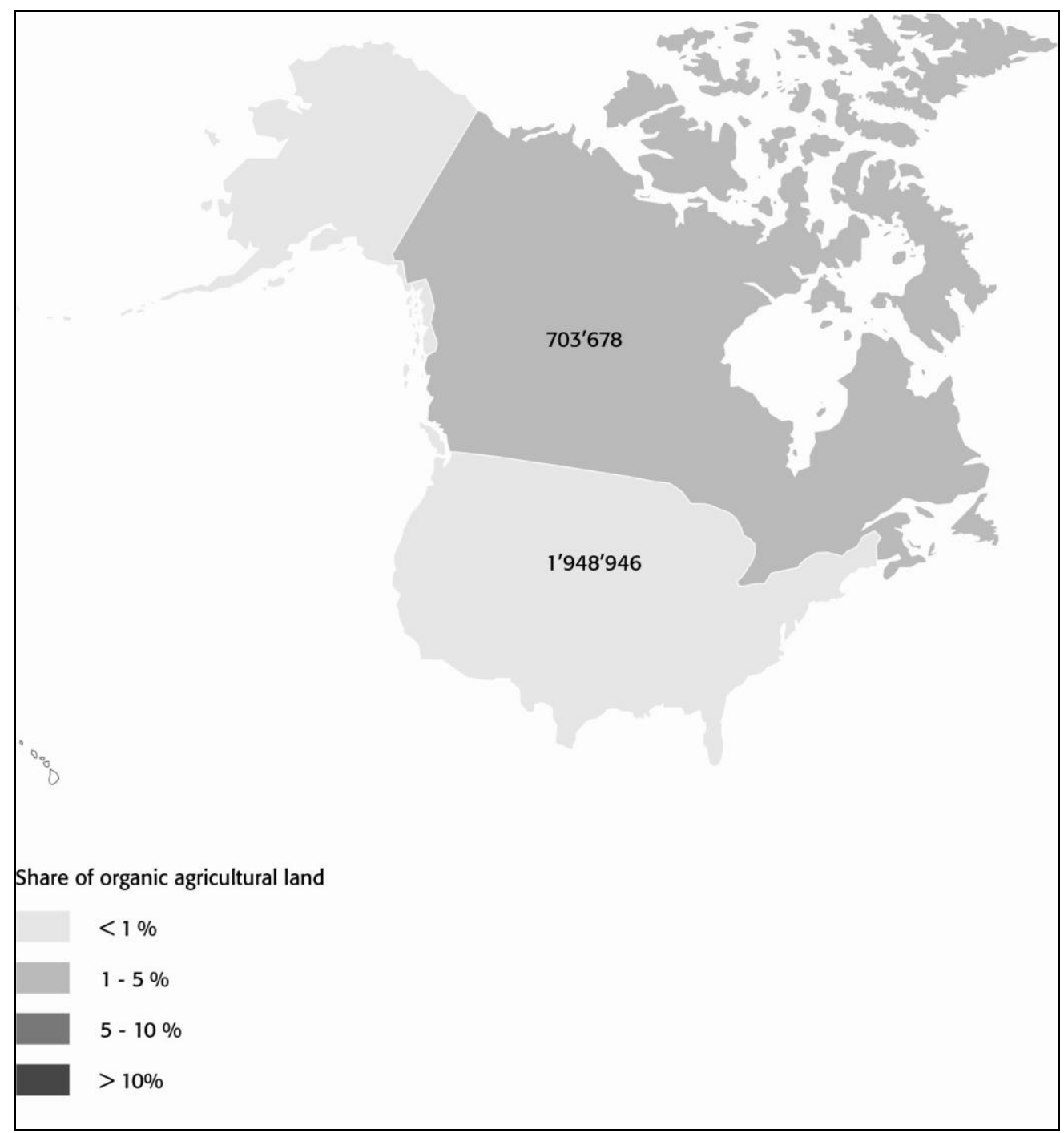

Fuente: IFOAM/FiBL año 2011

\subsubsection{América Latina}

En Latinoamérica las hectáreas ascienden a 8.558.910. Esto constituye el 23\% del territorio a nivel mundial. Los principales países son Argentina (4.397.851 hectáreas), Uruguay (930.965 hectáreas), Brasil (1.765.793 hectáreas) y México (332.485 hectáreas).

Países como Argentina, México, Brasil, Perú y Chile se han convertido en importantes productores, sin embargo sus mercados internos son aún muy reducidos, por lo cual más del $90 \%$ de las cosechas orgánicas están destinadas a la exportación. 


\begin{tabular}{|c|c|}
\hline Países & hectáreas \\
\hline Argentina & 4.397 .851 \\
\hline Brasil & 1.765 .793 \\
\hline Uruguay & 930.965 \\
\hline México & 332.485 \\
\hline Perú & 186.314 \\
\hline Chile & 82.327 \\
\hline
\end{tabular}

Fuente: IFOAM/FiBL año 2011

\begin{tabular}{|c|c|c|}
\hline Continente & hectáreas & \% s/convencional \\
\hline África & 1.026 .632 & $0,10 \%$ \\
\hline Asia & 3.581 .918 & $0,30 \%$ \\
\hline Europa & 9.259 .934 & $1,90 \%$ \\
\hline Unión Europea & 8.346 .372 & $4,70 \%$ \\
\hline Latinoamérica & 8.558 .910 & $1,40 \%$ \\
\hline Norteamérica & 2.652 .624 & $0,70 \%$ \\
\hline Oceanía & 12.152 .108 & $2,80 \%$ \\
\hline Total & $\mathbf{3 7 . 2 3 2 . 1 2 6}$ & $\mathbf{0 , 9 0 \%}$ \\
\hline
\end{tabular}

Fuente: IFOAM/FiBL año 2011

En el cuadro anterior podemos observar que Latinoamérica es el tercer continente de mayor superficie dedicada a la agricultura orgánica certificada, seguido por Asia.

Dentro de Latinoamérica, 15 países tienen legislación en agricultura orgánica, y tres países adicionales están actualmente desarrollando regulaciones orgánicas. Costa Rica y Argentina han alcanzado el status de tercer país de acuerdo con la regulación de la Unión Europea para agricultura orgánica.

El resto de los países necesitan ser re-certificados por una compaña de certificación Europea para entrar al mercado de la Unión Europea, salvo Argentina, donde las empresas de certificación son casi en su totalidad nacionales, en el resto de los países latinoamericanos la certificación es realizada por empresas de origen europeo o norteamericano. En este rubro, es importante destacar que algunas empresas argentinas de certificación han iniciado trabajos en otros países, exportando importantes servicios de certificación y "know how", demostrando su alta competitividad y capacidad de trabajo en terceros mercados. 
Gráfico N 51: Hectáreas Latinoamericanas divididas por país al año 2011:

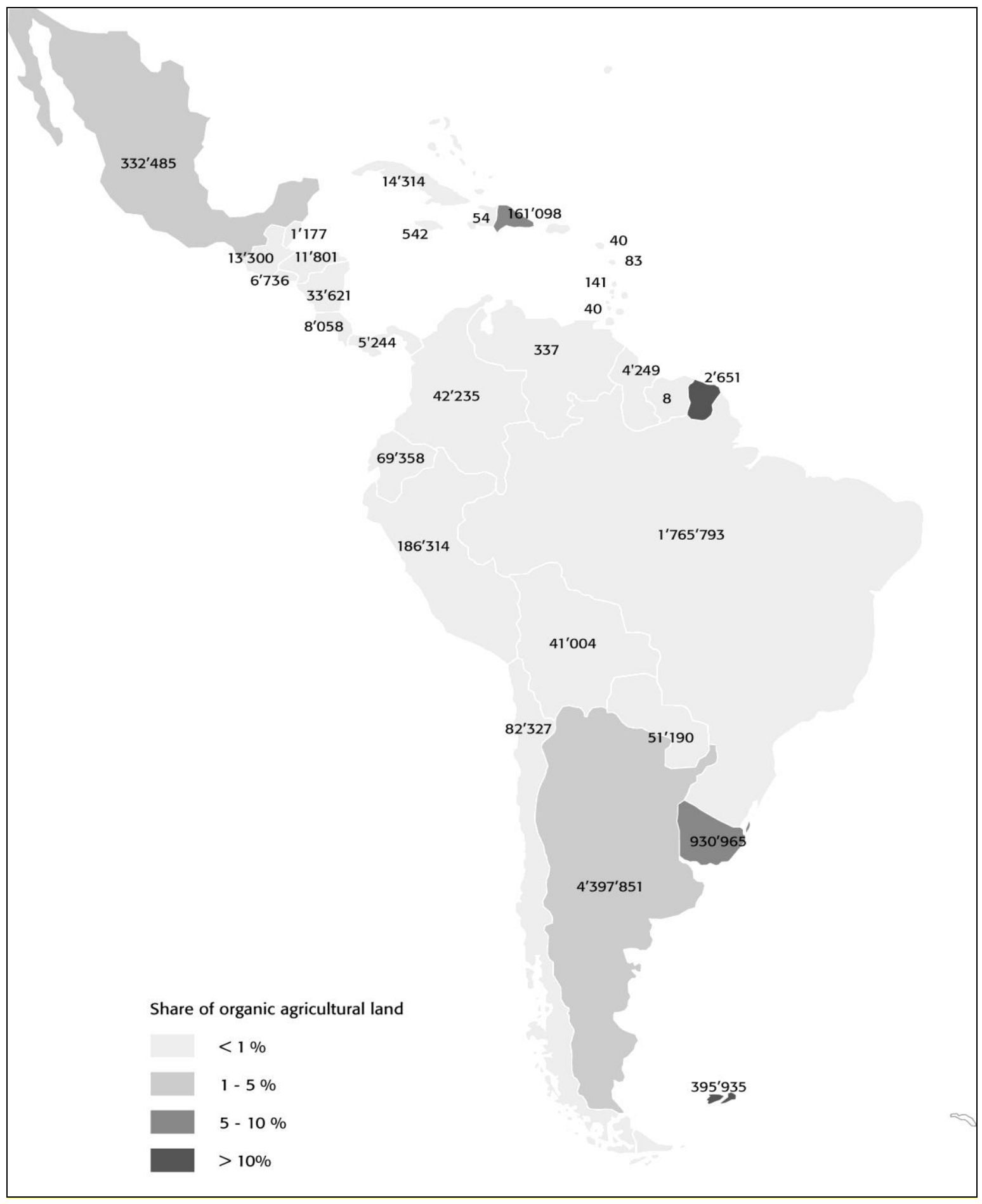

Fuente: IFOAM/FiBL año 2011 


\subsection{Principales producciones orgánicas en Latinoamérica57}

Tabla $N^{\circ}$ 23: Detalle de producciones latinoamericanas al año 2010:

\begin{tabular}{|c|c|c|c|c|c|c|c|c|}
\hline País & Frutas y Vegetales & Cereales y Oleaginosas & Café & Cacao & Azúcar & Vino & carnes & Lanas \\
\hline Argentina & $\begin{array}{c}\text { manzanas, peras, cítricos, } \\
\text { berries, frutas secas }\end{array}$ & $\begin{array}{l}\text { soja, maíz, girasol, lino, } \\
\text { trigo, arroz, otros }\end{array}$ & & & $x$ & $x$ & $x$ & $x$ \\
\hline Bolivia & papas & maíz y otros & $x$ & $x$ & & & & \\
\hline Brasil & $\begin{array}{c}\text { banana, manzana, mango, } \\
\text { piña, jugos }\end{array}$ & soja, trigo, arroz & $x$ & $x$ & $x$ & & $x$ & \\
\hline Chile & $\begin{array}{c}\text { manzanas, berries, } \\
\text { aguacate, espárragos, } \\
\text { cítricos, aceitunas }\end{array}$ & - & & & & $x$ & & $x$ \\
\hline Colombia & $\begin{array}{c}\text { banana, mango, procesados } \\
\text { de fruta }\end{array}$ & - & $x$ & $x$ & & & $x$ & \\
\hline Costa Rica & $\begin{array}{c}\text { mango, banana, piña y } \\
\text { procesados de fruta }\end{array}$ & - & $x$ & $x$ & $x$ & & & \\
\hline México & $\begin{array}{c}\text { vegetales, frutillas, banana, } \\
\text { manzana, vainilla, chiles, } \\
\text { aguacate, frutas disecadas, } \\
\text { tomates }\end{array}$ & soja, maíz & $x$ & $x$ & $x$ & & & \\
\hline Paraguay & cítricos & soja, maíz, sésamo & & & $x$ & & & \\
\hline Perú & $\begin{array}{c}\text { mango, banana, espárragos, } \\
\text { tomates, pimientos, } \\
\text { cebollas, papas }\end{array}$ & - & $x$ & $x$ & & & & \\
\hline Uruguay & cítricos & arroz, soja & & & & $x$ & $\boldsymbol{x}$ & $x$ \\
\hline
\end{tabular}

Fundación Exportar: Propuesta para una planificación estratégica sobre productos orgánicos año 2010.

La parte siguiente, brindará en resumen, datos de la situación de la producción y el mercado de varios países latinoamericanos, en el sector orgánico.

\subsubsection{Bolivia}

Este país tiene una tradición ancestral de la cultura orgánica, y sus primeras manifestaciones se remontan a unos 3000 años atrás.

En cuanto a la producción, en $2009^{58}$ Bolivia tenía 41.004 hectáreas certificados.

La Asociación de Productores Ecológicos (AOPEB) agrupa 56 asociaciones, contando con cerca de

\footnotetext{
${ }^{57}$ Fundación Exportar: Propuesta para una planificación estratégica sobre productos orgánicos año 2010.

${ }^{58}$ Últimos datos aportados por Bolivia a FiBL / IFOAM
} 


\subsection{3 productores.}

En Bolivia se encuentran cadenas de tiendas de productos orgánicos, sobre todo en La Paz, Cochabamba y Santa Cruz de la Sierra, ciudades donde se registran los mejores sueldos promedio del país. Bolivia tiene un certificador nacional acreditado, Bolicert. Además, numerosas organizaciones de certificación internacional actúan en el país.

\subsubsection{Brasil}

Este país cuenta con 1.765 .793 hectáreas certificadas en el año $2009^{59}$ con 7.250 productores registrados.

Brasil exporta café, bananas, maíz y carne. Además, el crecimiento del sector textil y cosmético fue presentado en numerosas ferias internacionales de orgánicos. Por otro lado tiene un gran potencial en otros productos como piña, azúcar, carne bovina, arroz, fruta fresca y alguna fruta seca como castaña de cajú. En toda América Latina, Brasil es el país que tiene el mayor mercado doméstico en el sector orgánico (45\% de las ventas). Existen supermercados que comercializan solamente productos orgánicos.

En Brasil, hay 12 agencias nacionales de certificación y 9 agencias internacionales que operan en el país. Dentro de ellas una es Argentina. Por otro lado, muchas ONG trabajan para desarrollar el sector.

Es importante destacar a efectos de este trabajo que dado el desarrollo que ha tenido el mercado interno brasilero en materia de productos orgánicos, se han comenzado a dar exportaciones desde la Argentina, Perú, Uruguay y Chile a este mercado, principalmente dada su proximidad regional y también su acceso facilitado por el MERCOSUR.

\subsubsection{Chile}

El país cuenta con unas 82.327 hectáreas de superficie de tierras certificadas, principalmente en su Patagonia, al año 2009.

El 90\% de la producción orgánica chilena se destina a la exportación. Estados Unidos es el mayor mercado importador ya que recibe el $70 \%$ de las exportaciones totales. Después siguen los mercados de Europa, Japón y Canadá.

El mercado interno es aún muy pequeño, pero en crecimiento; estos se encuentran en las grandes ciudades como Santiago, Temuco, La Serena y Valdivia.

La reglamentación nacional sobre la agricultura orgánica fue promulgada en enero de 2006. La agencia

\footnotetext{
${ }^{59}$ Datos obtenidos de FiBL / IFOAM año 2010.
} 
oficial Pro Chile brinda el soporte gubernamental para la promoción de las exportaciones.

Existe una asociación nacional para el movimiento orgánico llamada Agrupación de Agricultura Orgánica de Chile (AAOCH). Hay en el mercado operando tres certificadores nacionales, otras internacionales y una de Argentina.

Es importante destacar que en los últimos años se ha despertado un mayor interés por la certificación orgánica en este país comenzando a verse las primeras exportaciones de nuevos emprendimientos durante estos años. El potencial de Chile como exportador y competidor de Argentina en materia de exportación de productos orgánicos es importante, basando sus fortalezas en el clima, su alto status fito-zoosanitario y sus acuerdos comerciales preferenciales.

\subsubsection{Colombia}

La agricultura orgánica ha tenido tasas de crecimiento muy importantes en este país. En 2003, había cerca de 33.000 hectáreas de superficie certificada en Colombia. En Junio de 2010 las hectáreas ascendieron a 42.235 siendo a su vez, el número de productores 5.704 para este año mencionado.

Su principal producto es el café, con cerca del $40 \%$ del total de la tierra orgánica certificada. También produce aceite de palma, azúcar de caña, banana fresca y procesada, mango fresco, cacao y plantas medicinales.

El mercado doméstico es aún muy pequeño. La principal vía de comercialización es la de tiendas naturales, donde algunos productos orgánicos se venden junto a los referidos como "saludables".

Algunas cadenas de supermercado han comenzado a comercializar orgánicos, principalmente frutas y verduras. Paralelamente, otras vías de comercio han sido exploradas por emprendedores tales como Internet, restaurantes y hasta alimentación en colegios.

Es importante destacar que existe un Centro de Investigación de la Agricultura Orgánica (CIAO) que lleva adelante investigaciones y desarrollos productivos para este sector, generando conocimiento y valor agregado para los productores.

\subsubsection{Costa Rica}

Desde los años 80 se está desarrollando la producción agrícola orgánica con un importante crecimiento en la producción y la exportación. En 2009, el país tenía una superficie de 8.058 hectáreas de tierras certificadas, con 3000 productores certificados.

Costa Rica se beneficia de un Sistema Nacional de Control que fue reconocido como una equivalencia por la Unión Europea, en el año 2003. Desde entonces es parte de la lista de los países terceros de 
Europa junto con Argentina.

Costa Rica tiene dos certificadores nacionales: Ecológica y también Central American Institute for the Certification of Organic Products (AIMCOPOP). Están registrados 3 certificadores internacionales. Exporta una buena cantidad de productos, principalmente de carácter tropical, como la piña y el mango.

\subsubsection{México}

El crecimiento de las tierras orgánicas fue rápido. En 2000, se registraba en México 85.675 hectáreas certificadas. En el año 2002 tenía 215.843 hectáreas y en 2008, 332.485 hectáreas con 128.862 productores certificados. La mayoría de la producción orgánica se exporta, entre un 80 y un $85 \%$, sobre todo a Estados Unidos, Canadá y a Europa.

México es el mayor productor mundial de café orgánico. Más de la mitad de la superficie agrícola orgánica se dedica a la producción de café. Asimismo produce sésamo, maguey (planta nativa de la cual se pueden producir entre otras cosas bebidas alcohólicas), maíz azul, palta (aguacate), mango, piña y banana. También podemos encontrar productos originarios de este territorio como el Cacao y la Vainilla, ambos también orgánicos.

Hay varios certificadores internacionales que operan en México: OCIA México, Naturland México, Bioagricert, IMO, BCS, Oregon Tilth Certified Organic, Quality Assurance Internacional y FVO. Certimex es la agencia local de certificación más importante del país.

El mercado interno de México si bien es pequeño aún, tiene una amplia difusión en las grandes ciudades, tales como el Distrito Federal (D.F.), Guadalajara, Monterrey, Puebla, Morelia, Acapulco y Puebla, entre otras.

\subsubsection{Paraguay}

Este país posee la mayor área productiva de azúcar orgánico de Latinoamérica, contando con más del $50 \%$ de la superficie total cultivada en dicho territorio. Al año 2007 el país cuenta con 51.190 hectáreas con 11.401 productores certificados.

La producción de azúcar orgánico fue una oportunidad excelente para que el país se desarrolle en el sector orgánico y también para afrontar la caída de los precios internacionales del azúcar. En forma similar a lo que ocurre en Argentina, la producción de azúcar orgánico se encuentra altamente atomizada y concentra a una gran cantidad de productores minifundistas.

Otros productos producidos por Paraguay son el sésamo, el poroto de soja, el maíz y algunos otros 
cereales y oleaginosas.

\subsubsection{Perú}

Perú cuenta al año 2009 con 186.314 hectáreas certificadas ${ }^{60}$, con 54.904 productores certificados. El 97\% de la producción se exporta y un 94\% de estas exportaciones es café y cacao. Bananas, mango y piña son otros productos orgánicos que se suelen exportar en fresco o con algún grado de procesamiento. A su vez podemos encontrar en este mercado quínoa, algodón, nuez de Brasil, cebollas, espárragos, corazones de alcaucil, amaranto, tomate y semillas de sésamo entre otros.

Es importante destacar que a pesar de su desarrollo económico un poco menor que otros países de la región, Perú ha sabido construir una imagen de confianza y calidad de sus productos en el mundo y mucho tuvo que ver en esto las inversiones extranjeras y la tarea realizada por el Estado y el sector privado exportador.

La agencia local de certificación, Inkacert, se asoció con otra organización latinoamericana de certificadores para formar Bio Latina. Esa última fue aceptada y reconocida por la Unión Europea. Institucionalmente la producción orgánica en Perú cuenta con importantes actores públicos, privados y no gubernamentales. Los mismos interactúan entre sí generando distintas sinergias, que en buena medida explican el alto crecimiento alcanzado por este país en la última década.

\subsubsection{Uruguay}

El crecimiento de tierras orgánicas en éste país ha sido sorprendente ya que pasó de 1.200 hectáreas en 2000 a 930.965 hectáreas en 2007. La producción orgánica representa un 5\% de la agricultura uruguaya y es explotada por unos 650 productores.

El mercado doméstico es pequeño. Tiendas especializadas empezaron a vender productos orgánicos en 2005. La Asociación de Productores Pequeños de Uruguay organiza mercados semanales en Montevideo. Uruguay es un reconocido productor de carne bovina, carne ovina, vinos, miel, cereal y oleaginosas, como así también de productos lácteos.

\footnotetext{
${ }^{60}$ Según datos obtenidos en The World of Organic Agriculture. Statistics and Emerging Trends 2011.
} 


\subsection{Tierra orgánica dedicada a la agricultura.}

Tabla $\mathrm{N}^{\circ} 24$ : Detalle del total de hectáreas y número de productores a nivel mundial:

\begin{tabular}{|c|c|c|c|}
\hline Países & Año & Hectáreas & $N^{\circ}$ Productores \\
\hline Afghanistán & 2009 & 63 & 264 \\
\hline Albania & 2009 & 500 & 50 \\
\hline Alemania & 2009 & $947^{\prime} 115$ & $21^{\prime} 047$ \\
\hline Algeria & 2009 & 622 & 49 \\
\hline Andorra & 2009 & 2 & 1 \\
\hline Angola & 2009 & 2.486 & Sin dato \\
\hline Arabia Saudita & 2009 & $46^{\prime} 635$ & 63 \\
\hline Argentina & 2009 & 4.397 .851 & $1^{\prime} 894$ \\
\hline Armenia & 2009 & 600 & 31 \\
\hline Australia & 2009 & $12^{\prime} 001^{\prime} 724$ & $2^{\prime} 129$ \\
\hline Austria & 2009 & $518^{\prime} 757$ & $21^{\prime} 000$ \\
\hline Azerbaijan & 2009 & 20'339 & 288 \\
\hline Bangladesh & 2009 & 1'162 & 2 \\
\hline Belarus & 2009 & Sin dato & Sin dato \\
\hline Belgica & 2009 & $41^{\prime} 459$ & 997 \\
\hline Belize & 2009 & $1^{\prime} 177$ & 863 \\
\hline Benin & 2009 & 872 & 1'343 \\
\hline Bhutan & 2009 & Sin dato & Sin dato \\
\hline Bolivia & 2006 & $41^{\prime} 004$ & $11^{\prime} 743$ \\
\hline Bosnia Herzegovina & 2009 & 580 & 27 \\
\hline Brasil & 2007 & $1^{\prime} 765^{\prime} 793$ & $7^{\prime} 250$ \\
\hline Bulgaria & 2009 & $12^{\prime} 320$ & 379 \\
\hline Burkina Faso & 2009 & $14^{\prime} 693$ & $27^{\prime} 748$ \\
\hline Burundi & 2009 & 350 & 23 \\
\hline Cambodia & 2009 & $10^{\prime} 725$ & $8^{\prime} 841$ \\
\hline Camerún & 2009 & 292 & 126 \\
\hline Canada & 2009 & $703^{\prime} 678$ & 4'128 \\
\hline Chad & 2009 & Sin dato & Sin dato \\
\hline Channel Islands & 2008 & 430 & Sin dato \\
\hline Chile & 2009 & $82^{\prime} 327$ & 529 \\
\hline China & 2008 & 1'853'000 & Sin dato \\
\hline Chipre & 2009 & 3'816 & 732 \\
\hline Colombia & jun-10 & $42 ' 235$ & $5^{\prime} 704$ \\
\hline Comoros & 2009 & 1'330 & $1^{\prime} 514$ \\
\hline Congo & 2009 & $6^{\prime} 667$ & 1'117 \\
\hline Corea & 2009 & $13^{\prime} 343$ & $9^{\prime} 403$ \\
\hline Costa de Marfil & 2009 & $17^{\prime} 443$ & 265 \\
\hline Costa Rica & 2009 & $8^{\prime} 058$ & $3^{\prime} 000$ \\
\hline
\end{tabular}




\begin{tabular}{|c|c|c|c|}
\hline Croacia & 2009 & $14 ' 194$ & 817 \\
\hline Cuba & 2008 & $14^{\prime} 314$ & $2^{\prime} 467$ \\
\hline Dinamarca & 2009 & $156^{\prime} 433$ & $2^{\prime} 694$ \\
\hline Ecuador & 2009 & 69'358 & $13^{\prime} 930$ \\
\hline EE.UU & 2008 & 1'948'946 & $12^{\prime} 941$ \\
\hline Egipto & 2009 & $56 ' 000$ & 790 \\
\hline El Salvador & $2008 / 2009$ & 6'736 & $2^{\prime} 000$ \\
\hline Emiratos Árabes & 2009 & 373 & 8 \\
\hline España & 2009 & 1'330'774 & $25^{\prime} 291$ \\
\hline Estonia & 2009 & $95^{\prime} 167$ & 1'277 \\
\hline Ethiopia & 2009 & $122^{\prime} 727$ & $101^{\prime} 577$ \\
\hline Fiji & 2005 & 100 & Sin dato \\
\hline Filipinas & 2009 & $52 ' 546$ & 3'051 \\
\hline Finlandia & 2009 & $166^{\prime} 171$ & $4^{\prime} 087$ \\
\hline France & 2009 & $677^{\prime} 513$ & $16^{\prime} 446$ \\
\hline Georgia & 2009 & 1'208 & $1^{\prime} 044$ \\
\hline Ghana & 2009 & $29^{\prime} 140$ & 9'691 \\
\hline Granada & 2009 & 40 & Sin dato \\
\hline Grecia & 2009 & $326^{\prime} 252$ & $23^{\prime} 665$ \\
\hline Guadalupe (Francia) & 2009 & 83 & 26 \\
\hline Guatemala & 2009 & $13^{\prime} 300$ & 3'059 \\
\hline Guayaba Francesa & 2009 & $2^{\prime} 651$ & 18 \\
\hline Guyana & 2009 & $4^{\prime} 249$ & 74 \\
\hline Haití & 2009 & 54 & 40 \\
\hline Holanda & 2009 & $51 ' 911$ & $1^{\prime} 413$ \\
\hline Honduras & 2009 & $11^{\prime} 801$ & $1^{\prime} 113$ \\
\hline Hungría & 2009 & $140 ' 292$ & $1^{\prime} 617$ \\
\hline India & $2009 / 2010$ & 1'180'000 & $677^{\prime} 2571$ \\
\hline Indonesia & 2009 & $52 ' 133$ & 9'981 \\
\hline Irán & 2009 & $18^{\prime} 353$ & 700 \\
\hline Irlandia & 2009 & $47^{\prime} 864$ & 1'328 \\
\hline Islandia & 2009 & $6^{\prime} 661$ & 28 \\
\hline Islas Faroe & 2009 & 12 & Sin dato \\
\hline Islas Malvinas & 2009 & $395^{\prime} 935$ & 8 \\
\hline Islas Solomon & 2006 & 3'628 & 352 \\
\hline Isltas Cook & 2009 & 4 & 12 \\
\hline Israel & Oct/Sept 2009 & 6'969 & 393 \\
\hline Italia & 2009 & 1'106'684 & $43^{\prime} 029$ \\
\hline Jamaica & 2009 & 542 & 80 \\
\hline Japón & 2009 & $8^{\prime} 817$ & $3^{\prime} 815$ \\
\hline
\end{tabular}




\begin{tabular}{|c|c|c|c|}
\hline Jordania & 2009 & 1'053 & 16 \\
\hline Kazakistán & 2009 & $134 ' 862$ & 8 \\
\hline Kenya & 2009 & $4^{\prime} 227$ & $2^{\prime} 188$ \\
\hline Kyrgyzstan & 2009 & $11^{\prime} 415$ & $1^{\prime} 020$ \\
\hline Laos & 2009 & $4^{\prime} 878$ & $2^{\prime} 178$ \\
\hline Latvia & 2009 & $160^{\prime} 175$ & $4^{\prime} 016$ \\
\hline Lesotho & 2009 & 330 & 2 \\
\hline Líbano & 2009 & 3'332 & 267 \\
\hline Liechtenstein & 2009 & 1'005 & 32 \\
\hline Lituania & 2009 & $129^{\prime} 055$ & $2^{\prime} 652$ \\
\hline Luxemburgo & 2009 & 3'614 & 77 \\
\hline Macedonia & 2009 & $1^{\prime} 489$ & 99 \\
\hline Madagascar & 2009 & $14^{\prime} 069$ & $4^{\prime} 289$ \\
\hline Malasia & 2009 & 1'582 & 24 \\
\hline Malawi & 2009 & 994 & 9'003 \\
\hline Mali & 2009 & $21^{\prime} 681$ & 9'986 \\
\hline Malta & 2009 & 26 & 12 \\
\hline Marruecos & 2009 & $3^{\prime} 800$ & Sin dato \\
\hline Martinica (France) & 2009 & 141 & 27 \\
\hline Mauritius & 2009 & 6 & Sin dato \\
\hline México & 2008 & $332^{\prime} 485$ & $128^{\prime} 862$ \\
\hline Moldova & 2009 & $32 ' 105$ & 166 \\
\hline Montenegro & 2009 & $4^{\prime} 603$ & 29 \\
\hline Mozambique & 2009 & 1'556 & 395 \\
\hline Myanmar & 2009 & 555 & 6 \\
\hline Namibia & 2009 & 124 & 7961 \\
\hline Nepal & 2009 & $8^{\prime} 059$ & $1^{\prime} 470$ \\
\hline Nicaragua & 2009 & $33^{\prime} 621$ & $10^{\prime} 060$ \\
\hline Niger & 2009 & 355 & Sin dato \\
\hline Nigeria & 2009 & $8^{\prime} 202$ & 519 \\
\hline Niue & 2006 & 159 & 61 \\
\hline Noruega & 2009 & $56^{\prime} 737$ & $2^{\prime} 851$ \\
\hline Nueva Zelanda & 2009 & $124^{\prime} 463$ & $1^{\prime} 000$ \\
\hline Oman & 2009 & 39 & 4 \\
\hline Pakistan & 2009 & $20^{\prime} 321$ & $1^{\prime} 045$ \\
\hline Palestina & 2009 & $1^{\prime} 000$ & 500 \\
\hline Panamá & 2004 & $5^{\prime} 244$ & 7 \\
\hline Papua Nueva Guinea & 2009 & 3'321 & 4'559 \\
\hline Paraguay & 2007 & $51^{\prime} 190$ & $11^{\prime} 401$ \\
\hline Perú & 2009 & $186^{\prime} 314$ & $54 ' 904$ \\
\hline Polonia & 2009 & $367^{\prime} 062$ & $17^{\prime} 092$ \\
\hline Portugal & 2009 & $209^{\prime} 090$ & 1'902 \\
\hline Reino Unido & 2009 & $721^{\prime} 726$ & 5'156 \\
\hline
\end{tabular}




\begin{tabular}{|c|c|c|c|}
\hline República Checa & 2009 & $398^{\prime} 407$ & $2^{\prime} 665$ \\
\hline República Dominicana & 2009 & $161^{\prime} 098$ & $23 ' 371$ \\
\hline Réunion (France) & 2009 & 188 & 50 \\
\hline Romania & 2009 & $168^{\prime} 288$ & $3^{\prime} 078$ \\
\hline Rusia & 2009 & $78^{\prime} 449$ & 40 \\
\hline Rwanda & 2009 & 3'697 & 536 \\
\hline Samoa & 2009 & $9^{\prime} 714$ & 353 \\
\hline Santo Tomé y Principe & 2009 & 3'591 & 1'791 \\
\hline Senegal & 2009 & $25^{\prime} 351$ & $21^{\prime} 662$ \\
\hline Serbia & 2009 & $8^{\prime} 661$ & 2'969 \\
\hline Sierra Leona & 2009 & $72^{\prime} 472$ & $22 ' 515$ \\
\hline Siria & 2009 & $35^{\prime} 439$ & 204 \\
\hline Slovakia & 2009 & $145^{\prime} 490$ & 363 \\
\hline Slovenia & 2009 & $29 ' 388$ & $2^{\prime} 096$ \\
\hline Sri Lanka & 2009 & $21^{\prime} 156$ & 687 \\
\hline Suazilandia & 2009 & 46 & 2 \\
\hline Sudáfrica & 2009 & $59 ' 562$ & 689 \\
\hline Sudan & 2009 & 77'798 & 1'003 \\
\hline Suecia & 2009 & $391 ' 524$ & $4^{\prime} 816$ \\
\hline Suiza & 2009 & $114^{\prime} 050$ & 5'943 \\
\hline Surinam & 2009 & 8 & Sin dato \\
\hline Tailandia & 2009 & $29 ' 597$ & 5'358 \\
\hline Taiwan & 2009 & 2'962 & 1'277 \\
\hline Tajikistan & 2009 & 70 & 39 \\
\hline Tanzania & 2008 & $72^{\prime} 188$ & $85^{\prime} 366$ \\
\hline Timor-Leste & 2009 & 24'997 & 71 \\
\hline Togo & 2009 & 1'789 & $6^{\prime} 657$ \\
\hline Túnez & 2009 & $167 ' 302$ & 1'792 \\
\hline Turquía & 2009 & $325^{\prime} 831$ & $35^{\prime} 565$ \\
\hline Ucrania & 2009 & $271 ' 315$ & 121 \\
\hline Uganda & $2009 / 2010$ & $226^{\prime} 954$ & $187^{\prime} 893$ \\
\hline Uruguay & 2006 & 930 '965 & 630 \\
\hline Uzbekistan & 2009 & 324 & 5 \\
\hline Vanuatu & 2006 & 8'996 & Sin dato \\
\hline Venezuela & 2009 & 337 & 4 \\
\hline Vietnam & 2009 & $14 ' 012$ & $2^{\prime} 002$ \\
\hline Zambia & 2009 & 7'310 & $10^{\prime} 055$ \\
\hline Zimbawe & 2009 & 421 & 230 \\
\hline
\end{tabular}

Fuente: FiBL/IFOAM 2011. Datos de gobiernos, sector privado y certificadoras Willer, H. y Kilcher, L. 2011: The World of Organic Agriculture. 


\section{Detalle de áreas de producción de espárragos por continente}

Tabla $\mathrm{N}^{\circ}$ 25: Áreas producción asiática espárragos año 2010, cambios en hectáreas y los rendimientos promedios:

\begin{tabular}{|c|c|c|c|c|c|c|c|c|}
\hline ASIA & Hectáreas & Crecimiento & Rinde $\mathbf{k g} / \mathbf{h a}$ & Verde & Blanco & Fresco & Conserva & Congelado \\
\hline China & 57.000 & $\downarrow$ & 11.000 & $50 \%$ & $50 \%$ & $30 \%$ & $60 \%$ & $10 \%$ \\
\hline Japón & 7.000 & $=$ & 6.000 & $99 \%$ & $1 \%$ & $90 \%$ & $5 \%$ & $5 \%$ \\
\hline Tailandia & 3.000 & $\uparrow$ & 11.500 & $98 \%$ & $2 \%$ & $95 \%$ & $5 \%$ & - \\
\hline Taiwan & 1.500 & $\downarrow$ & 7.000 & $100 \%$ & - & $90 \%$ & $5 \%$ & $5 \%$ \\
\hline Filipinas & 1.400 & $\downarrow$ & 13.000 & $100 \%$ & - & $100 \%$ & - & - \\
\hline TOTAL & $\mathbf{6 9 . 9 0 0}$ & \multicolumn{7}{|c|}{ Fuente: Christian Befve año 2011. Website: www.befve.com } \\
\hline
\end{tabular}

Tabla N 26: Áreas producción norteamericana espárragos año 2010, cambios en área y rendimientos promedios:

\begin{tabular}{|c|c|c|c|c|c|c|c|c|}
\hline NORTEAMÉRICA & Hectáreas & Crecimiento & Rinde $\mathbf{k g} / \mathbf{h a}$ & Verde & Blanco & Fresco & Conserva & Congelado \\
\hline EE.UU. & 14.400 & $\downarrow$ & 3.700 & $98 \%$ & $2 \%$ & $90 \%$ & $5 \%$ & $5 \%$ \\
\hline Mexico & 19.000 & $\uparrow$ & 4.500 & $98 \%$ & $2 \%$ & $90 \%$ & - & $10 \%$ \\
\hline Canadá & 1.200 & $\downarrow$ & 4.000 & $98 \%$ & - & $97 \%$ & $1 \%$ & $2 \%$ \\
\hline TOTAL & 34.600 & \multicolumn{7}{|c|}{ Fuente: Christian Befve año 2011. Website: www.befve.com } \\
\hline
\end{tabular}

Tabla $N^{\circ}$ 27: Áreas producción latinoamericana espárragos año 2010, cambios en área y rendimientos promedios:

\begin{tabular}{|c|c|c|c|c|c|c|c|c|}
\hline AMÉRICA LATINA & Hectáreas & Crecimiento & Rinde $\mathbf{k g} / \mathbf{h a}$ & Verde & Blanco & Fresco & Conserva & Congelado \\
\hline Perú & 27.000 & $=$ & 8.740 & $80 \%$ & $20 \%$ & $60 \%$ & $30 \%$ & $10 \%$ \\
\hline Chile & 2.700 & $=$ & 5.500 & $100 \%$ & - & $40 \%$ & - & $60 \%$ \\
\hline Argentina & 500 & $\downarrow$ & 4.500 & $80 \%$ & $20 \%$ & $85 \%$ & $5 \%$ & $10 \%$ \\
\hline Colombia & 900 & $=$ & 4.700 & $100 \%$ & - & $100 \%$ & - & - \\
\hline Brasil & 400 & $\uparrow$ & 5.700 & $20 \%$ & $80 \%$ & $90 \%$ & - & $10 \%$ \\
\hline Ecuador & 300 & $\downarrow$ & 5.200 & $100 \%$ & - & $100 \%$ & - & - \\
\hline Uruguay & 50 & $\downarrow$ & 5.100 & $100 \%$ & - & $90 \%$ & - & $10 \%$ \\
\hline Guatemala & 50 & $\downarrow$ & 4.200 & $100 \%$ & - & $100 \%$ & - \\
\hline Nicaragua & 100 & $\downarrow$ & 4.500 & $100 \%$ & - & $90 \%$ & - \\
\hline TOTAL & 32.000 & \multicolumn{7}{|c|}{ Fuente: Christian Befve año 2011. Website: www.befve.com } \\
\hline
\end{tabular}


Tabla $N^{\circ}$ 28: Producción africana espárragos año 2010, cambios en el área y los rendimientos promedios:

\begin{tabular}{|c|c|c|c|c|c|c|c|c|}
\hline AFRICA & Hectáreas & Crecimiento & Rinde $\mathbf{k g} / \mathbf{h a}$ & Verde & Blanco & Fresco & Conserva & Congelado \\
\hline Sudáfrica & 1.200 & $=$ & 3.600 & $70 \%$ & $30 \%$ & $70 \%$ & $30 \%$ & - \\
\hline Marruecos & 800 & $\downarrow$ & 4.500 & $20 \%$ & $80 \%$ & $100 \%$ & - & - \\
\hline Egipto & 200 & $\uparrow$ & 5.600 & $25 \%$ & $75 \%$ & $100 \%$ & - & - \\
\hline Kenya & 200 & $\uparrow$ & 5.700 & $100 \%$ & - & $100 \%$ & - & - \\
\hline Túnez & 150 & $=$ & 3.500 & $40 \%$ & $60 \%$ & $100 \%$ & - & - \\
\hline TOTAL & $\mathbf{2 . 5 5 0}$ & \multicolumn{7}{|c|}{ Fuente: Christian Befve año 2011. Website: www.befve.com } \\
\hline
\end{tabular}

Tabla N 29: Áreas Oceanía producción espárragos año 2010, cambios en área y rendimientos promedios:

\begin{tabular}{|c|c|c|c|c|c|c|c|c|}
\hline OCEANÍA & Hectáreas & Crecimiento & Rinde $\mathbf{k g} / \mathbf{h a}$ & Verde & Blanco & Fresco & Conserva & Congelado \\
\hline Australia & 2.000 & $\downarrow$ & 6.100 & $95 \%$ & $5 \%$ & $90 \%$ & $10 \%$ & - \\
\hline Nueva Zelanda & 1.000 & $=$ & 4.700 & $95 \%$ & $5 \%$ & $70 \%$ & $20 \%$ & $10 \%$ \\
\hline TOTAL & 3.000 & \multicolumn{6}{|c|}{ Fuente: Christian Befve año 2011. Website: www.befve.com } \\
\hline
\end{tabular}

Tabla N 30: Áreas europeas producción espárragos año 2010, cambios en área y rendimientos promedios:

\begin{tabular}{|c|c|c|c|c|c|c|c|c|}
\hline EUROPA & Hectáreas & Crecimiento & Rinde $\mathbf{k g} / \mathbf{h a}$ & Verde & Blanco & Fresco & Conserva & Congelado \\
\hline Alemania & 18.814 & $=$ & 6.200 & $5 \%$ & $95 \%$ & $100 \%$ & - & - \\
\hline España & 11.000 & $\downarrow$ & 6.500 & $70 \%$ & $30 \%$ & $70 \%$ & $20 \%$ & $10 \%$ \\
\hline Francia & 7.400 & $\uparrow$ & 5.000 & $15 \%$ & $85 \%$ & $100 \%$ & - & - \\
\hline Grecia & 5.000 & $=$ & 4.300 & $3 \%$ & $97 \%$ & $100 \%$ & - & - \\
\hline Italia & 6.500 & $=$ & 6.800 & $80 \%$ & $20 \%$ & $90 \%$ & - & $10 \%$ \\
\hline Holanda & 2.600 & $\uparrow$ & 6.600 & $5 \%$ & $95 \%$ & $95 \%$ & - & $5 \%$ \\
\hline Polonia & 1.800 & $\uparrow$ & 3.300 & $5 \%$ & $95 \%$ & $90 \%$ & $10 \%$ & - \\
\hline Inglaterra & 1.500 & $\uparrow$ & 3.500 & $100 \%$ & $0 \%$ & $100 \%$ & - & - \\
\hline Hungría & 1.200 & $\uparrow$ & 4.500 & $5 \%$ & $95 \%$ & $100 \%$ & - & - \\
\hline Bélgica & 400 & $\uparrow$ & 5.100 & $5 \%$ & $95 \%$ & $100 \%$ & - & - \\
\hline Austria & 500 & $\uparrow$ & 5.200 & $2 \%$ & $98 \%$ & $100 \%$ & - & - \\
\hline TOTAL & 56.714 & & & Fuente: Christian Befve año 2011. Website: www.befve.com \\
\hline
\end{tabular}




\subsection{Estacionalidad de la producción espárragos}

Tabla $\mathrm{N}^{\circ}$ 31: Estacionalidad de la producción de los productores de espárragos.

\begin{tabular}{|c|c|c|c|c|c|c|c|c|c|c|c|c|}
\hline & Ene & Feb & Mar & $A b r$ & May & Jun & Jul & Ago & Sep & Oct & Nov & Dic \\
\hline \multicolumn{13}{|c|}{$A S I A$} \\
\hline China & & & & & & & 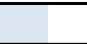 & & 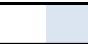 & & & \\
\hline India & & & & & & & & & & & & \\
\hline Indonesia & & & & & & & & & & & & \\
\hline Israel & & & & & & & & & & & & \\
\hline Irán & & & & & & & & & & & & \\
\hline Japón & & & & & & & & & & & & \\
\hline Corea & & & & & & & & & & & & \\
\hline Malasia & & & & & & & & & & & & \\
\hline Pakistan & & & & & & & & & & & & \\
\hline Filipinas & & & & & & & & & & & & \\
\hline Taiwan & & & & & & & & & & & & \\
\hline Tailandia & & & & & & & & & & & & \\
\hline Turquía & & & & & & & & & & & & \\
\hline Vietnam & & & & & & & & & & & & \\
\hline & & & & & & $O P E$ & & & & & & \\
\hline Austria & & & & & & & & & & & & \\
\hline Bélgica & & & & & & & & & & & & \\
\hline Bulgaria & & & & & & & & & & & & \\
\hline Chipre & & & & & & & & & & & & \\
\hline R. Checa & & & & & & & E & & & & & \\
\hline Dinamarca & & & & & & & & & & & & \\
\hline Francia & & & & & & & & & & & & \\
\hline Alemania & & & & & & & & & & & & \\
\hline Grecia & & & & & & & & & & & & \\
\hline Hungría & & & & & & & & & & & & \\
\hline Italia & & & & & & & & & & & & \\
\hline Moldova & & & & & & & & & & & & \\
\hline Holanda & & & & & & & & & & & & \\
\hline Noruega & & & & & & & & & & & & \\
\hline Polonia & & & & & & & & & & & & \\
\hline Portugal & & & & & & & & & & & & \\
\hline Rumania & & & 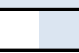 & & & & & & & & & \\
\hline Eslovaquia & & & & . & & & & & & & & \\
\hline Eslovenia & & & & & & & & & & & & \\
\hline España & & & & & & & 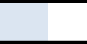 & & & & & \\
\hline Suiza & & & & & & & & & & & & \\
\hline Reino Unido & & & & & & & & & & & & \\
\hline
\end{tabular}




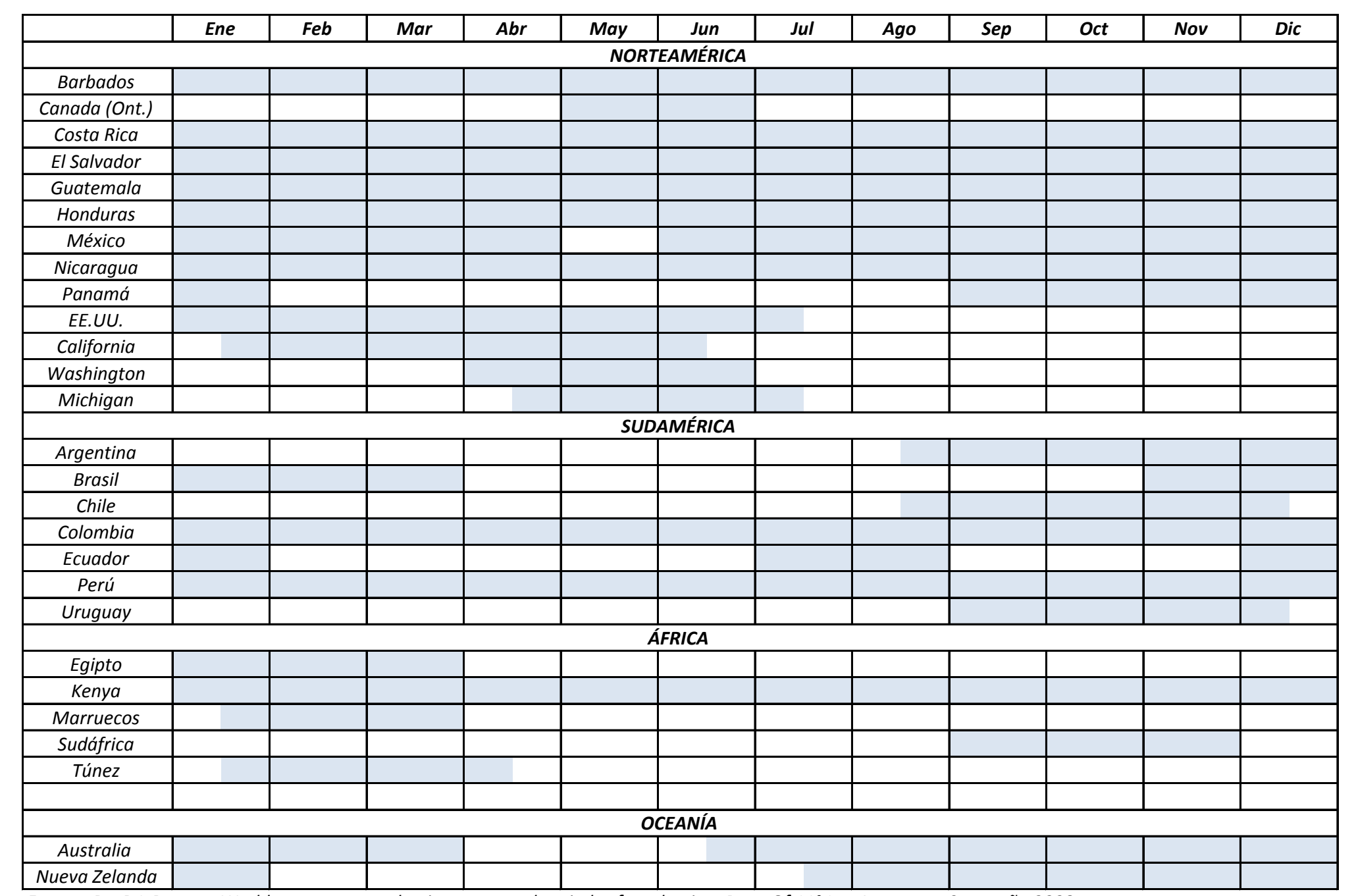

Fuente: Dr. B.L.Benson. World asparagus production areas and periods of production. Proc. Of $11^{\circ}$ Int. Asparagus Symp.año 2008

\subsection{Costos de mano de obra por kilo cosechado}

En base a trabajos realizados por el Dr. Christian Befve, se establecen los costos de mano de obra para la cosecha del espárrago.

Tal como ocurre con diversos productos, China, posee los costos más bajos en lo que a cosecha se refiere. Más allá de estos bajos costos, hay que recordar que el nombrado país, apunta su producción a espárragos en conserva. Para el caso de nuestro país, vemos que si comparamos lo acaecido en otros países competidores latinoamericanos, nos encontramos en una situación de desventaja, debido a que nuestros costos son casi el doble de lo que ocurre por ejemplo en Chile, superando ampliamente lo que ocurre en el Perú. 
Gráfico $N^{\circ}$ 52: Costos de mano de obra por kilogramo cosechado año 2010:

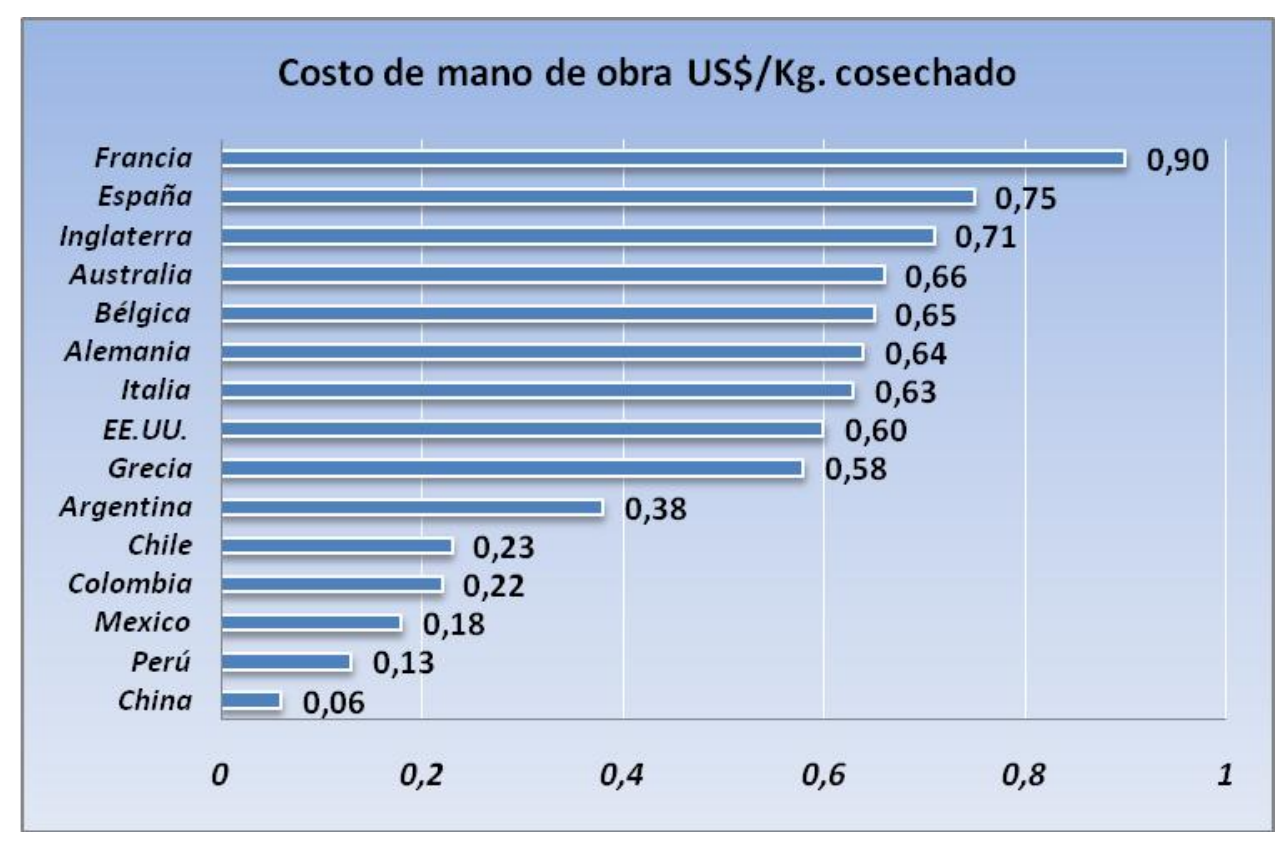

Fuente: Dr. Christian Befve 2010. 


\section{Situación argentina respecto de la agricultura orgánica}

\subsection{Superficie bajo seguimiento y tamaño medio de las explotaciones}

La superficie bajo seguimiento orgánico en el país aumentó el 10\% y alcanzó durante el año 2010 las 4,4 millones de hectáreas. De estas la superficie más significativa está dedicada a la producción ganadera con 3,9 millones de hectáreas, y más de 435 mil hectáreas correspondieron a superficie destinada a producción vegetal.

El número de explotaciones agropecuarias bajo seguimiento mostró un leve crecimiento.

Tabla $N^{\circ}$ 34: Establecimientos y superficie bajo seguimiento por provincias al año 2010.

\begin{tabular}{|c|c|c|c|c|c|c|c|c|}
\hline \multicolumn{9}{|c|}{ Establecimientos y superficie bajo seguimiento por provincias. Año 2010.} \\
\hline \multirow{3}{*}{ Provincia } & \multirow{2}{*}{\multicolumn{2}{|c|}{ Establecimientos (*) }} & \multicolumn{6}{|c|}{ Superficie $(* *)$} \\
\hline & & & \multicolumn{3}{|c|}{ Total de Establecimientos } & \multicolumn{3}{|c|}{ Superficie bajo seguimiento } \\
\hline & Cantidad & $\%$ & hectáreas & $\%$ pcial. & Media (ha) & (ha) & $\%$ pcial. & Media (ha) \\
\hline Buenos Aires & 229 & 12 & 285.631 & 7 & 1.269 & 278.069 & 7 & 1.236 \\
\hline Catamarca & 16 & 1 & 36.586 & 1 & 2.287 & 13.174 & 0 & 823 \\
\hline Chaco & 19 & 1 & 43.478 & 1 & 6.211 & 41.818 & 1 & 5.974 \\
\hline Chubut & 67 & 4 & 1.643 .875 & 37 & 24.535 & 1.572 .637 & 38 & 23.472 \\
\hline Córdoba & 37 & 2 & 25.349 & 1 & 1.152 & 9.482 & 0 & 431 \\
\hline Corrientes & 18 & 1 & 74.128 & 2 & 4.118 & 74.031 & 2 & 4.113 \\
\hline Entre Ríos & 56 & 3 & 55.046 & 1 & 1.529 & 48.952 & 1 & 1.360 \\
\hline Formosa & 220 & 12 & 14.603 & 0 & 2.434 & 13.861 & 0 & 2.310 \\
\hline Jujuy & 9 & 1 & 14.311 & 0 & 1.590 & 2.684 & 0 & 298 \\
\hline La Pampa & 20 & 1 & 68.156 & 2 & 6.816 & 67.074 & 2 & 6.707 \\
\hline La Rioja & 26 & 1 & 6.308 & 0 & 252 & 4.136 & 0 & 165 \\
\hline Mendoza & 232 & 13 & 31.817 & 1 & 149 & 29.126 & 1 & 136 \\
\hline Misiones & 474 & 26 & 18.108 & 0 & 38 & 9.611 & 0 & 20 \\
\hline Neuquén & 63 & 3 & 3.013 & 0 & 49 & 2.048 & 0 & 34 \\
\hline Río Negro & 168 & 9 & 333.662 & 8 & 1.986 & 319.656 & 8 & 1.903 \\
\hline Salta & 26 & 1 & 132.524 & 3 & 5.097 & 87.843 & 2 & 3.379 \\
\hline San Juan & 55 & 3 & 4.414 & 0 & 80 & 2.692 & 0 & 49 \\
\hline San Luis & 12 & 1 & 11.066 & 0 & 1.107 & 11.066 & 0 & 1.107 \\
\hline Santa Cruz & 18 & 1 & 1.289 .150 & 29 & 71.619 & 1.289 .150 & 31 & 71.619 \\
\hline Santa Fe & 26 & 1 & 21.183 & 1 & 1.513 & 15.014 & 0 & 1.072 \\
\hline Sgo. del Estero & 48 & 3 & 1.439 & 0 & 240 & 448 & 0 & 75 \\
\hline Tierra del Fuego & 6 & 0 & 277.796 & 6 & 46.299 & 277.796 & 7 & 46.299 \\
\hline Tucumán & 11 & 1 & 9.006 & 0 & 819 & 8.653 & 0 & 787 \\
\hline Total del Pais & 1.856 & 100 & 4.400 .649 & 100 & 2.926 & 4.179 .021 & 100 & 2.779 \\
\hline
\end{tabular}

Fuente: SENASA 2011. En base a información de Certificadoras.

$\left({ }^{*}\right)$ Incluye además a los establecimientos exclusivamente apicolas.

$\left.{ }^{* *}\right)$ No Incluye a los establecimientos exclusivamente apícolas. 
La provincia de Misiones presentó el mayor porcentaje de unidades productivas bajo seguimiento (26\%), manteniendo su importancia relativa con respecto al año 2009, debido a un importante número de pequeños productores reunidos en forma cooperativa. Se sigue destacando Mendoza con el 13\% de las unidades productivas.

En unidades productivas se destacó la provincia de Formosa la que desplazó a Río Negro del cuarto lugar.

Las provincias patagónicas de Chubut, Santa Cruz y Tierra del Fuego poseen grandes explotaciones dedicadas a la ganadería ovina orgánica. Dichas provincias suman el $76 \%$ de la superficie bajo seguimiento con sólo el 5\% de las explotaciones del país. La superficie promedio de las explotaciones bajo seguimiento fue de 80 mil hectáreas en Santa Cruz, más de 46 mil hectáreas en Tierra del Fuego y de 24,5 mil hectáreas en Chubut.

\subsection{Superficie agrícola orgánica bajo seguimiento}

Más de 435 mil hectáreas correspondieron a superficie bajo seguimiento destinada a agricultura orgánica. En comparación con el 2009 se destaca el aumento de la participación de la provincia de Buenos Aires que pasó del $36 \%$ al $40 \%$ de la superficie bajo seguimiento destinada a producción vegetal, encabezando la lista en orden de importancia.

Le siguen Salta con el $20 \%$ y Río Negro con el $8 \%$ de la superficie bajo seguimiento destinada a producción vegetal.

\subsection{Superficie orgánica cosechada}

Durante 2010 la superficie cosechada alcanzó un nivel de 69.339 mostrando un comportamiento ascendente en comparación al año 2009 (56.290 hectáreas) pero esto no alcanzó a los niveles del año 2008 que alcanzaron las 71.298 hectáreas. 
Tabla ํ3ㄴ Superficie Orgánica Cosechada por Grupos de Cultivos. (Ha) Año 2010.

\begin{tabular}{|c|c|c|c|c|c|c|c|c|c|}
\hline \multicolumn{9}{|c|}{ Superficie Orgánica Cosechada por Grupos de Cultivos. (ha) Año 2010 } \\
\hline Provincia & Cereales & Oleaginosas & $\begin{array}{c}\text { Cultivos } \\
\text { Industriales }\end{array}$ & Aromáticas & Hortalizas & Legumbres & Frutales & Otras & Total \\
\hline Buenos Aires & 17.195 & 11.283 & 1.361 & 90 & 254 & - & 58 & - & $\mathbf{3 0 . 2 4 1}$ \\
\hline Catamarca & - & - & 415 & - & 50 & - & - & - & $\mathbf{4 6 5}$ \\
\hline Chaco & - & - & - & - & 16 & - & 69 & - & 85 \\
\hline Chubut & 3 & - & - & 2 & 3 & - & 24 & 3 & $\mathbf{3 5}$ \\
\hline Córdoba & 685 & 1.291 & 1.091 & 16 & 26 & - & 14 & - & $\mathbf{3 . 1 2 3}$ \\
\hline Corrientes & 38 & - & - & - & 11 & - & 106 & - & $\mathbf{1 5 5}$ \\
\hline Entre Ríos & 3.981 & 1.825 & - & - & - & 10 & 10 & - & $\mathbf{5 . 8 2 6}$ \\
\hline Formosa & - & - & 5 & - & 11 & - & 72 & - & $\mathbf{8 8}$ \\
\hline Jujuy & - & - & 1.044 & - & - & - & - & - & $\mathbf{1 . 0 4 4}$ \\
\hline La Pampa & 45 & 35 & - & - & - & - & - & - & $\mathbf{8 0}$ \\
\hline La Rioja & - & - & 1.109 & 1 & - & - & - & - & $\mathbf{1 . 1 1 0}$ \\
\hline Mendoza & 1 & - & 2.302 & 9 & 497 & - & 738 & 31 & $\mathbf{3 . 5 7 8}$ \\
\hline Misiones & - & 187 & 1.768 & - & - & - & 2 & - & $\mathbf{1 . 9 5 7}$ \\
\hline Neuquén & - & - & - & - & 20 & - & 1.293 & 27 & $\mathbf{1 . 3 4 0}$ \\
\hline Río Negro & 5.013 & 2.601 & 98 & - & 107 & - & 2.598 & 4 & $\mathbf{1 0 . 4 2 1}$ \\
\hline Salta & - & 1.176 & 3.796 & - & - & 907 & - & - & 5.879 \\
\hline San Juan & 1 & - & 1.179 & - & 68 & - & 1 & 1 & $\mathbf{1 . 2 5 0}$ \\
\hline San Luis & - & 285 & 3 & 12 & 4 & - & 3 & - & $\mathbf{3 0 7}$ \\
\hline Santa Fe & 408 & 1.348 & - & - & 4 & - & - & - & $\mathbf{1 . 7 6 0}$ \\
\hline Sgo. del Estero & - & - & - & - & 7 & - & - & - & $\mathbf{7}$ \\
\hline Tucumán & - & - & - & - & 21 & - & 567 & - & $\mathbf{5 8 8}$ \\
\hline TOTAL & $\mathbf{2 7 . 3 7 0}$ & $\mathbf{2 0 . 0 3 1}$ & $\mathbf{1 4 . 1 7 1}$ & $\mathbf{1 3 0}$ & $\mathbf{1 . 0 9 9}$ & $\mathbf{9 1 7}$ & $\mathbf{5 . 5 5 5}$ & $\mathbf{6 6}$ & $\mathbf{6 9 . 3 3 9}$ \\
\hline
\end{tabular}

Fuente: SENASA 2011. En base a información de Certificadoras.

Por grupo de productos: La distribución de la superficie orgánica cosechada mostró mayor participación de la producción de cereales y oleaginosas orgánicos (60\%), seguida por los cultivos industriales orgánicos (27\%), las frutas (9\%) y las hortalizas y legumbres orgánicas (4\%).

Distribución regional: Con respecto a la distribución regional de la superficie cosechada, se observa que la provincia de Buenos Aires mostró 30.241 hectáreas, lo que equivale al $43 \%$ de la superficie orgánica cosechada. Las provincias de San Luis, Salta y Misiones también han presentado una importante reducción pero de mucho menor magnitud que en Buenos Aires. Por otra parte se observó un aumento importante de la superficie cosechada en la provincia de Río Negro donde se alcanzó 5.013 hectáreas cosechadas, principalmente con cultivos de cereales. 
En 2010 los Cereales y Oleaginosas, al igual que en años anteriores, se cultivaron principalmente en la provincia de Buenos Aires (52\%). Entre Ríos se mantiene en el segundo lugar con el 20\% y Río Negro volvió a mostrar un importante aumento alcanzando el 15\% de la superficie.

Las principales provincias productoras de Cultivos Industriales fueron Salta (28\%); La Rioja (15\%) y Mendoza (14\%).

Con relación a la superficie cosechada de frutas, la misma prácticamente no varió. Las principales provincias fueron Río Negro (46\%); Neuquén (24\%); Tucumán (12\%) y Mendoza (11\%); quienes contaron principalmente con cultivos de pepita, carozo y en el caso de Tucumán, limones y arándanos. 


\section{Detalle de la Norma Internacional de Calidad}

Para el ingreso en la Unión Europea, se exige el cumplimiento de normas de calidad según el Reglamento: UN/ECE FFV-04 relativa a la comercialización y control de calidad comercial de los ESPÁRRAGOS.

\section{Definición del Producto}

Esta norma se aplica a los brotes de las variedades (cultivares) obtenidas de Asparagus officinalis L. que habrán de suministrarse frescos al consumidor. Se excluyen los espárragos destinados a la elaboración industrial.

Los brotes de espárragos se clasifican en cuatro grupos según el color:

- espárragos blancos

- espárragos violetas, que tienen puntas de un color entre rosado y violeta o púrpura y una parte del brote blanca

- espárragos violeta/verdes, parte de los cuales es de color violeta y verde

- espárragos verdes que tienen la punta y la mayor parte del brote de color verde

Ésta Norma no se aplica a los espárragos de color verde y violeta/verde con un diámetro inferior a 6 milímetros ni a los espárragos blancos y violetas con un diámetro inferior a 8 milímetros, presentados en manojos uniformes o envases unitarios.

\section{Disposiciones relativas a la calidad}

La Norma tiene por objeto determinar los requisitos de calidad de los espárragos en la fase de control de la exportación, después de la preparación y el envasado.

\section{A. Requisitos mínimos}

En todas las categorías, de conformidad con las disposiciones especiales establecidas para cada categoría y las tolerancias permitidas, los brotes deberán ser:

- intactos 
- sanos; se excluye todo producto afectado por podredumbre o deterioro que haga que no sea apto para el consumo.

- exentos de daños causados por un lavado inadecuado (los brotes podrán haberse lavado pero no "remojado").

- limpios y prácticamente exentos de cualquier materia extraña visible

- de aspecto y aroma frescos

- prácticamente exentos de plagas

- prácticamente exentos de daños causados por plagas

- prácticamente exentos de magulladuras

- exentos de humedad externa anormal, es decir, suficientemente "secados" si se han lavado o refrigerado con agua fría

- exentos de cualquier olor y/o sabor extraños.

- El corte en la base de los brotes deberá ser lo más neto posible.

Además, los brotes no deberán estar huecos, partidos, pelados ni quebrados. Se permiten, sin embargo, pequeñas grietas que hayan aparecido después de la recolección, siempre que no superen los límites que se establecen en la sección IV. A. "Tolerancias de calidad".

El desarrollo y el estado de maduración de los espárragos deberán ser tales que les permitan:

- soportar el transporte y la manipulación; y

- llegar en estado satisfactorio al lugar de destino.

\section{B. Clasificación}

Los espárragos se clasifican en tres categorías, que se definen a continuación:

\section{i) Categoría "extra"}

Los brotes de esta categoría deberán ser de calidad superior, muy bien formados y prácticamente rectos. Teniendo en cuenta las características normales del grupo al que pertenecen, sus puntas deberán ser muy compactas. Sólo se permitirán unos pocos indicios muy leves de roya en los brotes, que puedan ser eliminados por el consumidor mediante un pelado normal. 
En lo que respecta al grupo de los espárragos blancos, las puntas y brotes deberán ser de color blanco; sólo se permite un matiz ligeramente rosado en los brotes. Los espárragos verdes deberán ser completamente verdes. No se permiten indicios de leñosidad en los brotes de esta categoría. El corte en la base de los brotes deberá ser lo más perpendicular posible. No obstante, para mejorar la presentación cuando los espárragos se envasan en manojos, los que se encuentran en la parte externa podrán ser ligeramente biselados, siempre que el biselado no supere 1 centímetro.

\section{ii) Categoría I}

Los brotes de esta categoría deberán ser de buena calidad y estar bien formados. Podrán ser ligeramente curvados. Teniendo en cuenta las características normales del grupo al que pertenecen, sus puntas deberán ser compactas.

Se permiten ligeros indicios de roya que puedan eliminados por el consumidor mediante un pelado normal.

En lo que respecta al grupo de los espárragos blancos, podrán presentar un matiz ligeramente rosado en las puntas y los brotes.

Los espárragos verdes deberán ser de ese color por lo menos en el 80 por ciento de su longitud.

En el grupo de los espárragos blancos no se permitirán brotes leñosos. Por lo que respecta a otros grupos, es admisible una leve leñosidad en la parte inferior siempre que tal leñosidad desaparezca mediante un pelado normal por el consumidor. El corte en la base de los brotes deberá ser lo más perpendicular posible.

\section{iii) Categoría II}

Esta categoría comprende los brotes que no pueden clasificarse en las categorías superiores, pero satisfacen los requisitos mínimos especificados anteriormente. En comparación con la Categoría I, puede que los brotes no estén tan bien formados y sean más curvos y que, teniendo en cuenta las características normales del grupo al que pertenecen, sus puntas estén ligeramente abiertas. Se permiten indicios de roya que puedan ser eliminados por el consumidor mediante un pelado normal.

Las puntas de los espárragos blancos podrán tener una coloración que incluya un matiz verde.

Las puntas de los espárragos violetas podrán tener un tinte ligeramente verde.

Los espárragos verdes deberán ser de ese color al menos en el 60 por ciento de su longitud. 
Los brotes podrán ser ligeramente leñosos. El corte en la base de los brotes podrá ser ligeramente oblicuo.

\section{Disposiciones sobre la clasificación por calibres}

El calibre se determina por la longitud y el diámetro de los brotes.

A. Determinación del calibre por la longitud

La longitud de los brotes deberá ser:

- $\quad$ superior a $17 \mathrm{~cm}$ para los espárragos largos;

- de 12 a 17 cm para los espárragos cortos;

- para los espárragos de la Categoría II dispuestos ordenadamente pero no presentados en manojos:

a) blancos y violetas: de 12 a $22 \mathrm{~cm}$;

b) violetas/verdes y verdes: de 12 a $27 \mathrm{~cm}$;

- inferior a $12 \mathrm{~cm}$. para las puntas de espárragos.

La longitud máxima permitida para los espárragos blancos y violetas es de $22 \mathrm{~cm}$, y para los espárragos violetas/verdes y verdes de $27 \mathrm{~cm}$.

La diferencia máxima de longitud de los brotes presentados en manojos firmemente sujetos no deberá ser superior a $5 \mathrm{~cm}$.

B. Determinación del calibre por el diámetro

El diámetro de los brotes se medirá en el punto medio de su longitud.

El diámetro mínimo y el calibre serán los siguientes: 
Tabla N ${ }^{\circ}$ 34: Clasificación Europea de espárragos frescos:

\begin{tabular}{|c|c|c|c|c|}
\hline Categoría de Calidad & Grupo de Color & Diámetro mínimo & \multicolumn{2}{|c|}{ Calibre } \\
\hline & Blanco y violeta & $12 \mathrm{~mm}$ & $12 \mathrm{a} 16 \mathrm{~mm}$ & $\begin{array}{c}16 \mathrm{~mm} \text { o mas con una variación } \\
\text { máxima de 8 mm en un solo } \\
\text { envase o manojo }\end{array}$ \\
\hline Violeta/verde y violeta & $10 \mathrm{~mm}$ & $10 \mathrm{a} 16 \mathrm{~mm}$ & 10 a $16 \mathrm{~mm}$ & $\begin{array}{c}16 \mathrm{~mm} \text { o mas con una variación } \\
\text { máxima de } 8 \text { mm en un solo } \\
\text { envase o manojo } \\
12 \text { mm o mas con una variación } \\
\text { máxima de 10 mm en un solo } \\
\text { envase o manojo }\end{array}$ \\
\hline II & Violeta/verde y violeta & $6 \mathrm{~mm}$ & 6 a $12 \mathrm{~mm}$ & $\begin{array}{c}\text { No existen disposiciones en cuanto a la } \\
\text { uniformidad }\end{array}$ \\
\hline
\end{tabular}

Fuente: Unión Europea

\section{Clasificación en Alemania}

Tabla $N^{\circ}$ 35: Clasificación Alemana de espárragos frescos:

\begin{tabular}{|c|c|c|c|}
\hline Clase & Equivalencia Clasificación UE & Largo en $\mathbf{~ m}$. & Diámetro en cm. \\
\hline $\boldsymbol{A}$ & Extra & 23 a 25 & 2,5 a 2,8 \\
\hline $\boldsymbol{B}$ & Clase I & 20 a 22 & 2,0 a 2,4 \\
\hline $\boldsymbol{C}$ & Clase I & 18 a 19,9 & 1,7 a 1,9 \\
\hline $\boldsymbol{D}$ & Clase II & 15 a 17,9 & 1,5 a 1,6 \\
\hline $\boldsymbol{E}$ & Clase III & 10 a 14,9 & 1,0 a 1,4 \\
\hline $\boldsymbol{F}$ & Clase III & menos de 9,9 & menos de 0,9 \\
\hline $\boldsymbol{G}$ & \multicolumn{2}{|c|}{ Clase A, B, Cy D, pero con cabeza lila o verde } \\
\hline $\boldsymbol{H}$ & \multicolumn{2}{|c|}{ Más pequeña que F pero con cabeza blanca } \\
\hline $\boldsymbol{I}$ & \multicolumn{2}{|c|}{ Más pequeña que F pero con cabeza lila o verde } \\
\hline
\end{tabular}

Fuente: Zentral Markt und Preis 


\section{Disposiciones sobre tolerancias}

En cada envase se permitirán tolerancias de calidad y de calibre para los productos que no satisfagan los requisitos de la categoría indicada.

\section{A. Tolerancias de calidad}

i) Categoría "extra"

El cinco por ciento en número o en peso de los brotes que no satisfagan los requisitos de esta categoría, pero que satisfaga los de la Categoría I o, excepcionalmente, que no superen las tolerancias establecidas para esta última, o que tengan ligeras grietas no cicatrizadas posteriores a la recolección.

\section{ii) Categoría I}

El diez por ciento en número o en peso de los brotes que no satisfagan los requisitos de esta categoría, pero que satisfagan los de la categoría II o, excepcionalmente, que no superen las tolerancias establecidas para esta última, o que tengan ligeras grietas no cicatrizadas posteriores a la recolección.

\section{iii) Categoría II}

El diez por ciento en número o en peso de los brotes que no satisfagan los requisitos de esta categoría ni los requisitos mínimos, a excepción de los brotes afectados por podredumbre o cualquier otra alteración que haga que no sean aptos para el consumo humano. Además, podrá permitirse el diez por ciento en número o en peso de brotes huecos o brotes que presenten grietas muy ligeras debidas al lavado. En ningún caso podrá haber más del 15 por ciento de brotes huecos en cada envase o manojo. B. Tolerancias de calibre

Para todas las categorías, el diez por ciento en número o en peso de los brotes que no correspondan al calibre indicado ni a los límites de longitud especificados, con una desviación máxima de $1 \mathrm{~cm}$ de longitud y de $2 \mathrm{~mm}$ de diámetro.

\section{Disposiciones relativas a la presentación}
A. Uniformidad 
El contenido de cada envase o de cada manojo de un mismo envase deberá ser homogéneo y estar constituido únicamente por espárragos del mismo origen, calidad, grupo de color y calibre ( si están clasificados por calibre).

No obstante, por lo que respecta al color, podrán permitirse brotes de un grupo de color diferente dentro de los límites siguientes:

a) espárragos blancos: 10 por ciento en número o en peso de espárragos violetas en las categorías "extra" y I, y 15 por ciento en la Categoría II;

b) espárragos violeta, violetas/verdes y verdes: 10 por ciento en número o en peso de espárragos de otro grupo de color.

En el caso de la Categoría II se permite una mezcla de espárragos blancos y violetas, siempre que se indique adecuadamente.

La parte visible del contenido del envase deberá ser representativa de todo el contenido.

\section{B. Envasado}

Los espárragos deberán envasarse de manera que queden debidamente protegidos.

El material utilizado en el interior de los envases deberá ser nuevo, estar limpio y ser de calidad tal que impida que se provoquen daños internos o externos al producto. Se permite el uso de materiales, en particular papel y sellos con indicaciones comerciales, siempre y cuando estén impresos, o etiquetados con tinta o pegamento no tóxicos. Los envases deberán estar exentos de toda materia extraña.

\section{Forma de presentación}

Los espárragos podrán presentarse:

i) En manojos firmemente sujetos. Los brotes de la parte externa de cada manojo deberán corresponder, en cuanto a aspecto y diámetro, al promedio de todo el manojo.

En la categoría "extra", los brotes de espárragos presentados en manojos deberán ser de la misma longitud. 
Los manojos deberán disponerse uniformemente en el envase, y cada manojo podrá estar protegido por un papel. Los manojos de un mismo envase deberán ser del mismo peso.

ii) Dispuestos ordenadamente, pero no presentados en manojos en el envase.

\section{Disposiciones relativas al marcado}

Cada envase ${ }^{61}$ deberá llevar la información que se indica a continuación, agrupada en el mismo lado, marcada de forma legible e indeleble y visible desde el exterior.

\section{A. Identificación}

Envasador y/o expedidor: Nombre y dirección o marca en clave oficialmente emitida o aceptada ${ }^{62}$

\section{B. Naturaleza del producto}

El término "Espárragos", seguido de la indicación "blancos", "violetas", "violetas/verdes" o "verdes"

si el contenido del envase no es visible desde el exterior y, cuando proceda, la indicación "cortos" o "puntas" o "mezcla de blancos y violetas".

\section{Origen del producto}

País de origen y, facultativamente, nombre del lugar, distrito, región o país de producción.

\section{Especificaciones comerciales}

- categoría

- calibre

a) expresado en diámetros mínimo y máximo para los espárragos sujetos a uniformidad;

b) expresado en diámetro mínimo, seguido del diámetro máximo o de la expresión "o más" para los espárragos no sujetos a normas de uniformidad.

- para los espárragos presentados en manojos o en envases unitarios, número de manojos o de envases unitarios.

\footnotetext{
${ }^{61}$ Las unidades de envase de productos envasados para la venta directa al consumidor no estarán sujetas a estas disposiciones de marcado, pero deberán ajustarse a los requisitos nacionales. No obstante, dicho marcado deberá figurar en cualquier caso en el embalaje de transporte que contenga tales envases unitarios.

${ }^{62}$ La legislación nacional de varios países exige la declaración explícita del nombre y la dirección. No obstante, en el caso en que se utilice una marca en clave, la expresión "envasador y/o exportador (o abreviaturas equivalentes)" deberá indicarse muy cerca de la marca en clave.
} 
E. Marca de inspección oficial (facultativo).

\subsection{Normas CODEX-STAN 225-2001}

Breve descripción de las Normas CODEX

Las Normas CODEX comprenden una serie de normas generales y específicas relativas a la seguridad alimentaria, que han sido formuladas con el objetivo de proteger la salud de los consumidores y de garantizar unas prácticas equitativas en el comercio de los productos alimentarios.

El Codex Alimentarius fue creado de forma conjunta en los años 60 por dos organizaciones de las Naciones Unidas: la Organización para la Agricultura y la Alimentación (Food and Agriculture Organization, FAO) y la Organización Mundial de la Salud (OMS). Su propósito era servir como pauta y fomentar la elaboración y el establecimiento de definiciones y requisitos para los alimentos, a fin de contribuir a su armonización y, de este modo, facilitar el comercio internacional. La mayor parte de la población mundial vive en los 166 países que son miembros del Codex Alimentarius. Estos países participan en la elaboración de las normas y a menudo en su aplicación a nivel nacional y regional.

Aunque las normas adoptadas por el Codex Alimentarius no son vinculantes desde el punto de vista jurídico, tienen un gran peso y una base científica sólida. Cuando procede, la Organización Mundial del Comercio recurre a las normas del Codex para resolver conflictos comerciales relativos a productos alimentarios. Las normas del Codex suelen servir como punto de partida para las legislaciones y las normativas nacionales y regionales. Básicamente, la influencia del Codex Alimentarius se extiende a todos los continentes, y su contribución a la protección de la salud pública y las prácticas equitativas en la industria alimentaria es extremadamente valiosa.

La norma CODEX, (CODEX STAN 225-2001) es idéntica a la norma CEPE/ONU FFV-04, con la salvedad que dentro de las disposiciones agrega 2 ítems más a lo enunciado anteriormente. Los ítems son los siguientes:

\section{Disposiciones sobre Contaminantes}

El producto al que se aplica las disposiciones de la presente Norma deberá cumplir con los niveles máximos de la Norma General del Codex para los Contaminantes y las Toxinas presentes en los Alimentos (CODEX STAN 193-1995). 
El producto al que se aplica las disposiciones de la presente Norma deberá cumplir con los límites máximos de residuos de plaguicidas establecidos por la Comisión del Codex Alimentarius.

\section{Higiene}

Se recomienda que el producto regulado por las disposiciones de la presente Norma se prepare y manipule de conformidad con las secciones apropiadas del Código Internacional Recomendado de Prácticas - Principios Generales de Higiene de los Alimentos (CAC/RCP 1-1969), Código de Prácticas de Higiene para Frutas y Hortalizas Frescas (CAC/RCP 53-2003) y otros textos pertinentes del Codex, tales como códigos de prácticas y códigos de prácticas de higiene.

El producto deberá ajustarse a los criterios microbiológicos establecidos de conformidad con los Principios para el Establecimiento y la Aplicación de Criterios Microbiológicos a los Alimentos (CAC/GL 21-1997). 


\section{Anexo Cap. 2: Oferta y Demanda de espárragos a nivel mundial, en}

\section{Alemania y Argentina}

\section{Importaciones y Exportaciones mundiales de espárragos en conserva}

Uno de los puntos importantes a destacar es el comercio internacional del espárrago en conserva.

Tabla $\mathrm{N}^{\circ}$ 36: Detalle de la evolución de las importaciones de espárragos en conserva en toneladas.

\begin{tabular}{|c|c|c|c|c|c|c|c|c|c|c|}
\hline & $\mathbf{2 0 0 1}$ & $\mathbf{2 0 0 2}$ & $\mathbf{2 0 0 3}$ & $\mathbf{2 0 0 4}$ & $\mathbf{2 0 0 5}$ & $\mathbf{2 0 0 6}$ & $\mathbf{2 0 0 7}$ & $\mathbf{2 0 0 8}$ & $\mathbf{2 0 0 9}$ & $\mathbf{2 0 1 0}$ \\
\hline Mundo & $\mathbf{1 6 0 . 6 3 7}$ & $\mathbf{1 7 1 . 7 3 0}$ & $\mathbf{1 5 9 . 7 1 7}$ & $\mathbf{1 6 6 . 0 4 7}$ & $\mathbf{1 7 7 . 1 3 4}$ & $\mathbf{1 4 3 . 9 0 4}$ & $\mathbf{1 6 6 . 3 5 8}$ & $\mathbf{1 6 7 . 8 1 4}$ & $\mathbf{1 4 1 . 9 2 6}$ & $\mathbf{1 2 5 . 3 9 1}$ \\
\hline España & 48.288 & 58.838 & 52.058 & 57.550 & 57.641 & 36.901 & 55.678 & 58.088 & 53.234 & 46.673 \\
\hline Alemania & 42.503 & 41.036 & 37.068 & 36.720 & 36.543 & 32.662 & 38.069 & 27.551 & 24.185 & 24.053 \\
\hline Francia & 23.469 & 24.842 & 23.013 & 22.788 & 26.843 & 25.470 & 23.293 & 25.364 & 18.297 & 20.001 \\
\hline EE.UU. & 1.278 & 1.651 & 4.699 & 5.484 & 8.409 & 12.205 & 11.578 & 18.497 & 14.252 & 10.449 \\
\hline Holanda & 9.918 & 9.675 & 8.104 & 5.727 & 5.457 & 3.944 & 4.817 & 6.262 & 5.400 & 9.567 \\
\hline Dinamarca & 5.417 & 6.281 & 5.007 & 4.928 & 5.497 & 5.046 & 7.080 & 5.698 & 4.412 & 5.689 \\
\hline Bélgica & 4.023 & 3.600 & 3.786 & 7.333 & 11.199 & 4.866 & 3.851 & 3.461 & 2.830 & 3.084 \\
\hline Australia & 3.423 & 3.674 & 4.043 & 4.033 & 3.732 & 3.798 & 4.071 & 3.146 & 3.147 & 2.867 \\
\hline Suecia & 2.079 & 2.041 & 1.809 & 1.643 & 2.055 & 1.827 & 1.694 & 1.264 & 1.093 & 1.567 \\
\hline Italia & 2.206 & 2.190 & 2.682 & 2.012 & 2.357 & 1.557 & 1.583 & 2.529 & 1.169 & 1.441 \\
\hline
\end{tabular}

Fuente: Elaboración propia en base a datos obtenidos en International Trade Centre 2011

Como podemos observar en la tabla anterior, el volumen de espárragos comerciados en 2010 llega a 125.391 toneladas, significando casi un $40 \%$ en lo que refiere a espárragos frescos (325.443 toneladas). Se puede apreciar que el comportamiento se ha mantenido constante en la última década, más allá de la baja a partir de 2008. En base a las cifras, observamos que España es el principal importador con 46.673 toneladas. Para lo que se refiere a espárragos frescos, éste país importa por 10.752 toneladas. A fines del presente trabajo, cabe destacar que Alemania es el segundo importador con 24.053 toneladas. Más allá de este lugar, debemos destacar que en la última década, Alemania ha reducido sus compras un 43,41\% (18.450 toneladas). Distinto comportamiento se puede apreciar con Holanda que ha mantenido constantes sus compras de espárragos en conserva, a diferencia del espárrago fresco, donde se ha posicionado en 2010 como el tercer país importador. 
Gráfico N 53: Evolución importaciones mundiales espárragos en conserva al año 2010:

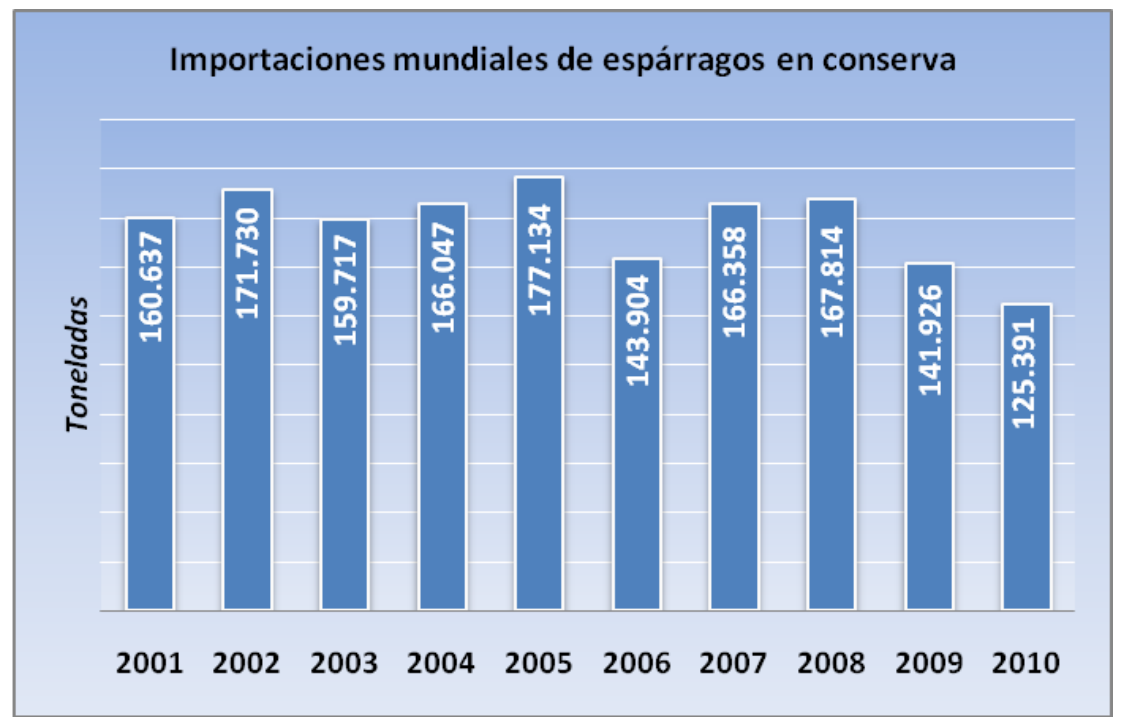

Fuente: elaboración propia en base a datos de World Trade Centre 2011

En el año 2010, el mayor exportador ha sido China con más del 48\% de la cantidad total, seguido por el Perú $(41 \%)$ y en una mínima participación a Holanda y España.

\section{Diferenciación entre exportación y consumo interno por continente}

Tabla $N^{\circ}$ 37: Asia: consumo doméstico y exportación de espárragos frescos o refrigerados años 2005-2009:

\begin{tabular}{|c|c|c|c|c|}
\hline \multirow{2}{*}{ ASIA } & 2009 & 2009 & 2005 & 2005 \\
\cline { 2 - 5 } & Exportación & Doméstico & Exportación & Doméstico \\
\hline China & 35 & 65 & 55 & 45 \\
\hline India & 0 & 100 & 0 & 100 \\
\hline Indonesia & 0 & 100 & 25 & 75 \\
\hline Israel & 0 & 100 & 0 & 100 \\
\hline Irán & - & - & 0 & 100 \\
\hline Japón & 1 & 99 & 1 & 99 \\
\hline Korea & 0 & 100 & 0 & 100 \\
\hline Malasia & 25 & 75 & 0 & 100 \\
\hline Pakistán & 0 & 100 & 0 & 100 \\
\hline Filipinas & 98 & 2 & 98 & 2 \\
\hline Sri Lanka & - & - & - & - \\
\hline Taiwan & 0 & 100 & - & - \\
\hline Tailandia & 42 & 58 & 70 & 30 \\
\hline Turquía & 0 & 100 & 0 & 100 \\
\hline Vietnam & 0 & 100 & - & - \\
\hline
\end{tabular}

Fuente: California Asparagus Seed \& Transplant. www.calif-asparagus-seed.com 2009 
Tabla N 38: Europa: consumo doméstico y exportación de espárragos años 2005-2009

\begin{tabular}{|c|c|c|c|c|}
\hline \multirow{2}{*}{ EUROPA } & 2009 & 2009 & 2005 & 2005 \\
\cline { 2 - 5 } & Exportación & Doméstico & Exportación & Doméstico \\
\hline Alemania & 2 & 98 & 1 & 99 \\
\hline Austria & 5 & 95 & 5 & 95 \\
\hline Bélgica & 6 & 94 & 6 & 94 \\
\hline Bulgaria & - & - & - & - \\
\hline Chipre & 50 & 50 & 100 & 0 \\
\hline Dinamarca & 0 & 100 & 0 & 100 \\
\hline Eslovaquia & 100 & 0 & 100 & 0 \\
\hline Eslovenia & 0 & 100 & 0 & 100 \\
\hline España & 30 & 70 & 30 & 70 \\
\hline Francia & 10 & 90 & 10 & 90 \\
\hline Grecia & 99 & 1 & 95 & 5 \\
\hline Holanda & 19 & 81 & 40 & 60 \\
\hline Hungría & - & - & 80 & 20 \\
\hline Italia & 10 & 90 & 5 & 95 \\
\hline Lituania & 0 & 100 & - & - \\
\hline Moldova & 0 & 100 & - & - \\
\hline Noruega & 0 & 100 & 0 & 100 \\
\hline Polonia & 70 & 30 & 67 & 33 \\
\hline Portugal & 80 & 20 & 80 & 20 \\
\hline Reino Unido & 0 & 100 & 0 & 100 \\
\hline Rep. Checa & 100 & 0 & 100 & 0 \\
\hline Rumania & 0 & 100 & 0 & 100 \\
\hline Suiza & 9 & 91 & 9 & 91 \\
\hline
\end{tabular}

Fuente: California Asparagus Seed \& Transplant. www.calif-asparagus-seed.com 2009

Tabla $\mathrm{N}^{\circ}$ 39: América: consumo doméstico y exportación de espárragos años 2005-2009

\begin{tabular}{|c|c|c|c|c|}
\hline \multirow{2}{*}{ NORTEAMÉRICA } & 2009 & 2009 & 2005 & 2005 \\
\cline { 2 - 5 } & Exportación & Doméstico & Exportación & Doméstico \\
\hline Canadá & 23 & 77 & - & - \\
\hline Costa Rica & 50 & 50 & 50 & 50 \\
\hline EE.UU. & 18 & 82 & 17 & 83 \\
\hline El Salvador & 100 & 0 & 100 & 0 \\
\hline Guatemala & 95 & 5 & 0 & 100 \\
\hline Honduras & 100 & 0 & 100 & 0 \\
\hline Mexico & 98 & 2 & 95 & 5 \\
\hline Nicaragua & 100 & 0 & 100 & 0 \\
\hline Panamá & 0 & 100 & 0 & 100 \\
\hline
\end{tabular}

Fuente: California Asparagus Seed \& Transplant. www.calif-asparagus-seed.com 2009 
Tabla ํ 40: Sudamérica: consumo doméstico y exportación de espárragos frescos años 2005-2009:

\begin{tabular}{|c|c|c|c|c|}
\hline \multirow{2}{*}{ SUDAMÉRICA } & 2009 & 2009 & 2005 & 2005 \\
\cline { 2 - 5 } & Exportación & Doméstico & Exportación & Doméstico \\
\hline Argentina & 30 & 70 & 50 & 50 \\
\hline Brasil & 0 & 100 & 0 & 100 \\
\hline Chile & 70 & 30 & 70 & 30 \\
\hline Colombia & 90 & 10 & 90 & 10 \\
\hline Ecuador & 98 & 2 & 100 & 0 \\
\hline Perú & 99 & 1 & 99 & 1 \\
\hline Uruguay & 0 & 100 & 0 & 100 \\
\hline Venezuela & 0 & 100 & 0 & 100 \\
\hline
\end{tabular}

Fuente: California Asparagus Seed \& Transplant. www.calif-asparagus-seed.com 2009

Tabla N 41: África: consumo doméstico y exportación de espárragos años 2005-2009

\begin{tabular}{|c|c|c|c|c|}
\hline \multirow{2}{*}{ ÁFRICA } & 2009 & 2009 & 2005 & 2005 \\
\cline { 2 - 5 } & Exportación & Doméstico & Exportación & Doméstico \\
\hline Egipto & 95 & 5 & 80 & 20 \\
\hline Kenya & 100 & 0 & - & - \\
\hline Marruecos & 100 & 0 & 98 & 2 \\
\hline Sudáfrica & 17 & 83 & 60 & 40 \\
\hline Túnez & 80 & 20 & 80 & 20 \\
\hline
\end{tabular}

Fuente: California Asparagus Seed \& Transplant. www.calif-asparagus-seed.com 2009

Tabla N 42: Oceanía: consumo doméstico y exportación de espárragos años 2005-2009

\begin{tabular}{|c|c|c|c|c|}
\hline \multirow{2}{*}{ OCEANÍA } & 2009 & 2009 & 2005 & 2005 \\
\cline { 2 - 5 } & Exportación & Doméstico & Exportación & Doméstico \\
\hline Australia & 60 & 40 & 70 & 30 \\
\hline Nueva Zelanda & 45 & 55 & 50 & 50 \\
\hline Vanuatu & 0 & 100 & - & - \\
\hline
\end{tabular}

Fuente: California Asparagus Seed \& Transplant. www.calif-asparagus-seed.com 2009 
Lic. Emanuel Borthiry Buide, Tomo 042, Folio 148, C.P.C.E.C.A.B.A. 120 Estudio de prefactibilidad para la exportación de espárragos orgánicos argentinos en Alemania

Tabla N ${ }^{\circ} 43$ : Detalle Europeo de Exportaciones e Importaciones año 2010 - 2001 en toneladas:

\begin{tabular}{|c|c|c|c|c|c|c|c|c|c|c|c|c|c|c|c|c|c|c|c|c|}
\hline \multirow{2}{*}{ Toneladas } & \multicolumn{2}{|c|}{2001} & \multicolumn{2}{|c|}{2002} & \multicolumn{2}{|c|}{2003} & \multicolumn{2}{|c|}{2004} & \multicolumn{2}{|c|}{2005} & \multicolumn{2}{|c|}{2006} & \multicolumn{2}{|c|}{2007} & \multicolumn{2}{|c|}{2008} & \multicolumn{2}{|c|}{2009} & \multicolumn{2}{|c|}{2010} \\
\hline & EXPO & IMPO & EXPO & IMPO & EXPO & $I M P O$ & EXPO & IMPO & EXPO & $I M P O$ & EXPO & IMPO & EXPO & IMPO & EXPO & IMPO & EXPO & $I M P O$ & EXPO & $I M P O$ \\
\hline Albania & 0 & 2 & 0 & 8 & 0 & 3 & 0 & 1 & 0 & 7 & 0 & 0 & 0 & 0 & 0 & 0 & 0 & 0 & 0 & 0 \\
\hline Alemania & 3.093 & 39.051 & 1.488 & 40.129 & 1.195 & 29.251 & 1.232 & 25.932 & 1.970 & 28.260 & 2.149 & 28.791 & 2.210 & 23.607 & 2.404 & 26.954 & 2.544 & 22.609 & 3.624 & 24.437 \\
\hline Andorra & 0 & 7 & 0 & 2 & 0 & 2 & 0 & 1 & 0 & 56 & 0 & 2 & 0 & 2 & 0 & 3 & 0 & 0 & 0 & 0 \\
\hline Austria & 483 & 1.939 & 641 & 1.830 & 545 & 1.801 & 752 & 2.139 & 406 & 2.650 & 457 & 2.608 & 498 & 2.852 & 557 & 2.175 & 526 & 2.887 & 541 & 2.714 \\
\hline Belarús & 0 & 0 & 0 & 0 & 0 & 0 & 0 & 0 & 0 & 0 & 0 & 1 & 0 & 1 & 0 & 2 & 0 & 2 & 0 & 2 \\
\hline Bélgica & 967 & 2.327 & 1.009 & 2.200 & 1.245 & 2.673 & 1.418 & 3.407 & 1.289 & 3.865 & 1.628 & 4.227 & 1.466 & 4.046 & 1.508 & 4.057 & 1.723 & 4.597 & 1.416 & 4.096 \\
\hline Bosnia & 0 & 0 & 0 & 0 & 0 & 0 & 0 & 1 & 0 & 2 & 0 & 1 & 0 & 1 & 0 & 1 & 0 & 1 & 0 & 1 \\
\hline Bulgaria & 45 & 0 & 70 & 0 & 31 & 1 & 48 & 0 & 40 & 1 & 64 & 3 & 45 & 7 & 0 & 10 & 0 & 6 & 0 & 7 \\
\hline Chipre & 0 & 1 & 0 & 1 & 0 & 1 & 35 & 18 & 11 & 4 & 21 & 4 & 0 & 12 & 0 & 12 & 0 & 10 & 0 & 18 \\
\hline Croacia & 0 & 2 & 0 & 6 & 0 & 3 & 0 & 4 & 0 & 10 & 0 & 11 & 0 & 20 & 0 & 25 & 0 & 12 & 0 & 18 \\
\hline Dinamarca & 4 & 986 & 6 & 1.143 & 10 & 1.329 & 17 & 1.367 & 11 & 1.369 & 24 & 1.619 & 18 & 1.763 & 30 & 2.042 & 49 & 1.870 & 47 & 1.808 \\
\hline Eslovaquia & 545 & 43 & 796 & 179 & 866 & 291 & 721 & 811 & 1.148 & 703 & 826 & 687 & 982 & 727 & 1.075 & 930 & 1.071 & 156 & 428 & 118 \\
\hline Eslovenia & 0 & 22 & 0 & 25 & 0 & 15 & 1 & 35 & 1 & 43 & 1 & 59 & 2 & 66 & 2 & 103 & 9 & 81 & 9 & 103 \\
\hline España & 27.032 & 3.760 & 24.011 & 4.804 & 32.919 & 6.329 & 19.090 & 6.271 & 16.836 & 9.211 & 17.582 & 9.371 & 14.164 & 8.820 & 13.700 & 9.997 & 13.376 & 10.110 & 11.950 & 10.752 \\
\hline Estonia & 0 & 2 & 7 & 2 & 1 & 5 & 0 & 1 & 0 & 2 & 0 & 2 & 0 & 2 & 0 & 4 & 0 & 6 & 0 & 11 \\
\hline Rusia & 0 & 52 & 0 & 85 & 0 & 115 & 0 & 142 & 0 & 130 & 0 & 224 & 0 & 315 & 0 & 365 & 0 & 319 & 0 & 318 \\
\hline Finlandia & 146 & 247 & 0 & 267 & 0 & 246 & 0 & 238 & 0 & 305 & 0 & 349 & 0 & 387 & 0 & 420 & 1 & 408 & 1 & 484 \\
\hline Francia & 6.979 & 14.987 & 7.326 & 18.375 & 6.481 & 13.153 & 4.707 & 14.299 & 4.407 & 12.511 & 4.610 & 13.481 & 4.033 & 17.118 & 3.345 & 15.266 & 3.755 & 14.912 & 2.913 & 12.320 \\
\hline Gibraltar & 0 & 0 & 0 & 2 & 0 & 2 & 0 & 4 & 0 & 3 & 0 & 5 & 0 & 5 & 0 & 8 & 0 & 4 & 0 & 3 \\
\hline Grecia & 19.327 & 27 & 19.256 & 30 & 14.362 & 151 & 13.994 & 673 & 11.423 & 870 & 12.424 & 942 & 12.713 & 815 & 14.655 & 688 & 13.729 & 487 & 10.275 & 583 \\
\hline Hungría & 1.913 & 2 & 2.369 & 2 & 2.310 & 14 & 2.213 & 7 & 2.117 & 36 & 1.974 & 17 & 2.460 & 33 & 3.141 & 12 & 2.870 & 69 & 3.303 & 49 \\
\hline Irlanda & 1 & 204 & 4 & 138 & 1 & 183 & 9 & 226 & 5 & 213 & 6 & 333 & 9 & 400 & 4 & 426 & 3 & 772 & 2 & 623 \\
\hline Islandia & 0 & 4 & 0 & 4 & 0 & 6 & 0 & 14 & 0 & 15 & 0 & 19 & 0 & 21 & 0 & 20 & 0 & 11 & 0 & 9 \\
\hline Islas Feroe & 0 & 0 & 0 & 2 & 0 & 1 & 0 & 1 & 0 & 1 & 0 & 1 & 0 & 2 & 0 & 2 & 0 & 2 & 0 & 2 \\
\hline Italia & 1.282 & 5.564 & 1.448 & 3.871 & 776 & 5.319 & 792 & 3.819 & 1.258 & 4.783 & 1.318 & 5.507 & 2.070 & 4.641 & 3.122 & 4.522 & 2.527 & 4.050 & 3.012 & 4.266 \\
\hline Macedonia & 0 & 0 & 0 & 0 & 73 & 1 & 288 & 0 & 308 & 0 & 240 & 0 & 362 & 0 & $s / d$ & $s / d$ & 350 & 0 & 0 & 0 \\
\hline Letonia & 0 & 3 & 0 & 3 & 0 & 3 & 0 & 3 & 2 & 22 & 0 & 12 & 0 & 9 & 1 & 53 & 0 & 13 & 0 & 7 \\
\hline Lituania & 0 & 3 & 0 & 3 & 0 & 3 & 0 & 3 & 5 & 9 & 63 & 39 & 125 & 11 & 132 & 125 & 138 & 137 & 302 & 301 \\
\hline Luxemburgo & 55 & 374 & 31 & 395 & 26 & 373 & 16 & 399 & 21 & 436 & 26 & 408 & 34 & 420 & 42 & 400 & 26 & 412 & 35 & 441 \\
\hline Malta & 0 & 8 & 0 & 6 & 0 & 8 & 0 & 9 & 0 & 9 & 0 & 9 & 0 & 10 & 0 & 39 & 0 & 17 & 0 & 9 \\
\hline Noruega & 0 & 426 & 0 & 554 & 0 & 736 & 2 & 797 & 0 & 925 & 0 & 992 & 3 & 1.133 & 0 & 1.321 & 0 & 1.257 & 0 & 1.384 \\
\hline Holanda & 6.239 & 4.168 & 7.780 & 6.965 & 6.910 & 7.424 & 7.827 & 7.224 & 7.356 & 6.895 & 8.068 & 5.938 & 10.210 & 8.423 & 11.981 & 10.858 & 13.875 & 15.211 & 11.688 & 22.406 \\
\hline Polonia & 829 & 0 & 1.498 & 0 & 1.934 & 0 & 1.736 & 298 & 1.601 & 118 & 1.032 & 53 & 1.310 & 116 & 1.318 & 87 & 1.382 & 58 & 2.066 & 100 \\
\hline Portugal & 0 & 125 & 0 & 145 & 0 & 189 & 0 & 234 & 22 & 135 & 2 & 190 & 9 & 217 & 0 & 230 & 3 & 212 & 1 & 155 \\
\hline Reino Unido & 53 & 6.427 & 62 & 5.667 & 126 & 6.103 & 78 & 6.035 & 218 & 8.076 & 135 & 9.215 & 144 & 8.745 & 253 & 9.930 & 281 & 9.245 & 312 & 9.823 \\
\hline Rep. Checa & 359 & 70 & 651 & 71 & 550 & 97 & 531 & 72 & 608 & 200 & 518 & 213 & 15 & 223 & 30 & 232 & 130 & 329 & 72 & 295 \\
\hline Moldova & 0 & 0 & 0 & 0 & 0 & 4 & 0 & 0 & 0 & 0 & 0 & 0 & 0 & 0 & 0 & 1 & 0 & 1 & 0 & 1 \\
\hline Rumania & 0 & 0 & 0 & 0 & 0 & 0 & 0 & 4 & 0 & 7 & 0 & 13 & 0 & 23 & 14 & 18 & 53 & 83 & 33 & 84 \\
\hline S. Montenegro & 0 & 0 & 58 & 0 & & 0 & 106 & 1 & 82 & 0 & 0 & 0 & 5 & 0 & 0 & 0 & 0 & 0 & 0 & 0 \\
\hline Suecia & 5 & 504 & 17 & 485 & 19 & 683 & 16 & 844 & 31 & 884 & 54 & 979 & 64 & 1.144 & 145 & 1.339 & 89 & 1.391 & 19 & 1.495 \\
\hline Suiza & 39 & 10.522 & 65 & 10.480 & 8 & 10.337 & 22 & 9.375 & 38 & 9.890 & 17 & 8.907 & 31 & 9.137 & 74 & 9.601 & 31 & 8.945 & 13 & 9.491 \\
\hline Ucrania & 0 & 1 & 0 & 0 & 0 & 0 & 0 & 0 & 0 & 5 & 0 & 15 & 0 & 27 & 0 & 39 & 0 & 30 & 0 & 30 \\
\hline Total & 69.396 & 91.860 & 68.593 & 97.879 & 70.388 & 86.855 & 55.651 & 84.709 & 51.214 & 92.661 & 53.239 & 95.247 & 52.982 & 95.301 & 57.533 & 102.317 & 58.541 & 100.722 & 52.062 & 108.764 \\
\hline
\end{tabular}

Fuente: Elaboración propia según datos de International Trade Centre, año 2011. 


\section{Importaciones alemanas de espárragos en conserva año 2010}

Otro de los puntos importantes a destacar es el consumo de espárragos preparados o en conserva. Considerando las cantidades importadas, se puede observar que han sido similares a las importaciones de espárragos frescos o refrigerados en lo que a toneladas se refiere. A diferencia de los espárragos frescos, cuyo principal proveedor ha sido Grecia; quién mas ha vendido en los últimos años es China.

Más allá de las cantidades importadas, se debe destacar que a partir del año 2007 las cantidades importadas han caído significativamente.

Dentro del estudio de campo realizado, se pudo llegar a la conclusión que las clases de menores ingresos son las que más consumen las diversas clases de estas conservas. Dentro del anexo fotográfico se puede observar tanto las distintas variedades de espárragos como así también los precios de los mismos.

Gráfico $\mathrm{N}^{\circ}$ 54: Evolución de las importaciones alemanas en espárragos en conserva:

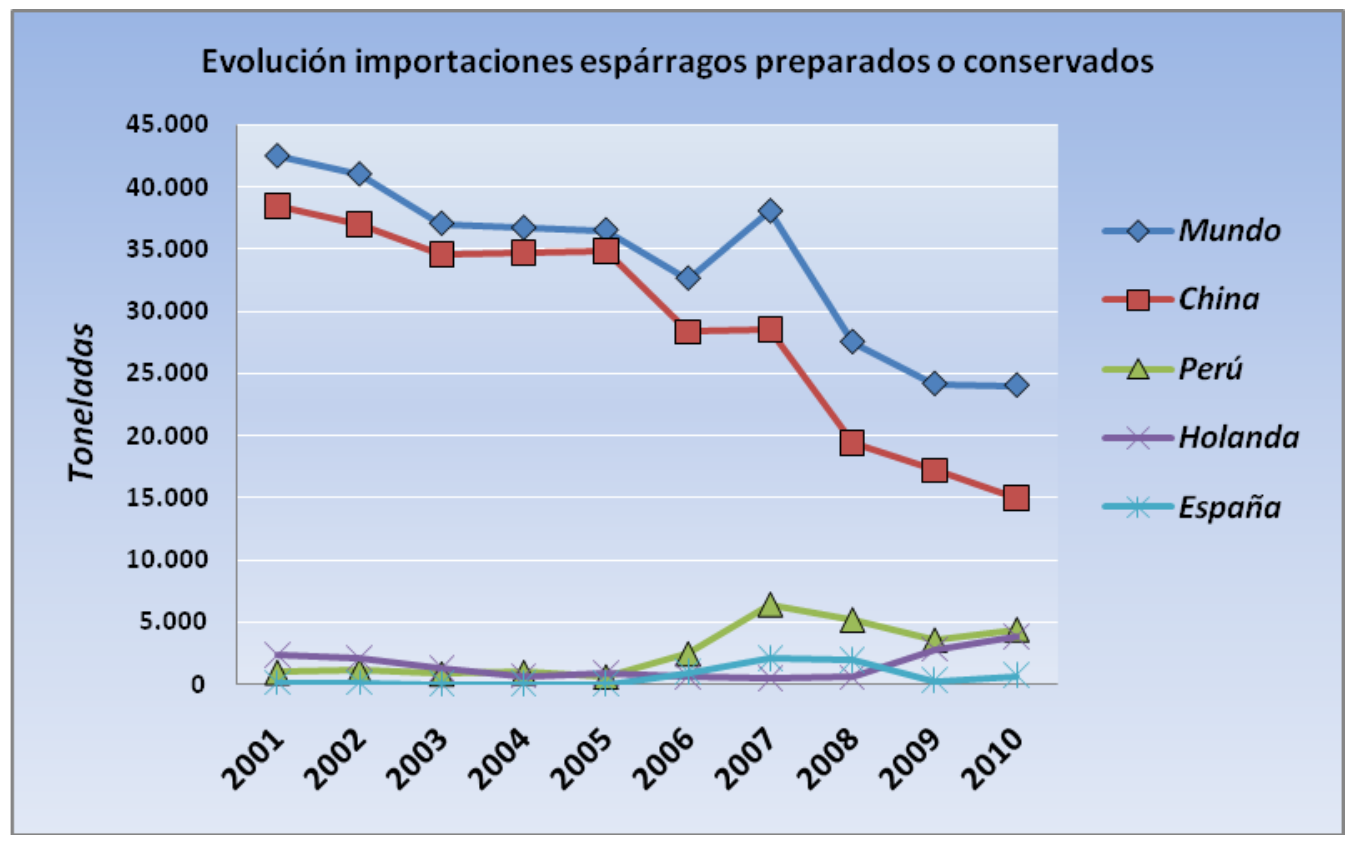

Fuente: elaboración propia en base a datos obtenidos en International Trade Centre ${ }^{63}$

${ }^{63}$ Disponible en www.trademap.org 
Tabla $N^{\circ} 44$ : Detalle principales proveedores espárragos conserva al mercado alemán años 2010-2001 en toneladas:

\begin{tabular}{|c|c|c|c|c|c|c|c|c|c|c|}
\hline & $\mathbf{2 0 0 1}$ & $\mathbf{2 0 0 2}$ & $\mathbf{2 0 0 3}$ & $\mathbf{2 0 0 4}$ & $\mathbf{2 0 0 5}$ & $\mathbf{2 0 0 6}$ & $\mathbf{2 0 0 7}$ & $\mathbf{2 0 0 8}$ & $\mathbf{2 0 0 9}$ & $\mathbf{2 0 1 0}$ \\
\hline Exportadores & $\mathbf{4 2 . 5 0 3}$ & $\mathbf{4 1 . 0 3 6}$ & $\mathbf{3 7 . 0 6 8}$ & $\mathbf{3 6 . 7 2 0}$ & $\mathbf{3 6 . 5 4 3}$ & $\mathbf{3 2 . 6 6 2}$ & $\mathbf{3 8 . 0 6 9}$ & $\mathbf{2 7 . 5 5 1}$ & $\mathbf{2 4 . 1 8 5}$ & $\mathbf{2 4 . 0 5 3}$ \\
\hline China & 38.534 & 37.042 & 34.615 & 34.775 & 34.905 & 28.387 & 28.560 & 19.484 & 17.261 & 15.004 \\
\hline Perú & 973 & 1.081 & 842 & 959 & 606 & 2.454 & 6.418 & 5.192 & 3.557 & 4.404 \\
\hline Holanda & 2.381 & 2.080 & 1.312 & 706 & 900 & 668 & 507 & 591 & 2.828 & 3.832 \\
\hline España & 98 & 84 & 21 & 27 & 15 & 973 & 2.093 & 1.925 & 309 & 721 \\
\hline Bélgica & 2 & 26 & 1 & 4 & 13 & 79 & 320 & 92 & 28 & 81 \\
\hline
\end{tabular}

Fuente: Elaboración propia en base a datos obtenidos en International Trade Centre 2011

Tabla $N^{\circ}$ 45: Detalle principales proveedores de espárragos en conserva al mercado alemán año 2010 en toneladas:

\begin{tabular}{|c|c|c|c|c|c|c|c|c|c|c|c|c|}
\hline Exportadores & Ene & Feb & Mar & Abr & May & Jun & Jul & Ago & Sep & Oct & Nov & Dic \\
\hline Mundo & $\mathbf{1 . 5 9 8}$ & $\mathbf{1 . 7 1 3}$ & $\mathbf{2 . 6 8 8}$ & $\mathbf{2 . 3 1 4}$ & $\mathbf{1 . 8 3 4}$ & $\mathbf{1 . 8 4 3}$ & $\mathbf{1 . 9 6 3}$ & $\mathbf{1 . 9 9 9}$ & $\mathbf{1 . 7 2 2}$ & $\mathbf{1 . 5 2 5}$ & $\mathbf{2 . 0 9 0}$ & $\mathbf{2 . 7 6 4}$ \\
\hline China & 1.032 & 979 & 1.523 & 1.720 & 1.288 & 844 & 1.156 & 1.312 & 1.197 & 1.100 & 1.071 & 1.783 \\
\hline Holanda & 336 & 243 & 431 & 377 & 253 & 343 & 132 & 253 & 160 & 205 & 477 & 623 \\
\hline Perú & 218 & 483 & 725 & 195 & 171 & 367 & 472 & 372 & 344 & 199 & 502 & 357 \\
\hline Austria & 0 & 0 & 0 & 0 & 0 & 0 & 0 & 0 & 0 & 0 & 0 & 1 \\
\hline España & 0 & 4 & 0 & 19 & 71 & 282 & 203 & 61 & 20 & 21 & 41 & 0 \\
\hline Bélgica & 3 & 4 & 9 & 3 & 52 & 7 & 1 & 1 & 0 & 1 & 0 & 0 \\
\hline
\end{tabular}

Fuente: Elaboración propia en base a datos obtenidos en World Trade Centre 2011

\subsection{Importaciones mensuales de espárragos preparados o conservados año 2010}

Para el año 2010, se experimentó un aumento en la producción de espárragos, lo que derivó en una disminución en las cantidades importadas. Si observamos en detalle podemos observar que la variabilidad de las compras en los espárragos en conserva, presenta una similitud en el consumo mensual del espárrago fresco.

Gráfico ํㅜ 55: Evolución de las importaciones mensuales en espárragos en conserva año 2010:

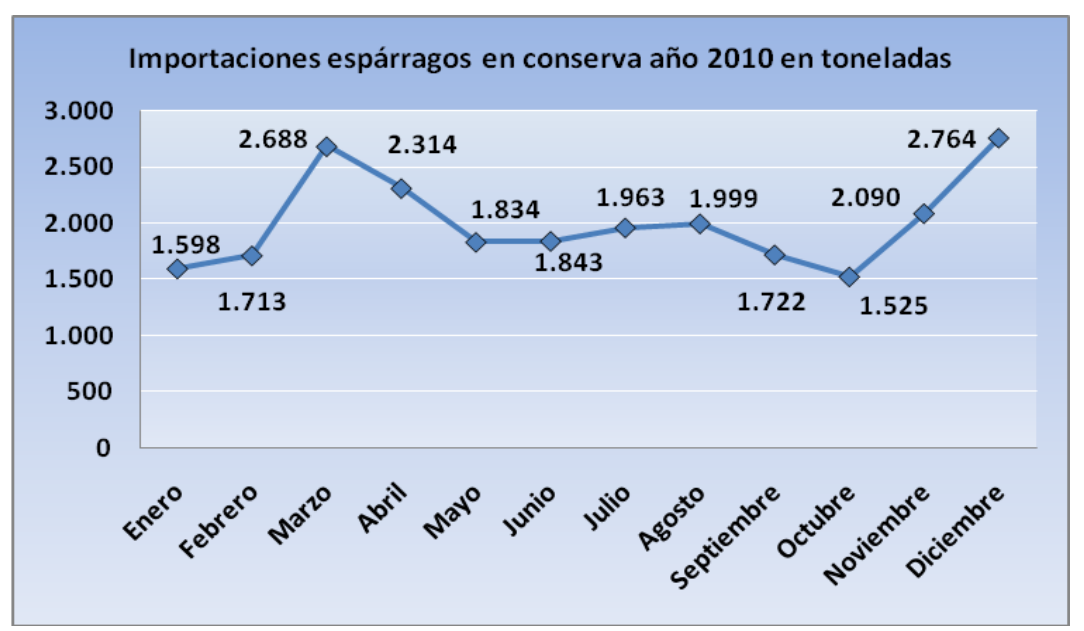

Fuente: elaboración propia en base a datos obtenidos en International Trade Centre 


\section{Importaciones alemanas de espárragos congelados año 2010}

Dentro de las 3 partidas importadas por Alemania, vemos que los espárragos congelados son los que menos se han comprado al exterior. Tal como ocurre con las otras 2 clases importadas, vemos que las cantidades han disminuido a lo largo de la última década. La disminución más notoria se dio en el año 2007, para luego mantenerse constante, mostrando un repunte en el último año. Igualmente como ocurre con los espárragos en conserva, China, mantiene con gran diferencia al resto de los demás proveedores, la supremacía en las exportaciones hacia Alemania.

Gráfico $N^{\circ}$ 56: Evolución de las importaciones mensuales en espárragos congelados año 2010:

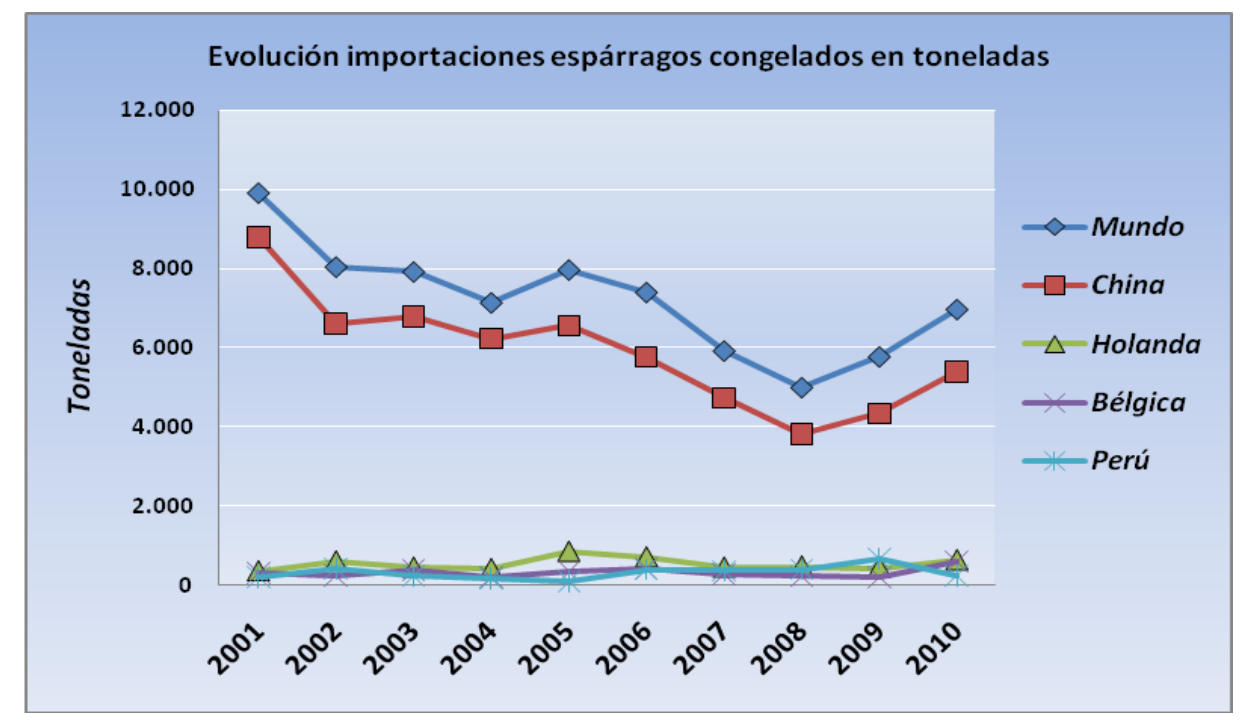

Fuente: elaboración propia en base a datos obtenidos en International Trade Centre 2011

Tabla N ${ }^{\circ} 46$ : Principales proveedores de espárragos congelados al mercado alemán años 2010-2001 en toneladas:

\begin{tabular}{|c|c|c|c|c|c|c|c|c|c|c|}
\hline & 2001 & 2002 & 2003 & 2004 & 2005 & 2006 & 2007 & 2008 & 2009 & 2010 \\
\hline Exportadores & 9.918 & 8.050 & 7.927 & 7.145 & 7.976 & 7.408 & 5.929 & 5.002 & 5.781 & 6.978 \\
\hline China & 8.785 & 6.601 & 6.775 & 6.230 & 6.555 & 5.763 & 4.736 & 3.821 & 4.343 & 5.405 \\
\hline Holanda & 364 & 616 & 457 & 422 & 867 & 724 & 458 & 487 & 451 & 647 \\
\hline Bélgica & 320 & 239 & 393 & 217 & 349 & 443 & 291 & 235 & 221 & 604 \\
\hline Perú & 197 & 411 & 234 & 164 & 93 & 396 & 365 & 394 & 668 & 251 \\
\hline Chile & 48 & 33 & 14 & 5 & 0 & 20 & 13 & 0 & 19 & 33 \\
\hline Francia & 53 & 38 & 38 & 28 & 43 & 32 & 24 & 20 & 20 & 21 \\
\hline Suecia & 0 & 0 & 8 & 10 & 9 & 10 & 10 & 10 & 8 & 9 \\
\hline Italia & 12 & 23 & 1 & 0 & 9 & 7 & 5 & 12 & 22 & 6 \\
\hline Austria & 11 & 4 & 0 & 23 & 1 & 1 & 0 & 1 & 17 & 1 \\
\hline Dinamarca & 0 & 0 & 0 & 0 & 0 & 0 & 0 & 3 & 9 & 1 \\
\hline España & 68 & 8 & 2 & 0 & 19 & 4 & 16 & 9 & 0 & 0 \\
\hline
\end{tabular}

Fuente: Elaboración propia en base a datos obtenidos en International Trade Centre 2011 
Considerando el detalle anual, vemos que el comportamiento mensual muestra un comportamiento más estable en comparación con los espárragos frescos y los espárragos en conserva. Se puede observar en el gráfico siguiente, que la mayor cantidad de experimenta en Abril, para luego descender notoriamente hasta Junio. Esto se da debido a que el período de producción y cosecha se da entre los nombrados meses.

Es notable en estos casos, la supremacía que tiene China, significando un $77,46 \%$ de las toneladas adquiridas por Alemania.

Tabla $N^{\circ}$ 47: Detalle mensual principales proveedores de espárragos congelados al mercado alemán año 2010 en toneladas:

\begin{tabular}{|c|c|c|c|c|c|c|c|c|c|c|c|c|c|}
\hline Exportadores & Ene & Feb & Mar & $A b r$ & May & Jun & Jul & Ago & Set & Oct & Nov & Dic & Total \\
\hline Mundo & 501 & 599 & 559 & 905 & 409 & 261 & 626 & 655 & 646 & 698 & 529 & 591 & 6.978 \\
\hline China & 424 & 568 & 450 & 615 & 275 & 139 & 538 & 615 & 503 & 481 & 334 & 465 & 5.405 \\
\hline Holanda & 34 & 4 & 55 & 73 & 61 & 31 & 37 & 31 & 59 & 98 & 106 & 58 & 647 \\
\hline Bélgica & 17 & 26 & 51 & 119 & 69 & 48 & 48 & 7 & 44 & 96 & 46 & 34 & 604 \\
\hline Perú & 23 & 0 & 0 & 88 & 0 & 41 & 1 & 0 & 35 & 22 & 41 & 0 & 251 \\
\hline Chile & 0 & 0 & 0 & 0 & 0 & 0 & 0 & 0 & 0 & 0 & 0 & 33 & 33 \\
\hline Francia & 1 & 1 & 1 & 4 & 3 & 1 & 0 & 2 & 4 & 1 & 2 & 0 & 21 \\
\hline Suecia & 2 & 0 & 1 & 0 & 1 & 1 & 2 & 0 & 1 & 2 & 0 & 1 & 9 \\
\hline Italia & 0 & 0 & 0 & 5 & 0 & 0 & 0 & 0 & 0 & 0 & 0 & 0 & 5 \\
\hline Austria & 0 & 0 & 0 & 0 & 0 & 0 & 0 & 0 & 0,1 & 0 & 0,3 & 0,4 & 0,8 \\
\hline Dinamarca & 0 & 0,4 & 0 & 0 & 0,1 & 0 & 0 & 0 & 0 & 0 & 0 & 0 & 0,5 \\
\hline
\end{tabular}

Fuente: Elaboración propia en base a datos obtenidos en World Trade Centre 2011.

Gráfico N 57: Evolución de las importaciones mensuales en espárragos congelados año 2010:

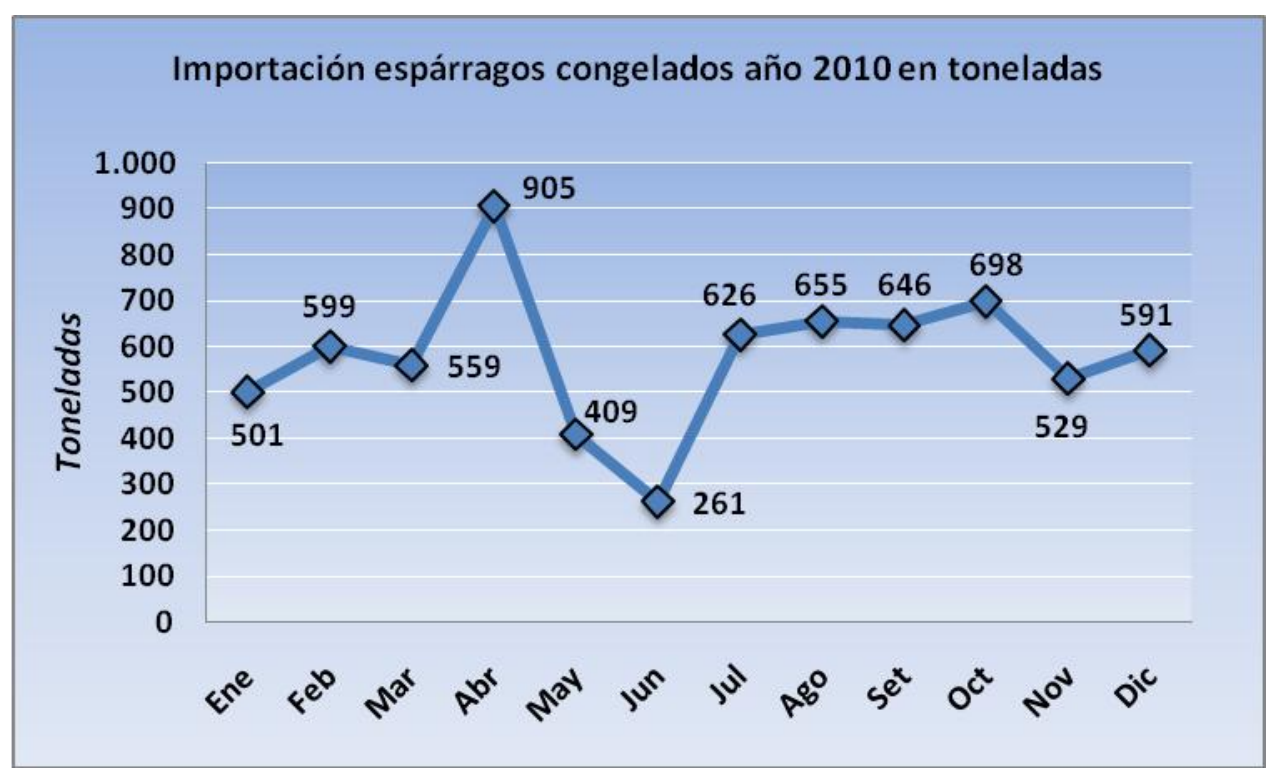

Fuente: elaboración propia en base a datos obtenidos en International Trade Centre 2011 


\section{Precios de importación}

En los cuadros siguientes se podrá observar el precio promedio por tonelada, pagado por Alemania para los espárragos frescos, espárragos en conserva y espárragos congelados en el período 2010-2001.

Como se puede apreciar en la Tabla $\mathrm{N}^{\circ}$ 47, en el año 2010 Alemania llegó a importar principalmente espárragos frescos procedentes de Grecia a un precio de US\$ 3,509 el kilogramo. A pesar de la distancia, los costos de transporte y seguro, entre otros, el Perú, con un precio de US\$ 4,820 por Kg. puede competir con los precios de espárragos procedentes de Europa y otros terceros países, tal como es el caso de España. Existen aún grandes oportunidades para proveedores que puedan ofrecer menores precios, es decir, ser más eficientes, tanto en términos de costos y rendimientos, como en el cumplimiento de los requisitos técnicos y calidad, además de las innovaciones en presentaciones y empaques.

Tabla N ${ }^{\circ}$ 48: Detalle anual del precio pagado por Alemania para la tonelada de espárrago fresco años 2010-2001:

\begin{tabular}{|c|c|c|c|c|c|c|c|c|c|c|}
\hline \multirow{2}{*}{ Exportadores } & 2.001 & 2.002 & 2.003 & 2.004 & 2.005 & 2.006 & 2.007 & 2.008 & 2.009 & 2.010 \\
\hline & US\$/Tn & US\$/Tn & US\$/Tn & US\$/Tn & US\$/Tn & USS/Tn & US\$/Tn & US\$/Tn & US\$/Tn & USS\$Tn \\
\hline Mundo & 2.909 & 2.281 & 3.139 & 3.208 & 3.481 & 4.090 & 4.090 & 4.624 & 3.793 & 3.898 \\
\hline Grecia & 2.623 & 1.825 & 2.497 & 2.460 & 3.107 & 3.759 & 3.721 & 4.219 & 3.046 & 3.509 \\
\hline Holanda & 3.577 & 3.369 & 3.881 & 3.999 & 4.032 & 5.051 & 4.466 & 5.082 & 4.692 & 4.286 \\
\hline España & 3.338 & 2.789 & 4.141 & 4.340 & 4.154 & 4.409 & 4.611 & 5.297 & 4.643 & 4.789 \\
\hline Polonia & 1.665 & 1.603 & 1.721 & 2.368 & 2.281 & 3.089 & 2.888 & 3.179 & 3.263 & 3.087 \\
\hline Hungría & 2.787 & 3.128 & 3.475 & 3.322 & 2.792 & 3.172 & 3.046 & 4.395 & 3.230 & 3.418 \\
\hline Italia & 2.880 & 2.480 & 2.823 & 3.042 & 2.906 & 4.350 & 4.611 & 4.664 & 4.122 & 4.444 \\
\hline Perú & 3.525 & 4.563 & 4.417 & 4.548 & 4.646 & 4.701 & 5.510 & 5.374 & 4.352 & 4.820 \\
\hline Austria & 4.024 & 3.438 & 4.023 & 4.642 & 3.965 & 5.097 & 6.056 & 6.235 & 4.286 & 4.938 \\
\hline Tailandia & 4.436 & 5.357 & 5.283 & 6.042 & 6.897 & 8.141 & 9.190 & 9.700 & 9.031 & 8.952 \\
\hline Francia & 4.418 & 3.895 & 5.418 & 6.665 & 5.682 & 5.460 & 6.524 & 6.552 & 6.065 & 4.661 \\
\hline Bélgica & 3.417 & 3.750 & 4.568 & 4.730 & 4.118 & 5.083 & 4.846 & 5.182 & 4.019 & 3.379 \\
\hline EE.UU. & 3.338 & 3.097 & 2.916 & 3.121 & 3.712 & 4.333 & 3.881 & 4.818 & 4.227 & 4.741 \\
\hline México & 4.833 & 4.000 & 3.000 & $S / D^{*}$ & 4.667 & 4.333 & 6.125 & 5.467 & 5.431 & 4.383 \\
\hline R. Checa & 3.000 & 3.111 & 3.824 & $S / D^{*}$ & 1.667 & 2.000 & $S / D$ & $S / D$ & $S / D$ & 1.716 \\
\hline Eslovaquia & 2.083 & 3.155 & 2.946 & 3.890 & 2.478 & 2.636 & 4.657 & 5.503 & 5.034 & 4.842 \\
\hline Kenya & $S / D$ & 2.000 & 4.000 & 5.000 & 6.500 & 6.000 & $S / D$ & 6.818 & 6.154 & 4.000 \\
\hline Marruecos & 2.333 & 2.333 & 2.333 & 2.750 & 4.250 & 4.752 & 4.750 & 6.777 & 5.600 & $S / D$ \\
\hline Sudafrica & 3.148 & 2.425 & 3.912 & 4.250 & $S / D$ & 2.750 & $S / D$ & 6.000 & 500 & $S / D$ \\
\hline Suecia & 1.500 & 2.000 & 2.250 & $S / D$ & $S / D$ & $S / D$ & 5.000 & $S / D$ & $S / D$ & $S / D$ \\
\hline Reino Unido & 2.778 & 2.500 & 3.750 & 4.667 & 2.667 & 4.500 & 7.000 & $S / D$ & $S / D$ & $S / D$ \\
\hline
\end{tabular}

Fuente: elaboración propia en base a datos obtenidos en World Trade Centre 2011

*S/D: Sin datos disponibles 
Tabla $N^{\circ}$ 49: Detalle anual precio pagado por Alemania para la tonelada de espárrago en conserva años 2010-2001:

\begin{tabular}{|c|c|c|c|c|c|c|c|c|c|c|}
\hline \multirow{2}{*}{ Exportadores } & $\mathbf{2 0 0 1}$ & $\mathbf{2 0 0 2}$ & $\mathbf{2 0 0 3}$ & $\mathbf{2 0 0 4}$ & $\mathbf{2 0 0 5}$ & $\mathbf{2 0 0 6}$ & $\mathbf{2 0 0 7}$ & $\mathbf{2 0 0 8}$ & $\mathbf{2 0 0 9}$ & $\mathbf{2 0 1 0}$ \\
\cline { 2 - 13 } & US\$/Tn & US\$/Tn & US\$/Tn & US\$/Tn & US\$/Tn & US\$/Tn & US\$/Tn & US\$/Tn & US\$/Tn & US\$/Tn \\
\hline Mundo & $\mathbf{1 . 0 9 4}$ & $\mathbf{1 . 2 1 4}$ & $\mathbf{1 . 4 0 9}$ & $\mathbf{1 . 3 5 1}$ & $\mathbf{1 . 4 0 7}$ & $\mathbf{1 . 9 4 9}$ & $\mathbf{2 . 6 8 6}$ & $\mathbf{2 . 4 2 8}$ & $\mathbf{1 . 9 0 8}$ & $\mathbf{1 . 4 8 7}$ \\
\hline China & 1.052 & 1.181 & 1.366 & 1.297 & 1.390 & 1.960 & 2.770 & 2.372 & 1.855 & 1.312 \\
\hline Holanda & 1.624 & 1.726 & 1.876 & 1.708 & 1.686 & 2.478 & 2.886 & 1.975 & 2.516 & 2.067 \\
\hline Perú & 1.152 & 1.268 & 2.154 & 3.062 & 1.927 & 1.553 & 2.273 & 2.295 & 1.715 & 1.638 \\
\hline España & 2.439 & 2.048 & 2.667 & 2.778 & 2.733 & 2.116 & 2.744 & 3.195 & 1.968 & 1.165 \\
\hline Bélgica & 1.000 & 1.808 & 1.000 & 2.750 & 4.000 & 4.266 & 3.381 & 2.228 & 1.821 & 988 \\
\hline
\end{tabular}

Fuente: elaboración propia en base a datos obtenidos en World Trade Centre 2011

Tabla $N^{\circ}$ 50: Detalle anual precio pagado por Alemania para la tonelada de espárrago congelado años 2010-2001:

\begin{tabular}{|c|c|c|c|c|c|c|c|c|c|c|}
\hline \multirow{2}{*}{ Exportadores } & $\mathbf{2 0 0 1}$ & $\mathbf{2 0 0 2}$ & $\mathbf{2 0 0 3}$ & $\mathbf{2 0 0 4}$ & $\mathbf{2 0 0 5}$ & $\mathbf{2 0 0 6}$ & $\mathbf{2 0 0 7}$ & $\mathbf{2 0 0 8}$ & $\mathbf{2 0 0 9}$ & $\mathbf{2 0 1 0}$ \\
\cline { 2 - 12 } & US\$/Tn & US\$/Tn & US\$/Tn & US\$/Tn & US\$/Tn & US\$/Tn & US\$/Tn & US\$/Tn & US\$/Tn & US\$/Tn \\
\hline Mundo & $\mathbf{1 . 4 9 9}$ & $\mathbf{1 . 5 5 5}$ & $\mathbf{1 . 5 7 5}$ & $\mathbf{1 . 3 6 7}$ & $\mathbf{1 . 4 9 4}$ & $\mathbf{2 . 3 6 6}$ & $\mathbf{2 . 4 2 1}$ & $\mathbf{2 . 6 2 3}$ & $\mathbf{2 . 1 0 4}$ & $\mathbf{2 . 1 0 5}$ \\
\hline China & 1.429 & 1.457 & 1.452 & 1.227 & 1.395 & 2.305 & 2.342 & 2.483 & 1.867 & 2.018 \\
\hline Holanda & 2.131 & 2.002 & 2.249 & 2.515 & 1.718 & 2.393 & 2.688 & 2.939 & 2.770 & 2.623 \\
\hline Bélgica & 2.098 & 2.178 & 2.336 & 2.430 & 2.310 & 3.111 & 3.186 & 3.835 & 3.525 & 2.267 \\
\hline Perú & 1.852 & 1.931 & 2.089 & 1.833 & 1.496 & 2.167 & 2.444 & 2.642 & 2.477 & 1.849 \\
\hline Chile & 1.579 & 1.945 & 1.806 & 2.308 & $S / D^{*}$ & 3.050 & 2.000 & $S / D^{*}$ & 4.278 & 3.313 \\
\hline Francia & 3.013 & 3.010 & 3.554 & 3.921 & 3.939 & 3.801 & 2.845 & 3.920 & 3.897 & 3.302 \\
\hline Italia & 2.712 & 870 & 3.333 & 3.333 & 2.778 & 3.824 & 2.667 & 3.051 & 3.196 & 3.929 \\
\hline Austria & 2.091 & 2.857 & $S / D^{*}$ & 1.000 & 2.000 & 4.286 & $S / D^{*}$ & 8.000 & 1.916 & 4.615 \\
\hline España & 2.632 & 1.538 & 3.636 & 3.508 & 2.903 & 5.116 & 2.994 & 4.706 & $S / D^{*}$ & 3.375 \\
\hline
\end{tabular}

Fuente: elaboración propia en base a datos obtenidos en World Trade Centre 2011

*S/D: Sin datos disponibles

\section{Exportaciones alemanas de espárragos frescos o refrigerados}

De acuerdo a las estadísticas de International Trade Centre, Alemania exportó en 2010 espárragos frescos o refrigerados por un total de 3.624 toneladas. El principal destino de las exportaciones de espárragos frescos o refrigerados fueron los países miembros de la Unión Europea con un total del $89 \%$ del total de las exportaciones. Francia ha sido el principal comprador, seguido por Dinamarca y Holanda. En cuanto a los países extra-comunitarios se tiene como principal destino a Suiza, con el 95\% del total de las exportaciones extra-comunitarias. 
Tabla $N^{\circ}$ 51: Detalle anual de las exportaciones alemanas de espárrago fresco en toneladas años 2010-2001:

\begin{tabular}{|c|c|c|c|c|c|c|c|c|c|c|}
\hline Importadores & 2001 & 2002 & 2003 & 2004 & 2005 & 2006 & 2007 & 2008 & 2009 & 2010 \\
\hline Mundo & 3.093 & 1.488 & 1.195 & 1.232 & 1.970 & 2.149 & 2.210 & 2.404 & 2.544 & 3.624 \\
\hline Suiza & 104 & 85 & 205 & 281 & 227 & 258 & 385 & 397 & 615 & 1.105 \\
\hline Francia & 1.875 & 227 & 446 & 288 & 408 & 467 & 344 & 676 & 754 & 970 \\
\hline Holanda & 467 & 485 & 72 & 175 & 294 & 233 & 283 & 240 & 114 & 441 \\
\hline Italia & 157 & 116 & 86 & 74 & 332 & 324 & 413 & 303 & 268 & 410 \\
\hline Austria & 346 & 188 & 142 & 187 & 309 & 443 & 425 & 398 & 289 & 308 \\
\hline Dinamarca & 15 & 49 & 33 & 35 & 67 & 126 & 149 & 150 & 151 & 164 \\
\hline Suecia & 72 & 156 & 101 & 71 & 54 & 82 & 24 & 37 & 46 & 71 \\
\hline Luxemburgo & 4 & 31 & 25 & 48 & 61 & 64 & 13 & 12 & 69 & 56 \\
\hline República Checa & 1 & 6 & 5 & 26 & 16 & 29 & 16 & 61 & 19 & 35 \\
\hline Polonia & 3 & 8 & 1 & 7 & 25 & 15 & 33 & 9 & 9 & 22 \\
\hline Reino Unido & 0 & 9 & 0 & 0 & 1 & 1 & 24 & 10 & 10 & 10 \\
\hline Finlandia & 1 & 1 & 8 & 6 & 25 & 30 & 37 & 31 & 7 & 8 \\
\hline España & 15 & 95 & 33 & 3 & 40 & 13 & 11 & 11 & 115 & 7 \\
\hline Bélgica & 26 & 9 & 31 & 19 & 6 & 27 & 14 & 39 & 38 & 4 \\
\hline Singapur & 0 & 0 & 1 & 0 & 1 & 1 & 3 & 3 & 3 & 4 \\
\hline Hungría & 0 & 0 & 0 & 0 & 0 & 0 & 4 & 5 & 19 & 2 \\
\hline Japón & 0 & 0 & 1 & 2 & 1 & 1 & 3 & 2 & 2 & 2 \\
\hline Letonia & 0 & 0 & 0 & 0 & 0 & 0 & 0 & 1 & 1 & 1 \\
\hline Portugal & 4 & 4 & 4 & 3 & 1 & 6 & 3 & 2 & 1 & 1 \\
\hline
\end{tabular}

Fuente: Elaboración propia en base a datos obtenidos en World Trade Centre 2011.

Tabla $\mathrm{N}^{\circ}$ 52: Detalle anual de las exportaciones alemanas de espárrago en conserva en toneladas años 2010-2001:

\begin{tabular}{|c|c|c|c|c|c|c|c|c|c|c|}
\hline Importadores & $\mathbf{2 0 0 1}$ & $\mathbf{2 0 0 2}$ & $\mathbf{2 0 0 3}$ & $\mathbf{2 0 0 4}$ & $\mathbf{2 0 0 5}$ & $\mathbf{2 0 0 6}$ & $\mathbf{2 0 0 7}$ & $\mathbf{2 0 0 8}$ & $\mathbf{2 0 0 9}$ & $\mathbf{2 0 1 0}$ \\
\hline Mundo & $\mathbf{9 . 4 5 7}$ & $\mathbf{8 . 9 1 8}$ & $\mathbf{7 . 4 7 9}$ & $\mathbf{7 . 0 5 2}$ & $\mathbf{8 . 9 8 4}$ & $\mathbf{7 . 2 6 5}$ & $\mathbf{5 . 6 7 9}$ & $\mathbf{6 . 3 0 6}$ & $\mathbf{3 . 1 5 4}$ & $\mathbf{2 . 6 2 6}$ \\
\hline Francia & 4.287 & 3.349 & 3.086 & 2.963 & 3.459 & 2.756 & 2.047 & 2.782 & 1.207 & 849 \\
\hline Dinamarca & 598 & 507 & 260 & 212 & 350 & 697 & 435 & 352 & 289 & 682 \\
\hline Holanda & 939 & 1.261 & 1.055 & 782 & 972 & 914 & 468 & 664 & 431 & 356 \\
\hline Polonia & 2 & 0 & 0 & 24 & 177 & 152 & 173 & 275 & 289 & 269 \\
\hline Austria & 384 & 201 & 230 & 326 & 446 & 306 & 150 & 494 & 120 & 135 \\
\hline España & 1.403 & 1.701 & 1.449 & 1.512 & 1.908 & 1.160 & 1.216 & 598 & 99 & 86 \\
\hline Bélgica & 1.094 & 983 & 687 & 474 & 981 & 764 & 740 & 551 & 385 & 80 \\
\hline Italia & 298 & 461 & 422 & 403 & 275 & 213 & 206 & 164 & 108 & 55 \\
\hline Noruega & 4 & 5 & 0 & 0 & 2 & 3 & 1 & 20 & 52 & 29 \\
\hline Eslovaquia & 4 & 0 & 0 & 24 & 20 & 60 & 42 & 65 & 39 & 27 \\
\hline Hungría & 0 & 0 & 0 & 5 & 44 & 9 & 7 & 17 & 10 & 12 \\
\hline Eslovenia & 0 & 0 & 0 & 3 & 4 & 8 & 8 & 24 & 20 & 9 \\
\hline Reino Unido & 315 & 203 & 139 & 129 & 52 & 56 & 36 & 95 & 25 & 9 \\
\hline Afganistán & 0 & 0 & 0 & 2 & 1 & 0 & 0 & 5 & 15 & 8 \\
\hline R. Checa & 1 & 8 & 0 & 24 & 76 & 19 & 17 & 32 & 28 & 8 \\
\hline Portugal & 71 & 81 & 75 & 82 & 108 & 64 & 56 & 62 & 6 & 5 \\
\hline Luxemburgo & 2 & 2 & 1 & 1 & 1 & 0 & 0 & 0 & 1 & 2 \\
\hline Paraguay & 2 & 0 & 0 & 1 & 0 & 0 & 0 & 1 & 1 & 2 \\
\hline
\end{tabular}

Fuente: Elaboración propia en base a datos obtenidos en World Trade Centre 2011 
Tabla $N^{\circ}$ 53: Detalle anual de las exportaciones alemanas de espárrago congelado en toneladas 2010-2001:

\begin{tabular}{|c|c|c|c|c|c|c|c|c|c|c|}
\hline Importadores & 2001 & 2002 & 2003 & 2004 & 2005 & 2006 & 2007 & 2008 & 2009 & 2010 \\
\hline Mundo & 957,8 & 1228,6 & 943,3 & 1094,8 & 1760,5 & 430,8 & 642,7 & 612,4 & 483,1 & 511,6 \\
\hline Francia & 34,2 & 7,7 & 36,9 & 23 & 158,8 & 109,7 & 154,5 & 167,4 & 129,3 & 101,2 \\
\hline Austria & 107,8 & 114,8 & 83,3 & 468,6 & 95,3 & 93,2 & 118,4 & 125,6 & 70,5 & 74 \\
\hline Holanda & 207,6 & 145,5 & 75,3 & 135,9 & 1173 & 7,4 & 89,2 & 48,7 & 104,4 & 73,6 \\
\hline Bélgica & 431,9 & 755,8 & 651,5 & 350 & 171,5 & 60,4 & 117,9 & 119,1 & 64,9 & 71,7 \\
\hline Italia & 19,5 & 28,5 & 57,4 & 23 & 11 & 35,8 & 5,2 & 8,2 & 41,6 & 58,9 \\
\hline Finlandia & 0 & 0 & 1,3 & 1,3 & 28,3 & 26,1 & 21 & 17 & 15 & 24,5 \\
\hline R. Checa & 0 & 0 & 0 & 0 & 0 & 0 & 1,9 & 8,8 & 3,5 & 15,1 \\
\hline Luxemburgo & 9,9 & 3,5 & 2,8 & 3,5 & 1,1 & 2,1 & 5,2 & 7,3 & 9,5 & 14,5 \\
\hline España & 2,3 & 1,4 & 0,9 & 15 & 12,2 & 13,3 & 46,4 & 56,1 & 19,2 & 11,8 \\
\hline Hungría & 0 & 0 & 0 & 0 & 0 & 0 & 0 & 0 & 0 & 10,1 \\
\hline Suiza & 111,9 & 102,3 & 20,4 & 12,6 & 46,4 & 45,7 & 6,9 & 26 & 8,6 & 5,7 \\
\hline
\end{tabular}

Fuente: Elaboración propia en base a datos obtenidos en World Trade Centre 2011. 


\section{Precios espárragos por mayor y menor dependiendo de la semana del año}

Tabla $\mathrm{N}^{\circ}$ 54: Detalle de precio mayorista espárragos alemanes y griegos "Clase Extra”, por semana y en Euros por Kg.:

\begin{tabular}{|c|c|c|}
\hline \multicolumn{3}{|c|}{ Espárrago Blanco alemán } \\
\hline \multicolumn{3}{|c|}{$16-26 \mathrm{~mm}, 100 \mathrm{Kg}$} \\
\hline Semana & 2009 & 2010 \\
\hline 1 & - & - \\
\hline 2 & - & - \\
\hline 3 & - & - \\
\hline 4 & - & - \\
\hline 5 & - & - \\
\hline 6 & - & - \\
\hline 7 & - & - \\
\hline 8 & - & - \\
\hline 9 & - & - \\
\hline 10 & - & $1.320,00$ \\
\hline 11 & $1.278,44$ & $1.418,06$ \\
\hline 12 & $1.391,67$ & $1.404,21$ \\
\hline 13 & $1.328,23$ & $1.488,06$ \\
\hline 14 & $1.237,80$ & $1.080,71$ \\
\hline 15 & $1.148,66$ & 786,67 \\
\hline 16 & 558,30 & 699,34 \\
\hline 17 & 429,93 & 556,43 \\
\hline 18 & 339,73 & 503,31 \\
\hline 19 & 387,50 & 614,38 \\
\hline 20 & 382,33 & 695,86 \\
\hline 21 & 433,68 & 554,63 \\
\hline 22 & 411,63 & 429,35 \\
\hline 23 & 452,08 & 405,29 \\
\hline 24 & 509,17 & 382,50 \\
\hline 25 & 633,75 & 520,97 \\
\hline 26 & 790,00 & 588,25 \\
\hline 27 & 500,00 & 452,75 \\
\hline 28 & - & 685,00 \\
\hline 29 & - & - \\
\hline 30 & - & - \\
\hline$\ldots$ & - & - \\
\hline 52 & - & - \\
\hline
\end{tabular}

Fuente: AMI - Marktbilanz Gemüse 2011

\begin{tabular}{|c|c|c|}
\hline \multicolumn{3}{|c|}{ Espárrago Blanco griego } \\
\hline \multicolumn{3}{|c|}{$16-26 \mathrm{~mm}, 100 \mathrm{Kg}$} \\
\hline Semana & 2009 & 2010 \\
\hline 1 & - & - \\
\hline 2 & - & - \\
\hline 3 & - & - \\
\hline 4 & - & - \\
\hline 5 & - & - \\
\hline 6 & - & - \\
\hline 7 & - & - \\
\hline 8 & - & - \\
\hline 9 & - & - \\
\hline 10 & - & 762,50 \\
\hline 11 & 658,33 & 865,91 \\
\hline 12 & 620,00 & 826,67 \\
\hline 13 & 696,25 & 848,33 \\
\hline 14 & 684,33 & 622,22 \\
\hline 15 & 717,60 & 457,39 \\
\hline 16 & 371,20 & 397,21 \\
\hline 17 & 238,00 & 328,33 \\
\hline 18 & 202,50 & 267,50 \\
\hline 19 & - & 327,29 \\
\hline 20 & - & 390,00 \\
\hline 21 & 235,00 & 346,88 \\
\hline 22 & - & 252,78 \\
\hline 23 & - & 225,00 \\
\hline 24 & - & - \\
\hline 25 & - & - \\
\hline 26 & - & - \\
\hline 27 & - & - \\
\hline 28 & - & - \\
\hline 29 & - & - \\
\hline 30 & - & - \\
\hline$\ldots$ & - & - \\
\hline 52 & - & - \\
\hline
\end{tabular}

Fuente: AMI - Marktbilanz Gemüse 2011 
Tabla N 55: Detalle de precio mayorista de espárragos alemanes y griegos "Clase I" detallado por semana:

\begin{tabular}{|c|c|c|}
\hline \multicolumn{3}{|c|}{ Espárrago blanco extranjero } \\
\hline \multicolumn{3}{|c|}{ Clase $1 € / k g$} \\
\hline Semana & 2009 & 2010 \\
\hline 1. Enero & - & - \\
\hline 2. & - & - \\
\hline 3. & - & - \\
\hline 4. & - & - \\
\hline 5. & - & - \\
\hline 6. Febrero & - & - \\
\hline 7. & - & - \\
\hline 8. & - & - \\
\hline 9. & - & - \\
\hline 10. Marzo & - & - \\
\hline 11. & - & - \\
\hline 12. & - & - \\
\hline 13. & 5,60 & 5,82 \\
\hline 14. Abril & 5,79 & 5,49 \\
\hline 15. & 5,89 & 4,75 \\
\hline 16. & 4,84 & 4,16 \\
\hline 17. & 4,07 & 4,24 \\
\hline 18. & 3,51 & 3,95 \\
\hline 19. Mayo & 3,21 & 4,00 \\
\hline 20. & 3,63 & 4,39 \\
\hline 21. & 3,90 & 5,33 \\
\hline 22. & 3,75 & 5,16 \\
\hline 23. Junio & - & - \\
\hline 24. & - & - \\
\hline 25. & - & - \\
\hline 26. & - & - \\
\hline 27. Julio & - & - \\
\hline 28. & - & - \\
\hline 29. & - & - \\
\hline 30. & - & - \\
\hline$\ldots$ & - & - \\
\hline 52. & - & - \\
\hline
\end{tabular}

Fuente: AMI - Marktbilanz Gemüse 2011

\begin{tabular}{|c|c|c|}
\hline \multicolumn{3}{|c|}{ Espárrago blanco alemán } \\
\hline \multicolumn{3}{|c|}{ Clase $1 € / k g$} \\
\hline Semana & 2009 & 2010 \\
\hline 1. Enero & - & - \\
\hline 2. & - & - \\
\hline 3. & - & - \\
\hline 4. & - & - \\
\hline 5. & - & - \\
\hline 6. Febrero & - & - \\
\hline 7. & - & - \\
\hline 8. & - & - \\
\hline 9. & - & - \\
\hline 10. Marzo & - & - \\
\hline 11. & - & - \\
\hline 12. & - & - \\
\hline 13. & - & - \\
\hline 14. Abril & - & - \\
\hline 15. & - & - \\
\hline 16. & 7,12 & 7,46 \\
\hline 17. & 5,73 & 6,48 \\
\hline 18. & 5,03 & 5,78 \\
\hline 19. Mayo & 4,47 & 5,79 \\
\hline 20. & 4,87 & 6,21 \\
\hline 21. & 5,21 & 6,16 \\
\hline 22. & 5,2 & 5,70 \\
\hline 23. Junio & 5,48 & 5,15 \\
\hline 24. & 5,59 & 5,02 \\
\hline 25. & 6,00 & 4,99 \\
\hline 26. & - & - \\
\hline 27. Julio & - & - \\
\hline 28. & - & - \\
\hline 29. & - & - \\
\hline 30. & - & - \\
\hline$\ldots$ & - & - \\
\hline 52. & - & - \\
\hline
\end{tabular}

Fuente: AMI - Marktbilanz Gemüse 2011

Tal como podemos observar en las tablas precedentes, el espárrago fresco es muy sensible a la época del año, como así también a la procedencia del mismo. 


\section{Canales de distribución en el mercado alemán para bienes de consumo perecederos 64}

¿Es Alemania una puerta de entrada a Europa? La respuesta es afirmativa y negativa a la vez. Aquel que logre establecer una buena base comercial en este país, ciertamente ya cumple con algunas de las condiciones para obtener el éxito en Europa. Pero, por otra parte aquel que disfruta del éxito en otros países europeos, no debe esperar que Alemania se encuentre a su disposición, y esto se debe a que:

- Dentro del contexto europeo, Alemania es el mercado más exigente en cuanto a calidad, precios y procesos de producción;

- Alemania es el país mejor consolidado desde el punto de vista comercial. Hacer que su producto forme parte del listado alemán significa un gran volumen de negocios, distribución con alcance nacional, y por ende, potencial para la ampliación de los negocios;

- Las cadenas comerciales alemanas se extienden con gran agresividad por otros países del continente (incluso Rusia y los nuevos miembros de la Unión Europea). Las centrales de compra de dichas cadenas comerciales se desempeñan en firmar sociedades que extiendan sus filiales;

- $\quad$ La legislación comercial alemana es la más exigente de toda Europa.

Por otro lado existe la posibilidad de desarrollar negocios directamente con otros países europeos. Pero, por sus propias características, el comercio con los países vecinos a Alemania casi nada significan en cuanto a la entrada a su mercado. Para los eventuales socios comerciales alemanes, eso no representa ganar en experiencia o credibilidad.

Cabe destacar dos aspectos:

${ }^{64}$ Elaborado en base a material y entrevistas realizadas en la Cámara de Industria y Comercio Argentino Alemana (DeutschArgentinische Industrie und Handelskammer). 
- Alemania no es un país para negocios oportunistas. Como empresarios, los proveedores latinoamericanos tienen que contar con un periodo de tiempo de uno a dos años para la consolidación de sus negocios. Ese período cubre las etapas comprendidas entre el contrato inicial, adecuación del producto/marketing al mercado alemán, etapa de experiencia y decisión final para su inclusión en el listado de compras. En contrapartida, grandes volúmenes de ventas, transparencia en los acuerdos y sociedades confiables se vislumbran como futura recompensa.

- La exportación no puede ser delegada. Transferir la exportación a agentes alemanes representa siempre un alto riesgo. Se vuelve imprescindible en la mayoría de los casos, invertir en la adecuación de los productos al mercado del consumidor. Asimismo es indispensable que los encargados de llevar adelante las negociaciones dominen el idioma.

Es bueno recordar que el comercio alemán se encuentra siempre en la búsqueda de la diversificación de productos, al que de lo que los proveedores argentinos pueden jactarse de contar con abundancia.

\subsection{El mercado alemán}

Con más de 82,5 millones de habitantes y una elevada renta per cápita Alemania es uno de los principales mercados del mundo. Con un alto grado de apertura es el segundo importador del mundo y absorbe el 7,4\% del comercio mundial. El mercado alemán es muy competitivo y segmentado, en él prima la calidad y la garantía de servicio. Con una de las normativas más restrictivas de la Unión Europea, Alemania marca tendencias en estándares y normativas.

Dos rasgos característicos del mercado son su polarización en diferentes segmentos de precios así como un creciente endurecimiento de la competencia que se traslada paulatinamente a los proveedores. Es uno de los países a escala mundial con mayor número de ferias internacionales.

Entre las distintas ciudades alemanas con gran tradición ferial, Düsseldorf goza de gran prestigio internacional. La Feria de Düsseldorf es uno de los tres recintos feriales alemanes con mayor volumen de ventas. De las aproximadamente 40 ferias sectoriales internacionales anuales, más de 20 son líderes en el ámbito internacional de los respectivos sectores.

\subsubsection{Su estructura}

El panorama de la distribución agroalimentaria alemana está dominado, al igual que en el resto de Europa, por la gran distribución organizada. Cada uno de estos grupos o cadenas de distribución 
alemanas tiene sus propias subcadenas en una estructura de tipo piramidal y suelen disponer de establecimientos en prácticamente todo el espectro de canales de venta de alimentación

El sistema de distribución en Alemania es muy eficaz y el esquema típico de los canales de distribución presenta un primer nivel de distribución en el que se puede optar por diversas alternativas, principalmente importadores y agentes comerciales.

En el segundo nivel comercial, aparecen las centrales de compra del comercio organizado ("cadenas de establecimientos de alimentación"), en algunos casos con delegaciones de compra en el ámbito regional repartidas por la geografía alemana.

El último escalón del nivel minorista, el comercio no organizado incluye el comercio minorista tradicional, las tiendas especializadas y tiendas "Feinkost" (Gourmet), éstos últimos con productos de un segmento alto.

\subsubsection{Canales de Distribución Mayorista}

Los principales canales de distribución mayorista en Alemania son los siguientes:

Cash \& Carry: establecimiento de venta mayorista dirigido a los comerciantes, que compran al contado y retiran los productos en el momento y con sus propios medios de transporte.

Zustellgrosshandel (mayoristas/repartidores): mayoristas que suministran regularmente una amplia gama de productos a domicilio a minoristas.

Großverbraucherzustelldienst (mayoristas para el canal Horeca): suministro regular de una gama de productos especializada a grandes clientes (gastronomía, cantinas y comedores sociales, etc.).

Großmärkte (mercados mayoristas): mercados mayoristas de productos alimentarios, con amplio surtido de frutas y hortalizas.

El sector Cash \& Carry lo lideran en Alemania los grupos Metro y Rewe. Metro Cash \& Carry es líder 
del mercado con una cuota del 57,7\% sobre el total de la facturación mayorista y 115 establecimientos. El negocio mayorista del grupo Rewe se compone principalmente de los establecimientos Cash \& Carry Fegro/Selgros. Los dos grupos de distribución dan gran importancia a los productos hortofrutícolas y, en general a los productos frescos dentro de su línea de negocio mayorista.

Los mercados mayoristas mueven en Alemania alrededor de cuatro millones de toneladas de frutas y hortalizas anualmente. Esta vía de distribución ha ido perdiendo importancia a lo largo de los años a medida que los canales de distribución minoristas organizados han fortalecido su presencia en el mercado.

Alrededor de 1.500 mayoristas, importadores y productores trabajan en los mercados mayoristas alemanes. Los principales consumidores de la oferta mayorista son minoristas independientes de alimentación, hoteles y restaurantes y otros grandes compradores como hospitales o cantinas, tiendas especializadas en frutas y hortalizas y mercados semanales.

Estos distribuidores son conscientes de la necesidad de mantener su cuota de mercado en un ambiente altamente competitivo en el que los precios cambian permanentemente. Para reposicionarse, el mercado mayorista está tratando de diferenciarse mediante una oferta de gran calidad, fresca y saludable (posible gracias a la unión de los productores) e innovadora (oferta de productos con un gran potencial de demanda, como los productos ecológicos).

Asimismo, hay una tendencia a la organización y asociación de los diferentes comercios mayoristas para crear una estructura fuerte que les permita, al menos, mantener su posición actual en el mercado.

En este sentido hay que mencionar la iniciativa de la asociación GFI Deutsche Grossmärkte ${ }^{65}$ que agrupa a mercados mayoristas alemanes en las principales ciudades como Berlín (Berliner Grossmarkt), Bremen (Grossmarkt Bremen), Düsseldorf (Grossmarkt Düsseldorf), Duisburg (Grossmarkt Duisburg), Dortmund (Grossmarkt Dortmund), Essen (Frischezentrum Essen), Frankfurt (Frische Zentrum Frankfurt am Main), Hamburg (Grossmarkt Hamburg), Hannover (Grossmarkt Hannover), Karlsruhe (Grossmarkt Karlsruhe), Mannheim (Grossmarkt Mannheim), München (Grossmarkthalle Munchen), Stuttgart (Grossmarkt Stuttgart).

\subsubsection{Canales de Distribución Minorista}

El negocio hortofrutícola mueve anualmente en el mercado alemán más de once mil millones de euros y es uno de los sectores de alimentación con mayor cuota de mercado. No obstante, las ventas se

\footnotetext{
${ }^{65}$ Disponible en www.grossmaerkte.org
} 
producen principalmente en establecimientos de tipo Discount. En la distribución de frutas y hortalizas dentro de los canales organizados de distribución minoristas, aproximadamente el $40 \%$ de facturación y el $50 \%$ del volumen vendido se realiza en establecimientos de descuento.

Desde hace unos años se observa que el canal de descuento está incrementando su oferta en frutas y hortalizas frescas, a pesar de que tradicionalmente su estrategia se ha venido concentrando en un surtido reducido de productos con alta rotación de ventas. El grupo discount LIDL es, en ese sentido, puntero con su oferta de más de 50 artículos en hortalizas y 30 en frutas, seguido por las tiendas de descuento Netto Schels, del grupo EDEKA.

Debido al auge de los establecimientos de tipo discount, que se han convertido en los principales lugares de compra de productos alimenticios, los pequeños supermercados, mercados de la calle y tiendas de alimentación especializadas han ido perdiendo parte de su clientela. Aunque los consumidores aún acuden a establecimientos especializados, mercados semanales, incluso directamente al productor, la tendencia parece imparable.

Los principales canales de distribución minorista en Alemania son los siguientes:

SB-Warenhaus (Gran Hipermercado): establecimiento de autoservicio situado fuera de los centros de las ciudades, con una superficie superior a $\operatorname{los} 5000 \mathrm{~m}^{2}$, con un amplio surtido de productos del sector alimentación (Food) y Non Food.

Verbrauchermarkt (Hipermercado de Alimentación): establecimiento de autoservicio con surtido único en alimentación y una superficie superior a $1500 \mathrm{~m}^{2}$ e inferior a $5000 \mathrm{~m}^{2}$.

Grosser Supermarkt (antes: Kleinverbrauchermarkt-Pequeño Hipermercado): establecimiento de autoservicio con surtido único en alimentación y una superficie superior a $800 \mathrm{~m}^{2}$ e inferior a $1500 \mathrm{~m}^{2}$.

Warenhaus (Gran Almacén): establecimientos situados en el centro de una ciudad, con amplio surtido textil, productos para el hogar y alimentación, separados por departamentos. La mayoría del surtido en estos establecimientos corresponde a productos no alimentarios. 
Kaufhaus (Almacén): local de similar situación al anterior, pero con surtido más reducido en cantidad, calidad y precio. Al igual que los grandes almacenes, la mayoría de los productos que conforman el surtido de estos establecimientos pertenecen al área de nonfood.

Supermarkt (Supermercado): establecimiento de autoservicio con surtido en alimentación y una superficie entre 400 y $800 \mathrm{~m}^{2}$.

SB-Geschäft (Autoservicio de Alimentación): tienda de alimentación con una superficie de hasta 400 $\mathrm{m}^{2}$.

Convenience Store (Tienda de "Conveniencia"): pequeño establecimiento de autoservicio con una superficie de hasta $350 \mathrm{~m}^{2}$, diseñado para satisfacer las necesidades urgentes de los consumidores, así como para su comodidad, con un surtido limitado de productos, principalmente platos preparados, snacks, bebidas, dulces, etc.

Tankstellen Shop (Tienda de Gasolinera): tienda de autoservicio, generalmente con un surtido limitado de productos, no sólo de alimentación, orientado a las compras de último momento o a las llamadas compras de impulso.

Discountgeschäft y Hard-Discount (Tienda de Descuento y Descuento Duro): tienda de alimentación, con una superficie inferior a $700 \mathrm{~m}^{2}$, incluyendo también frescos. Los establecimientos de descuento se caracterizan por un reducido surtido de productos, una decoración sencilla y, sobre todo, por los bajos precios y ausencia de servicio al cliente.

Drogeriemarkt (Droguería): establecimiento especializado de autoservicio de productos de droguería, aseo personal, limpieza e higiene, aunque también con cierto surtido en alimentos (alimentación seca, functional food, etc).

Tiendas minoristas especializadas: establecimientos especializados en una gama de productos: 
Feinkost (Gourmet): con productos de calidad superior o especialidades.

$>$ Metzgereien (carnicerías).

$>$ Bäckereifachmarkt (panadería/confitería).

$>$ Obst - und Gemüseläden (fruterías).

Pasando a analizar los principales grupos de distribución alimentaria en Alemania, los grupos más importantes son: Edeka (Edeka + AVA), Rewe (Rewe AG + Rewe Dortmund), Aldi (Nord + Sud), Metro (Real + Metro + Kaufhof + Extra), Lidl + Schwarz (Kaufland + Lidl), Tengelmann (Plus + Kaiser's), SPAR, y Grupo Dohle.

Gráfico $\mathrm{N}^{\circ}$ 58: Participación de los grupos empresarios en la distribución:

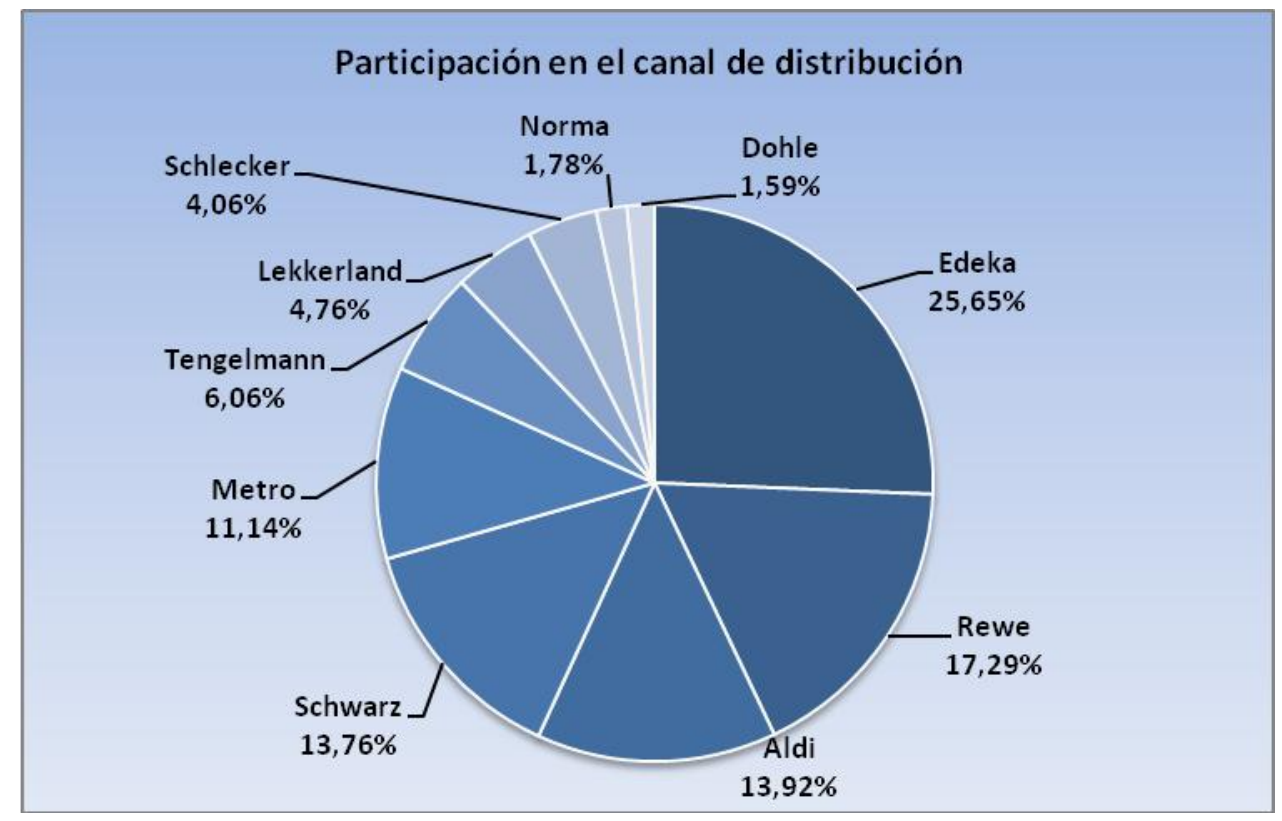

Fuente $^{66}:$ M-M Eurodata 2010

\subsubsection{Fuerte competencia por la ubicación}

La competencia en el mercado ocurre en función al precio y a la ubicación de los locales. Como los buenos locales son difíciles de encontrar, muy caros (€200 a €600 por $\mathrm{m}^{2} / \mathrm{mes}$ ) y provistos de contratos de alquiler a largo plazo (10 a 20 años), los eventuales puntos de venta que demuestren no ser lucrativos, no pueden simplemente ser cerrados. A consecuencia de ello, son frecuentes las caídas de

\footnotetext{
${ }^{66}$ Datos obtenidos en www.mm-eurodata.com y del Servicio de Comercio Exterior Español, www.icex.es.
} 
rentabilidad con fuerte presión sobre los precios de compra y venta de los productos. Lo que ocurre también es que se intenta retornar a los proveedores todos los costos relacionados con la inversión en filiales y el proceso de comercialización.

\subsubsection{Gran enfoque en el precio}

- En Alemania los precios de los alimentos prácticamente no aumentaron después de haber finalizado la Segunda Guerra Mundial.

- El comercio alemán se entiende mas como logística que como comercialización. A eso se debe la focalización en el precio de compra, logística, ubicación de locales y eficiencia en los procesos.

- El retroceso en el desarrollo mercadotécnico en casi todos los segmentos, eleva la disputa de la participación del mercado.

- Presentación muy transparente de los precios y sus descuentos. El aumento de precios es un hecho casi desconocido para el consumidor, ya que las reducciones son duraderas.

- La búsqueda de mejores precios se convirtió en una costumbre de los consumidores.

- Los consumidores se ven forzados a adoptar comportamientos más conscientes con relación al precio a la hora de efectuar las compras debido a la condición de los empleos, el estancamiento de los niveles salariales y por las difusas perspectivas de fututo (v.g. con relación a las jubilaciones).

- Análisis de producto y consumo, como "Stiftung Warentest" y "Öko-test", refuerzan siempre la ventaja cualitativa de las marcas propias. 


\subsubsection{Triunfo de las marcas propias y de las tiendas de descuento}

- El área de las marcas propias presenta un crecimiento, siendo hoy en día cada segundo producto vendido de una marca propia.

- Esencial para esta tendencia es la búsqueda de la credibilidad y diferenciación. Por un lado, el consumidor espera encontrar en todas las cadenas, productos de calidad a los precios ofrecidos por ALDI (= eslabón básico del precio) y, por otro lado, el comercio solamente puede diferenciarse entre sí mediante la venta de marcas exclusivas o de marcas propias (=marcas propias con alto valor agregado).

- Todas las redes ofrecen marcas propias comparables a la red de ALDI. El principio es claro: calidad de la marca líder, al precio de ALDI. Cada uno o dos años, se reevalúa la situación de cada producto.

- La competencia de comercialización ha mejorado. De momento, se desarrollan marcas propias de alto valor que son bien aceptadas por los consumidores.

- El único canal de distribución con crecimiento real es el almacén minorista de alimentos y el negocio de las farmacias, ambos con descuento.

\subsubsection{Protección al consumidor}

Las organizaciones de protección al consumidor son de suma importancia en Alemania. El comercio impone sus exigencias aún cuando desde el punto de vista del consumidor no siempre son importantes los análisis y el otorgamiento de sellos de calidad. Si el resultado de un análisis de calidad, efectuado por una institución de renombre fuere insatisfactorio, la consecuencia inmediata generalmente es el retiro del producto del mercado.

Las instituciones y los sellos de calidad más importantes son: 
- Öko-Test: Es el análisis ecológico que evalúa la sustentabilidad ecológica de los productos y embalajes.

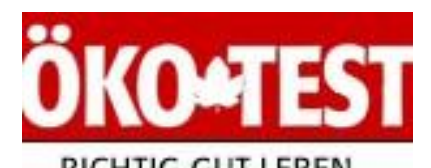

RICHTIG GUT LEBEN

- Stiftung Warentest: Se trata de un análisis de productos que es efectuado por una fundación que evalúa y compara la calidad de las marcas y de las marcas propias.

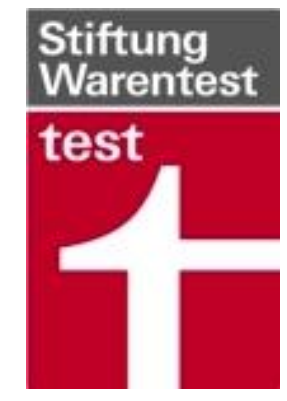

- TÜV: Es el análisis efectuado por la Asociación Alemana de Control Técnico, que certifica la aptitud para el tránsito, especialmente de productos técnicos.

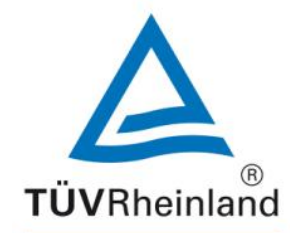

- Sellos de calidad expedidos por asociaciones: Los sellos para productos cosméticos naturales, como los de la BDIH, se han convertido en una condición para aparecer en los estantes (lo que en la práctica, significa también una barrera para la entrada de productos extranjeros). 


\subsubsection{Algunas costumbres del comercio alemán}

El lema principal de los compradores alemanes es reducir los precios y no incurrir en errores. Por eso, nuevos proveedores y nuevos productos son observados con escepticismo. En cada negociación también debieran de ser discutidas las responsabilidades por los riesgos objetivos y subjetivos, aparte de evaluar las posibilidades con que cuenta un nuevo producto. El comprador alemán NO es un emprendedor.

Con relación a las costumbres del comercio alemán es dable destacar:

- No se realizan contratos específicos con tópicos como: definición de productos, precio de entrega, plazo de pago, actividades promocionales, etc. El mercado simplemente transfiere todos los riesgos al proveedor.

- Generalmente son válidos los acuerdos de un año de duración. En el caso de los precios de compra para marcas, los valores son líquidos. Para marcas propias, inciden costos adicionales de publicidad, y también se deben prever negociaciones intermedias en un periodo inferior a un año.

- Es normal que exista competencia entre marcas propias. En el caso de las marcas, se esperan mejoras de precio del orden del $2 \%$ anual.

- No se acostumbra el uso de tarjetas de crédito o instrumentos similares.

- Los plazos de pago oscilan entre 30 y 60 días, ("puesto de depósito"- DDP), a partir de la fecha de entrega.

- Se solicita a menudo un aval bancario como garantía contra el no suministro.

- Las exigencias logísticas son muy particulares y nada flexibles. Las entregas del tipo CIF o FOB no son usuales. (El pago en el depósito es un factor importante, con transferencia de riesgos al proveedor). En el comercio minorista de alimentos, es común que se entregue todo el conjunto 
de mercaderías, en lotes semanales y según las normas ECR. En el mercado de farmacias es común efectuar un pago anticipado y la entrega parcial en filiales.

- El idioma comercial es el alemán. La presencia personal del socio durante las negociaciones es absolutamente indispensable.

- La inclusión de un proveedor en un sistema centralizado de tecnologías de la información (information technology), generalmente es asociada con costos elevados (informaciones bancarias, inclusión en el sistema de reciclaje - punto verde-, etc.). Toda esta burocracia acarrea casi siempre la necesidad de una representación comercial (física y jurídica) en Alemania.

\subsection{Detalle de los supermercados en Alemania67}

El presente apartado tiene como objetivo dar un panorama general de cómo se encuentra organizado el sector super e hipermercadista en Alemania. A continuación se presentan los datos de contacto de las distintas cadenas, junto a una breve descripción de las mismas y del mercado en el cual operan. Con más de 82 millones de habitantes, el mercado alemán es uno de los más importantes de toda Europa. Además, se caracteriza por ser muy competitivo y segmentado, con una saturación de la oferta en numerosos sectores y productos, apareciendo en él como primordiales la calidad y los servicios. Las principales zonas económicas son las de Renania-Westfalia, Baden Württemberg (estado federado alemán en el que se basa el presente trabajo de investigación), Baviera, Hamburgo, Berlín y Hannover así como Leipzig.

La estructura de la distribución alemana se caracteriza por:

• Un gran número de pequeños almacenes independientes.

- Bajo nivel de concentración del sector, en comparación con los principales mercados europeos (Francia, Reino Unido, Bélgica).

\footnotetext{
${ }^{67}$ Basado en trabajos realizados por el ICEX (instituto de comercio exterior español) y de la Fundación ExportAr.
} 
- Predominio de la distribución en ciudades y zonas urbanas.

• Escasa implantación del formato "hipermercado".

- Dominación del formato "hard discount" y la importancia de la venta a distancia (comercio electrónico, telecompra).

La distribución alemana se organiza según los siguientes canales: Comercio al por menor tradicional (24,8\%); Grandes superficies especializadas (22\%); Cadenas de almacenes no alimentarias (13\%); Grandes superficies de Bricolaje (11,7\%); Hard Discount (11\%); Supermercados (7,9\%); Venta a domicilio (5,8\%) y Grandes almacenes $(3,8 \%)$.

Los tres primeros grupos de distribución alemanes son Metro, Rewe y Edeka/Ava. El "hard discount" es el primer formato de distribución alimentaria, registrando un crecimiento interanual que ronda el $10 \%$, generando un $40 \%$ de las ventas alimentarias totales.

El desarrollo de los "hard discount" como LIDL o ALDI obligó a los distribuidores a sumergirse en una guerra de precios: de esta manera, existe el riesgo de que los insuficientes márgenes retrasen la modernización de los puntos de venta y el desarrollo de los nuevos conceptos de distribución. Una tendencia a la concentración tuvo lugar y grupos como Karstadt-Quelle (que a mediados de esta década sufrió dificultades económicas) y Edeka-Tengelmann libran una competencia dura, haciendo bajar los márgenes de los proveedores. 


\subsubsection{Listado de los principales supermercados}

Tabla $\mathrm{N}^{\circ}$ 56: Listado de los principales supermercados en Alemania:

\begin{tabular}{|c|c|}
\hline $\begin{array}{l}\text { escas. } \\
\text { omicilio: Benzstrasse 10, (24148) Kiel. } \\
\text { el.: (49 43) } 17250-0 \\
\text { leb: http://www.alles.coop } \\
\text { mail: info@coop.de } \\
\text { ontacto: Birol Cay (Departamento de compras) } \\
\text { irol.cay@coop.de } \\
\text { el: (49 43) } 17285-3\end{array}$ & $\begin{array}{l}\text { Ratio Handel Gmbh \& Co. } \\
\text { Principales productos importados: Productos } \\
\text { alimenticios en general. } \\
\text { Domicilio: Albersloher Weg 194, (48155) Münster } \\
\text { Tel.: (49 25) } 16960 \\
\text { Fax: (49 25) } 1696283 \\
\text { E-mail: info@ratio-handel.de } \\
\text { Web: Http://www.ratio-handel.de } \\
\text { Contacto: Reinhard Winkler: rwinkler@ratio-handel.de }\end{array}$ \\
\hline $\begin{array}{l}\text { Edeka Group } \\
\text { Principales productos importados: Congelados, } \\
\text { conservas, frutas y hortalizas frescas. } \\
\text { Domicilio: New-York-Ring 6, (22297) Hamburgo. } \\
\text { Tel.: (49 40) } 6770 /(4940) 302090 \\
\text { Fax: (49 40) } 63772231 \\
\text { E-mail: info@edeka.de } \\
\text { Web: http://www.edeka.de } \\
\text { Contacto: A. Wittner: alain.wittner@edeka.de } \\
\text { Tel.: (49 40) } 63772637 \text { (Manager-Departamento de }\end{array}$ & $\begin{array}{l}\text { Rewe Group } \\
\text { Principales productos importados: Frutas y hortalizas. } \\
\text { Domicilio: Domstraße 20, (50688) Köln } \\
\text { Tel.: (49 22) } 1490 \\
\text { Fax: (49 22) } 11499000 \\
\text { Web: Http://www.rewe-group.com } \\
\text { Contacto: Arun Mehara: arun.mehara@rewe- } \\
\text { group.com }\end{array}$ \\
\hline $\begin{array}{l}\text { rincipales productos importados: Aliment } \\
\text { ongelados y en conserva. } \\
\text { omicilio: Schlueterstrasse 3, (40235) Dusseldorf. } \\
\text { el.: (49 21) } 19690 \\
\text { ax: (49 21) } 19694904503 \\
\text {-mail: kontakt@metro-mgb.com } \\
\text { Veb: http://www.metrogroup.de }\end{array}$ & $\begin{array}{l}\text { Domicilio: Gerloser Weg 72, (36039) Fulda. } \\
\text { Tel.: (49 66) } 11040 \\
\text { Fax: (49 66) } 1104876 \\
\text { E-mail: info@tegut.com } \\
\text { Web: Http://www.tegut.com } \\
\text { Contacto: C. Mueller: mueller_c@tegut.com; S. } \\
\text { Rauschenberg: rauschenberg_s@tegut.com }\end{array}$ \\
\hline
\end{tabular}




\subsubsection{Listado de importadores alemanes de espárragos frescos}

Tabla $N^{\circ}$ 57: Listado de los principales importadores alemanes de espárragos frescos:

\begin{tabular}{|c|c|}
\hline $\begin{array}{l}\text { A \& B Fruchthandels GmbH } \\
\text { Dirección: Im Bregel 7, Esslingen. } \\
\text { Teléfono: } 0049711-5407497 \\
\text { Fax : (0049) } 711-5407499 \\
\text { Email: info@abfruchthandel.com } \\
\text { Web: www.abfruchthandel.de } \\
\end{array}$ & $\begin{array}{l}\text { Agentur Preis\&Wert Glutenfreier Delikatessen } \\
\text { Shop } \\
\text { Dirección: Schlesier Str. 10, Limburgerhof. } \\
\text { Teléfono: 0049-175-5253377 } \\
\text { Fax:0049-6236-46026 } \\
\text { Email: preis.wert@t-online.de } \\
\text { Web: www.glutenfreier-delikatessen-shop.de } \\
\end{array}$ \\
\hline $\begin{array}{l}\text { D \& G Fruchtagentur Import - Export } \\
\text { Dirección: Langwiesenweg 32, Stuttgart. } \\
\text { Teléfono: 0049-0711-2488277 } \\
\text { Fax: 0049-0711-4800324 } \\
\text { Web: www.dilbaz.com.tr } \\
\text { Contacto: Herr Ahmet Dilbaz. }\end{array}$ & $\begin{array}{l}\text { DDV Früchte Handels GmbH } \\
\text { Dirección: Karlstraße 13, Tettnang. } \\
\text { Teléfono: 0049-07542-93370 } \\
\text { Fax:0049-07542-53332 } \\
\text { Email: info@ddv-fruit.com } \\
\text { Web: www.ddv-fruit.de }\end{array}$ \\
\hline $\begin{array}{l}\text { Niggemann Food Frische Market GmbH } \\
\text { Dirección: Speicherstrasse 6-8 D-44809, Bochum. } \\
\text { Teléfono: 0049-234-9037-00 } \\
\text { Fax: 0049-234-9037-124 } \\
\text { Email: info@niggemann.de } \\
\text { Web: www.niggemann.de }\end{array}$ & $\begin{array}{l}\text { Francesco Albrizio GmbH } \\
\text { Dirección: Schiestlstraße 10, München. } \\
\text { Teléfono: 0049-89-74735690 } \\
\text { Fax:0049-89-7254223 } \\
\text { Email: albrizio@t-online.de }\end{array}$ \\
\hline $\begin{array}{l}\text { E.H. Worlee \& Co. (GmbH \& Co.) } \\
\text { Dirección: Grusonstrasse } 22 \text { D-22113, Hamburg. } \\
\text { Teléfono: 0049-40-733-33-0 } \\
\text { Fax: 0049-40-733-33-1170 } \\
\text { Email: info@worlee.de } \\
\text { Web: www.worlee.de }\end{array}$ & $\begin{array}{l}\text { G. Zondler Früchte GmbH \& Co. KG } \\
\text { Dirección: Schaffhausenstraße 109, Tübingen. } \\
\text { Teléfono: 0049-07071-33035 } \\
\text { Fax: 0049-07071-31430 } \\
\text { Email: m.zondler@zondler.de } \\
\text { Web: www.zondler.de }\end{array}$ \\
\hline $\begin{array}{l}\text { Mario Andretta \& Co. Fruchthandelgesellschaft } \\
\text { m.b.H. } \\
\text { Dirección: Thalkirchner Straße 81, München. } \\
\text { Teléfono: 0049-089-726150 } \\
\text { Fax:0049-089-7261542 } \\
\text { Email: ag@andretta.de } \\
\text { Web: www.andretta.de }\end{array}$ & $\begin{array}{l}\text { International Fruchtimport Gesellschaft } \\
\text { Weichert \& Co. } \\
\text { Dirección: Bankstrasse 28 D-20097 Hamburg } \\
\text { Teléfono: 0049-40-329000 } \\
\text { Fax: 0049-40-329000199 } \\
\text { Email: info@interweichert.de } \\
\text { Web: www.interweichert.de } \\
\end{array}$ \\
\hline $\begin{array}{l}\text { Kretschmer GmbH } \\
\text { Dirección: Josef-Eicher-Str.10, Frankfurt. } \\
\text { Teléfono: 0049-69439632 } \\
\text { Fax: 0049- 69439632 } \\
\text { Contacto: Frau Miehrig } \\
\text { Email: kretschmer-frucht@live.de }\end{array}$ & $\begin{array}{l}\text { Nordgemüse Hamburg Krogmann KG } \\
\text { Dirección: Barsbüttlerstrasse 67, Hamburg. } \\
\text { Teléfono: 0049-40-6540940 } \\
\text { Fax: 0049-40-65492480 } \\
\text { Email: info@nordgemuese.de } \\
\text { Web: www.nordgemuese.de }\end{array}$ \\
\hline
\end{tabular}




\begin{tabular}{|c|c|}
\hline $\begin{array}{l}\text { Prima-fruta Fruchthandelsgesellschaft mbH } \\
\text { Dirección: Fabrikastationstraße 26, Mannheim. } \\
\text { Teléfono: 0049-0621-4389111 } \\
\text { Fax: 0049-0621-4389130 } \\
\text { Email: baron@prima-frutta.com } \\
\text { Web: www.prima-frutta.com }\end{array}$ & $\begin{array}{l}\text { Sahin GmbH } \\
\text { Dirección: Weinweg 43, Karlsruhe. } \\
\text { Teléfono: 0049-0721-6189920 } \\
\text { Fax: 0049-0721-6189929 } \\
\text { Email: sahingmbh@t-online.de } \\
\text { Web: www.sahinggmbh.de }\end{array}$ \\
\hline $\begin{array}{l}\text { Wilhelm Braun GmbH } \\
\text { Dirección: Eckstraße 3, Bretzfeld. } \\
\text { Teléfono: 0049-7946-9499081 } \\
\text { Fax: 0049-7946-9499082 } \\
\text { Email: Contacto a través de la página web } \\
\text { Web: www.wilhelm-braun.com }\end{array}$ & $\begin{array}{l}\text { Zerres \& Co. GmbH } \\
\quad \text { Dirección: Wilhelm-Herbst-Strasse 12, Bremen. } \\
\text { Teléfono: 0049-421-9898480 } \\
\text { Fax: 0049-421-98984882 } \\
\text { Email: info@zerresfruitpartners.com } \\
\text { Web: www.zerresfruitpartners.com }\end{array}$ \\
\hline $\begin{array}{l}\text { T. PORT (GmbH \& Co) } \\
\text { Dirección: Kontorhaus Grossmarkt - Lippelstrasse } \\
1 \text { D-20097 Hamburg } \\
\text { Teléfono: 0049-40-301000-22 } \\
\text { Fax:0049-40-301000-66 } \\
\text { Email: info@port-international.de } \\
\text { Web: www.tport.de }\end{array}$ & $\begin{array}{l}\text { Werner Ebert GmbH + Co. KG } \\
\text { Dirección: Langwiesenweg 30, Stuttgart. } \\
\text { Teléfono: 0049-0711-4804510 } \\
\text { Fax: 0049-0711-48045150 } \\
\text { Email: werner-ebert@werner-ebert.de } \\
\text { Web: www.werner-ebert.de }\end{array}$ \\
\hline $\begin{array}{l}\text { Organix4u GmbH } \\
\text { Dirección: Buchweg 4, Denklingen. } \\
\text { Teléfono: 0049-8243-9609216 } \\
\text { Fax: 0049-8243-9609217 } \\
\text { Email: info@organix4u.com } \\
\text { Web: www.organix4u.com }\end{array}$ & $\begin{array}{l}\text { Kärcher GmbH \& Co. KG } \\
\text { Dirección: Langwiesenweg 30, Stuttgart. } \\
\text { Teléfono: 0049-0711-168870 } \\
\text { Fax: 0049-0711-1686542 } \\
\text { Email: stuttgart@kaercher-fruchtimport.de } \\
\text { Web: www.kaercher-fruchtimport.de }\end{array}$ \\
\hline $\begin{array}{l}\text { Leo Ochs Fruchtimport - Agentur } \\
\text { Dirección: Im Schiffelland 18, St. Ingbert / Saar. } \\
\text { Teléfono: 0049-06894-870021 } \\
\text { Fax: 0049-06894-870700 } \\
\text { Email: leo.ochs@fruchtagentur.de } \\
\text { Web: www.leo-ochs-fruchagentur.de }\end{array}$ & $\begin{array}{l}\text { Görger \& Zorn GmbH } \\
\text { Dirección: Weinweg } 43-D-76137, \text { Karlsruhe. } \\
\text { Teléfono: 0049-721-902040 } \\
\text { Fax: 0049-721-96204-32 } \\
\text { Email: info@goerzo.de } \\
\text { Web: www.goergerzorn.de }\end{array}$ \\
\hline $\begin{array}{l}\text { Fritz Burger GmbH \& Co. KG } \\
\text { Dirección: Leyherstraße 107, Nürnberg. } \\
\text { Teléfono: (0049) } 911-313119 \\
\text { Fax: (0049) } 911-317543 \\
\text { Email: burger.fruchtimport@arcor.de } \\
\text { Web: www.burger-fruchtimport.de }\end{array}$ & $\begin{array}{l}\text { Conti-Frucht Busam GmbH } \\
\text { Dirección: Raiffeisenstraße 20, Oberkirch. } \\
\text { Teléfono: 0049-7802-928730 } \\
\text { Fax: 0049-7802-50330 } \\
\text { E-mail: busam@conti-frucht.de } \\
\text { Web: www.conti-frucht.de }\end{array}$ \\
\hline
\end{tabular}




\subsubsection{Listado de importadores alemanes de espárragos en conserva}

Tabla $\mathrm{N}^{\circ}$ 58: Listado de los principales importadores alemanes de espárragos en conserva:

\begin{tabular}{|c|c|}
\hline $\begin{array}{l}\text { Vinothello Weine \& Spezialitäten KG } \\
\text { Dirección: Laufamholzstraße 51, Nürnberg. } \\
\text { Teléfono: 0049-911-5698723 } \\
\text { Fax: 0049-911-5698724 } \\
\text { Contacto: Frau Manuela Lutz } \\
\text { Email: info@vinothello.de } \\
\text { Web: www.vinothello.de }\end{array}$ & $\begin{array}{l}\text { dwp eG } \\
\text { Dirección: Hinzistobler Str. 10, Ravensburg } \\
\text { Teléfono: 0049-751-361550 } \\
\text { Fax: 0049-751-36155044 } \\
\text { E-mail: info@dwp-rv.de } \\
\text { Web: www.dwpeg.de }\end{array}$ \\
\hline $\begin{array}{l}\text { Fa. TiLa-Lachenmaier GmbH \& Co. KG } \\
\text { Dirección: Reisersberg 8, Plüderhausen. } \\
\text { Teléfono: 0049-7181-80040 } \\
\text { Fax: 0049-7181-800460 } \\
\text { Email: info@tila-lachenmaier.de } \\
\text { Web: www.tila-lachenmaier.de }\end{array}$ & $\begin{array}{l}\text { Gaumenfreuden24.de } \\
\text { Dirección: Zeppelinstr. 13, München. } \\
\text { Teléfono: 0049-89-96169770 } \\
\text { Email: gaumenfreuden24@aol.de } \\
\text { Web: www.gaumenfreunden24.de }\end{array}$ \\
\hline $\begin{array}{l}\text { Gourmet Berner }{ }^{\circledast} \text { GmbH \& Co. KG } \\
\text { Dirección: Boschstr. 7, Weinstadt. } \\
\text { Teléfono: 0049-7151-2051360 } \\
\text { Fax: 0049-7151-2051361 } \\
\text { Email: info@gourmetberner.de } \\
\text { Web: www.johannesberner.de }\end{array}$ & $\begin{array}{l}\text { Rolf Nagel GmbH } \\
\text { Dirección: Bismarckstraße 6, Versmold. } \\
\text { Teléfono: 0049-5423-94660 } \\
\text { Fax: 0049-5423-946666 } \\
\text { Email: zentrale@rolfnagel.de } \\
\text { Web: www.rolfnagel.de }\end{array}$ \\
\hline $\begin{array}{l}\text { GUSTUS Feinkost K. Tuncay } \\
\text { Dirección: Neustadt Str. 22, Moosburg. } \\
\text { Teléfono: 0049-8761-7291911 } \\
\text { Fax:0049-8761-729344 } \\
\text { Email: gustus-feinkost@gmx.de } \\
\text { Web: www.gustus-feinkost.de }\end{array}$ & $\begin{array}{l}\text { Hans Speidel GmbH - Obst und Gemüse Import } \\
\text { Dirección: Frischezentrum / Josef-Eichler-Str. 10, } \\
\text { Frankfurt am Main. } \\
\text { Teléfono: 0049-69-432845 } \\
\text { Fax: 0049-69-4930425 } \\
\text { Email: info@speidel-fruchtimport.de } \\
\text { Web: www.speidel-fruchtimport.de }\end{array}$ \\
\hline $\begin{array}{l}\text { Hausladen Fruchthandelsgesellschaft mbH } \\
\text { Dirección: Schäftlarnstr. 8, München. } \\
\text { Teléfono: 0049-089-720140 } \\
\text { Fax:0049-089-7201450 } \\
\text { Email: info@hausladen-frucht.de } \\
\text { Web: www.hausladen-frucht.de }\end{array}$ & $\begin{array}{l}\text { Hebert van der Hamm } \\
\text { Dirección: Gottlieb-Daimler-Strasse 14, Mannheim. } \\
\text { Teléfono: 0049-0621-460070 } \\
\text { Fax:0049-0621-4600742 } \\
\text { Email: info@vanderhamm.de } \\
\text { Web: www.vanderhamm.de }\end{array}$ \\
\hline $\begin{array}{l}\text { IMEX Handelgesellschaft } \\
\quad \text { Dirección: Äußere Wiener Str.19, Regensburg. } \\
\text { Teléfono: 0049-941-466720 } \\
\text { Fax: 0049-941-4667230 } \\
\text { Email: IMEX-Regensburg@t-online.de } \\
\text { Web: www.imex-regensburg.de }\end{array}$ & $\begin{array}{l}\text { Importhaus Wilms / Impuls GmbH \& Co. KG } \\
\text { Dirección: Am Klingenweg 6a, Walluf. } \\
\text { Teléfono: 0049-6123-99900 } \\
\text { Fax: 0049-6123-9990199 } \\
\text { Email: info@importhaus-wilms.de } \\
\text { Web: www.importhaus-wilms.de }\end{array}$ \\
\hline
\end{tabular}




\section{JoWa Handels GmbH}

Dirección: Am Mühlenberg 8, Wittenburg.

Teléfono: 0049-38852-233005

Email: info@jowahandel.de

Contactos: Frau Katrin Gural,

katrin.gural@jowahandel.de

Web: www.JoWaHandel.de

Kurt Ullrich Geflügel - Wild - Tiefkühlkost

Dirección: Von-Humboldt Strasse 10, Heppenheim.

Teléfono: 0049-6252-126050

Fax: 0049-6252-1260510

Email: info@kurtullrich.de

Web: www.kurtullrich.de

Messmer Import Export GmbH

Dirección: An der Mühle 3, Bliedersdorf.

Teléfono: 0049-4163-81490

Email: info@messmer-import.de

Web: www.messmer-import.de

\section{Feinkost Spina GmbH}

Dirección: Maria-Probst-Str. 49, München.

Teléfono: 0049-89-3169390

Fax: 0049-89-31693999

Email: info@spina.de

Web: www.spina.de

Bioexpress - Toni Marchetti

Dirección: Hauptstrasse 43, Karben.

Teléfono: 0049-6039-933904

Fax: 0049-6039-933914

Email: service@bioexpress.de

Web: www.bioexpress.de

Frank Hoffmann Konserven $\mathbf{G m b H}$

Dirección: Dachweg 12 - 51109 Köln (Brück)

Teléfono: 0049-221-8295800

Fax: 0049-221-82958018

Email: contact@victor-konserven.com

Web: www.victor-konserven.com

Oberpfälzische Konserven-Industrie Schwandorf GmbH

\& Co. $K G$

Dirección: In der Trift 92421 Schwandorf

Teléfono: 0049-9431- 71660

Fax: 0049-40-9431-4 2988

Email: info@okis.de

web: www.okis.de
Küper - Import H. Küper GmbH

Dirección: Revierstr. 7-9, Oberhausen.

Teléfono: 0049-208-629550

Fax: 0049-208-6295555

Email: info@kueper-import.de

Web: www.kueper-import.de

Lazzaro Tavaglione Import Gmbh

Dirección: Siemensstr. 17, Hasloch.

Teléfono: 0049-6324-80388

Fax: 0049-6324-82390

Email: contacto a través de la página web

Web: www.tavaglionegmbh.de

Feinkost Böhm GmbH

Dirección: Kronprinzstraße 6, Stuttgart.

Teléfono: 0049-711-227560

Fax: 0049-711-292625

Email: kontakt@feinkost-boehm.de

Web: www.feinkost-boehm.de

Fine Food Feinkost Mühlenberg GmbH \& Co.KG

Dirección: Südring 3, Wittenburg .

Teléfono: 0049-38852-52376

Fax: (0049) $38852-53008$

Web: www.fine-food-feinkost.de

Edwin Lorenz GmbH \& Co. KG

Dirección: Hogenfelde 28 - D-22848 Hamburg.

Teléfono: 0049-40-528877-40

Fax: 0049-40-528877-41

Email: kontakt@edwinlorenz.de

Web: www.edwinlorenz.de

Feinkost Lange GmbH \& Co. KG

Dirección: Ahauser Hof 4-5 D-48527 Nordhorn

Teléfono: 0049-5921-4021

Fax: 0049-5921-2654

Email: info@feinkost-lange.de

Web: www.feinkost-lange.de

\section{Otto Franck Import $K G$}

Dirección: Stätzliger Str. 63 - 86165 Augsburg

Teléfono: 0049-821-79 402-0

Fax: 0049-821-79 402-23

Email: ofri@ottofranck.de

Web: www.ottofranck.de

Contacto: Dr. Rudolf Graus 


\subsubsection{Listado de Importadores alemanes de alimentos orgánicos}

Tabla $\mathrm{N}^{\circ}$ 59: Listado de los principales importadores alemanes de alimentos orgánicos:

\begin{tabular}{|c|c|}
\hline $\begin{array}{l}\text { AlnaturA Produktions- und Handels GmbH } \\
\text { Darmstädter Strasse 3, D-64404 Bickenbach. } \\
\text { + } 4962579322-0 \\
\text { + } 4962579322-144 \\
\text { info@alnatura.de } \\
\text { www.alnatura.de } \\
\text { Señor Peter Jakobs }\end{array}$ & $\begin{array}{l}\text { basic AG } \\
\quad \text { Richard-Strauss-Straße 48/1. OG, } 81677 \text { München. } \\
\text { Tel.: + } 49893066896-0 \\
\text { Fax: + } 49893066896-690 \\
\text { Email: info@basic-ag.de }\end{array}$ \\
\hline $\begin{array}{l}\text { Egger Innovations-und Handelsges. } \mathbf{m b H} \\
\text { Pasinger Strasse 94,D-82166 Gräfelfing } \\
\text { Tel.: + } 49898543048 \\
\text { Fax: + } 49898545652 \\
\text { info@laselva.de } \\
\text { www.laselva.de } \\
\text { Señor Peter Hüller }\end{array}$ & $\begin{array}{l}\text { BlueBioTech International GmbH } \\
\text { Langelohe 65,D-25337 Elmshorn } \\
\text { Tel.: + } 49412126236-0 \\
\text { Fax: + } 49412126236-26 \\
\text { info@bluebiotech.de } \\
\text { www.bluebiotech.de } \\
\text { Señora Janina Petersen } \\
\text { Señor Rouven Gercke }\end{array}$ \\
\hline $\begin{array}{l}\text { Davert GmbH } \\
\text { Ascheberger Straße 2,D-48308 Senden } \\
\text { Tel: + } 492598.6954 \\
\text { Fax: }+492598.6923 \\
\text { www.davert.de } \\
\text { info@davert.de }\end{array}$ & $\begin{array}{l}\text { Delphi Organic GmbH } \\
\text { Kroeger Weg 16, D-48155 Münster } \\
\text { Tel: + } 49251.2805610 \\
\text { Fax: + } 49251.2805620 \\
\text { www.delphiorganic.com } \\
\text { mhebendanz@delphiorganic.com }\end{array}$ \\
\hline $\begin{array}{l}\text { Terra Naturkost Handels KG } \\
\text { Gradestrasse 92, } 12347 \text { Berlin. } \\
\text { Tel: + 49 30-639993-0 } \\
\text { Fax: + } 49 \text { 30-639993-99 } \\
\text { info@terra-natur.de }\end{array}$ & $\begin{array}{l}\text { Demeter-Felderzeugnisse } \\
\text { Im Klingen 16, D-64665 Alsbach } \\
\text { Tel: }+496257.93400 \\
\text { Fax: }+496257.934019 \\
\text { www.felderzeugnisse.de } \\
\text { mhebendanz@delphiorganic.com }\end{array}$ \\
\hline $\begin{array}{l}\text { EPOS Kommunikation und Handel GmbH } \\
\text { Griesstrasse 18, D-85567 Grafing } \\
\text { Tel: + } 49809283783 \\
\text { Fax: }+49809283788 \\
\text { info@eposgmbh.de } \\
\text { www.eposgmbh.de } \\
\text { Contacto: Herr Oswald }\end{array}$ & $\begin{array}{l}\text { Heirler Cenovis GmbH } \\
\text { Schützenstrasse 24, D-78315 Radolfzell. } \\
\text { Tel: + } 4977328071 \\
\text { Fax: + } 497732807201 \\
\text { info@heirler-cenovis.de } \\
\text { www.heirler-cenovis.de } \\
\text { Contacto: Herr Alexander Moosmann }\end{array}$ \\
\hline $\begin{array}{l}\text { Horst Bode Import-Export GmbH } \\
\text { Havighorster Weg 6f, D-21031 Hamburg. } \\
\text { Tel: + } 4947393320 \\
\text { info@bodenaturkost.de } \\
\text { www.bodenaturkost.de } \\
\text { Señor Frank Bode }\end{array}$ & $\begin{array}{l}\text { Inkoop Verbrauchermärkte GmbH } \\
\text { Elbinger Strasse 32, D-27755 Delmenhorst. } \\
\text { Tel: + } 4942219621-0 \\
\text { Fax: + } 494221962145 \\
\text { info@Inkoop.de } \\
\text { www.Inkoop.de } \\
\text { Señor Helmut Kosten }\end{array}$ \\
\hline $\begin{array}{l}\text { Lea-lebe anders GmbH } \\
\text { St.-Bernhard-Strasse 1, D-86438 Kissing. } \\
\text { Tel: }+49823373990-0 \\
\text { Fax: }+49823373990-9 \\
\text { info@lebe-anders.de } \\
\text { www.lebe-anders.de } \\
\text { Contacto: Herr Andreas Mika }\end{array}$ & $\begin{array}{l}\text { MD BioService GmbH } \\
\text { Beckerfelder Strasse 96, D-47269 Duisburg. } \\
\text { Tel: + } 49203608889-0 \\
\text { Fax: + } 49203608889-8 \\
\text { info@md-bioservice.com } \\
\text { www.md-bisoservice.com } \\
\text { Contacto: Herr Drescher }\end{array}$ \\
\hline
\end{tabular}


Menson biologische Erzeugnisse GmbH
Krebäckerstrasse 10, D-71364 Winnenden
Tel: + $497195186-0$
Fax: + 497195 186-87
info@menson.de
www.menson.de
Contacto: Herr Joachim Kögel

ÖkoNova Handelsgesellschaft f. Produkte aus kontrolliertem ökologischen Anbau $\mathbf{m b H}$

Rudolf-Diesel-Ring 17, D-82054 Sauerlach.

Tel: $+4981046692-0$

Fax: $+4981046692-66$

info@oekonova.de

www.oekonova.de

Contacto: Herr Nikolaus Progner

Vita Naturalis Holzbau \& Naturprodukte GmbH

Mittlere Stämmig 4, D-97292 Uettingen.

Tel.: + 499369990952

Fax: + 499369980827

vita-naturalis@onlinehome.de

www.vita-naturalis.de

Contacto: Herr Jürgen Moese

\section{Allos Walter Lang $\mathbf{G m b H}$}

Zum Streek 5, D-49457 Drebber.

Tel.: + 495445 9899-0

Fax: + 495445 9899-114

info@allos.de

www.allos.de

Contacto: Herr Gernot Friemel

\section{ECOLAND Herbs \& Spices $\mathbf{G m b H}$}

Haller Straße 20, D-74549 Wolpertshausen.

Tel: + 497192.930321

Fax: +497192.930322

www.ecoland.de

Pio.ecoland.hs@besh.de

\section{Naturwarenhandels GmbH}

Raiffeisenstraße 2, D-72829 Engstingen

Tel: + 497129.1410

Fax: +497129.141500

www.paxan-direkt.de

info@paxan.de

\section{Phönix Naturprodukte $\mathbf{G m b H}$}

Siemensstraße 3, D-61191 Rosbach.

Tel: +496003.91290

Fax: +496003.912946

www.phoenix-naturkost.de

phoenix@phoenix-naturkost.net
GSE-Vertrieb GmbH

Saargemünder Straße 13, D-66119 Saarbrücken.

Tel: +49681.954570

Fax: +49681.9545729

www.gse-vertrieb.de

info@gse-vertrieb.de

\section{RAPUNZEL NATURKOST AG}

Haldergasse 9, D - 87764 Legau.

Tel.: + $498330 / 910-0$

Fax: $+498330 / 910-188$

e-mail: handel@rapunzel.de

Konrad Haberberger Handels- und Consulting $\mathbf{G m b H}$

Eisenlohstrasse 6, D-84076 Pfeffenhausen.

Tel.: + 4987828596

Fax: +4987828320

haberbergergmbh@t-online.de

www.haberberger-gmbh.de

Contacto: Herr Haberberger

\section{Ökohof Gemüsehandel GmbH}

Stahlbachstrasse 11, D-29556 Suderburg

Tel.: + 495826 9587-0

Fax: + 495826958720

info@oekohof-gmbh.de

www.oekohof-gmbh.de

Contacto: Herr Luhn

\section{Ökoring Handels $\mathbf{G m b H}$}

Dieselstrasse 9, D-82291 Mammendorf.

Tel.: + 498145 9308-30993083030830

Fax: + 498145 9308-39

zentrale@oekoring.com

www.oekoring.com

Contacto: Herr Robert Dax

\section{Riegel Peter Weinimport GmbH}

Steinäcker 12, D-78359 Orsingen-Neunzingen.

Tel:+49 777493130

Fax:+49 7774931312

www.riegel.de

weinimport@riegel.de

Contacto: Herr Peter Riegel

Port International GmbH

Kontorhaus Großmarkt

Lippeltstraße 1, 20097 Hamburg

Tel.: + 494 0) 301000 - 0

eMail: info@port-international.com 


\begin{tabular}{|c|c|}
\hline $\begin{array}{l}\text { Pural Vertriebs GmbH } \\
\text { Kiefernstraße 11, D-76532 Baden-Baden. } \\
\text { Tel: + } 497221.5096-15 \\
\text { Fax: + } 497221.509629 \\
\text { info@pural.de }\end{array}$ & $\begin{array}{l}\text { Waldnieler Fruchtsaft GmbH } \\
\text { Berg 49, D-41366 Schwalmtal } \\
\text { Tel: + } 4921639455-0 \\
\text { Fax: }+4921639455-30 \\
\text { waldnieler@t-online.de } \\
\text { www.waldnieler-fruchtsaft.de } \\
\text { Contacto: Herr Gerd Steffens }\end{array}$ \\
\hline $\begin{array}{l}\text { DE-VAU-GE GmbH } \\
\text { Johann-Pülsch-Strasse 2, D-36088 Hünfeld. } \\
\text { Tel: + } 496652183-0 \\
\text { Fax: + } 496652183-111 \\
\text { info@de-vau-ge.de } \\
\text { www.de-vau-ge.de } \\
\text { Contacto: Herr Koslowsi }\end{array}$ & $\begin{array}{l}\text { Kupfer's Natursäfte } \\
\text { Ringstrasse 9, D-91336 Heroldsbach } \\
\text { Tel: + } 499190217 \\
\text { Fax: + } 4991901682 \\
\text { info@kupfers-natursaefte.de } \\
\text { www.kupfers-natursaefte.de } \\
\text { Contacto: Frau Angelika Dippacher }\end{array}$ \\
\hline $\begin{array}{l}\text { Atlanta AG } \\
\text { Breitenweg 29-33, D-28195 Bremen. } \\
\text { Tel.: }+49-421-3092-1 \\
\text { Fax: }+49-421-13617 \\
\text { info@atlanta.de } \\
\text { www.atlanta.de }\end{array}$ & $\begin{array}{l}\text { Naturkost Ernst Weber GmbH } \\
\text { Postfach } 750981, \text { D - } 81339 \text { München. } \\
\text { Tel.: }+49-89-7463420 \\
\text { Fax: }+49-89-74634222 \\
\text { info@naturkostweber.de } \\
\text { www.naturkostweber.de } \\
\text { Contacto: Herr Ernst Weber }\end{array}$ \\
\hline $\begin{array}{l}\text { Naturkost Schramm GmbH } \\
\text { Ludwig-Winter-Strasse 6, D - } 77767 \text { Appenweier. } \\
\text { Tel.: + } 49-7805-96680 \\
\text { Fax: + } 49-7805-966880 \\
\text { team@naturkost-schramm.de } \\
\text { www.naturkost-schramm.de }\end{array}$ & $\begin{array}{l}\text { Landlinie Lebensmittel Vertrieb GmbH \& Co. KG } \\
\text { An der Hasenkaule 24, D - } 50354 \text { Hürth. } \\
\text { Tel.: + } 49 \text { - } 2233-974510 \\
\text { Fax: + } 49 \text { - } 2233 \text { - } 9745199 \\
\text { info@landlinie.de } \\
\text { www.landlinie.de }\end{array}$ \\
\hline $\begin{array}{l}\text { Biosanica Naturprodukte GmbH } \\
\text { Tannenweg 10, } 97854 \text { Steinfeld. } \\
\text { Tel: + } 499359909090 \\
\text { Fax: + } 4993599090910 \\
\text { www.biosanica.de } \\
\text { info@biosanica.de }\end{array}$ & $\begin{array}{l}\text { Hügli Nahrungsmittel GmbH } \\
\text { Güttinger Straße 23, D-78315 Radolfzell. } \\
\text { Tel: + } 497732.807-515 \\
\text { Fax: + } 497732.807-463 \\
\text { www.huegli.de } \\
\text { wolfgang.zeh@huegli.de } \\
\end{array}$ \\
\hline $\begin{array}{l}\text { Juers Import-Export } \\
\text { Robert-Bosch-Str. 2, } 79395 \text { Neuenburg am Rhein. } \\
\text { Tel. + } 497631 / 749720 \\
\text { Fax.: 07631/749718 } \\
\text { Email: probst@juers.com } \\
\text { Email: sbikowski@juers.com }\end{array}$ & $\begin{array}{l}\text { Oasis Teehandel } \\
\text { Boschstraße 18, D-71149 Bondorf } \\
\text { Tel: }+497457.94600 \\
\text { Fax: }+497457.946090 \\
\text { www.oasistee.de } \\
\text { info@oasistee.de }\end{array}$ \\
\hline $\begin{array}{l}\text { Bio-Eventagentur Querbeet } \\
\text { Berliner Straße 100, D-13189 Berlin. } \\
\text { Tel: }+4930.47370750 \\
\text { Fax: }+4930.94380977 \\
\text { www.bio-eventagentur.de } \\
\text { info@bio-eventagentur.de } \\
\text { Contacto: Herr Robert Nees }\end{array}$ & $\begin{array}{l}\text { Biogarten Handels GmbH } \\
\text { Liebigstraße 1a-5, D-40721 Hilden. } \\
\text { Tel: }+492103.95030 \\
\text { Fax: + } 492103.950351 \\
\text { www.biogarten.de } \\
\text { service@biogarten.de }\end{array}$ \\
\hline
\end{tabular}




\begin{tabular}{|c|c|}
\hline $\begin{array}{l}\text { BioMarken Handels GmbH } \\
\text { Gleiwitzer Straße 11 a , D-85276 Pfaffenhofen. } \\
\text { Tel: + 49-8441-7836644 } \\
\text { Fax: + 49-8441-7836645 } \\
\text { info@biomarken.com }\end{array}$ & $\begin{array}{l}\text { Isana Naturfeinkost GmbH \& Co.KG } \\
\text { Gewerbering 22, D-86922 Eresing. } \\
\text { Tel: + } 498193.93270 \\
\text { Fax: }+498193.932799 \\
\text { www.isana.de } \\
\text { info@isana.de }\end{array}$ \\
\hline $\begin{array}{l}\text { Biozeit Handelsagentur } \\
\text { Aachgrund 6, D-78333 Wahlwies } \\
\text { Tel: }+497771.875770 \\
\text { Fax: }+497771.875771 \\
\text { www.biozeit.de } \\
\text { info@biozeit.de } \\
\text { Contacto: Herr Stephan Schleuter }\end{array}$ & $\begin{array}{l}\text { Bluegreen Vertriebs-GmbH } \\
\text { Kreuzstraße 9, D-64846 Groß-Zimmern } \\
\text { Tel: + } 49800258347336 \\
\text { www.bluegreen.de } \\
\text { info@bluegreen.de }\end{array}$ \\
\hline $\begin{array}{l}\text { BODAN Großhandel für Naturkost GmbH } \\
\text { Bruckfelder Straße 6, D-88662 Überlingen } \\
\text { Tel: + } 497553.824-0 \\
\text { Fax: }+497553.824-28 \\
\text { www.bodan.de } \\
\text { info@bodan.de }\end{array}$ & $\begin{array}{l}\text { Bode Naturkost Import-Export GmbH } \\
\text { Havighorster Weg 6f, D-21031 Hamburg. } \\
\text { Tel: + } 4940.7393320 \\
\text { Fax: }+4940.7397035 \\
\text { www.bodenaturkost.de } \\
\text { info@bodenaturkost.de }\end{array}$ \\
\hline $\begin{array}{l}\text { Dennree Versorgungs GmbH } \\
\text { Hofer Str.11, D - } 95183 \text { Töpen. } \\
\text { Tel.: + } 49-9295-180 \\
\text { Fax: + } 49-9295-1850 \\
\text { www.dennree.de } \\
\text { zentrale@dennree.de }\end{array}$ & $\begin{array}{l}\text { Bios Gabriele Rempe GmbH } \\
\text { Grossmarkt-Frischezentrum, D - } 59010 \text { Hamm } \\
\text { Tel.: + } 49-2381 \text { - } 543250 \\
\text { Fax: + } 49 \text { - } 2381 \text { - } 5432540 \\
\text { www.bios-rempe.de } \\
\text { Info@bios-rempe.de }\end{array}$ \\
\hline $\begin{array}{l}\text { Bio-Betrieb Käpplein GmbH } \\
\text { Am Fernmeldeturm } 6 \\
\text { D - } 68753 \text { Waghäusel } \\
\text { Tel.: }+49-7254-60975 \\
\text { Fax: }+49-7254-950228 \\
\text { www.bio-betrieb-kaepplein.de } \\
\text { BioBetrieb-Kaepplein@t-online.de }\end{array}$ & $\begin{array}{l}\text { Gut Rosenkrantz Handelsgesell für Naturprodukte } \\
\text { Oderstr. 45, 24539 Neumünster. } \\
\text { Tel.: + 49-04321-990-0 } \\
\text { Fax: + 49-04321-990-20 } \\
\text { www.gut-rosenkrantz.de } \\
\text { hg@gut-rosenkrantz.de }\end{array}$ \\
\hline $\begin{array}{l}\text { HENRY LAMOTTE GmbH } \\
\text { Merkurstr. 47, } 28197 \text { Bremen. } \\
+49 \text { (0) } 421 \text { - } 52390 \\
+49 \text { (0) } 421 \text { - } 5239199 \\
\text { www.lamotte.de } \\
\text { info@lamotte.de } \\
\text { Contacto: Herr Kurt Becker }\end{array}$ & $\begin{array}{l}\text { Gemüsesaft GmbH } \\
\text { Obere Mäurichstraße 4, D-74196 Neuenstadt-Stein. } \\
\text { Tel: + } 496264.92230 \\
\text { Fax: + } 496264.922318 \\
\text { www.gemuesesaft.de } \\
\text { info@gemuesesaft.de }\end{array}$ \\
\hline $\begin{array}{l}\text { BRAUNs FRUCHTSAFTAGENTUR e.K. } \\
\text { Apfelstieg 40, D-21680 Stade. } \\
\text { Tel.: + } 49414144035 \\
\text { Fax: + } 49414144039 \\
\text { www.brauns-apfel.de } \\
\text { e-mail: Gerhard@brauns-apfel.de } \\
\text { Contacto: Herr Gerhard Braun }\end{array}$ & $\begin{array}{l}\text { Beutelsbacher } \\
\text { Fruchtsaftkelterei GmbH, Birkelstr. } 11 \\
\text { D - } 71384 \text { Weinstadt-Endersbach } \\
\text { Tel.: }+49-7151-995150 \\
\text { Fax: }+49-7151 \text { - } 9951555 \\
\text { info@beutelsbacher.de } \\
\text { www.beutelsbacher.de }\end{array}$ \\
\hline
\end{tabular}




\begin{tabular}{|c|c|}
\hline $\begin{array}{l}\text { RILA Feinkost- Importe GmbH \& Co. KG } \\
\text { Hinterm Teich 5, } 32351 \text { Stemwede-Levern } \\
\text { 05745-945-0 } \\
\text { 05745-945-139 } \\
\text { www.rila.de } \\
\text { info@rila.de } \\
\text { Contacto: Herr Holger Wankelmann }\end{array}$ & $\begin{array}{l}\text { Rohstoffagentur Witte \& Partner } \\
\text { Uppenbergstraße 9, } 48149 \text { Münster } \\
\text { Tel.: +49 } 2511627837 \\
\text { Fax: +49 } 2512007685 \\
\text { www.rohstoffagentur.de } \\
\text { info@rohstoffagentur.de } \\
\text { Contacto: Herr Franz Joseph Witte }\end{array}$ \\
\hline $\begin{array}{l}\text { Ulrich Walter GmbH } \\
\text { Postfach 1269, } 49342 \text { Diepholz. } \\
\text { Tel. + } 49 \text { 5441/9856-0 } \\
\text { Fax: + } 49 \text { 5441/9856-101 } \\
\text { info@lebensbaum.de } \\
\text { Contacto: Herr Manfred Winker }\end{array}$ & $\begin{array}{l}\text { Voelkel KG } \\
\text { Frucht- und Gemüsesäfte } \\
\text { Pevestorf 23, D - } 29478 \text { Höhbeck } \\
\text { Tel.: + } 49-5846-9500 \\
\text { Fax: + } 49 \text { - } 5846-95050 \\
\text { http://www.voelkeljuice.de } \\
\text { voelkeljuice@t-online.de }\end{array}$ \\
\hline $\begin{array}{l}\text { HiPP GmbH \& Co. Vertrieb KG } \\
\text { Georg-Hipp-Str. 7, D - } 85276 \text { Pfaffenhofen a.d.IIm } \\
\text { Tel.: + 49-8441 - } 757658 \\
\text { Fax: + 49-8441-897005 } \\
\text { www.hipp.de } \\
\text { umweltschutz@hipp.de } \\
\text { Contacto: Herr Herr Hanf }\end{array}$ & $\begin{array}{l}\text { Grüner Punkt Naturkost GmbH } \\
\text { Schwanenkirchner Str. 28, D - } 94491 \text { Hengersberg. } \\
\text { Tel.: + } 49-9901-18172 \\
\text { Fax: + } 49-9901-18179 \\
\text { www.gruener-punkt-naturkost.de } \\
\text { qs@gruener-punkt-naturkost.de }\end{array}$ \\
\hline $\begin{array}{l}\text { Georg Rösner Vertriebs GmbH } \\
\text { Stettiner Straße 12, D-94315 Straubing. } \\
\text { Tel: + } 499421.30060 \\
\text { Fax: + } 499421.300679 \\
\text { www.roesner-vertrieb.de } \\
\text { roesner-vertrieb@roesner-vertrieb.de }\end{array}$ & $\begin{array}{l}\text { ERNST RICKERTSEN TROCKENFRUCHT Import } \\
\text { Handelsges. } \mathbf{m b H} \\
\text { Biedenkamp } 13 \text { a, } 21509 \text { Glinde. } \\
\text { Tel: }+49040-6549760 \\
\text { Fax: + 49 040-6539206 } \\
\text { www.erik.de } \\
\text { info@erik.de } \\
\text { Contacto: Frau Gerda Landt }\end{array}$ \\
\hline $\begin{array}{l}\text { nabuko Bio Großverbraucher-Service } \\
\text { von Estorff Str. 26-30, } 29525 \text { Uelzen. } \\
\text { Tel: }+49-0581-97618-0 \\
\text { Fax: }+49-0581-97618-18 \\
\text { www.nabuko-biogvs.de } \\
\text { info@nabuko-biogvs.de } \\
\text { Contacto: Frau Christine Bunge }\end{array}$ & $\begin{array}{l}\text { Neuform handelskontor } \\
\text { Ernst-Litfaß-Str. 16, 19246 Zarrentin. } \\
+4938851-51-112 \\
+4938851-51299 \\
\text { neuform-handelskontor@neuform.de } \\
\text { Contacto: Arndt Rose }\end{array}$ \\
\hline $\begin{array}{l}\text { Naturkost Nord GmbH die Frischekompetenz } \\
\text { Billhorner Röhrendamm 16, } 20539 \text { Hamburg } \\
\text { + } 49 \text { 40-78086-110 } \\
\text { + } 49 \text { 40-78086-119 } \\
\text { info@naturkost-nord.de } \\
\text { Contacto: Herr Jan Timm }\end{array}$ & $\begin{array}{l}\text { BioTropic GmbH } \\
\text { Beckerfelder Straße 96, D-47269 Duisburg } \\
\text { Tel: + } 49 \text { 203.3189590 } \\
\text { Fax: + } 49 \text { 203.31895984 } \\
\text { www.biotropic.com } \\
\text { marketing@biotropic.com }\end{array}$ \\
\hline $\begin{array}{l}\text { BioGourmet GmbH } \\
\text { Hinter den Gärten 9, D-87730 Bad Grönenbach } \\
\text { Tel: }+498334.5294000 \\
\text { Fax: }+498334.5294000 \\
\text { www.bio-gourmet.com } \\
\text { office@bio-gourmet.com }\end{array}$ & $\begin{array}{l}\text { Bio Korb } \\
\text { Darmstädter Straße 52, D-64397 Modautal } \\
\text { Tel: + } 496167.913-9742 \\
\text { Fax: + } 49 \text { 6167.913-480 } \\
\text { www.bio-korb.de } \\
\text { post@bio-korb.de }\end{array}$ \\
\hline
\end{tabular}




\section{Ferias del sector orgánico en Alemania}

Fruit Logística (Salón internacional de frutas y hortalizas)

- Ámbito: Internacional

- Fecha: Del 4 al 6 de febrero de cada año

- Frecuencia: Anual

- Lugar de celebración: Berlín

- Horario de la feria: 09:00 - 18:00 Horas

- Sectores: Todos aquellos que se amparan en el mercado de productos frescos de fruta y hortaliza, desde sus semillas hasta tecnologías de empaquetado, a la vez que la logística posterior para la comercialización de los mismos.

- Superficie: $88.000 \mathrm{~m}^{2}$ (superficie bruta).

- Número de visitantes: más de 50.000 provenientes de 120 países

- Tipo de visitantes: Profesionales

- Medios de transporte

Metro: U2, dirección Ruhleben, parada Kaiserdamm.

Tranvía: S41, 42, 46 Messe Nord; S75, S9 Messe Süd.

Autobús: M49, X34, X49, 104, 139.

Avión: Aeropuerto de Tegel; autobús gratuito a la feria cada 30 minutos.

Aeropuerto de Schönefeld; autobús gratuito a la feria cada 30 minutos y línea S9 Süd.

Aeropuerto de Tempelhof; línea 104 dirección Neu-Westend, Brixplatz, parada "Haus des

Rundkunks".

- Precio de la entrada año 2010:

Venta por Internet:

- Un día: 22 euros

- Toda la feria: 53 euros

- Toda la feria y asistencia al Foro de frutas y hortalizas frescas: 85 euros

Venta en ventanilla:

- Un día: 25 euros

- Toda la feria: 60 euros 
- Director /Organizador: MESSE BERLIN GMBH.

Messedamm, 22 - 14055 Berlin

Tel: 0049-30-3038-2044, -2045, -2336

Fax: 0049-30-3038-2020

E-mail: fruitlogistica@messe-berlin.de

Web: www.fruitlogistica.com

En cooperación con la publicación FRUCHTHANDEL

- Precios de Participación

Puesto adosado, abierto por un frente: 180 euros/ $\mathrm{m}^{2}$

Puesto situado en esquina, abierto por dos costados: 194 euros/ $\mathrm{m}^{2}$

Puesto abierto por tres lados: 208 euros/ $\mathrm{m}^{2}$

Puesto libre/en bloque, abierto por cuatro costados: 222 euros/ $\mathrm{m}^{2}$

Feria Biofach de Nürnberg (Salón internacional de productos ecológicos)

- Ámbito: Internacional

- Fecha: Del 10 al 12 de febrero de cada año

- Frecuencia: Anual

- Lugar de celebración: Nürnberg

- Horario de la feria: 09:00 - 18:00 Horas

- Sectores: Todos aquellos productos de alimentación orgánicos o "Bio".

- Superficie: $44.587 \mathrm{~m}^{2}$ (superficie neta).

- Total de expositores: más de 2.500 provenientes de 86 países.

- Tipo de visitantes: Profesionales

- Director /Organizador: NÜRNBERG MESSE GmbH.

Messezentrum, D-904712 - Nürnberg

Tel: 0049-0-1186060

Fax: 0049-9-11-86068228

Web: www.nuernbergmesse.de

E-mail: info@nuernbergmesse.de 


\section{Productos orgánicos argentinos con destino a exportación}

Tabla $N^{\circ}$ 60: Productos Orgánicos de Origen Vegetal Certificados con destino a la exportación. Año 2010 (kg)

\begin{tabular}{|c|c|c|c|c|c|c|}
\hline \multicolumn{7}{|c|}{ Productos Orgánicos de Origen Vegetal Certificados con destino a la exportación. Año 2010 (kg) } \\
\hline Destino & U. Europea & EE.UU. & Suiza & Japón & Otros & Total \\
\hline Total expo 2010 & 64.106 .645 & 30.853.487 & 3.627 .601 & 808.172 & 20.311 .858 & 119.707 .762 \\
\hline Cereales & 1.046 .888 & 2.317.183 & 2.091 .370 & 90.535 & 7.119.508 & 12.665 .484 \\
\hline Trigo pan & 76.050 & - & 2.091 .370 & - & 4.318 .888 & 6.486 .308 \\
\hline Arroz & 536.000 & 2.208 .800 & & - & 382.000 & 3.126 .800 \\
\hline Maíz & 195.650 & 68.425 & - & 90.535 & 1.912 .630 & 2.267 .240 \\
\hline Sorgo & - & - & - & - & 468.090 & 468.090 \\
\hline Maíz pisingallo & 221.188 & 39.958 & - & - & - & 261.146 \\
\hline Cebada & - & - & - & - & 21.000 & 21.000 \\
\hline Avena & 18.000 & - & - & - & - & 18.000 \\
\hline Mijo & - & - & - & - & 16900 & 16.900 \\
\hline Oleaginosas & 10.533 .240 & 7.187 .231 & 601.220 & 126.000 & 2.144 .730 & 20.592 .421 \\
\hline Soja & 7.115 .100 & 5.666 .410 & - & 126.000 & 1.671 .520 & 14.579 .030 \\
\hline Lino & 1.531 .420 & 549.910 & - & - & 246.950 & 2.328 .280 \\
\hline Girasol & 578.720 & - & 601.220 & - & 49.860 & 1.229 .800 \\
\hline Cártamo & 1.115 .020 & - & - & - & 100.000 & 1.215 .020 \\
\hline Maní & 155.340 & 485.674 & - & - & 76.400 & 717.414 \\
\hline Colza & - & 468000 & - & - & - & 468.000 \\
\hline Pepita de girasol & 37.640 & 17237 & - & - & - & 54.877 \\
\hline Frutas & 23.393 .215 & 8.932 .676 & 0 & 0 & 7.026 .528 & 39.352 .419 \\
\hline Pera & 12.608 .732 & 4.913 .719 & - & - & 5.761 .009 & 23.283 .460 \\
\hline Manzana & 10.006 .813 & 3.859 .463 & - & - & 1.135 .637 & 15.001 .913 \\
\hline Ciruela & 292.823 & 82.074 & - & - & 74.720 & 449.617 \\
\hline Uva & 306.282 & & - & - & 117 & 306.399 \\
\hline Arándano & 147.601 & 7.940 & - & - & 41.965 & 197.506 \\
\hline Cereza & 6.644 & 43.430 & - & - & 13.080 & 63.154 \\
\hline Durazno & - & 26050 & - & - & - & 26.050 \\
\hline Damasco & 24.320 & - & - & - & - & 24.320 \\
\hline Hortalizas & 8.202 .338 & 354.582 & 0 & 22.000 & 226.379 & 8.805 .299 \\
\hline Cebolla & 2.505 .380 & - & - & - & 50.000 & 2.555 .380 \\
\hline Ajo & 2.164 .690 & 243.318 & - & 22.000 & 22.000 & 2.452 .008 \\
\hline Zapallo & 2.117 .686 & - & - & - & 49.800 & 2.167 .486 \\
\hline Poroto & 1.012 .000 & 20.000 & - & - & & 1.032 .000 \\
\hline Zapallo Anco & 335.382 & - & - & - & 104.129 & 439.511 \\
\hline Espárrago & 30.380 & 91.264 & - & - & 450 & 122.094 \\
\hline Echalote & 36.820 & - & - & - & - & 36.820 \\
\hline Total Aromáticas & 4.300 & 13.035 & - & - & 1.056 & 18.391 \\
\hline Hierbas aromáticas & - & 8.884 & - & - & 1.056 & 9.940 \\
\hline Orégano & 3.300 & 2.149 & - & - & - & 5.449 \\
\hline Hisopo & 1.000 & 2.002 & - & - & - & 3.002 \\
\hline Total Otros & 35.433 & - & 521 & - & 17.800 & 53.754 \\
\hline Rosa mosqueta & 34.500 & - & - & - & 16.800 & 51.300 \\
\hline Chía & - & - & - & - & 1.000 & 1.000 \\
\hline Stevia & 213 & - & 521 & - & - & 734 \\
\hline Semilla de pomelo & 720 & - & - & - & - & 720 \\
\hline
\end{tabular}


Lic. Emanuel Borthiry Buide, Tomo 042, Folio 148, C.P.C.E.C.A.B.A.

Estudio de prefactibilidad para la exportación de espárragos orgánicos argentinos en Alemania

\begin{tabular}{|c|c|c|c|c|c|c|}
\hline Destino & U. Europea & EE.UU. & Suiza & Japón & Otros & Total \\
\hline Productos Industrializados & 20.891 .231 & 12.048 .780 & 934.490 & 569.637 & 3.879 .985 & 38.324 .123 \\
\hline Azúcar de caña & 13.141 .925 & 4.380 .000 & 750.000 & 140.800 & 1.891 .800 & 20.304 .525 \\
\hline Vino & 3.105 .027 & 802.475 & 164.178 & 281.351 & 646.736 & 4.999 .767 \\
\hline Jugo concentrado manzana & 203.298 & 1.336 .473 & - & - & - & 1.539 .771 \\
\hline Harina de soja & 380.920 & 951.962 & - & - & 198.000 & 1.530 .882 \\
\hline Expeller de girasol & 1.115 .100 & 247.200 & - & - & 56.890 & 1.419 .190 \\
\hline Aceite de girasol & 21.000 & 843.330 & - & - & - & 864.330 \\
\hline Pulpa de manzana & 162.959 & 386.379 & - & - & 213.990 & 763.328 \\
\hline Mosto concentrado de uva & - & 547.858 & - & 118.548 & 86.310 & 752.716 \\
\hline Pulpa de pera & 288.711 & 138.358 & - & - & 262.629 & 689.698 \\
\hline Jugo concentrado de pera & 185.878 & 450.726 & - & - & - & 636.604 \\
\hline Pasas de uva & 297.500 & 142.884 & - & - & 174.846 & 615.230 \\
\hline Aceite de oliva & - & 376.204 & - & 12.675 & 126.199 & 515.078 \\
\hline Expeller de soja & 416.920 & - & - & - & - & 416.920 \\
\hline Jugo concentrado de limon & 163.750 & 167.800 & - & 9.000 & 5.000 & 345.550 \\
\hline Residuo vegetal de maní & - & 304.000 & - & - & - & 304.000 \\
\hline Alcohol & - & 266.261 & - & - & - & 266.261 \\
\hline Aceite de soja & 237.080 & - & - & - & - & 237.080 \\
\hline Jugo conc. congelado naranja & 197.425 & - & - & - & 23.320 & 220.745 \\
\hline Maní tostado & 175.650 & - & - & - & 35.400 & 211.050 \\
\hline Pasta de maní & - & 190.990 & - & - & - & 190.990 \\
\hline Frutilla IQF & 139.453 & - & - & - & 46.784 & 186.237 \\
\hline Aceite de jojoba & 156.560 & 7200 & - & 5400 & - & 169.160 \\
\hline Yerba mate & 36.282 & 96.196 & 20.247 & 1.862 & 12.389 & 166.976 \\
\hline Pulpa de zapallo & 69.471 & 18.469 & - & - & 15.191 & 103.131 \\
\hline Polenta & 72.000 & 18.000 & - & - & - & 90.000 \\
\hline Jugo conc. cong. mandarina & 89.040 & - & - & - & - & 89.040 \\
\hline Manzana deshidratada & 64.388 & 18.169 & - & - & 1.000 & 83.557 \\
\hline Jugo past. conc. cong. naranja & 72.000 & - & - & - & - & 72.000 \\
\hline Jugo conc. de uva & 71.568 & - & - & - & - & 71.568 \\
\hline Ciruela deshidratada & 45.550 & - & - & - & 21.300 & 66.850 \\
\hline Harina de maní & 49.400 & - & - & - & - & 49.400 \\
\hline Jugo cong. de naranja & 48.000 & - & - & - & - & 48.000 \\
\hline Jugo past. congelado naranja & 48.000 & - & - & - & - & 48.000 \\
\hline Aroma de manzana & 330 & 45.400 & - & - & - & 45.730 \\
\hline Hominy grits & - & - & - & - & 44.000 & 44.000 \\
\hline Melaza & - & 38.700 & - & - & - & 38.700 \\
\hline$T e$ & 100 & 19.200 & 65 & - & 8.504 & 27.869 \\
\hline Aceite esencial de limón & 16.560 & 5.400 & - & - & - & 21.960 \\
\hline Pulpa de damasco & 19.218 & - & - & - & - & 19.218 \\
\hline Mani frito salado & - & 18.000 & - & - & - & 18.000 \\
\hline Jugo conc. cong. Limón & 3.750 & - & - & - & 7.500 & 11.250 \\
\hline Aceite esencial de naranja & 10.440 & - & - & - & - & 10.440 \\
\hline Aroma de pera & - & 4.086 & - & - & - & 4.086 \\
\hline Lámina de tabaco & 3.600 & - & - & - & - & 3.600 \\
\hline Hojas rojas secas de vid & 2.449 & - & - & - & - & 2.449 \\
\hline Jugo conc. De mandarina & - & - & - & - & 2.120 & 2.120 \\
\hline Aceite de maní & - & 2.010 & - & - & - & 2.010 \\
\hline Aceite esencial de pomelo & 1.980 & - & - & - & - & 1.980 \\
\hline Pera deshidratada & 1.520 & - & - & - & - & 1.520 \\
\hline Palo de tabaco & 1.260 & - & - & - & - & 1.260 \\
\hline Aceite esencial de mandarina & 220 & - & - & - & - & 220 \\
\hline Aceite de paramela & - & - & - & - & 50 & 50 \\
\hline Grits de soja & - & - & - & - & 27 & 27 \\
\hline
\end{tabular}

Fuente: SENASA 2011. En base a información de Certificadoras. 


\begin{tabular}{|c|c|c|c|c|c|c|c|c|c|c|c|}
\hline Productos & Alemania & Austria & Bélgica & Bulgaria & Dinamarca & España & Estonia & Finlandia & Francia & Grecia & Irlanda \\
\hline Total exportaciones 2010 & 8.280 .301 & 1.125 & 2.840 .950 & 140.000 & 1.431 .038 & 1.534 .916 & 4.199 & 485.066 & 2.114 .098 & 352.325 & 1.458 \\
\hline Cereales & 288.000 & 0 & 198.150 & 140.000 & 140.000 & 74.540 & 0 & 0 & 18.000 & 0 & 0 \\
\hline Arroz & 200.000 & - & 100.000 & 140.000 & - & - & - & - & - & - & - \\
\hline Maíz pisingallo & 40.000 & - & - & - & - & - & - & - & - & - & - \\
\hline Maíz & 48.000 & - & 73.110 & - & 74.540 & - & - & - & - & - & - \\
\hline Trigo pan & - & - & 25.040 & - & - & - & - & - & - & - & - \\
\hline Avena & - & - & - & - & - & - & - & 18.000 & - & - & - \\
\hline Oleaginosas & 671.390 & 0 & 39.370 & 0 & 0 & 0 & 0 & 0 & 996.550 & 0 & 0 \\
\hline Soja & - & - & - & - & - & - & - & - & - & - & - \\
\hline Lino & 480.000 & - & 39.370 & - & - & - & - & - & - & - & - \\
\hline Cártamo & 133.750 & - & - & - & - & - & - & - & 750.000 & - & - \\
\hline Girasol & & - & - & - & - & - & - & - & 186.350 & - & - \\
\hline Maní & 20.000 & - & - & - & - & - & - & - & 60.200 & - & - \\
\hline Pepita de girasol & 37.640 & - & - & - & - & - & - & - & - & - & - \\
\hline Frutas & 925.728 & 0 & 657.516 & 0 & 178.302 & 123.198 & 0 & 84.504 & 80.543 & 66.325 & 0 \\
\hline Pera & 322.223 & - & 470.370 & - & 42.600 & 35.830 & - & 5.880 & 37.737 & 66.325 & - \\
\hline Manzana & 530.736 & - & 106.086 & - & 135.702 & 87.368 & - & 78.624 & 42.806 & - & - \\
\hline Uva & 71.040 & - & 81.060 & - & - & - & - & - & - & - & - \\
\hline Ciruela & - & - & - & - & - & - & - & - & - & - & - \\
\hline Arándano & 720 & - & - & - & - & - & - & - & - & - & - \\
\hline Damasco & - & - & - & - & - & - & - & - & - & - & - \\
\hline Cereza & 1.009 & - & - & - & - & - & - & - & - & - & - \\
\hline Hortaliazas y Legumbres & 970.496 & 0 & 130.000 & 0 & 0 & 866.530 & 0 & 0 & 312.805 & 0 & 0 \\
\hline Cebolla & 231.000 & - & 86.000 & - & - & - & - & - & 130.025 & - & - \\
\hline Ajo & 22.000 & - & 44.000 & - & - & 843.530 & - & - & 128.380 & - & - \\
\hline Zapallo & 559.956 & - & - & - & - & - & - & - & 17.580 & - & - \\
\hline Poroto & - & - & - & - & - & 23.000 & - & - & - & - & - \\
\hline Zapallo Anco & 157.540 & - & - & - & - & - & - & - & - & - & - \\
\hline Echalote & - & - & - & - & - & - & - & - & 36.820 & - & - \\
\hline Espárrago & - & - & - & - & - & - & - & - & - & - & - \\
\hline
\end{tabular}


Tabla N 61: Productos Orgánicos de Origen Vegetal Certificados con destino a la Unión Europea. Año 2010 (kg)

\begin{tabular}{|c|c|c|c|c|c|c|c|c|c|c|c|}
\hline Productos & Alemania & Austria & Bélgica & Bulgaria & Dinamarca & España & Estonia & Finlandia & Francia & Grecia & Irlanda \\
\hline Productos Industrializados & 5.385 .887 & 1.125 & 1.815 .914 & 0 & 1.112 .736 & 470.648 & 4.199 & 399.629 & 706.200 & 286.000 & 1.458 \\
\hline Azúcar de caña & 3.478 .000 & - & 1.532 .000 & - & 1.060 .000 & 470.000 & - & - & 696.300 & - & - \\
\hline Vino & 779.161 & 1.125 & 265.914 & - & 52.736 & 648 & 4.199 & 356.408 & 9.900 & - & 1.458 \\
\hline Expeller de girasol & - & - & - & - & - & - & - & - & - & 260.000 & \\
\hline Expeller de soja & - & - & 18.000 & - & - & - & - & - & - & - & - \\
\hline Harina de soja & - & - & - & - & - & - & - & - & - & 26.000 & - \\
\hline Pasas de uva & 192.500 & - & - & - & - & - & - & - & - & - & - \\
\hline Pulpa de pera & 180.873 & - & - & - & - & - & - & - & - & - & - \\
\hline Aceite de soja & - & - & - & - & - & - & - & - & - & - & - \\
\hline Jugo conc. Manzana & 42.840 & - & - & - & - & - & - & - & - & - & - \\
\hline Jugo conc. Cong. Naranja & - & - & - & - & - & - & - & - & - & - & - \\
\hline Jugo concentrado pera & 136.125 & - & - & - & - & - & - & - & - & - & - \\
\hline Jugo conc. De limón & - & - & - & - & - & - & - & - & - & - & - \\
\hline pulpa de manzana & 18.938 & - & - & - & - & - & - & - & - & - & - \\
\hline Aceite de jojoba & 153.860 & - & - & - & - & - & - & 2.700 & - & - & - \\
\hline Frutilla IQF & 139.453 & - & - & - & - & - & - & - & - & - & - \\
\hline Jugo conc. Cong. Mandarina & - & - & - & - & - & - & - & - & - & - & - \\
\hline Polenta & 72.000 & - & - & - & - & - & - & - & - & - & - \\
\hline Jugo past. conc. cong. naranja & - & - & - & - & - & - & - & - & - & - & - \\
\hline Jugo conc. De uva & 71.568 & - & - & - & - & - & - & - & - & - & - \\
\hline Pulpa de zapallo & - & - & - & - & - & - & - & - & - & - & - \\
\hline Manzana deshidratada & 64.388 & - & - & - & - & - & - & - & - & - & - \\
\hline Jugo cong. De naranja & - & - & - & - & - & - & - & - & - & - & - \\
\hline Jugo pasteuriz. cong. naranja & - & - & - & - & - & - & - & - & - & - & - \\
\hline Ciruela deshidratada & 45.550 & - & - & - & - & - & - & - & - & - & - \\
\hline Yerba mate & 9.111 & - & - & - & - & - & - & 8.772 & - & - & - \\
\hline Aceite de girasol & - & - & - & - & - & - & - & - & - & - & - \\
\hline Pulpa de damasco & - & - & - & - & - & - & - & - & - & - & - \\
\hline Aceite esencial de limón & - & - & - & - & - & - & - & 16.560 & - & - & - \\
\hline Aceite esencial de naranja & - & - & - & - & - & - & - & 10.440 & - & - & - \\
\hline Jugo conc. Cong. Limón. & - & - & - & - & - & - & - & - & - & - & - \\
\hline Lámina de tabaco & - & - & - & - & - & - & - & - & - & - & - \\
\hline Hojas rojas secas de vid & - & - & - & - & - & - & - & 2.449 & - & - & - \\
\hline Aceite esencial de pomelo & - & - & - & - & - & - & - & 1.980 & - & - & - \\
\hline Pera deshidratada & 1.520 & - & - & - & - & - & - & - & - & - & - \\
\hline Palo de tabaco & - & - & - & - & - & - & - & - & - & - & - \\
\hline Aroma de manzana & - & - & - & - & - & - & - & - & - & - & - \\
\hline Aceite esencial de mandarina & - & - & - & - & - & - & - & 220 & - & - & - \\
\hline $\mathrm{Te}$ & - & - & - & - & - & - & - & 100 & - & - & - \\
\hline Aromáticas & 4.300 & 0 & 0 & 0 & 0 & 0 & 0 & 0 & 0 & 0 & 0 \\
\hline Orégano & 3.300 & - & - & - & - & - & - & - & - & - & - \\
\hline Hisopo & 1.000 & - & - & - & - & - & - & - & - & - & - \\
\hline Otros & 34.500 & 0 & 0 & 0 & 0 & 0 & 0 & 933 & 0 & 0 & 0 \\
\hline Rosa mosqueta & 34.500 & - & - & - & - & - & - & - & - & - & - \\
\hline Semilla de pomelo & - & - & - & - & - & - & - & 720 & - & - & - \\
\hline Stevia & - & - & - & - & - & - & - & 213 & - & - & - \\
\hline
\end{tabular}




\begin{tabular}{|c|c|c|c|c|c|c|c|c|c|c|}
\hline Productos & Italia & Lituania & Luxemburgo & Holanda & Polonia & Portugal & Reino Unido & R. Checa & Rumania & Suecia \\
\hline Total exportaciones 2010 & 4.985 .833 & 7.200 & 450 & 27.829 .937 & 14.901 & 21.878 & 9.941 .699 & 90 & 450 & 4.254.447 \\
\hline Cereales & 41.020 & 0 & 0 & 161.168 & 0 & 0 & 126.010 & 0 & 0 & 0 \\
\hline Arroz & 21.000 & - & - & - & - & - & 75.000 & - & - & - \\
\hline Maíz pisingallo & 20.020 & - & - & 161.168 & - & - & - & - & - & - \\
\hline Maíz & - & - & - & - & - & - & - & - & - & - \\
\hline Trigo pan & - & - & - & - & - & - & 51.010 & - & - & - \\
\hline Avena & - & - & - & - & - & - & - & - & - & - \\
\hline Oleaginosas & 899.500 & 0 & 0 & 1.764 .950 & 0 & 0 & 3.709 .250 & 0 & 0 & 2.452 .230 \\
\hline Soja & 791.180 & - & - & 270.000 & - & - & 3.709 .250 & - & - & 2.344 .670 \\
\hline Lino & 58.180 & - & - & 953.870 & - & - & - & - & - & - \\
\hline Cártamo & - & - & - & 231.270 & - & - & - & - & - & - \\
\hline Girasol & - & - & - & 284.810 & - & - & - & - & - & 107.560 \\
\hline Maní & 50.140 & - & - & 25.000 & - & - & - & - & - & - \\
\hline Pepita de girasol & - & - & - & & - & - & - & - & - & - \\
\hline Frutas & 1.860 .719 & 0 & 0 & 15.788 .027 & 0 & 21.878 & 3.276 .555 & 0 & 0 & 326.844 \\
\hline Pera & 1.380 .325 & - & - & 8.378 .412 & - & 9.138 & 1.774 .843 & - & - & 85.050 \\
\hline Manzana & 469.694 & - & - & 7.017 .485 & - & 12.740 & 1.283 .776 & - & - & 241.794 \\
\hline Uva & - & - & - & 154.182 & - & - & - & - & - & - \\
\hline Ciruela & 10.700 & - & - & 193.803 & - & - & 88.320 & - & - & - \\
\hline Arándano & - & - & - & 17.265 & - & - & 129.616 & - & - & - \\
\hline Damasco & - & - & - & 24.320 & - & - & - & - & - & - \\
\hline Cereza & - & - & - & 2.560 & - & - & - & - & - & - \\
\hline Hortaliazas y Legumbres & 1.488 .594 & 0 & 0 & 3.058 .403 & 0 & 0 & 1.375 .510 & 0 & 0 & 0 \\
\hline Cebolla & 171.250 & - & - & 1.559 .025 & - & - & 328.080 & - & - & - \\
\hline Ajo & 304.344 & - & - & 519.776 & - & - & 302.660 & - & - & - \\
\hline Zapallo & - & - & - & 934.246 & - & - & 605.904 & - & - & - \\
\hline Poroto & 989.000 & - & - & - & - & - & - & - & - & - \\
\hline Zapallo Anco & 24.000 & - & - & 43.440 & - & - & 110.402 & - & - & - \\
\hline Echalote & - & - & - & - & - & - & - & - & - & - \\
\hline Espárrago & - & - & - & 1.916 & - & - & 28.464 & - & - & - \\
\hline
\end{tabular}


Lic. Emanuel Borthiry Buide, Tomo 042, Folio 148, C.P.C.E.C.A.B.A.

Estudio de prefactibilidad para la exportación de espárragos orgánicos argentinos en Alemania

\begin{tabular}{|c|c|c|c|c|c|c|c|c|c|c|}
\hline Productos & Italia & Lituania & Luxemburgo & Holanda & Polonia & Portugal & Reino Unido & R. Checa & Rumania & Suecia \\
\hline Productos Industrializados & 696.000 & 7.200 & 450 & 7.057 .389 & 14.901 & 0 & 1.454 .374 & 90 & 450 & 1.475 .373 \\
\hline Azúcar de caña & 696.000 & - & - & 4.220 .000 & - & - & 800.000 & - & - & 189.625 \\
\hline Vino & - & 7.200 & 450 & 118.287 & 5.940 & - & 425.535 & - & 450 & 1.074 .448 \\
\hline Expeller de girasol & - & - & - & 650.100 & - & - & - & - & - & 205.000 \\
\hline Expeller de soja & - & - & - & 398.920 & - & - & - & - & - & \\
\hline Harina de soja & - & - & - & 354.920 & - & - & - & - & - & \\
\hline Pasas de uva & - & - & - & 70.000 & - & - & 35.000 & - & - & - \\
\hline Pulpa de pera & - & - & - & 89.820 & - & - & 18.018 & - & - & - \\
\hline Aceite de soja & - & - & - & 237.060 & - & - & - & - & - & - \\
\hline Jugo conc. Manzana & - & - & - & 44.490 & - & - & 115.968 & - & - & - \\
\hline Jugo conc. Cong. Naranja & - & - & - & 197.425 & - & - & - & - & - & - \\
\hline Jugo concentrado pera & - & - & - & 49.753 & - & - & - & - & - & - \\
\hline Jugo conc. De limón & - & - & - & 163.750 & - & - & - & - & - & - \\
\hline pulpa de manzana & - & - & - & 125.837 & - & - & 18.183 & - & - & - \\
\hline Aceite de jojoba & - & - & - & - & - & - & - & - & - & - \\
\hline Frutilla IQF & - & - & - & - & - & - & - & - & - & - \\
\hline Jugo conc. Cong. Mandarina & - & - & - & 89.040 & - & - & - & - & - & - \\
\hline Polenta & - & - & - & - & - & - & - & - & - & - \\
\hline Jugo past. conc. cong. naranja & - & - & - & 72.000 & - & - & - & - & - & - \\
\hline Jugo conc. De uva & - & - & - & - & - & - & - & - & - & - \\
\hline Pulpa de zapallo & - & - & - & 35.589 & - & - & 33.882 & - & - & - \\
\hline Manzana deshidratada & - & - & - & - & - & - & - & - & - & - \\
\hline Jugo cong. De naranja & - & - & - & 48.000 & - & - & - & - & - & - \\
\hline Jugo pasteuriz. cong. naranja & - & - & - & 48.000 & - & - & - & - & - & - \\
\hline Ciruela deshidratada & - & - & - & - & - & - & - & - & - & - \\
\hline Yerba mate & - & - & - & 100 & 8.961 & - & 7.788 & 90 & - & 1.440 \\
\hline Aceite de girasol & - & - & - & 21.000 & - & - & - & - & - & - \\
\hline Pulpa de damasco & - & - & - & 19.218 & - & - & - & - & - & - \\
\hline Aceite esencial de limón & - & - & - & - & - & - & - & - & - & - \\
\hline Aceite esencial de naranja & - & - & - & - & - & - & - & - & - & - \\
\hline Jugo conc. Cong. Limón. & - & - & - & 3.750 & - & - & - & - & - & - \\
\hline Lámina de tabaco & - & - & - & - & - & - & - & - & - & 3.600 \\
\hline Hojas rojas secas de vid & - & - & - & - & - & - & - & - & - & - \\
\hline Aceite esencial de pomelo & - & - & - & - & - & - & - & - & - & - \\
\hline Pera deshidratada & - & - & - & - & - & - & - & - & - & - \\
\hline Palo de tabaco & - & - & - & - & - & - & - & - & - & 1.260 \\
\hline Aroma de manzana & - & - & - & 330 & - & - & - & - & - & - \\
\hline Aceite esencial de mandarina & - & - & - & - & - & - & - & - & - & - \\
\hline $\mathrm{Te}$ & - & - & - & - & - & - & - & - & - & - \\
\hline Aromáticas & 0 & 0 & 0 & 0 & 0 & 0 & 0 & 0 & 0 & 0 \\
\hline Orégano & - & - & - & - & - & - & - & - & - & - \\
\hline Hisopo & - & - & - & - & - & - & - & - & - & - \\
\hline Otros & 0 & 0 & 0 & 0 & 0 & 0 & 0 & 0 & 0 & 0 \\
\hline Rosa mosqueta & - & - & - & - & - & - & - & - & - & - \\
\hline Semilla de pomelo & - & - & - & - & - & - & - & - & - & - \\
\hline Stevia & - & - & - & - & - & - & - & - & - & - \\
\hline
\end{tabular}


Tabla ${ }^{\circ}$ 62: Exportaciones argentinas de espárragos frescos en toneladas 2010 - 2001:

\begin{tabular}{|c|c|c|c|c|c|c|c|c|c|c|}
\hline Importadores & 2001 & 2002 & 2003 & 2004 & 2005 & 2006 & 2007 & 2008 & 2009 & 2010 \\
\hline Mundo & 352 & 781 & 608 & 556 & 696 & 388 & 346 & 165 & 274 & 245 \\
\hline EE.UU. & 213 & 480 & 281 & 254 & 274 & 123 & 89 & 82 & 184 & 188 \\
\hline Reino Unido & 12 & 7 & 3 & 0 & 18 & 64 & 79 & 36 & 8 & 26 \\
\hline Italia & 0 & 29 & 13 & 15 & 32 & 22 & 25 & 14 & 56 & 21 \\
\hline España & 0 & 80 & 102 & 137 & 251 & 133 & 96 & 17 & 25 & 6 \\
\hline Canadá & 0 & 16 & 49 & 30 & 14 & 9 & 5 & 0 & 1 & 1 \\
\hline Holanda & 9 & 31 & 13 & 14 & 38 & 8 & 5 & 3 & 0 & 1 \\
\hline Francia & 40 & 69 & 122 & 85 & 45 & 15 & 8 & 0 & 0 & 1 \\
\hline Uruguay & 0 & 0 & 0 & 1 & 1 & 3 & 2 & 3 & 0 & 1 \\
\hline Bélgica & 1 & 1 & 0 & 0 & 0 & 0 & 1 & 0 & 0 & 0 \\
\hline Brasil & 0 & 9 & 10 & 1 & 5 & 1 & 0 & 4 & 0 & 0 \\
\hline Chile & 0 & 4 & 0 & 0 & 0 & 0 & 28 & 4 & 0 & 0 \\
\hline Alemania & 33 & 30 & 3 & 3 & 1 & 1 & 3 & 0 & 0 & 0 \\
\hline Japón & 0 & 0 & 0 & 0 & 0 & 0 & 0 & 1 & 0 & 0 \\
\hline Paraguay & 0 & 0 & 0 & 0 & 0 & 0 & 0 & 1 & 0 & 0 \\
\hline Suiza & 44 & 25 & 12 & 16 & 17 & 9 & 5 & 0 & 0 & 0 \\
\hline
\end{tabular}

Fuente: Elaboración propia en base a datos obtenidos en World Trade Centre 2011 y SENASA 2011

Tabla $N^{\circ}$ 63: Exportaciones argentinas de espárragos frescos en cifras en US\$ 2010 - 2001:

\begin{tabular}{|c|c|c|c|c|c|c|c|c|c|c|}
\hline Importadore & 2001 & 2002 & 2003 & 2004 & 2005 & 2006 & 2007 & 2008 & 2009 & 2010 \\
\hline Mundo & 889.000 & 1.663 .000 & 1.461 .000 & 1.712 .000 & 2.010 .000 & 1.336 .000 & 1.380 .000 & 809.000 & 1.060 .000 & 1.053 .000 \\
\hline EE.UU. & 398.000 & 935.000 & 465.000 & 646.000 & 610.000 & 277.000 & 335.000 & 316.000 & 701.000 & 543.000 \\
\hline Reino Unido & 39.000 & 24.000 & 4.000 & 0 & 91.000 & 375.000 & 454.000 & 289.000 & 46.000 & 170.000 \\
\hline Italia & 1.000 & 82.000 & 51.000 & 97.000 & 225.000 & 89.000 & 111.000 & 51.000 & 142.000 & 98.000 \\
\hline España & 0 & 184.000 & 239.000 & 392.000 & 782.000 & 441.000 & 312.000 & 55.000 & 78.000 & 19.000 \\
\hline Canadá & 10.000 & 44.000 & 138.000 & 136.000 & 78.000 & 33.000 & 54.000 & 51.000 & 86.000 & 210.000 \\
\hline Holanda & 28.000 & 74.000 & 48.000 & 42.000 & 50.000 & 21.000 & 30.000 & 10.000 & 6.000 & 4.000 \\
\hline Francia & 299.000 & 244.000 & 464.000 & 377.000 & 147.000 & 73.000 & 59.000 & 6.000 & 0 & 6.000 \\
\hline Uruguay & 2.000 & 0 & 0 & 1.000 & 2.000 & 10.000 & 2.000 & 5.000 & 0 & 3.000 \\
\hline Bélgica & 8.000 & 8.000 & 0 & 0 & 0 & 0 & 1.000 & 0 & 0 & 0 \\
\hline Brasil & 0 & 6.000 & 9.000 & 2.000 & 10.000 & 3.000 & 0 & 8.000 & 0 & 0 \\
\hline Chile & 0 & 1.000 & 0 & 0 & 0 & 0 & 2.000 & 1.000 & 0 & 0 \\
\hline Alemania & 104.000 & 61.000 & 43.000 & 19.000 & 15.000 & 5.000 & 14.000 & 4.000 & 1.000 & 0 \\
\hline Japón & 0 & 0 & 0 & 0 & 0 & 0 & 0 & 9.000 & 0 & 0 \\
\hline Paraguay & 0 & 0 & 0 & 0 & 0 & 0 & 0 & 4.000 & 0 & 0 \\
\hline Suiza & 0 & 0 & 0 & 0 & 0 & 9.000 & 6.000 & 0 & 0 & 0 \\
\hline
\end{tabular}

Fuente: Elaboración propia en base a datos obtenidos en World Trade Centre 2011 


\section{El caso productivo - comercial del Perú}

Por las cualidades del desarrollo del espárrago en el Perú, y siendo este además el mayor productor mundial de espárragos frescos es que considero importante destacar el mismo.

En el mercado de espárragos, el Perú se ha convertido en un fenómeno en términos de productividad, calidad y competitividad internacional. Las características naturales, climatológicas y biológicas del suelo permiten la reproducción de esta especie de manera óptima. En el año 2010 fue el primer exportador de espárragos frescos con un total de 123.176 toneladas. Esta vigorosidad le permitió a Perú filtrarse en mercados de tradición productora y consumidora como España y EE.UU.

\subsection{Superficie y producción peruana}

Como se anticipó, la ventaja que obtuvo Perú en términos agregados frente al resto del mundo fue notable, la producción en toneladas entre 2000 y 2010 se incrementó un 46,84\%, y la superficie cosechada pasó de 20.974 en 2000 a 28.289 hectáreas en $2010^{68}$, lo que se deduce el importante avance tecnológico en el campo de la producción esparraguera.

Gráfico $\mathrm{N}^{\circ}$ 59: Evolución producción peruana de espárragos:

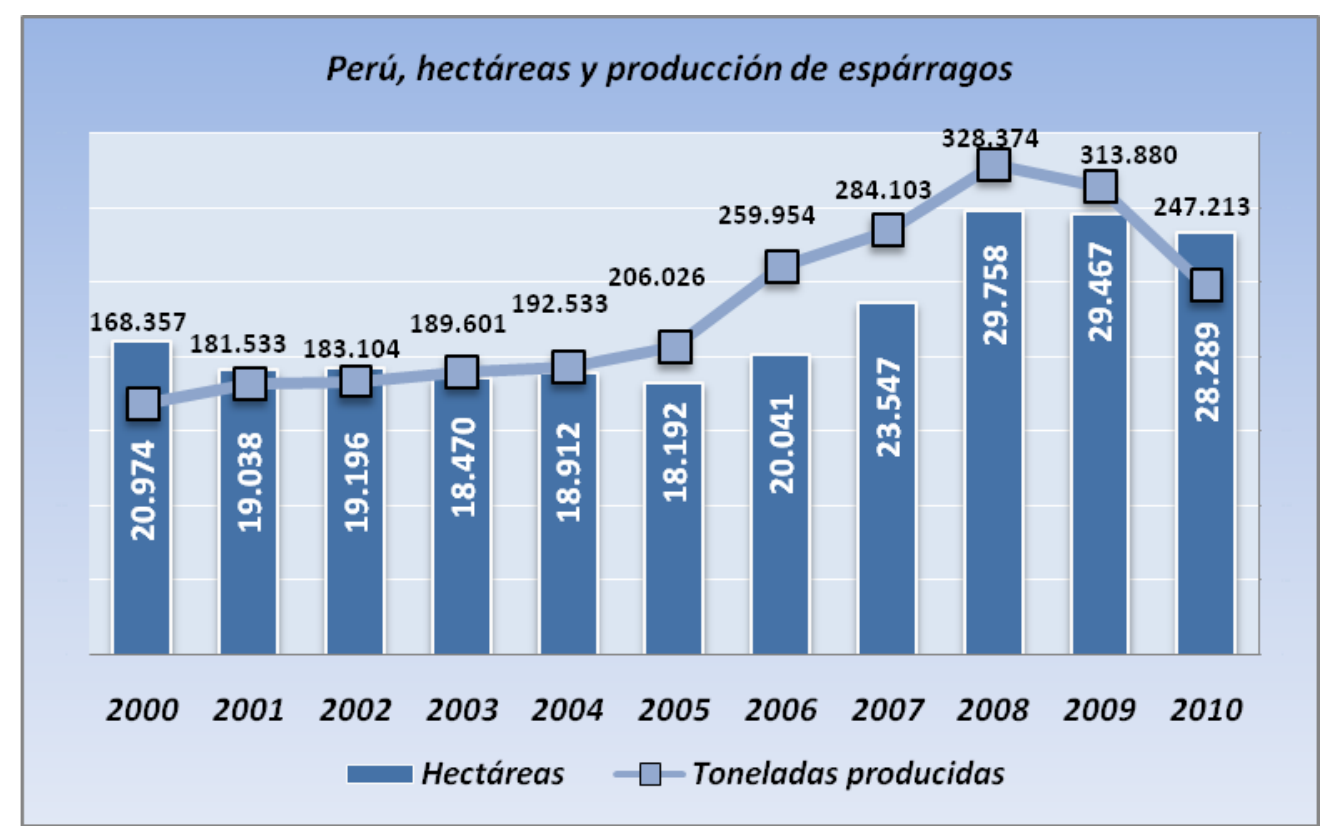

Fuente: elaboración propia en base a datos del Ministerio de Agricultura del Perú 2011

\footnotetext{
${ }^{68}$ Según datos del Ministerio de Agricultura del Perú al año 2011. http://www.minag.gob.pe
} 
En territorio peruano existen seis áreas productivas: Ancash, Ica, La Libertad, Lambayeque, Lima y Piura, pero entre dos de ellas concentran el $80 \%$ de la producción total; La Libertad acapara el $41 \%$ e Ica el 39\%. La producción característica de La Libertad es el espárrago blanco cuyo destino es principalmente Europa, en cambio, en Ica se produce el espárrago verde, cuyo principal mercado se encuentra en EE.UU. En la primera región se cosecha durante todo el año lo que le concede una posición de absoluto privilegio en un producto fuertemente condicionado por la estacionalidad. El departamento de Ica posee iguales cualidades, aunque no tiene cosecha en los meses de marzo y agosto.

Tabla N 64: Evolución de la producción de espárragos en el Perú año 2010 - 2000.

\begin{tabular}{|c|c|c|c|c|c|c|c|c|c|c|c|}
\hline Perú & $\mathbf{2 0 0 0}$ & $\mathbf{2 0 0 1}$ & $\mathbf{2 0 0 2}$ & $\mathbf{2 0 0 3}$ & $\mathbf{2 0 0 4}$ & $\mathbf{2 0 0 5}$ & $\mathbf{2 0 0 6}$ & $\mathbf{2 0 0 7}$ & $\mathbf{2 0 0 8}$ & $\mathbf{2 0 0 9}$ & $\mathbf{2 0 1 0}$ \\
\hline Hectáreas & 20.974 & 19.038 & 19.196 & 18.470 & 18.912 & 18.192 & 20.041 & 23.547 & 29.758 & 29.467 & 28.289 \\
\hline Toneladas producidas & 168.357 & 181.533 & 183.104 & 189.601 & 192.533 & 206.026 & 259.954 & 284.103 & 328.374 & 313.880 & 247.213 \\
\hline Kilos por hectárea & 8.027 & 9.535 & 9.539 & 10.265 & 10.180 & 11.325 & 12.971 & 12.065 & 11.035 & 10.652 & 8.739 \\
\hline
\end{tabular}

Elaboración propia en base a datos del Ministerio de Agricultura del Perú, año 2011.

\subsection{Exportaciones peruanas de espárragos frescos}

El espárrago es un producto muy importante en la estructura exportadora peruana. En 2010 se ubicó en el primer lugar como exportador de espárragos frescos. Los volúmenes exportados han crecido convincentemente a partir de la década del '90. En el año 1994 el país exportó un total de 11.350 toneladas y se ubicaba como el quinto exportador mundial detrás de Estados Unidos, México, España y Grecia.

El principal mercado de exportación es Estados Unidos que adquiere casi el 70\% del espárrago fresco exportado (123.176 toneladas en 2010).

El segundo lugar lo ocupa Holanda, un país que ha aumentado sus volúmenes en la última década.

El tercer lugar lo ocupa España que supo ser un gran productor de espárragos y que fue perdiendo competitividad en este rubro. 
Gráfico $\mathrm{N}^{\circ}$ 60: Evolución de las exportaciones peruanas de espárragos frescos:

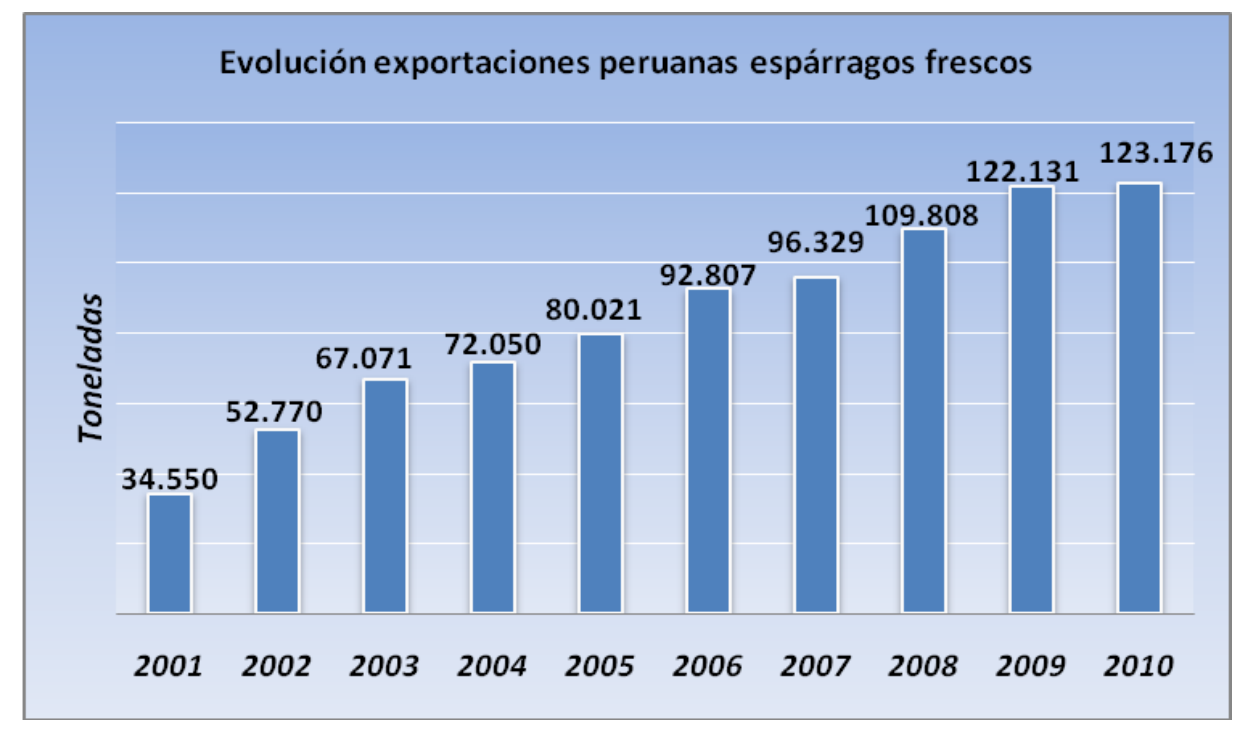

Fuente: elaboración propia en base a datos de World Trade Centre 2011

Tabla $\mathrm{N}^{\circ}$ 65: Detalle de las exportaciones peruanas de espárragos frescos por país.

\begin{tabular}{|c|c|c|c|c|c|c|c|c|c|c|}
\hline En toneladas & 2001 & 2002 & 2003 & 2004 & 2005 & 2006 & 2007 & 2008 & 2009 & 2010 \\
\hline Mundo & 34.550 & 52.770 & 67.071 & 72.050 & 80.021 & 92.807 & 96.329 & 109.808 & 122.131 & 123.176 \\
\hline EE.UU. & 27.525 & 43.016 & 53.122 & 55.743 & 59.133 & 68.613 & 70.099 & 79.615 & 87.663 & 85.340 \\
\hline Holanda & 2.413 & 3.270 & 4.260 & 4.451 & 5.430 & 6.518 & 7.463 & 10.406 & 13.338 & 13.338 \\
\hline España & 2.415 & 3.663 & 5.307 & 5.068 & 6.562 & 7.349 & 7.026 & 7.521 & 7.951 & 9.027 \\
\hline Reino Unido & 1.475 & 1.875 & 2.764 & 3.628 & 4.682 & 5.179 & 5.361 & 6.429 & 6.084 & 6.323 \\
\hline Japón & 5 & 17 & 59 & 264 & 403 & 614 & 510 & 426 & 857 & 1.501 \\
\hline Australia & 0 & 0 & 52 & 231 & 506 & 748 & 955 & 821 & 1.206 & 1.270 \\
\hline Francia & 137 & 262 & 277 & 285 & 370 & 611 & 653 & 754 & 713 & 785 \\
\hline Brasil & 80 & 97 & 95 & 102 & 153 & 206 & 257 & 367 & 489 & 644 \\
\hline Canadá & 11 & 4 & 18 & 116 & 248 & 110 & 459 & 304 & 286 & 637 \\
\hline Italia & 139 & 156 & 279 & 232 & 258 & 334 & 424 & 510 & 708 & 605 \\
\hline Alemania & 64 & 90 & 235 & 623 & 575 & 598 & 566 & 545 & 301 & 569 \\
\hline México & 53 & 39 & 130 & 148 & 208 & 402 & 284 & 270 & 345 & 485 \\
\hline Suiza & 12 & 11 & 30 & 89 & 215 & 364 & 579 & 418 & 536 & 478 \\
\hline Chile & 16 & 47 & 103 & 38 & 76 & 193 & 286 & 382 & 411 & 460 \\
\hline Bélgica & 45 & 54 & 161 & 671 & 762 & 541 & 473 & 209 & 218 & 346 \\
\hline Panamá & 2 & 5 & 35 & 11 & 28 & 47 & 129 & 63 & 128 & 161 \\
\hline Nueva Zelandia & 0 & 0 & 0 & 0 & 0 & 0 & 0 & 22 & 37 & 146 \\
\hline Suecia & 0 & 1 & 16 & 87 & 92 & 27 & 165 & 169 & 153 & 141 \\
\hline Dinamarca & 0 & 0 & 0 & 0 & 0 & 35 & 108 & 150 & 145 & 113 \\
\hline Sudáfrica & 0 & 0 & 0 & 0 & 40 & 97 & 110 & 78 & 67 & 103 \\
\hline
\end{tabular}

Elaboración propia en base a datos del World Trade Centre, año 2011. 
Gráfico $N^{\circ}$ 61: Evolución de las exportaciones peruanas de espárragos en conserva:

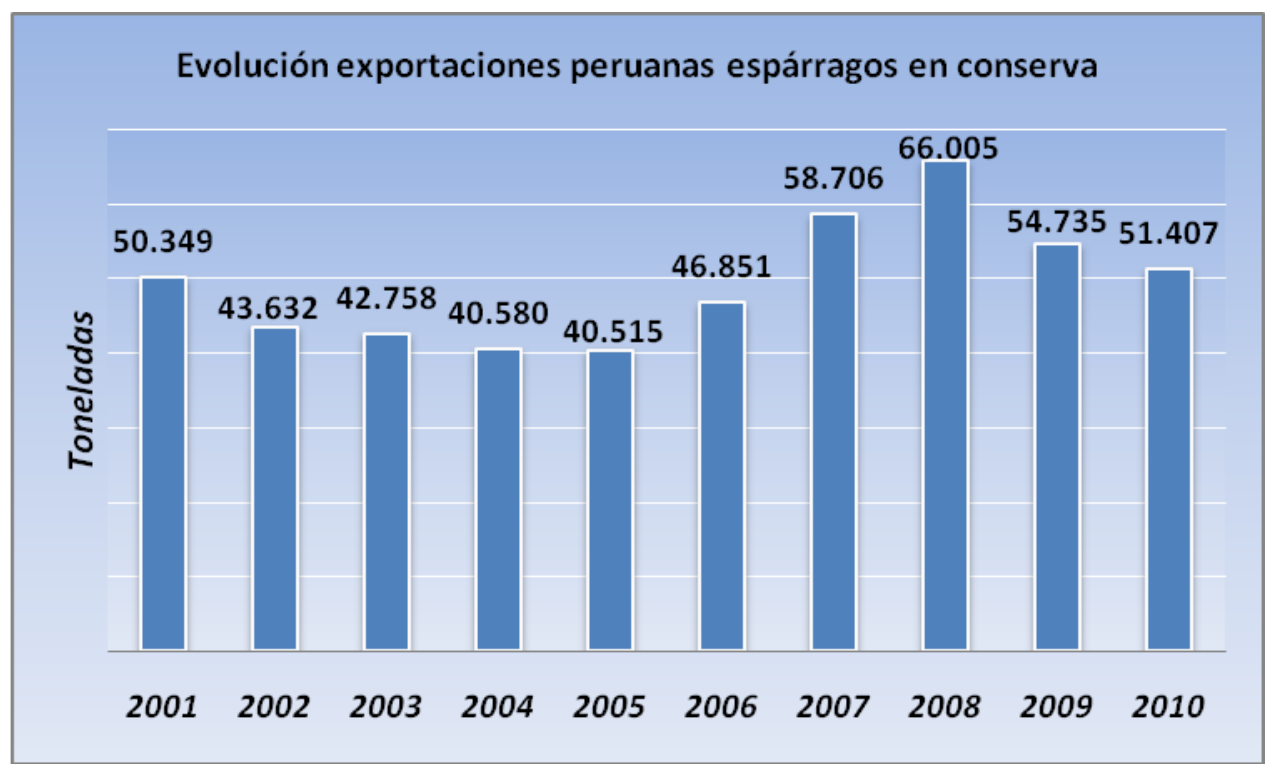

Fuente: elaboración propia en base a datos de World Trade Centre 2011

Tabla $\mathrm{N}^{\circ}$ 66: Detalle de las exportaciones peruanas de espárragos en conserva por país.

\begin{tabular}{|c|c|c|c|c|c|c|c|c|c|c|}
\hline En toneladas & 2001 & 2002 & 2003 & 2004 & 2005 & 2006 & 2007 & 2008 & 2009 & 2010 \\
\hline Mundo & 50.349 & 43.632 & 42.758 & 40.580 & 40.515 & 46.851 & 58.706 & 66.005 & 54.735 & 51.407 \\
\hline España & 29.876 & 25.593 & 23.814 & 22.423 & 17.400 & 13.597 & 19.587 & 21.924 & 24.761 & 18.787 \\
\hline EE.UU. & 2.062 & 1.011 & 3.785 & 4.868 & 7.973 & 12.273 & 11.550 & 17.895 & 12.378 & 10.644 \\
\hline Francia & 7.390 & 7.699 & 7.172 & 6.476 & 7.244 & 9.906 & 11.199 & 11.120 & 6.960 & 9.391 \\
\hline Alemania & 2.185 & 2.472 & 2.037 & 1.616 & 1.016 & 2.528 & 5.501 & 4.578 & 3.086 & 4.423 \\
\hline Dinamarca & 851 & 992 & 411 & 694 & 1.845 & 2.149 & 3.037 & 2.121 & 1.436 & 1.933 \\
\hline Australia & 1.577 & 1.030 & 1.572 & 1.666 & 1.389 & 1.210 & 865 & 1.248 & 1.358 & 1.467 \\
\hline Holanda & 3.173 & 2.458 & 1.250 & 735 & 916 & 1.629 & 2.853 & 1.945 & 1.393 & 987 \\
\hline Italia & 347 & 346 & 653 & 229 & 313 & 681 & 933 & 1.420 & 683 & 974 \\
\hline Canadá & 234 & 439 & 596 & 512 & 1.072 & 891 & 497 & 694 & 645 & 605 \\
\hline Bélgica & 236 & 277 & 273 & 336 & 278 & 565 & 864 & 1.221 & 212 & 595 \\
\hline Brasil & 134 & 104 & 52 & 65 & 53 & 383 & 455 & 406 & 271 & 462 \\
\hline Chile & 137 & 100 & 135 & 87 & 87 & 136 & 206 & 183 & 332 & 283 \\
\hline Reino Unido & 392 & 344 & 409 & 378 & 429 & 330 & 361 & 319 & 248 & 182 \\
\hline Venezuela & 152 & 83 & 27 & 66 & 98 & 85 & 61 & 86 & 97 & 113 \\
\hline Japón & 73 & 12 & 3 & 0 & 6 & 0 & 8 & 46 & 76 & 99 \\
\hline
\end{tabular}

Elaboración propia en base a datos del World Trade Centre, año 2011. 
Gráfico $N^{\circ}$ 62: Evolución de las exportaciones peruanas de espárragos congelados:

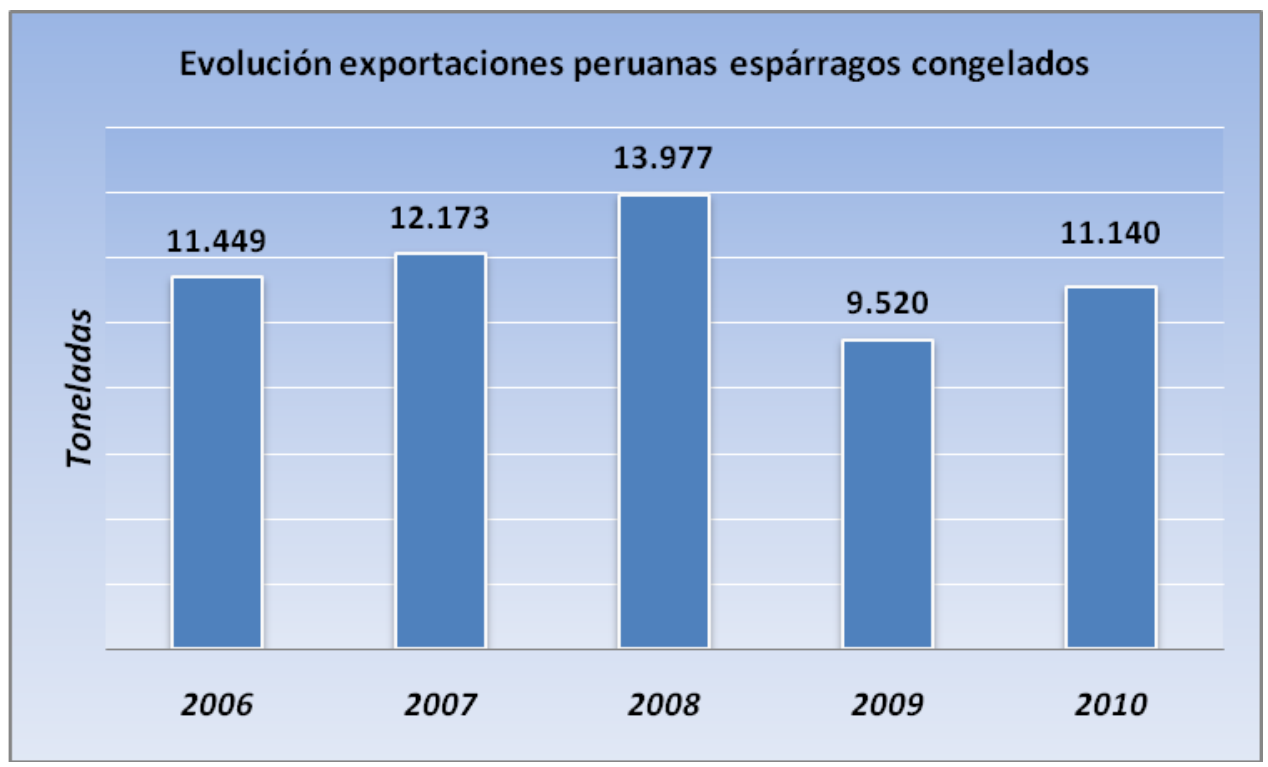

Fuente: elaboración propia en base a datos de World Trade Centre 2011

Tabla $N^{\circ}$ 67: Detalle de las exportaciones peruanas de espárragos congelados por país:

\begin{tabular}{|c|c|c|c|c|c|}
\hline En toneladas & $\mathbf{2 0 0 6}$ & $\mathbf{2 0 0 7}$ & $\mathbf{2 0 0 8}$ & $\mathbf{2 0 0 9}$ & $\mathbf{2 0 1 0}$ \\
\hline Mundo & $\mathbf{1 1 . 4 4 9}$ & $\mathbf{1 2 . 1 7 3}$ & $\mathbf{1 3 . 9 7 7}$ & $\mathbf{9 . 5 2 0}$ & $\mathbf{1 1 . 1 4 0}$ \\
\hline EE.UU. & 4.120 & 5.214 & 6.345 & 5.034 & 5.662 \\
\hline España & 2.632 & 2.638 & 3.150 & 1.165 & 2.054 \\
\hline Japón & 486 & 559 & 594 & 558 & 856 \\
\hline Italia & 1.203 & 1.082 & 1.297 & 1.069 & 851 \\
\hline Holanda & 465 & 440 & 817 & 467 & 525 \\
\hline Canadá & 138 & 59 & 80 & 130 & 311 \\
\hline Bélgica & 381 & 388 & 421 & 206 & 303 \\
\hline Reino Unido & 969 & 705 & 457 & 166 & 237 \\
\hline Alemania & 410 & 314 & 388 & 460 & 163 \\
\hline Francia & 413 & 311 & 90 & 114 & 84 \\
\hline Suecia & 171 & 287 & 295 & 119 & 61 \\
\hline Dinamarca & 23 & 62 & 0 & 15 & 14 \\
\hline Panamá & 0 & 0 & 0 & 0 & 12 \\
\hline Suiza & 0 & 0 & 0 & 0 & 2 \\
\hline Corea & 0 & 0 & 0 & 0 & 2 \\
\hline Chile & 40 & 113 & 43 & 0 & 2 \\
\hline Portugal & 0 & 0 & 0 & 0 & 1 \\
\hline Brasil & 0 & 0 & 0 & 1 & 0 \\
\hline México & 0 & 0 & 0 & 16 & 0 \\
\hline
\end{tabular}

Elaboración propia en base a datos del World Trade Centre, año 2011. 


\subsection{Conclusiones de la experiencia peruana}

El auge productivo del espárrago a partir de la década del '90 en Perú, podría comprenderse conjuntamente con el suceso en las exportaciones y el aumento en los rendimientos en el mismo producto, formando un círculo virtuoso y demostrando, además que este país posee condiciones agroecológicas únicas para el cultivo de esta especie.

Indudablemente las exportaciones impulsaron en buena manera la producción y el aumento sostenido de la productividad. En este rumbo las exportaciones a Estados Unidos parecen arrastrar en cadena las exportaciones globales, la producción y la productividad dentro del sector específico.

Una forma de encarar la comprensión de este fenómeno, es analizar los diferentes tratados comerciales de los Estados Unidos con la comunidad Andina en vistas a desplazar los cultivos de coca, tradicionales en los países de la región, debido a su rentabilidad.

En 1993 se firmó el acuerdo denominado ATPA (Andean Trade Preference Act), por el cual cuarenta artículos de Bolivia, Ecuador, Perú y Colombia tenían la posibilidad de competir libre de impuestos y aranceles en el mercado americano. Este programa produjo un impacto primario que impulsó la producción de espárragos en Perú. El acuerdo caducó a fines de 2001, y fue reemplazado por la Ley de Promoción Comercial Andina y Erradicación de la Droga (ATPDEA), firmada en octubre de 2002, esta al ser más abarcativa en cuanto a cantidad de productos incluidos, ha sido todo un éxito (según funcionarios peruanos), superando a la ley que la precedió. Por lo tanto este país se ubicaba con un acceso preferencial al mercado estadounidense pudiendo competir de manera eficiente con los productores mexicanos y los mismos americanos. Esto fue un factor de atracción para los capitales europeos que viendo una buena forma de ingresar al mercado estadounidense optaron por mudar sus aparatos productivos a este país.

Esta transformación básicamente consistió en un proceso, donde los capitales productivos españoles migraron, buscando nuevas oportunidades para producir con más ventajas en materia de costos (especialmente laborales), según argumenta el Instituto Para la Libre Empresa (ILE) ${ }^{69}$ con respecto a esta peculiaridad: "la necesidad de satisfacer la demanda y mejorar los retornos del negocio,

\footnotetext{
${ }^{69}$ Disponible en http://www.ileperu.org
} 
impulsaron a algunos empresarios españoles a buscar, fuera de España, zonas con condiciones climáticas apropiadas, pero sobre todo, con costos de mano de obra menores. Así, luego de muchos ensayos, los países escogidos fueron China y Perú. Grupos españoles han invertido cantidades millonarias en plantas situadas en ambos países. En Europa misma, incluso, las plantaciones han ido emigrando del norte hacia el sur, buscando costos de producción más bajos". Esto se verifica en que las principales empresas exportadoras de conservas son las europeas Industrias Alimentarias de Navarra (España) y Danper Trujillo (Dinamarca), junto a las nacionales peruanas Agroindustrias Backus y Sol Produce. En la búsqueda de las pequeñas ventajas estratégicas reside una parte importante del éxito de las exportaciones agrícolas no tradicionales. Está verificado que estos productos son sensibles al nivel arancelario. Es decir pueden ingresar en forma rentable a un mercado si el arancel es suficientemente bajo o nulo, como es el caso del espárrago.

Asimismo y más allá de las condiciones anteriormente enunciadas, el Gobierno del Perú ha establecido que el espárrago es un "Cultivo de Importancia Nacional”, lo que lleva consigo un constante apoyo a todos los productores esparragueros del país. 


\section{Datos generales sobre Alemania}

Alemania es el cuarto PBI más grande del mundo con 3.305.898 (millones de US\$) según ranking del Banco Mundial 2010, siendo asimismo el tercer exportador mundial en los últimos cinco años (equivale a aproximadamente el 20\% del PIB total de la Unión Europea). Por regla general, la comercialización de productos en el mercado alemán requiere largos periodos de preparación, por lo que no procede hablar de oportunidades transitorias de negocio.

\subsection{Situación, superficie, superficie agrícola, relieve y clima}

La República Federal de Alemania está situada en Europa Central. Tiene una extensión de 357.050 $\mathrm{Km}^{2}$, el $53 \%$ de los cuales son superficie agraria y el $30 \%$ forestal.

Los Alpes alemanes, cuyo pico más alto $(2.963 \mathrm{~m})$ es el Zugspitze, sólo ocupan una estrecha franja de la región alpina que desciende hacia la meseta bávara. El territorio alemán perteneciente a la Europa media está constituido por un conjunto de pequeños macizos cubiertos de bosques y separados por depresiones. El norte del país está surcado por ríos y canales.

El clima es intermedio entre marítimo y continental con precipitaciones frecuentes.

Aumenta el carácter continental según se avanza hacia el Este. Con la altura se incrementan el frío y las precipitaciones acuosas; en Frankfurt, (98 m altitud) las temperaturas medias fluctúan en Enero de $3^{\circ}$ a $1^{\circ} \mathrm{C}$ y en Julio $15-20^{\circ} \mathrm{C}$, mientras que las precipitaciones anuales medias oscilan en torno a los $655 \mathrm{~mm}$.

\subsection{Población, etnias, densidad demográfica y tasa de crecimiento}

La población de Alemania en 2010 es de 82,6 millones de habitantes. Las principales minorías son la turca con 1,69 millones y la italiana con 0,52 millones. Su densidad poblacional, (230 habitantes/km²), es la más alta de Europa, después de Bélgica y Países Bajos. La densidad de población es mucha menor en la parte oriental que en la occidental. En esa región vive únicamente una quinta parte (16,5 millones) de la población total de Alemania en, aproximadamente, el 30\% de la superficie. Un informe de la ONU estima la inmigración ilegal en Alemania entre medio millón y un millón de personas. 
Tabla Nº 68: Datos demográficos de Alemania:

\begin{tabular}{|c|c|c|c|c|}
\hline Estado Federal & Extensión $\left(\mathrm{Km}^{2}{ }^{2}\right)$ & Población & Densidad (hab./ $\mathrm{km}^{2}$ ) & Capital \\
\hline Baden Württemberg & 35.751 & 10.744 .921 & 301 & Stuttgart \\
\hline Bayern & 70.550 & 12.510.331 & 177 & Münich \\
\hline Berlín & 892 & 3.442 .675 & 3.861 & Berlín \\
\hline Brandenburg & 29.482 & 2.511 .525 & 85 & Potsdam \\
\hline Bremen & 404 & 661.716 & 1.637 & Bremen \\
\hline Hamburg & 755 & 1.774 .224 & 2.349 & Hamburg \\
\hline Hessen & 21.115 & 6.061 .951 & 287 & Wiesbaden \\
\hline Mecklenburg - Vorpommern & 23.189 & 1.651 .216 & 71 & Schwerin \\
\hline Niedersachen & 47.635 & 7.928 .815 & 166 & Hannover \\
\hline Nordrhein - Westfalen & 34.088 & 17.872 .763 & 524 & Düsseldorf \\
\hline Rheinland - Pfalz & 19.854 & 4.012 .675 & 202 & Mainz \\
\hline Saarland & 2.569 & 1.022 .585 & 398 & Saarbrücken \\
\hline Sachsen & 18.420 & 4.168 .732 & 226 & Dresden \\
\hline Sachsen - Anhalt & 20.449 & 2.356 .219 & 115 & Magdeburg \\
\hline Schleswig - Holstein & 15.799 & 2.832 .027 & 179 & Kiel \\
\hline Thüringen & 16.172 & 2.249 .882 & 139 & Erfurt \\
\hline
\end{tabular}

\subsubsection{Población urbana y de las principales ciudades}

La población urbana, entendiendo por tal a la que vive en centros con más de 5.000 habitantes, asciende al 83,9\% del total. Las ciudades más populosas son Berlín con 3,4 millones, Hamburgo con 1,77 millones y Münich 1,3 millones.

\subsubsection{Distribución de la población por edades y sexos}

El 51\% de la población es femenina y el $49 \%$ es masculino. Por edades, la población se distribuye de la siguiente manera: un 13,7\% de menores de 15 años; 20,1\% de más de 65 años y un 66,2 \% de entre 15 y 65 años. Se estima que hacia el año 2030 uno de cada tres alemanes tendrá 60 o más años, con los consiguientes efectos sobre la actividad económica y las finanzas públicas.

\subsubsection{Población activa}

La población activa en Alemania a fines del 2010 asciende a 43,5 personas. En diciembre de 2009 ha habido 3,28 millones de parados, de los cuales un 30,5\% aproximadamente son de larga duración, para una tasa de paro del 7,8\%. Dicha cifra supone un aumento de más de 180.000 parados respecto a diciembre de 2008, lo que refleja los efectos de la crisis financiera y económica, aunque la tasa de paro es relativamente baja. De todos modos la aplicación de mecanismos de paro parcial consistentes en subvencionar la reducción de carga de trabajo sin una reducción paralela de la plantilla, puede estar encubriendo una cifra real de paro más elevada. 
Persiste el diferencial de empleo existente entre los antiguos y los nuevos Länder. La tasa de paro fue del 6,6\% en los antiguos Länder y del 11,8\% en los nuevos.

El sector servicios ha aumentado su nivel de ocupación pero a un ritmo muy inferior a años anteriores. La cuota de ocupación en los últimos años ha reflejado un descenso progresivo de la industria y la agricultura.

\subsection{Organización político-administrativa}

Alemania presenta el perfil político de un estado social y democrático de derecho, con elecciones regulares, pluripartidismo, separación de poderes, parlamentarismo bicameral, federalismo y protección de los derechos humanos. El sistema se caracteriza además por una gran estabilidad, los gobiernos acostumbran a contar con mayorías sólidas y las convocatorias electorales anticipadas ocurren raramente.

\subsubsection{Gobierno, partidos políticos y parlamento}

El Gobierno Federal ejerce el Poder Ejecutivo. Se compone del Canciller Federal y los Ministros Federales. Sólo el Canciller es elegido por el Bundestag, a propuesta del Presidente Federal, mientras que los Ministros se nombran por el Presidente a propuesta del Canciller. El Canciller determina la política del Gobierno y responde de ella ante el parlamento. Para la destitución de un Canciller Federal, la Ley Fundamental prevé como única posibilidad una "moción de censura constructiva", por la que el Bundestag tiene que elegir, con la mayoría de sus miembros, un sucesor en este cargo y solicitar al Presidente Federal que le nombre nuevo Canciller.

Las últimas elecciones tuvieron lugar el día 27 de septiembre de 2009, en las que la coalición CDU/CSU obtuvo la mayoría de escaños (239), seguidos del SPD (146) y FPD (93). CDU/CSU han llegado a un acuerdo con el FPD para formar Gobierno. La Sra. Angela Merkel, de la CDU, seguirá siendo Canciller hasta las próximas elecciones.

El Gobierno alemán de la Canciller Angela Merkel cuenta con 16 carteras: 8 de ellas son ocupadas por la CDU, 3 por la CSU y 5 por el FDP. Los Miembros del nuevo Gobierno con carteras de contenido económico son: Rainer Brüderle (Economía y Tecnología, FDP), Wolfgang Schäuble (Finanzas, CDU), Ursula von der Leyen (Trabajo, CDU), Annette Schavan (Educación, CDU), Peter Ramsauer (Transporte y Construcción, CSU) y Norbert Röttgen (Medio Ambiente, CDU).

La Cartera de Exteriores recae sobre el líder del Partido Liberal, Guido Westerwelle, vicecanciller del Gobierno. El Bundesrat es la Cámara Alta del Parlamento y en ella están representados los Länder, que 
cuentan con un número de votos desigual, atendiendo a su población. Los miembros son elegidos por el Parlamento de cada Land. La distribución de votos por Länder es la que sigue:

\subsubsection{Organización administrativa y territorial del Estado}

La Ley Fundamental de 1949 define la República Federal de Alemania como Estado Federal democrático y social. Originariamente constaba de 11 estados, a los que se añadieron otros 5 en 1990, tras la reunificación. Dichos Estados Länder son:

Tabla N 69: Antiguos y Nuevos Länder de Alemania:

\begin{tabular}{|c|c|}
\hline Antiguos Länder & Nuevos Länder \\
\hline Baden Württemberg & Brandenburgo \\
Baviera & Mecklenburgo-Pomerania \\
Berlín & Sajonia \\
Bremen & Sajonia-Anhalt \\
Hamburgo & Turinga \\
Hesse & \\
Baja Sajonia & \\
Renania del Norte - Westfalia & \\
Renania Palatinado & \\
Sarre & \\
Schleswig - Holstein &
\end{tabular}

\subsubsection{La Administración Económica y Comercial y distribución de competencias}

Las principales áreas de la política económica y comercial son competencia exclusiva de la Federación, aunque los Estados federados ejercen también competencias legislativas o de ejecución en forma exclusiva o concurrente con la Federación. Esta coincidencia se da principalmente en materia tributaria, mercantil, de ordenación del comercio interior, de fomento de la inversión, etc.

El Ministerio de Finanzas gestiona la Hacienda Pública, es responsable de la elaboración de los Presupuestos. El actual ministro de Finanzas es Wolfgang Schäuble, de la CDU. 


\subsection{Relaciones internacionales/regionales}

Es miembro de los principales organismos financieros internacionales, aunque no es perceptor de fondos. Dentro de la OMC rigen para Alemania los acuerdos negociados a través de la Unión Europea en la Ronda Uruguay.

\subsection{Estructura de la economía}

Alemania presenta en el año 2011 la estructura económica propia de un país altamente desarrollado, donde la agricultura tiene un escaso peso en el PBI. El sector industrial es comparativamente más importante, que en otros países, pero también está perdiendo importancia frente al sector servicios, tanto en ocupación, como en generación de valor añadido.

\subsubsection{Principales sectores de la economía}

\section{Agrícolas y de consumo}

Según datos del Ministerio de Finanzas, el sector primario alemán (agricultura, ganadería y pesca) ocupa a unas 860.000 personas, aproximadamente un $2 \%$ de la población ocupada y genera alrededor del 1\% del PBI. La Superficie Agrícola Útil (SAU) se ha mantenido estable durante los últimos 15 años y es de unas 17 millones de hectáreas.

La explotación agrícola tiene características diferentes según se trate de los antiguos o los nuevos Länder:

En los antiguos Länder predomina la explotación de pequeño tamaño (29 hectáreas de promedio). En general se trata de explotaciones unipersonales o familiares. El trabajo asalariado sólo alcanza al 30\% de la población ocupada.

En los Länder de la antigua Alemania del Este, por el contrario, hay relativamente pocas explotaciones pero de mayor tamaño (184 hectáreas). Predomina el trabajo asalariado, que comprende casi al 75\% de la población ocupada, y el resto lo forman los empresarios individuales o familiares.

De todos modos en todo el territorio nacional se está manifestando la misma tendencia hacia la concentración de las explotaciones, con su consiguiente disminución en número y aumento en superficie. 
La producción nacional sirve para cubrir aproximadamente el $80 \%$ de las necesidades de consumo doméstico, siendo cubierto el resto con importaciones.

El principal cultivo es el cereal, que ocupa el $58 \%$ de la SAU, destacando el trigo, el centeno y la cebada. Le siguen en importancia las plantas forrajeras y después las oleaginosas. Por volumen de producción también predominan los cereales, seguidos por la patata y la colza de invierno.

\section{Industriales y de servicios}

El sector industrial, la minería, la construcción y el suministro de agua y energía se agrupan en las estadísticas alemanas bajo el nombre de Sector Productivo (Produzierendes Gewerbe).

La industria emplea a unos 8 millones de personas, aproximadamente el $20 \%$ del total. Las características fundamentales son la elevada productividad y la fuerte orientación hacia los mercados exteriores.

En los primeros años 90 la aportación en valor añadido bruto del sector disminuyó, debido al importante desmantelamiento industrial operado en la antigua Alemania del este tras la reunificación. Aunque el $90 \%$ de las empresas son pymes, sólo generan el $42 \%$ de la facturación industrial total y dan empleo al $43 \%$ de la población ocupada en el sector.

Por ramas de actividad la importancia principal corresponde a las más clásicas, como el automóvil, el sector químico, la maquinaria y la electrónica y la electrotecnia. En las tres primeras, al menos dos tercios de la facturación proceden de la exportación. Entre los sectores en ascenso destaca la biotecnología y el equipamiento de medio ambiente.

En los sectores del automóvil, maquinaria e industria química es donde se realiza el mayor gasto en I + D y también aquellos en que la balanza comercial arroja un superávit más elevado.

La minería alemana está especializada en el carbón, mayormente localizada en la cuenca del Ruhr. El sector está sumido en una larga crisis de difícil salida. Su origen hay que buscarlo en el alto coste de extracción, en comparación con el carbón de importación, de modo que la única opción es reducir producción y empleo.

El sector industrial en general y la energía en particular están muy condicionados en los últimos años

por las necesidades de ahorro y la normativa medioambiental. Esta se traduce en un aumento cada vez 
mayor de la tributación de los combustibles fósiles y la limitación de los derechos de emisión de gases con efecto invernadero. Por otra parte se está fomentando el empleo de las energías renovables mediante la imposición de remuneraciones mínimas, al tiempo que se subvenciona la investigación en estas energías.

La construcción en Alemania es un sector dual; existe una multitud de pequeñas empresas, con facturación inferior a 1.000 millones de euros y sólo tres grandes empresas, de facturación superior a 3.000 millones de euros, que son Hochtief, Bilfinger Berger y Strabag. Las grandes empresas tienden a concentrarse en el sector de la gran obra pública donde dominan el mercado, y las empresas medianas o pequeñas están más presentes en la construcción residencial, industrial o comercial.

Hasta ahora la modalidad de construcción PPP (Public Private Partnership) ha tenido un desarrollo inferior al habitual en otros países europeos. Ello se debe en parte a la falta de concesionalidad de las obras públicas, sobre todo las autopistas.

La modificación estructural más importante de la economía alemana en los últimos años ha sido el descenso en la participación del PIB del sector primario y el sector productivo frente al aumento del sector servicios. Así en 1970 el sector productivo y el de servicios tenían aproximadamente el mismo peso en el PIB, un 48\%, y el sector primario un 4\%. En el año 2008 el sector servicios - sin contar la construcción - contabiliza el 69\% del PIB, mientras que el sector productivo y el primario aportan sólo el $26 \%$ y el $1 \%$ respectivamente.

Dicho aumento ha tenido lugar principalmente por el aumento de empleo y recursos en el sector, mientras que en cambio el aumento de productividad ha sido siempre inferior al del sector productivo. El subsector de servicios, financieros, el de alquileres y en general el de servicios a empresas ha aumentado considerablemente su participación dentro del total de los servicios.

También se trata de los servicios más productivos, puesto que dando empleo al $23 \%$ de la población ocupada en el sector servicios, generan el $42 \%$ del valor total generado por estos. Por el contrario se ha reducido la aportación relativa al PIB por parte del comercio, la hostelería, el transporte y las comunicaciones. La misma evolución se ha venido observando en cuanto a la creación de empleo. El descenso en la aportación al PIB por el sector productivo y el correlativo ascenso en el segmento de los 
servicios a empresas llevan a la conclusión, de que ha habido un cambio de empleo de aquél a éstos, originado por el aumento de la subcontratación o outsourcing de terceros por parte de la industria.

\section{El sector exterior: relaciones comerciales}

Alemania cuenta con gran tradición exportadora. Para el año 2010 se sitúa como tercer exportador mundial de mercancías después de China y EE.UU., según datos de International Trade Centre ${ }^{70}$. La balanza de servicios ha sido tradicionalmente deficitaria para Alemania, pero desde 1999 se observa una notable reducción del déficit, debido sobre todo al fuerte aumento en la exportación de servicios. La mayor parte de las exportaciones alemanas, el 53\%, son realizadas a países de la Unión Europea, circunstancia habitual de los países miembros, aunque en la mayoría de éstos la cuota se encuentra en un $70 \%$. Se observa que desde algunos años está disminuyendo el peso de la UE-15 como destino de las exportaciones alemanas. Entre los terceros países destacan los EE.UU. y los países del Este de Europa.

La distribución geográfica de las importaciones es parecida a la de las exportaciones. Llaman la atención la progresión de las importaciones de los antiguos Países del Este, así como en el comercio con China. Por contrario, las importaciones del sudeste de Asia son comparativamente poco importantes.

Al estar la economía alemana especializada en sectores de media y alta tecnología, resulta menos vulnerable a la competencia de los países extracomunitarios de salarios bajos.

La mayor parte de los otros servicios tienen un comportamiento global mucho más equilibrado, con un claro superávit de los servicios de transporte y los tránsitos comerciales y un casi equilibrio del resto de las partidas.

\footnotetext{
${ }^{70}$ Disponible en www.intracen.org.
} 


\subsection{Infraestructura de transporte}

La República Federal de Alemania es una sociedad industrial moderna y como tal posee un sistema de transporte altamente desarrollado. Es justamente este sistema el que le da la eficiencia y la flexibilidad necesaria a la industria y el comercio.

El movimiento de transportes se realiza mayoritariamente a través de las autopistas. La extensa red de carreteras con doble carril cumple un papel por demás especial. Las rutas entre ciudades tiene una extensión de aproximadamente $231.000 \mathrm{~km}$; mas de 12.000 son autopistas de doble mano. De esta manera Alemania posee, después de EE.UU., la red de carreteras más larga del mundo. El transporte rápido puerta a puerta es impensable sin camiones. Los vehículos automotores continuarán siendo el principal medio de transporte.

Probablemente por esta razón hay que contar con frecuentes congestiones de tráfico en las mismas, sobre todo en los alrededores o circunvalaciones de las grandes ciudades.

Desde 2005, los vehículos de peso total autorizado superior a 12 toneladas están obligados a satisfacer un peaje en autopistas (LKW-Maut).

Las carreteras normales, sin doble carril en ambos sentidos, son igualmente muy abundantes y con buen trazado y firme. Su único problema es su paso por las ciudades y pueblos de un país de tan alta densidad de población.

La velocidad en autopista, continúa sin limitación salvo, naturalmente, en los tramos señalizados. En las carreteras nacionales (Bundesstrassen), la velocidad máxima es de $100 \mathrm{Km} / \mathrm{h}$. En las vías urbanas, el límite está en $50 \mathrm{Km} / \mathrm{h}$, pero es muy frecuente verlo reducido a $30 \mathrm{Km} / \mathrm{h}$ en zonas residenciales. El límite de alcoholemia se ha reducido recientemente al 0,5 por mil.

Las infracciones de tráfico son sancionadas con bastante rigor, que llega fácilmente a la retirada temporal o definitiva del permiso de conducir.

La red ferroviaria suma actualmente $41.000 \mathrm{~km}$. de vía, de los que casi $20.000 \mathrm{~km}$. están electrificados. Esto se traduce en una densidad de 106 kilómetros de vía por cada $1.000 \mathrm{~km}^{2}$, siendo la cuarta mayor densidad de la Unión Europea. Casi todas las grandes ciudades alemanas están conectadas a la red 
ferroviaria de alta velocidad, Deutsche Bahn. Circulan a diario más de 630 trenes de largo recorrido, a intervalos de una hora, que enlazan más de 250 ciudades.

Existen 1.800 kilómetros de línea de alta velocidad en Alemania, un 3,3\% del total. El tren Inter City Express (ICE), designa a los trenes de alta velocidad. Estos trenes fueron desarrollados a partir del año 1985 por Siemens. La primera generación, conocida como ICE 1, alcanza una velocidad máxima de $280 \mathrm{~km} / \mathrm{h}$. Desde el año 2000 circulan ya los ICE 3, la versión más moderna y más rápida de estos trenes, que alcanza una velocidad máxima de $330 \mathrm{~km} / \mathrm{h}$.

En algunas regiones se complementan las líneas férreas y el asfalto. Existen vagones especiales para el transporte de camiones de carga y el uso de contenedores también es un medio de conexión importante en la corriente de transporte.

Actualmente las líneas de alta velocidad enlazan entre sí a las principales ciudades alemanas, como Münich, Hamburg, Berlín, Frankfurt, Köln y Hannover.

Las tarifas son más bien elevadas. El precio medio por $\mathrm{km}$. es de aproximadamente 0,13 Euros en segunda clase y 0,2 Euros en primera. En los trenes de largo recorrido hay que abonar, además, un suplemento fijo de 3 Euros. Un billete individual de ida a vuelta entre Berlín y Münich cuesta unos $160 €$. Entre Frankfurt y Köln unos $70 €$.

Estas son las tarifas normales, pero hay modalidades de abonos reducidos para viajeros habituales, familias y grupos. Entre otros servicios que presta el ferrocarril, es interesante citar el de paquetería exprés, que garantiza la entrega en cualquier punto del país en la mañana siguiente al día del despacho. 
Gráfico $N^{\circ}$ 63: Principales hidrovías de Alemania:

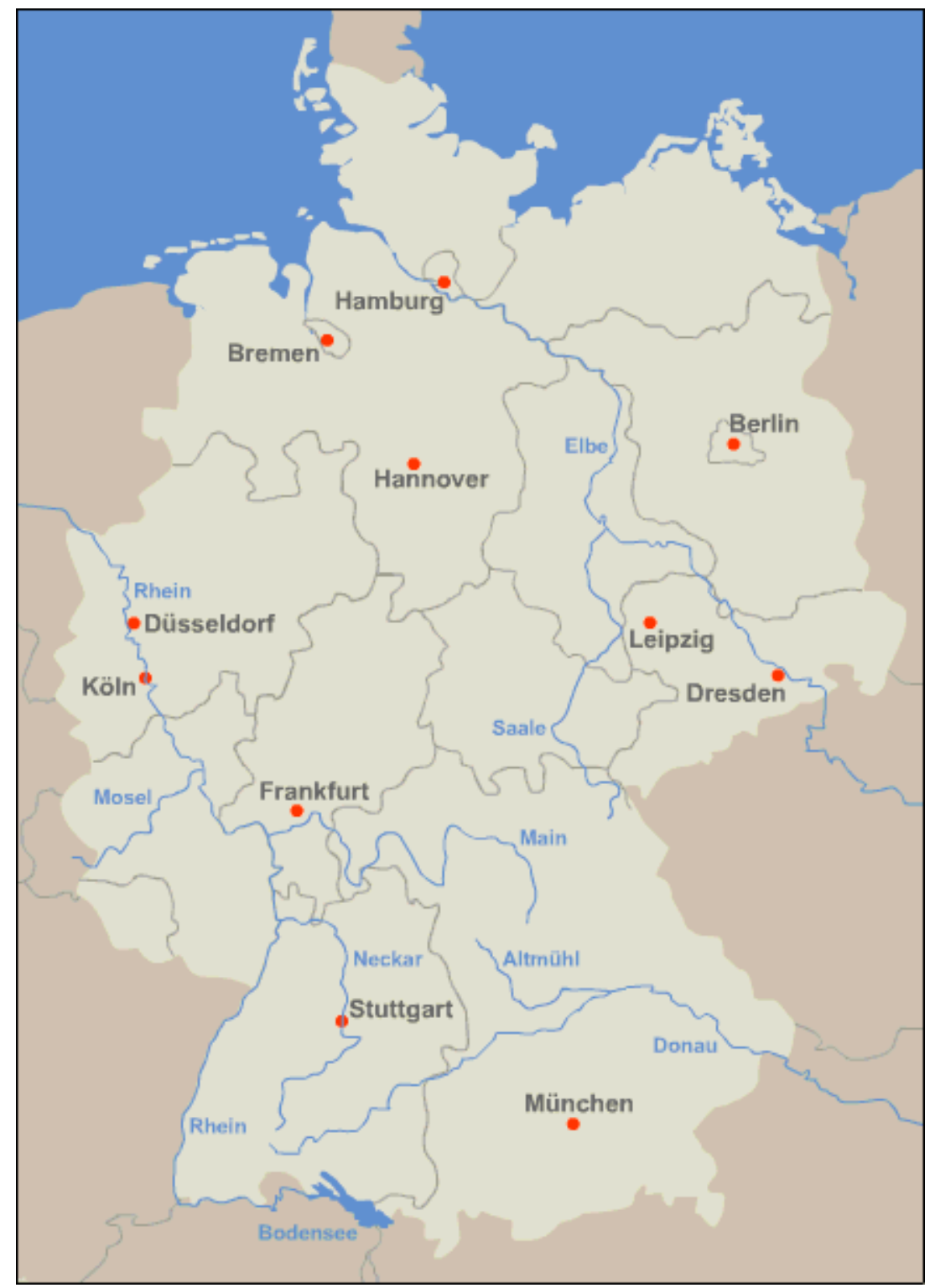

Los puertos marítimos canalizan un tráfico de mercancías total de 315 millones de toneladas, de los que más del $97 \%$ es tráfico de comercio exterior según la agencia de estadística del Gobierno Alemán. Los puertos principales son Hamburg, Bremen-Bremerhaven, Wilhelmshaven, Lübeck y Rostock.

Es también muy importante el tráfico interior y con el exterior por vía fluvial (ríos y canales), que se extiende por $6.700 \mathrm{Km}$ navegables. El volumen de tráfico de mercancías por esta vía alcanza los 248 millones toneladas, de las que más del $60 \%$ es comercio exterior. El mayor puerto fluvial del mundo está ubicado en la ciudad alemana de Duisburg. La principal hidrovía del mundo es el río Rhin; en la que se transportan dos tercios de las cargas internas de Alemania. Cerca de 3.400 embarcaciones 
alemanas circulan por ríos y canales, cuya extensión total alcanza los $6.900 \mathrm{~km}$. Es dable destacar la vía del Rhin, que comunica Basilea con Rotterdam a través de algunas de las principales zonas económicas alemanas. Asimismo casi todas las ciudades poseen sus aeropuertos. El mayor aeropuerto es el de Frankfurt am Main, que es también uno de los más importantes de Europa. Los aeropuertos internacionales se encuentran en las siguientes ciudades: Berlín, Bremen, Düsseldorf, Hamburg, Hannover, Köln, Münich, Nürnberg, Sarrebruck, Stuttgart y Halle/Leipzig. Existe asimismo toda una serie de aeropuertos de importancia regional.

Gráfico $N^{\circ}$ 64: Principales autopistas de Alemania:

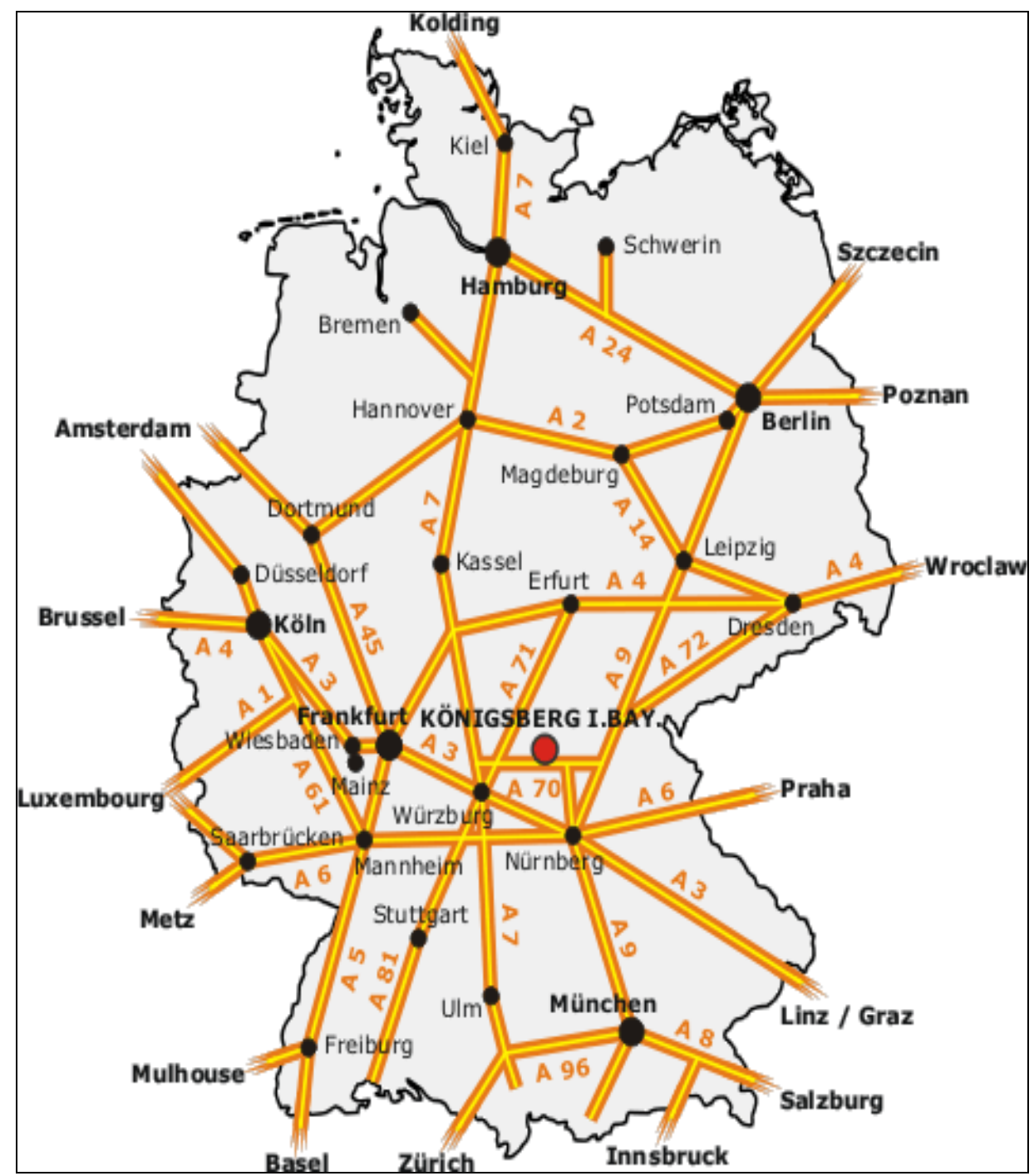


Gráfico $\mathrm{N}^{\circ}$ 65: Principales aeropuertos de Alemania:

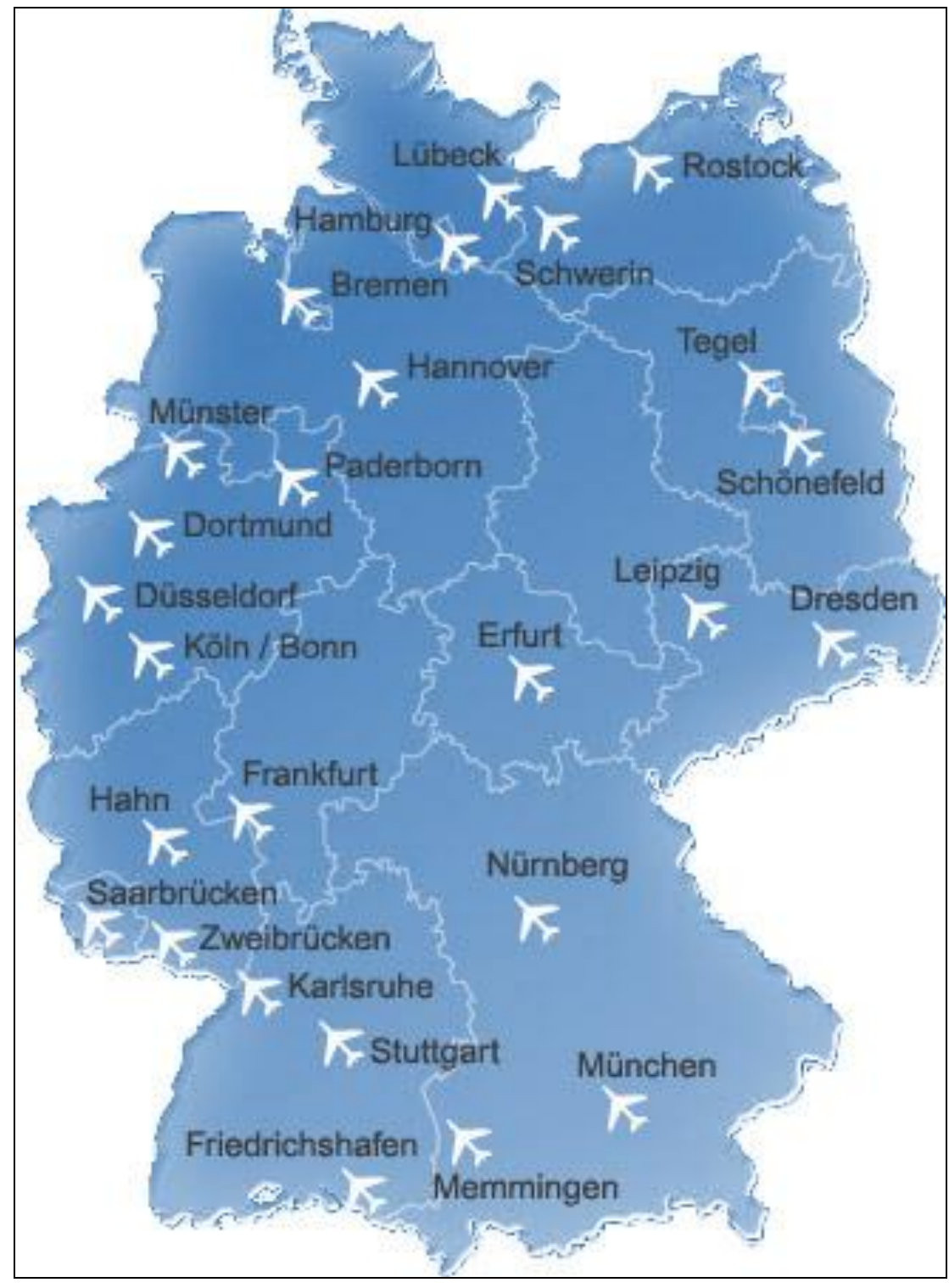




\section{Información práctica}

\subsection{Costes de establecimiento}

La constitución de una sociedad de responsabilidad limitada $(\mathrm{GmbH})$ con un capital social de $€ 25.000$ tiene un coste total de unos $€ 400$ por gastos de notaría, más $€ 200$ de inscripción en el Registro Mercantil. El alta de actividad en el ayuntamiento cuesta $€$ 25. La inscripción en la Cámara de Comercio es obligatoria y consta de una cuota fija anual, que oscila entre $€ 50$ y $€ 150$, más una cuota variable en función de la facturación de la empresa.

\subsection{Formalidades de entrada y salida}

Los ciudadanos de la UE sólo necesitan pasaporte o DNI para entrar en Alemania. Los ciudadanos de los países miembros del Acuerdo de Schengen, no precisan formalidad ninguna.

No se exige ni se requiere medida sanitaria alguna. Para animales domésticos hay que presentar certificados veterinarios que acrediten las correspondientes vacunas. No se les aplica ningún tipo de cuarentena.

Tampoco existe control de cambios. Hay libertad absoluta en materia de divisas, aunque si existe una obligación estadística de declarar importes en efectivo superiores a $€ 10.000$.

\subsection{Costumbres peculiares en el trato de clientes y socios comerciales}

$\checkmark$ Las costumbres y patrones sociales alemanes en determinados sectores se diferencian de gran manera con respecto a los latinoamericanos.

$\checkmark$ En Alemania es común que las personas que se conocen desde hace mucho tiempo, ya sea en el medio profesional o en el día a día, se traten por el apellido. Las personas unas el apretón de mano como saludo; en el ámbito de los negocios no se estila besar en el rostro.

$\checkmark$ El socio o cliente alemán espera puntualidad en los compromisos. Cuando no sea posible llegar en hora a una reunión, se recomienda informar a la otra parte telefónicamente en un tiempo prudencial.

Los alemanes acostumbran a ser bastantes directos en las negociaciones comerciales, es decir que no dan rodeos o "vueltas" al expresar lo que desean y lo que piensan sobre una cooperación. Decir "NO" es perfectamente normal en Alemania, contrariamente a los países latinos, donde se 
prefiere evitar decir "NO". En los contratos se debe observar que la confiabilidad de las partes y la calidad constante del producto o servicio son de suma importancia para el contratante alemán.

$\checkmark$ No es imperativo ofrecer obsequios, pero un pequeño presente, particularmente típico del país visitante, puede perfectamente facilitar el inicio de una conversación.

$\checkmark$ En cuanto a la indumentaria, se debe prestar especial atención en una apariencia bien prolija, en la que se incluyen el traje o una combinación de saco y corbata.

\subsection{Vacaciones y días festivos}

Hay otras fiestas fijas o móviles que varían de Land a Land. Las más comunes son:

- Año Nuevo (en todo el país, el $1^{\circ}$ de enero).

- Viernes Santo, (en todo el país).

- Lunes de Pascua, (en todo el país).

- Lunes de Pentecostés, (en todo el país).

- Día de la Ascensión, (en zonas católicas).

- Corpus Christi, (en zonas católicas).

- Fiesta del Trabajo (en todo el país, 1 de mayo).

- Reunificación de Alemania (en todo el país, 3 de octubre).

- Navidad (en todo el país, 25/26 de diciembre).

Cada Land determina los demás días festivos. Por ejemplo en Renania del Norte-Westfalia, se celebra, adicionalmente a todas las que acabamos de relacionar, el lunes de carnaval.

El número máximo de días festivos al año oscila entre 12 y 13.

El periodo de vacaciones escolares es variable de año en año y según Estados. Las de verano constan de 6 semanas y oscilan entre Julio y Agosto. Hay también una o dos semanas a mediados de Octubre, entre 15 y 20 días en Navidades, alrededor de dos semanas en Pascua y de uno a diez días después de Pentecostés. 


\subsection{Vías de comunicación con Argentina}

Operan numerosas compañías, las más utilizadas son Air France, Swiss Air, British Airlines, Iberia y Lufthansa (entre otras). Las comunicaciones con Argentina son numerosas y frecuentes. El mayor número de vuelos directos desde Argentina llegan o salen de Frankfurt, como así también a Stuttgart. También existen conexiones directas con Berlín, Düsseldorf, Münich, Hamburg, Stuttgart y Köln/Bonn.

Las principales compañías aéreas de "low cost" han adquirido una gran relevancia en el transporte aéreo en Alemania. Easyjet, Ryanair, y las alemanas Germanwings o Air Berlin, por citar a las más relevantes, han establecido rutas aéreas entre las principales ciudades alemanas tanto con grandes ciudades europeas como destinos turísticos. Por lo demás, el tráfico charter entre Alemania y Europa es muy intenso.

El aeropuerto de Frankfurt, es uno de los enlaces más usados por viajeros para destinos en el Este de Europa y en Asia.

\subsection{Direcciones útiles}

\section{Embajada Alemana en Argentina}

Calle Villanueva 1055, C1426 BMC - Buenos Aires

Teléfono:(00 - 54-11) 4778-2500

Fax: (00 -54-11) 4778-2550

Horario de atención del Consulado: lunes a viernes 08:30 a 11:00hs.

Otros horarios previa coordinación

Sitio web: http://www.buenos-aires.diplo.de

\section{Embajada Argentina en Alemania}

Calle: Kleiststraße 23-26, 10787 Berlín, República Federal de Alemania

Teléfono: +49(0)302266890

Fax: +49(0)302291400

Sitio web: http://www.embajada-argentina.de/

Email: info@embargent.de 


\section{Sección Consular de la Embajada de la República Argentina en Berlín:}

Calle: Kleiststraße 23-26, 10787 Berlín, República Federal de Alemania.

Tel.: +49(0)302266890

Fax: +49(0)302291400

Email: consulado@embargent.de

Circunscripción consular:

Ciudad de Berlín y Estados Federados de Brandeburgo, Sajonia, Sajonia-Anhalt y Turingia.

\section{Consulado de la República Argentina en Bonn:}

Calle: Robert Koch-Strasse 104, 53127 Bonn, República Federal de Alemania.

Tel.: +49(0)228 $2496288 / 384$

Fax: +49(0)228 2496287

Email: consuladoargbonn@t-online.de

Circunscripción consular:

Estados Federados de Renania del Norte-Westfalia, Renania Palatinado y Sarre.

Consulado General y Centro de Promoción Comercial de la República Argentina en Frankfurt am Main:

Calle: Eschersheimer Landstrasse 19-21, 60322 Frankfurt, República Federal de Alemania.

Tel.: +49(0)69 9720030

Fax: +49 (0)69 175419

Email: coarg@t-online.de

Circunscripción consular:

Estados Federados de Baden Württemberg, Baviera y Hesse.

\section{Consulado General de la República Argentina en Hamburgo:}

Calle: Mittelweg 141, 20148 Hamburgo, República Federal de Alemania.

Tel.: +49(0)40 4418460

Fax: +49(0)40 4105103

Email: chamb@mrecic.gov.ar 
Circunscripción consular:

Estados Federados de Hamburgo, Bremen, Baja Sajonia, Schleswig-Holstein y Mecklenburgo Pomerania Occidental.

\subsection{Otros datos útiles}

\subsubsection{Hoteles}

Existen numerosas páginas para la reserva de hoteles en internet. Una de las más extendidas es el servicio de reserva de hoteles, (Hotel Reservation System) cuya dirección de Internet es:

Sitio web: http://www.hotel.de

\subsubsection{Guía de direcciones locales de Internet de interés}

\section{Gobierno e Instituciones}

Federación: http://www.bund.de

Presidente Federal: http://www.bundespraesident.de

Cancillería: http://www.bundeskanzler.de

Ministerio de Finanzas: http://www.bundesfinanzministerium.de

Ministerio de Economía: http://www.bmwi.de

Banco Central: http://www.bundesbank.de

Instituto de Estadística: http://www.destatis.de

Parlamento Cámara Baja: http://www.bundestag.de

Parlamento Cámara Alta: http://www.bundesrat.de

Instituto Nacional de Empleo: http://www.arbeitsamt.de

\section{Partidos Políticos}

SPD: http://www.spd.de

CDU: http://www.cdu.de

CSU: http://www.csu.de

FDP: http://www.fdp.de

Los Verdes: http://www.gruene.de

PDS: http://www.die-linke.de 


\section{Asociaciones Empresariales}

Asociación Alemana de la Industria: http://www.bdi-online.de

Asociación de los Empresarios Alemanes: http://www.bda-online.de

Asociación de la Industria del Automóvil: http://www.bda.de

Asociación de Bancos: http://www.bdb.de

\section{Sindicatos}

Servicios: http://www.verdi.de

Industria: http://www.igmetall.de

Asociación de los Sindicatos Alemanes: http://www.dgb.de

\section{Televisión}

http://www.ard.de

http://www.tagesschau.de

http://www.zdf.de

\section{Prensa}

http://www.faz.de

http://www.handelsblatt.de

http://www.boersen-zeitung.com

http://www.spiegel.de

http://www.bild.t-online.de

http://www.wiwo.de

\section{Radio}

http://www.dwelle.de

http://www.dradio.de

http://www.wdr.de

\section{Empresas Sectores Estratégicos:}

Telefonía e Internet: http://www.telekom.de

Correos: http://www.dpwn.com

Energía Eléctrica: http://www.rwe.de 


\section{Comunicaciones}

http://www.bertelsmann.com

\section{Transportes}

http://www.lufthansa.com

http://www.bahn.de

\section{Banca}

http://www.deutsche-bank.de

http://www.hypovereinsbank.de

http://www.dresdner-bank.de

http://www.commerzbank.de

http://www.allianz.de

http://www.kfw.de

\section{Bolsas de valores}

http://www.boerse.de

http://www.deutsche-boerse.com

http://www.dax.de 
Bibliografía

AMI - MARKTBILANZ. Gemüse 2011. Informe anual de las verduras en Alemania.

BUND ÖKOLOGISCHE LEBENSMITTELWIRTSCHAFT. Zahlen, Daten, Fakten. Die Bio-Branche 2011. (Ed. 2011). Publicación de la Federación de empresas alimenticias ecológicas alemanas.

BUNDESANSTALT FÜR LANDWIRTSCHAFT UND ERNÄHRUNG. Geschäftsbericht 2010. Publicación del Ministerio Alemán para la Agricultura.

CÁMARA DE COMERCIO E INDUSTRIA PERUANO-ALEMANA. Perfil de Mercado del espárrago fresco en Alemania.

CONSULADO GENERAL DE LA REPÚBLICA ARGENTINA EN FRANKFURT. Estudio de Mercado Horti-Fructicultura Orgánica en Alemania (Ed. 2010).

DRUCKER, P., 2002. La Gerencia. Tareas, responsabilidades y prácticas. (44 - 52).

FUNDACIÓN EXPORT-AR. Los negocios del futuro. Un radar de oportunidades. Primera Edición (Ed. Año 2009). Publicación de la Fundación ExportAr.

INSTITUTO ESPAÑOL DE COMERCIO EXTERIOR. Guía País, Alemania (Ed. 2009). Revista Española de Comercio Exterior.

INTERNATIONAL TRADE CENTRE. Organic Products (Ed. 2010). Publicación del Centro Internacional de comercio.

KOCH, Michael. AMI Agrarmarkt Informations - Gesellschaft mbH. World, Europe, Germany 2010 Key facts Asparagus (Ed. 2010).

KOTLER, P., 2008. Mercadotecnia. 
LIDDELL HART, B., 1984. Estrategia. La aproximación indirecta. (549 - 590)

LÜBCKE, J. Brandenbuger Spargel - Eine märkische Erfolgsgeschichte (Ed. 2010).

MARTÍNEZ, Christian. Propuesta para una planificación estratégica en Productos Orgánicos (Ed. 2009). Publicación de la Fundación ExportAr.

MENDENHALL, W., (Ed. 2003). Estadística para administradores.

PADEL, S. THE ORGANIC RESEARCH CENTRE. The Market for Organic Food (Ed. 2011).

PARIS, J. A., 2008. Marketing Internacional desde la óptica latinoamericana.

PORTER, M., 2000. Técnicas para el Análisis de los Sectores Industriales y de la Competencia.

RICHTER, T. Ökologische Märkte Erschliessen Bundesministerium für Verbraucherschutz, Ernährung und Landwirtschaft (Ed. 2010). Publicación del Ministerio Alemán para la Agricultura.

RIOBOO PIÑEIRO, S., INSTITUTO ESPAÑOL DE COMERCIO EXTERIOR. Perfiles de los principales grupos de distribución agroalimentaria en Alemania (Ed. 2009). Revista Española de Comercio Exterior.

RIOBOO PIÑEIRO, S., INSTITUTO ESPAÑOL DE COMERCIO EXTERIOR. La comercialización de frutas y hortalizas en Alemania (Ed. 2009). Revista Española de Comercio Exterior.

RIPPIN, M. AGRO MILAGRO RESEARCH. Bio-Importe nach Deutschland - Biofach (Ed. 2011). Publicación para la feria anual de productos orgánicos Biofach de Nürnberg.

SCHAACK, D. AGRARIAN MARKET INFORMATION COMPANY. The German Organic Market (Ed. 2010). Publicación para la feria anual de productos orgánicos Biofach de Nürnberg. 
SCHAACK, D. AGRARMARKT INFORMATIONS-GmbH. Bio-Importe nach Deutschland Biofach (Ed. 2011). Publicación para la feria anual de productos orgánicos Biofach de Nürnberg.

SCHAER, B. A glimpse on Organic markets in Eastern Europe - Biofach (Ed. 2011). Publicación para la feria anual de productos orgánicos Biofach de Nürnberg.

SENASA, Situación de la producción orgánica en Argentina durante el año 2010. (Ed. Marzo 2010). Publicación anual del Servicio Nacional de Sanidad y Calidad Agroalimentaria - SENASA.

SOIL ASSOCIATION. Organic Market Report (Ed. 2009). Publicación de la Asociación SOIL.

STATISTISCHES BUNDESAMT. Land und Forstwirtschaft, Fischerei. Wachstum und Ernte „Gemüse” (Ed. 2010). Publicación de la oficina estadística del Gobierno Alemán.

STOLZ, H., STOLZE, M. Preference and willingness top ay for products with Organic Plus arguments (Ed. 2010). Publicación para la feria anual de productos orgánicos Biofach de Nürnberg.

VACLAVIK, T. Green Marketing. How Organic retailers cope with the Economic downturn. (Ed. 2010).

WILLER, H. and KILCHER, L.: The World of Organic Agriculture. Statistics and Emerging Trends 2011, IFOAM, Bonn, and FiBL, Frick (Ed. 2011). Publicación anual de la Federación Internacional de Movimientos y Agricultura Orgánica.

ZAPATA, C. I. (2008) La Competitividad de las PyMEs exportadoras. Publicación de FedEx PyMEx Business Center.

ZAPATA, C. I. y Colaboradores (1997). Negocios y Comercialización Internacional. Ediciones Macchi (19-35). 


\section{Sitios Web Consultados}

Agro Los Andes S.A. (Establecimiento argentino productor de espárragos orgánicos): http://www.agrolosandes.com.ar

Agramarkt Informations Gesellschaft:

http://www.marktundpreis.de

AMI-Informiert

http://www.ami-informiert.de

Argencert:

http://www.argencert.com.ar/

Argentina Orgánica

http://www.argentina-organica.com/

Argentina Trade Net:

http://www.argentinatradenet.gov.ar/

Baden Württemberg (Portal de Baden Württemberg):

http://www.baden-wuerttemberg.de/

Baden Württembergischer Industrie und Handelskammertag:

http://www.bw.ihk.de/

Befve Christian (Consultor Internacional de Espárragos):

http://www.befve.com

Biofach (Feria de Productos orgánicos de Nürnberg):

http://www.biofach.de

Bundesministerium für Ernährung Landwirschaft und Verbraucherschutz BMELV (Ministerio Alemán para el Desarrollo Agrícola y del Cuidado del Medio Ambiente):

http://www.bmelv.bund.de

California Asparagus Seed and Transplants, Inc:

http://www.calif-asparagus-seed.com/

Cámara Argentina de Certificadoras de alimentos, productos orgánicos y afines:

http://www.cacer.org.ar/home.htm

Cámara de Exportadores de la República Argentina:

http://www.cera.org.ar/ 
Cámara de Importadores de la República Argentina:

http://www.cira.org.ar/

Das Spargel Informationsportal (Portal de información sobre espárragos):

http://www.spargel.net/

Embajada Alemana en Argentina:

http://www.buenos-aires.diplo.de/Vertretung/buenosaires/es/Startseite.html

Embajada Argentina en Alemania:

http://www.argentinische-botschaft.de/

Europa. El portal de la Unión Europea:

http://europa.eu/documentation/statistics-polls/index_es.htm

Eurostat Statistics on Organic Farming (Estadísticas Europeas sobre Agricultura Orgánica):

http://epp.eurostat.ec.europa.eu/

Exportapymes:

http://www.exportapymes.com/

Food and Agriculture Organization of the United Nations, FAO (Organización de las Naciones Unidas para la Agricultura y Alimentación):

http://www.fao.org/organicag.

http://faostat.fao.org/default.aspx

Fundación ExportAr:

http://www.exportar.org.ar

Global Market for Organic Food \& Drink (Mercado global de alimentos y bebidas orgánicas):

http://www.organicmonitor.com

Green Patagonia (Establecimiento argentino productor de espárragos orgánicos):

http://www.greenpatagonia.com.ar

Industrie und Handelskammer (IHK) Region Stuttgart:

http://www.stuttgart.ihk24.de/

Industrie und Handelskammer (IHK) Reutlingen:

http://www.reutlingen.ihk.de/start.oscms/0/2458/7001/Home.html

Instituto Nacional de Tecnología Agropecuaria INTA:

http://www.inta.gov.ar/index.asp

International Centre for Organic Agriculture EkoConnect (Centro Internacional de la Agricultura Orgánica):

http://www.ekoconnect.org/en_index.html 
International Federation of Organic Agriculture Movements IFOAM:

http://www.ifoam.org

International Trade Centre:

http://www.intracen.org/organics

Ministerio de Agricultura, Ganadería y Pesca:

http://www.minagri.gob.ar/site/index.php

Ministerio de Asuntos Agrarios de la provincia de Buenos Aires:

http://www.maa.gba.gov.ar/2010/index.php

Ministerio de la Producción de la provincia de Buenos Aires:

http://www.mp.gba.gov.ar/

Ministerio de Relaciones Exteriores, Comercio Internacional y Culto:

http://www.mrecic.gov.ar/

Movimiento Argentino para la producción orgánica

http://www.mapo.org.ar

Mundo Orgánico:

http://www.organic-world.net

National Agricultural Statistics Service NASS:

http://www.nass.usda.gov

National Association for the Specialty Food Trade Inc. NASFT:

http://www.specialtyfood.com

La Meco S.R.L. (Establecimiento argentino productor de espárragos orgánicos):

http://www.lamecosrl.com.ar/

Lebensmittel Zeitung (Informativo alemán sobre alimentación):

http://www.lebensmittelzeitung.net/

Organic Market Info:

http://www.organic-market.info

Organic Monitor:

http://www.organicmonitor.com

Pampa Store (Establecimiento productor de espárragos orgánicos):

http://www.pampastore.com 
PROPLANTA: Das Informationzentrum für die Landwirtschaft (Centro de Información alemán para la agricultura):

http://www.proplanta.de

Research Institute of Organic Agriculture, FiBL (Instituto de Investigación para la Agricultura Orgánica):

http://www.fibl.org

Secretaría PyME, Ministerio de Industria Argentino:

http://www.sepyme.gob.ar/

Schmeck den Süden - Baden Württemberg:

http://www.schmeck-den-sueden.de/index.php

Schweizerische Eidgenossenschaft (Confederación Suiza):

http://www.seco.admin.ch/

SENASA:

http://www.senasa.gov.ar

Spargel Seiten. Wissenswertes Über Spargel (Portal alemán sobre espárragos).

http://www.spargelseiten.de/

Spargel Treff (Portal alemán sobre espárragos):

http://www.spargeltreff.de/

Spargelerzeugerverband Südbayern (Portal alemán sobre espárragos):

http://www.spargel.de/

Statistisches Landesamt Baden Württemberg (Oficina estadística de Baden Württemberg):

http://www.statistik.baden-wuerttemberg.de/

Stiftung Ökologie und Landbau (Fundación Alemana para la Agricultura Ecológica).

http://www.soel.de

The International Fund for Agricultural Development IFAD (Fundación Internacional para el Desarrollo de la Agricultura):

http://www.ifad.org

The Organic Standard (TOS):

http://www.organicstandard.com

United States Department of Agriculture, Economic Research Service (Departamento de Agricultura del Gobierno de Norteamérica):

http://www.ers.esda.gov 
Verband Süddeutschland Spargel und Erdbeeranbauer (Asociación del Sud de Alemania para los cultivadores de Espárragos y Fresas):

http://www.vsse.de 


\section{Aclaración:}

"Yo, Emanuel Borthiry Buide, declaro bajo juramento que esta tesis fue elaborada por mí, que no utilicé ningún otro material que no haya dado a conocer en las referencias y que no utilicé frases o párrafo de otros autores, que este trabajo de tesis nunca ha sido presentado ante un comité de evaluación de tesis y que no transgredí derechos de terceros". 


\section{Anexo Fotográfico}

